RECINOS

ORNLTM-12956

DEC 131995

OSTI

OAK RIDGE NATIONAL LABORATORY

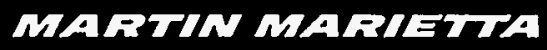

\title{
Analytical and Experimental Investigation of the Dispersion Process During Rapid Transients for the Aluminum-Based Nuclear Fuel Plates
}

\author{
V. Georgevich \\ R. P. Taleyarkhan \\ S. H. Kim \\ T. Fuketa \\ K. Soyama \\ K. Ishijima
}


This report has been reproduced directly from the best available copy.

Available to DOE and DOE contractors from the Office of Scientific and Technical information, P.O. Box 62, Oak Ridge, TN 37831; prices available from (615) 576-8401, FTS 626-8401.

Aveilable to the public from the National Technical Information Service, U.S. Department of Commerce, 5285 Port Royal Rd., Springfield, VA 22161.

This report was prepared as an account of work sponsored by an agency of the United States Government. Neither the United States Government nor any agency thereof, nor any of their employees, makes any wartanty, express or implied, or assumes any legal llability or responsibility for the accuracy, completeness, or usefulness of any information, apparatus, product, or process disclosed, or represents that its use would not infringe privately owned rights. Reference herein to any specific commercial product, process, or service by trade name, trademark, manufacturer, or otherwise, does not necessarily constttute or imply its endorsement, recommendation, or favoring by the United States Government or any agency thereof. The views and opinions of authors expressed herein do not necessarily state or reflect those of the United States Government or any agency thereof. 


\section{DISCLAIMER}

Portions of this document may be illegible in electronic image products. Images are produced from the best available original document. 


\section{ANALYTICAL AND EXPERIMENTAL INVESTIGATION OF THE DISPERSION PROCESS DURING RAPID TRANSIENTS FOR THE ALUMINUM-BASED NUCLEAR FUEL PLATES}

V. Georgevich, R. P. Taleyarkhan, S. H. Kim ETD, Oak Ridge National Laboratory. and

T. Fuketa, K.Soyama, K. Ishijima

Japan Atomic Energy Research Institute, Japan

JUNE 1995

Prepared by the

OAK RIDGE NATIONAL LABORATORY

Oak Ridge, Tennessee 37831 managed by

LOCKHEED MARTIN ENERGY SYSTEMS, INC.

for the

U.S. Department of Energy

under Contract No. DE-AC05-840R21400 


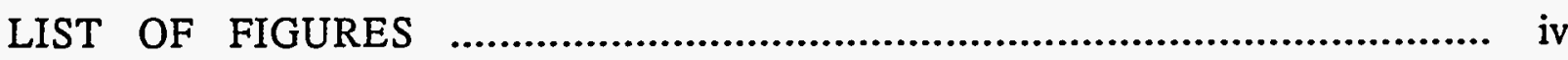

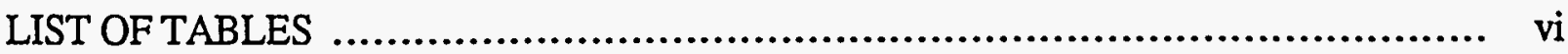

LIST OF ACRONYMS ............................................................... viI

ACKNOWLEDGEMENTS .......................................................... viil

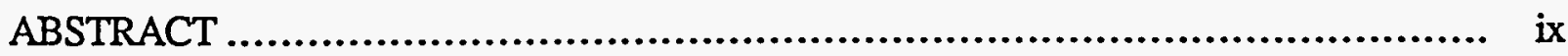

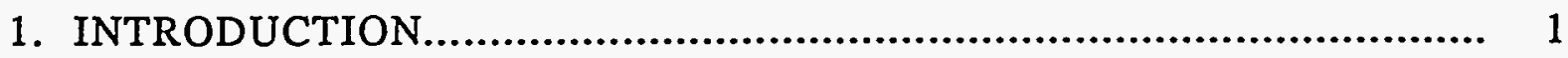

2 STRAIN RATE MODEL ............................................................. 2

2.1 LOCAL STRAIN RATE ........................................................ 2

2.2 GLOBAL STRAIN RATE ................................................. 3

3. THERMAL ENERGY TRANSFER MODEL ..................................... 6

3.1 CONSERVATION OF ENERGY EQUATIONS .............................. 6

3.2 THE EXOTHERMIC ENERGY RELEASE FROM FUEL-AL REACTION....... 7

3.3 THE ENERGY RELEASE FROM ALUMINUM-WATER REACTIONS

4. SOURCES OF ENERGY ........................................................... 9

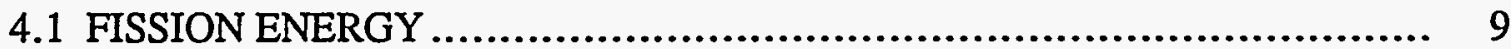

4.1.1 NSRR Energy Depositions Transients .................................. 10

4.1.2 TREAT Energy Deposition Transients ................................. 12

4.2 EXOTHERMIC ENERGY RELEASE FROM FUEL-AL REACTION ........... 15

4.2.1 Empirical method of determining reaction rates ............................. 16

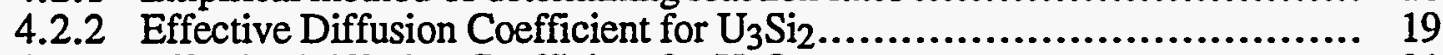

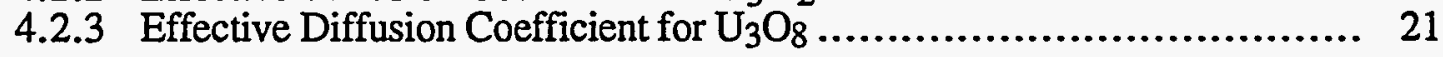

4.3 ENERGY RELEASE FROM ALUMINUM-WATER REACTION................ 23

5. STRAIN RATE MODELING AND ANALYSIS FRAMEWORK......................... 25

5.1 THE EFFECT OF NEGLECTING MATERIAL STRENGTH PROPERTIES..... 25

5.2 EFFECT OF FUEL IRRADIATION ON DISPERSION ......................... 25

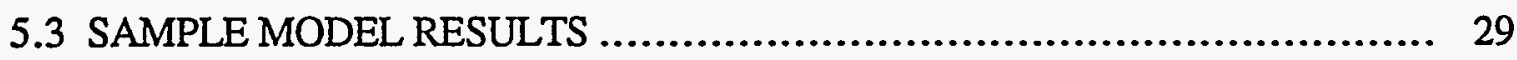

6. ANALYSIS OF EXPERIMENTAL RESULTS ..................................... 31

6.1 SL-1 FUEL TESTS IN TREAT....................................................... 31 
6.3 JMTR FUEL PLATE TESTS IN NSRR

6.4 ANS FUEL PLATE TESTS IN NSRR

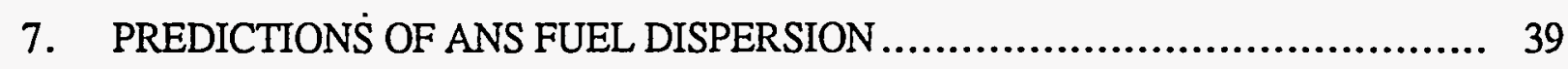

8 GENERAL OBSERVATIONS AND DISCUSSION.................................. 41

9. SUMMARY AND CONCLUSION............................................... 44

10. LITERATURE CITED......................................................... 45

APPENDIX A: Mathematical input and results for HFIR Plate Test Simulations.............. 58 


\section{LIST OF FIGURES}

Fig. 1. Illustration of the effect of localized expansion............................................ 3

Fig. 2. Illustration of the effect of multiple expansion sites.............................. 4

Fig. 3. Illustration of the JMTR fuel plates irradiated in the NSRR ..................... 10

Fig. 4. ANS fuel plate dimensions. ................................................. 11

Fig. 5. Dimensions of the SL-1 fuel plate tested in treat facility........................ 13

Fig.6 Dimensions of the HFIR fuel plate tested in the treat facility..................... 14

Fig. 7. Temperature profile used to illustrate the modeling approach ..................... 18

Fig. 8. Dimensionless temperature calculated using Eq. $38 \ldots \ldots \ldots \ldots \ldots \ldots \ldots \ldots \ldots \ldots \ldots$

Fig. 9. Hyperbolic tangent of the dimensionless temperature .......................... 18

Fig. 10. Illustration of general shape of the reaction rate parameter............................ 19

Fig. 11. Comparison of data points to the calculated reaction rate parameter. .............. 20

Fig. 12. Components of power density deposited in the fuel plate during a transient test... 21

Fig. 13. Energy release as a function of $\mathrm{U}_{3} \mathrm{O}_{8}$ - aluminum mass fraction ................ 21

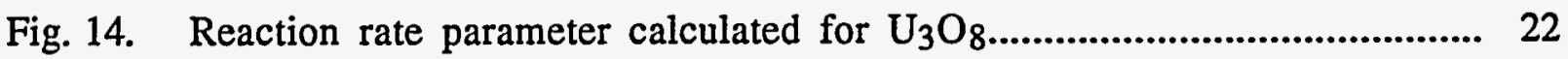

Fig.15 Calculated power deposition density into HFIR fuel plate test caused by fissioning and chemical reaction process during a TREAT test................................... 23

Fig. 16. Ilustration of diffusive oxidation and vapor phase burning ..................... 24

Fig. 17. The effect of aluminum surface tension on the internal pressure

of gases trapped in spherical pockets.......................................... 27

Fig. 18. Effective volume fraction for a given mass fraction of volatile fission products if the gas is allowed to expand to ambient pressure.............................. 27

Fig. 19. Predicted strain rate for $1 \%$ effective gas volume fraction...................... 28

Fig. 20. Predicted strain rate for $25 \%$ effective gas volume fraction........................... 28

Fig. 21. The effect of effective volume fraction on the peak strain (expansion) rate........ 29

Fig. 22. llustration of various expansion modes. ....................................... 30 
Fig. 23. Strain rate and fragmented fraction as a function of cumulative deposited energy for SL-1 fuel plate tests in the TREAT facility.

Fig. 24. Peak computed surface temperatures for different energy depositions in SL-1 fuel tests conducted in the TREAT facility.

Fig. 25. Comparison of computed peak strain rate as a function of energy for different initial temperature

Fig. 26. Comparison of computed peak strain rate to experimentally measured fragmented fraction as a function of cumulative deposited energy

Fig. 27. Fraction of aluminum oxidation and peak computed temperatures for HFIR fuel tests as a function of energy deposition.

Fig. 28. Comparison of fission and chemical energy deposited for a given fission energy deposited and their corresponding temperatures

Fig.29. Strain rate predicted by fission heating only and the combined fission heating and the fuel - aluminum chemical energy source.

Fig 30. Peak center line and clad temperature for a given fission energy deposition with chemical energy model.

Fig. 31. Computed strain rate and temperature variation for ANS fuel (1.4 g/cc loading) as a function of deposited energy for a fixed $25 \mathrm{~ms}$ pulse width.

Fig. 32. Peak strain rate and peak temperatures as a function of pulse width for $2.15 \mathrm{MJ} / \mathrm{kg}$ energy deposition as a function of pulse width 


\section{LIST OF TABLES}

Table 1. JMTR tests in NSRR facility ............................................... 11

Table 2. ANS fuel tests in NSSR facility ........................................... 12

Table 3. SL-1 fuel tests in TREAT facility ............................................. 13

Table 4. General description of tests performed on the HFIR fuel in the TREAT facility.... 14

Table 5. Estimated reaction rate parameters for $\mathrm{U}_{3} \mathrm{Si}_{2}$ fuel............................... 20

Table 6. Preliminary estimate of the material properties of irradiated silicide fuel plates

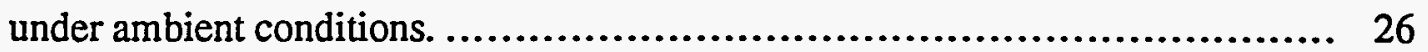

Table 7. JMTR tests in NSRR facility ................................................ 35 


\title{
LIST OF ACRONYMS
}

\author{
ANS - Advanced Neutron Source \\ FCI - Fuel Coolant Interaction \\ HFIR - High Flux Isotope Reactor \\ JMTR - Japan Materials Test Reactor \\ NSRR - Nuclear Safety Research Reactor
}




\section{ACKNOWLEDGMENTS}

The authors wish to acknowledge the cooperation and technical discussions with J. Snelgrove, J. Rest, and G. Hoffman of Argonne National Laboratory. 


\begin{abstract}
A thermally induced fuel-plate dispersion model was developed to analyze for dispersive potential and determine the onset of fuel plate dispersion for aluminum-based research and test reactor fuels. The effect of rapid energy deposition in a fuel plate was simulated. Several data types for aluminum-based fuels tested in the Nuclear Safety Research Reactor (NSRR) facility in Japan and in the Transient Reactor Test (TREAT) facility in Idaho, U.S.A., were reviewed. Analyses of experiments show that the onset of fuel dispersion is clearly linked to a sharp rise in the predicted strain rate, which further coincides with the onset of aluminum vaporization. Analysis also shows that aluminum oxidation and exothermal chemical reaction between the fuel and aluminum can significantly affect: the energy deposition characteristics (and, therefore dispersion onset connected with aluminum vaporization, and the onset of aluminum vaporization.
\end{abstract}




\subsection{INTRODUCTION}

Containment loads during hypothetical severe accidents of research and test reactor systems using uranium-aluminum (U-Al) based fuel can be significantly impacted by energetic fuel coolant interaction (FCI) events. To analyze energetics of FCI events the molten material breakup or dispersion characteristics need to be evaluated. Material type plays an important role in determining the phenomenological process that will disperse the fuel. Under rapid heating, aluminum-based fuels disperse at temperatures that are significantly above the melting temperature of the fuel plate. Dispersion of aluminum-based fuel is proposed to be a function of volumetric strain rate. The concept of using strain rate as the measure of dispersive potential originates from the requirement that the fuel has to be accelerated to a certain velocity in order for it to fragment into smaller pieces. The strain rate concept is used extensively in determining the spallation[1] characteristics for high strain rate high deformation problems.

To determine the mechanism by which acceleration occurs, several separate mechanisms for strain rate were implemented in the model. These mechanisms include the strain rates caused by thermal expansion in solid state, expansion due to melting-induced phase change, thermal expansion in liquid state, expansion due to the presence of gases in the plate (present at fabrication or caused by fission product gases), and expansion due to vaporization-induced phase change. Since material strength properties are not well characterized, the modeling procedure used to determine the strain rates consists of using the concept of predicting the potential for generating strain rates. To illustrate the concept of using the potential for generating strain rates, the analogy of the conversion of potential to kinetic energy can be applied. Using the potential energy analogy, and by determining the potential for achieving a certain strain rate, the model can then be used to predict the onset of dispersion as long as material properties do not interfere with the evaluation in the range of interest. Results from analysis described in subsequent sections and associated analyses shows the assumption is justified. 


\section{STRAIN RATE MODEL}

The strain rate model uses a local strain rate and integrates it to a global value. The peak time dependent global strain rate value is compared for different energy depositions. The next section describes how to determine the local strain and the following section describes the integration process used to determine the global strain rate.

\subsection{LOCAL STRAIN RATE}

To evaluate the dispersion potential, the maximum possible velocity or strain rate must be determined during the transient. To understand and rank the primary mechanisms leading to the onset of fuel-aluminum mixture dispersion, a one-dimensional (1-D) modeling framework centered on the prediction of material strain rates was developed. Strain is defined as

$$
\varepsilon=\frac{\Delta L}{L}
$$

where $\varepsilon$ is the strain, $\Delta \mathrm{L}$ is the change in length, and $\mathrm{L}$ is the original length. A dimensionless approach was taken to eliminate the effect of fuel-plate thickness on the results. Differentiation with respect to time results in the strain rate given by Eq. (2).

$$
\dot{\varepsilon}=\frac{d}{d t}\left(\frac{\Delta L}{L}\right)
$$

Strain rate for the physical process described earlier can be expressed by

$$
\dot{\varepsilon}=(1-f)\left\{\dot{\varepsilon}_{\mathrm{th}}+\dot{\varepsilon}_{\mathrm{m}}+\dot{\varepsilon}_{\mathrm{v}}\right\}+\mathrm{f} \dot{\varepsilon}_{\mathrm{gas}},
$$

where $\mathrm{f}$ is the fraction of original volume composed of vapor or gas, $\varepsilon_{\mathrm{th}}$ is the thermally induced strain rate, $\varepsilon_{\mathrm{m}}$ is the melting-induced strain rate, $\varepsilon_{\mathrm{v}}$ is the vaporizing induced strain rate, $\varepsilon_{\mathrm{gas}}$ is the strain rate induced by the expansion of gases. The volumetric change rate due to the thermal expansion of material at a particular location is given by

$$
\begin{aligned}
\dot{\varepsilon}_{\mathrm{th}}(\mathrm{z}, \mathrm{t}) & =\frac{\mathrm{d}}{\mathrm{dt}}\left(\frac{\Delta \mathrm{L}}{\mathrm{L}}\right)=\frac{\mathrm{d}}{\mathrm{dt}}\left(\beta\left\{\mathrm{T}(\mathrm{z}, \mathrm{t})-\mathrm{T}_{\mathrm{o}}\right\}\right) \\
& =\beta \frac{\mathrm{dT}(\mathrm{z}, \mathrm{t})}{\mathrm{dt}},
\end{aligned}
$$

where $\beta$ is the thermal expansion coefficient, $T(z, t)$ is the temperature, and $T_{0}$ is the initial temperature. When a material such as aluminum is undergoing a phase change, the density change will cause a change in volume. If material is melting at a certain rate, then the strain rate is

$$
\dot{\varepsilon}_{m}(z, t)=\frac{\rho_{s}-\rho_{f}}{\rho_{f}} \frac{d x_{m}(z, t)}{d t},
$$

where $x_{m}$ is the melt quality (fraction) and $\rho_{s}$ and $\rho_{\mathrm{f}}$ are the solid and liquid densities, respectively. Similarly, for vaporization phase change the strain rate is 


$$
\dot{\varepsilon}_{v}(z, t)=\frac{\rho_{f}-\rho_{v}}{\rho_{v}} \frac{d x_{v}(z, t)}{d t}
$$

where $x_{v}$ is vapor quality (fraction) and $\rho_{v}$ is the vapor density. As gases and fission products heat up, they expand. The strain rate (the rate of change of volume) due to the gas expansion (assuming ideal gas behavior) is given by

$$
\dot{\varepsilon}_{\mathrm{gas}}(\mathrm{z}, \mathrm{t})=\frac{1}{\mathrm{~T}(\mathrm{z}, \mathrm{t})} \frac{\mathrm{dT}(\mathrm{z}, \mathrm{t})}{\mathrm{dt}} .
$$

From Eqs. (5-7) the strain rate can be seen to depend on the change in temperature. To determine the rate of change in temperature as a function of time, position, and energy deposition rate, thermal energy transfer under various regimes needs to be evaluated. Section IV discusses the method used to determine the transient temperature profile. Evaluation of the local strain rate caused by several different mechanisms was previously explained. How the local strain rates interact with each other is outlined in the next section.

\subsection{GLOBAL STRAIN RATE}

Local strain rate acting at the center of the fuel plate will not affect the plate identically as the same magnitude strain rate acting closer to the plate surface. The expansion at the center will cause movement of the material starting from the center to the surface whereas, the expansion close to the surface will cause the expansion from that location to the surface. These are illustrated by the Figs 1 . \& 2 . below. The first example will cause the entire plate to expand with velocity $\mathrm{v}$ whereas the second example will cause the last three nodes to expand with velocity v.
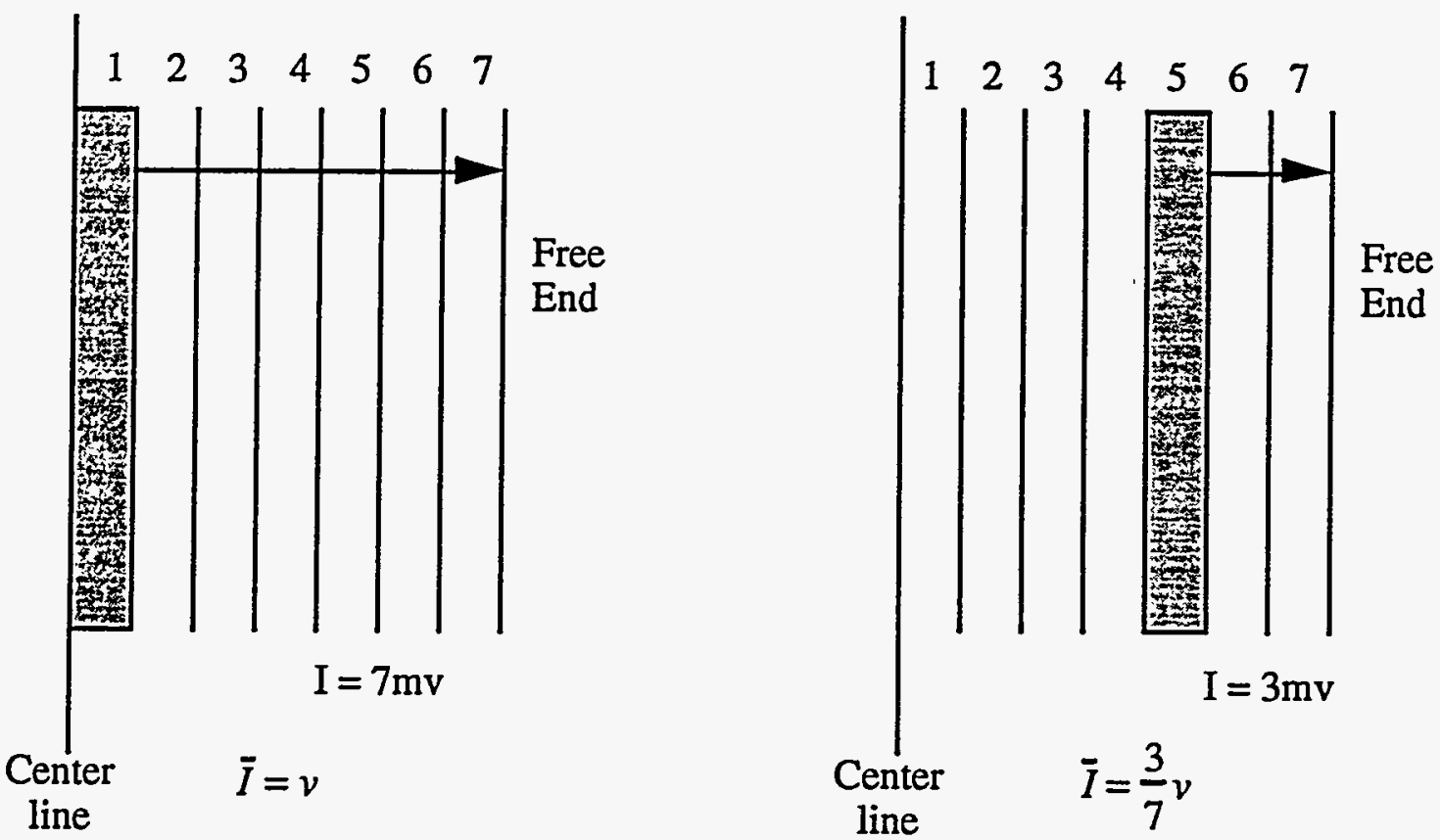

Fig. 1. Illustration of the effect of localized expansion. 
If both nodes are expanding with velocity $\mathrm{v}$ then the first through the fourth node will expand with velocity $\mathrm{v}$ and the fifth through the seventh will expand with velocity $2 \mathrm{v}$. This example illustrates the spatial effect of expansion. This has significant implications in predicting behavior of plates that have steep temperature gradients.

Mathematically the expression is justified by determining the effective impulse that the plate is experiencing. Local impulse (I) imparted to the plate at position $\mathrm{x}$ is given by the mass of material after point $x$ that is affected by expansion at point $x$ multiplied by the expansion velocity.

$$
\mathrm{I}(\eta)=\mathrm{m}(\mathrm{L}-\eta) \mathrm{v}(\eta)=\mathrm{v}(\eta) \int_{\eta}^{\mathrm{L}} \rho(\mathrm{x}) \mathrm{Adx} .
$$

Overall impulse, $(\bar{I})$ defined as by the integral of the impulse over the entire plate normalized by the plate thickness.

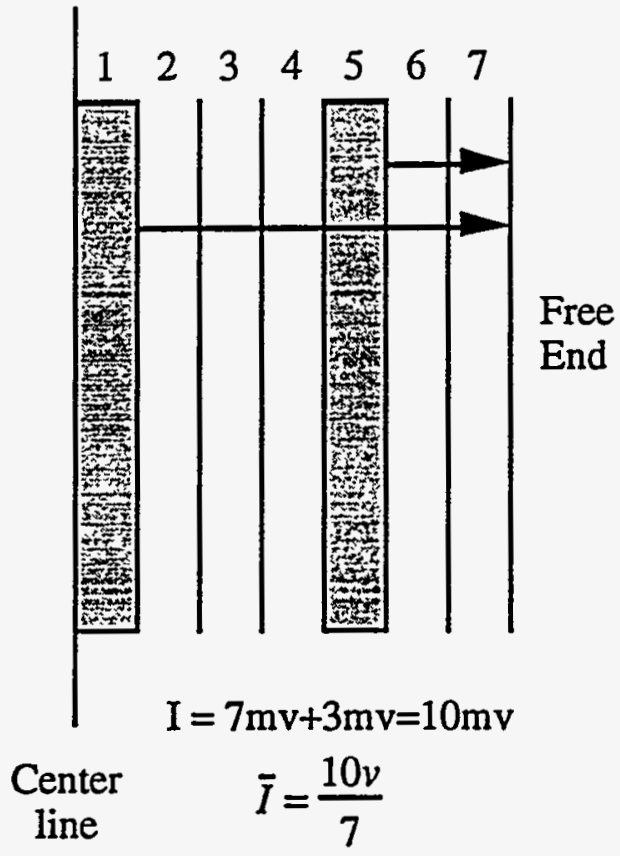

Fig. 2. Illustration of the effect of multiple expansion sites.

$$
\overline{\mathrm{I}}=\frac{\int_{0}^{L} \mathrm{I}(\eta) \mathrm{d} \eta}{\int_{0}^{\mathrm{L}} \mathrm{d} \eta}=\frac{\int_{0}^{\mathrm{L}} \mathrm{v}(\eta)\left\{\int_{\eta}^{L} \rho(\mathrm{x}) \mathrm{Adx}\right\} \mathrm{d} \eta}{\int_{0}^{L} \mathrm{~d} \eta} .
$$

Simplifying Eq. (9) results in 


$$
\overline{\mathrm{I}}=\overline{\mathrm{v}} \mathrm{m}_{\mathrm{t}}=\overline{\mathrm{v}} \int_{0}^{\mathrm{L}} \rho(\mathrm{x}) \mathrm{Ad} \eta=\frac{\int_{0}^{\mathrm{L}} \mathrm{v}(\eta)\left\{\int_{\eta}^{\mathrm{L}} \rho(\mathrm{x}) \mathrm{Adx}\right\} \mathrm{d} \eta}{\int_{0}^{L} \mathrm{~d} \eta},
$$

where, average velocity is given by

$$
\overline{\mathrm{v}}=\frac{\int_{0}^{\mathrm{L}} \mathrm{v}(\eta)\left\{\int_{\eta}^{\mathrm{L}} \rho(\mathrm{x}) \mathrm{dx}\right\} \mathrm{d} \eta}{\mathrm{L} \int_{0}^{L} \rho(\mathrm{x}) \mathrm{d} \eta} .
$$

If strain is defined as the change in original length, then the strain rate is given by the rate of change of length divided by the original length

$$
\overline{\dot{\varepsilon}}=\frac{\int_{0}^{L} \dot{\varepsilon}(\eta)\left\{\int_{\eta}^{L} \rho(x) d x\right\} d \eta}{L \int_{0}^{L} \rho(x) d \eta} .
$$

Therefore, the local strain rate can be integrated into a global value strain rate for the entire plate using Eq. 12. Evaluating a local strain rate, spatial transient temperature profile needs to be determined. Section 4 describes the procedure used to determine the temperature profile. 


\section{THERMAL ENERGY TRANSFER MODEL}

Determining the global strain rate requires knowledge of spatial transient temperature behavior of the plate. To determine the transient temperature profile energy deposition rates need to be available along with the material properties for each material that composes the fuel plate. Using the conservation of energy equation the transient temperature profile can be determined. Method of solving the energy conservation equation is outlined next.

\subsection{CONSERVATION OF ENERGY EQUATIONS}

The conservation of energy equation that determines the 1-D transient temperature profile in a fuel plate is given by

$$
k \frac{d^{2} T(z, t)}{d z^{2}}+q^{\prime \prime \prime}=\rho c_{p} \frac{d T(z, t)}{d t},
$$

where $T(z, t)$ is the position and time-dependent temperature, $c_{p}$ is the specific heat capacity, $q$ "' is the volumetric heat generation source, and $\mathrm{k}$ is the material thermal conductivity. In a finite difference approximation the conservation equation for the $\mathrm{i}^{\text {th }}$ node is given by:

$$
\frac{T_{i-1}}{\Delta z^{2}}-\left(\frac{2}{\Delta z^{2}}+\frac{\alpha_{i}}{\Delta t}\right) T_{i}+\frac{T_{i+1}}{\Delta z^{2}}+=-\frac{q_{i}^{\prime \prime \prime}}{k}-\alpha_{i} \frac{T_{i}^{*}}{\Delta t}
$$

where $\alpha_{i}$ is the thermal diffusivity for the $i_{t h}$ node, $T_{i}$ is the temperature for node $i$ during the current time step, $\mathrm{T}_{\mathrm{i}}^{*}$ is the temperature for node $\mathrm{i}$ during a previous time step, $\mathrm{dz}$ is the mesh size, and dt is time step. If any node is undergoing a phase change from solid to liquid, Eq. (10) determines the extent of change:

$$
k \frac{d^{2} T}{d z^{2}}+q^{\prime \prime \prime}=\rho h_{s f} \frac{d x_{s}}{d t},
$$

where $x_{s}$ is the melting quality of the solid, and $h_{s f}$ is the latent heat of fusion. In a finite difference - form Eq. (10) is given by

$$
x_{s i}=x_{s i}^{*}+\frac{d t}{\rho h_{s f}}\left\{k\left(\frac{T_{i+1}^{*}+T_{i-1}^{*}-2 T_{i}^{*}}{\Delta z^{2}}\right)+q^{\prime \prime \prime}\right\} .
$$

Equation (16) is the conservation equation involving a material vaporization process, and Eq. (17) is its finite difference approximation.

$$
k \frac{d^{2} T}{d z^{2}}+q^{\prime \prime \prime}=\rho h_{f g} \frac{d x_{f}}{d t},
$$

where $x_{f}$ is the mass quality of the liquid, and $h_{f g}$ is the latent heat of vaporization.

$$
x_{f i}=x_{f i}^{*}+\frac{\Delta t}{\rho h_{f 8}}\left\{k\left(\frac{T_{i+1}^{*}+T^{*}{ }_{i-1}-2 T_{i}^{*}}{\Delta z^{2}}\right)+q^{\prime \prime \prime}\right\}
$$


The qualities $x_{s}$ and $x_{f}$ are defined over a range from zero to one. When the value of $x_{s}$ is zero, the node is fully solid, and when $x_{s}$ is equal to one, the node is liquid. Similarly, when material changes phases from liquid to vapor, $x_{f}$ tracks the quality in an analogous manner.

An implicit method determines the transient temperature solution to Eq. (8). When melting or vaporization temperature of node $i$ is reached, the temperature in the main matrix for node $i$ is set to a constant melting temperature until the node fully melts or vaporizes. During the phase change process, energy equation for $\mathrm{i}^{\text {th }}$ node is given by Eqs. (17) or (19). These equations consider the energy deposited in the node and the energy flowing into or out of the node to determine the new quality. To solve the conservation equations, fuel plate boundary conditions have to be defined. The left boundary corresponds to the center line of the fuel (symmetry boundary condition) and the right boundary corresponds to the edge (convective/radiative boundary condition). The boundary conditions are given by Eqs. (20) and (21), respectively:

$$
\begin{aligned}
& \frac{d T}{d z}=0, \text { and } \\
& k \frac{d T(L, t)}{d z}=h\left(T(L, t)-T_{\text {inf }}\right),
\end{aligned}
$$

where $h$ is the heat transfer coefficient for the plate surface and $T_{\text {inf }}$ is the bulk coolant temperature. Section 4.2 discusses the heat transfer coefficient modeling approach in more detail.

Results from this modeling method have been compared with thermal simulations using HEATING 7 code $^{14}$. The spatial temperature predictions were always within $4 \%$ of each other.

\subsection{Plate SURFACE HEAT TRANSFER COEFFICIENT}

Energy that is transferred from the surface of a heated fuel plate to the coolant is a function of temperature difference between the fuel plate surface and the medium that surrounds the fuel plate. Depending on the temperature of the fuel plate and the amount of energy that is generated in the plate, the heat transfer between the plate and the fluid can fall into several regimes. One regime corresponds to convective heat transfer from the surface to the liquid. The second region corresponds to the nucleate boiling regime or subcooled boiling, and the third region corresponds to the film boiling regime. Heat transfer characteristics in each of the states can be predicted using established steady state heat transfer correlations if the temperature of the plate surface does not change rapidly. If the surface changes rapidly, then the steady state heat transfer from the surface to the fluid may not be appropriate. Heat transfer during rapid transients can be significantly enhanced.

The mechanism by which the heat transfer is enhanced has to do with the physical characteristics of bubble formation process. Physical characteristics of bubble formation tend to change the liquid boundary layer condition. These bubble formation characteristics tend to change with the frequency of the energy generation. 12 For very short periods (high frequencies) heat transfer is significantly enhanced by the production of a larger number of bubbles that are smaller in size. The heat transfer enhancement can be up to 10 times larger than the heat transfer measured at steady state conditions 13,14 .

The question that needs to be answered consists of determining the effective fraction of energy that the plate rejects by the transient boiling mechanism vs the amount of energy rejected 
while in the film boiling stage. Analysis shows that the energy rejection mechanism for lower energy deposition where temperature of the plate does not enter film boiling regime is dominated by the transient boiling phenomena. If the energy deposition is large, the effect of the transient boiling heat transfer is not sufficient to justify a complex heat transfer model because the film boiling is reached quickly and the film boiling regime dominates the heat rejection mode.

For, large energy depositions such as in the cases where dispersion occurs, the film boiling condition is reached rapidly (viz., during the first $10 \%$ time duration of the pulse). Therefore, the heat transfer coefficient is not significantly affected by the transient nature of nucleate boiling heat transfer as much as during the lower energy deposition tests. [2] 


\section{SOURCES OF ENERGY}

There are several sources of energy that a fuel plate can experience during a pulse type transient. One source of energy is caused by fission heating of energy where uranium atoms release energy during fissioning process. The second source of energy is caused by chemical reaction. The chemical energy can be released by two processes. The first process is caused by the energy released when fuel particles react exothermically with the aluminum. The second process is caused by aluminum reaction with oxygen in water to form aluminum oxide. The following subsections describe the treatment of each of the energy release processes.

\subsection{FISSION ENERGY}

The fission energy during a pulse type tests is deposited into the test specimen (fuel ) by neutron interaction with the uranium-235. The energy release follows the neutron flux level during the transient given by:

$$
P(t)=\gamma \Sigma_{f} \phi(t) .
$$

where

$P(t)$ is the time dependent energy density generation rate $\left(W / m^{3}\right)$

$$
\begin{aligned}
& \gamma \text { - energy released per fission (J) } \\
& \phi \text { - neutron flux (neutrons } / \mathrm{cm}^{2} / \mathrm{s} \text { ) } \\
& \Sigma_{\mathrm{f}} \text { - fission cross section }(1 / \mathrm{cm})
\end{aligned}
$$

Determining the energy deposition is more involved than simply taking the neutron flux and integrating it over time. The complexity is caused by the inability to accurately measure the neutron flux incident on the plate. A method used to estimate the cumulative time integrated incident flux consists of identifying the activity of fission products in the irradiated fuel plate. Based on the activity of certain isotopes, total number of fission are back calculated. This activity represents the cumulative neutron-uranium interactions. Neutron flux from every nuclear reactor has a prompt and delayed neutron spectrum. Since the component of energy that is released immediately during the pulse is of interest, prompt and delayed neutron components need to be known for each transient. If the delayed neutrons are not subtracted, the amount of energy predicted by using the measured fission product activity can be overestimated. This detail of predicting the amount of energy deposited can be found in a paper presented by Ohnishi et. al 11 .

Each transient has its own specific ratio of prompt to delayed neutron fractions that has to be determined for each test. This procedure also depends on the type of test specimen. Once the calculation is performed to determine the cumulative amount of prompt energy that is deposited in the fuel plate, the temporal neutron flux distribution is then used as a shape function to distribute the energy.

The method in the evaluations is described in the following Sects. 5.1.1 and 5.1.2 for NSRR tests an TREAT tests respectively. 


\subsubsection{NSRR Energy Depositions Transients}

As mentioned previously, examination of the irradiated fuel leads to determination of the amount of energy deposited in the fuel plates. The temporal shape of the prompt neutron flux is obtained from the measurement taken at the experimental facility. The time vs neutron flux data points from the experiment was then interpolated and normalized such that the integral of the neutron flux multiplied by the energy release per fission corresponded to the total number of prompt fissions within the plate.

$$
\dot{Q}(t)=E \frac{\phi(t)}{\int_{0}^{\tau} \phi(t) d t} \quad 0<t<\tau .
$$

Where:

$Q=$ energy release rate

$\phi=$ neutron flux

$\mathrm{E}=$ Energy released during the transient. $(\mathrm{J})$

$\tau=$ time span of the transient

Two types of fuel plate samples irradiated the NSRR facility. One was the JMTR fuel and the second was ANS reactor fuel. The tested fuel was $\mathrm{U}_{3} \mathrm{Si}_{2}$ aluminum based fuel. The two types of fuel samples had the same overall dimensions. Therefore, the difference between the samples was the fuel meat density, fuel meat thickness, and cladding thickness. Figure 3 represents the JMTR fuel plate and Fig. 4 represents the dimensions of the ANS fuel plate.

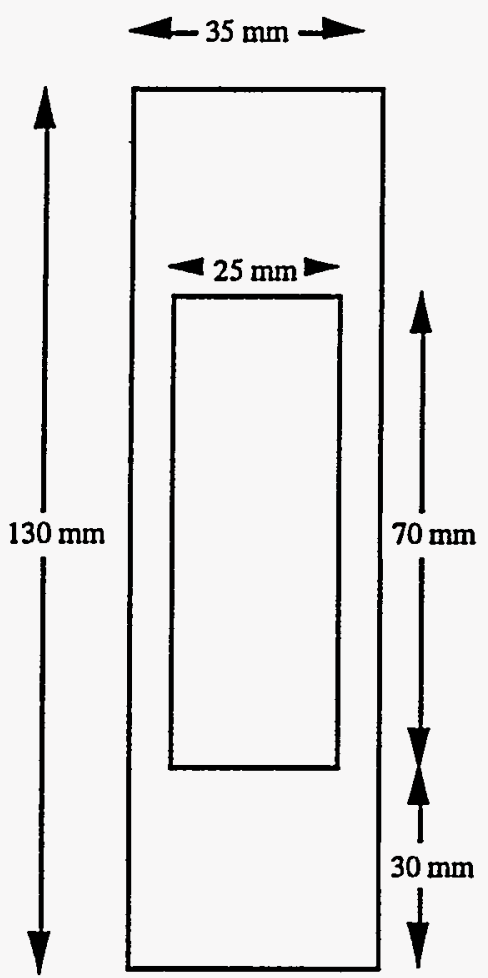

Front view of the JMTR plate with dimension

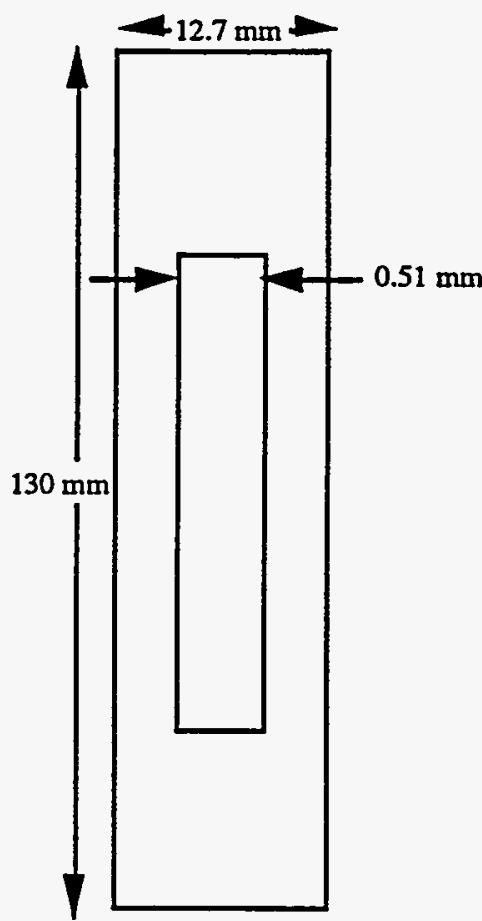

Profile of the JMTR fuel plate with dimensions

Fig. 3. Illustration of the JMTR fuel plates irradiated in the NSRR. 
Table 1 shows the number of tests and the corresponding test conditions for the JMTR test.

Table 1. JMTR tests in NSRR facility

\begin{tabular}{|c|c|c|}
\hline Test ID & $\begin{array}{c}\text { Energy Deposited } \\
\text { into JMTR } \\
\text { Mini-Fuel Plate (kJ) }\end{array}$ & Notes \\
\hline $\mathbf{5 0 8 - 5 1}$ & 7.74 & plate melted \\
\hline $\mathbf{5 0 8 - 5 2}$ & 9.17 & plate melted \\
\hline $\mathbf{5 0 8 - 5 3}$ & 10.81 & plate melted \\
\hline $\mathbf{5 0 8 - 5 4}$ & 12.25 & Melted \& Relocated \\
\hline $\mathbf{5 0 8 - 5 5}$ & 13.71 & Melted \& Relocated \\
\hline $\mathbf{5 0 8 - 5 6}$ & 16.05 & Fuel Dispersion \\
\hline
\end{tabular}

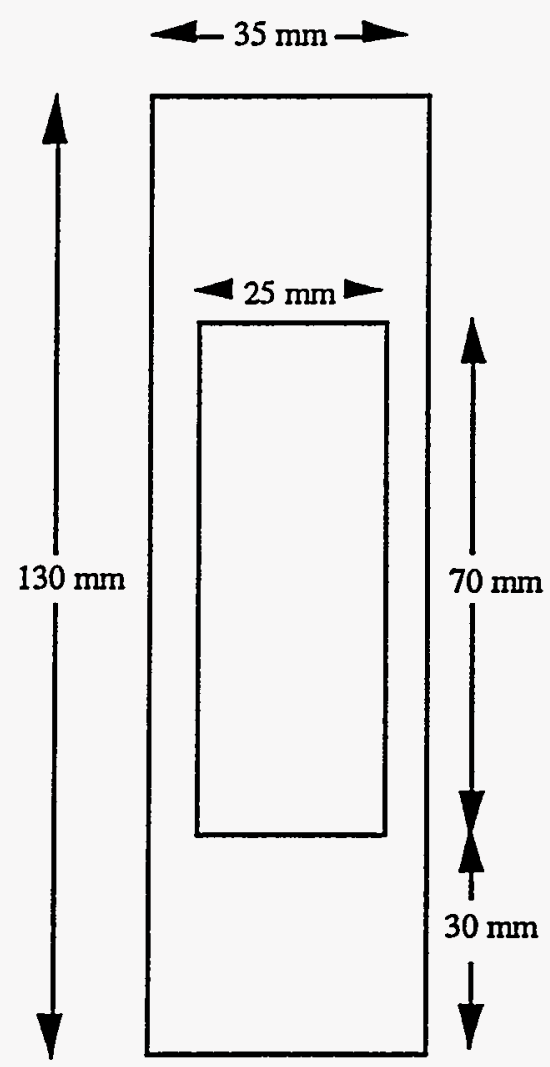

Front view of the ANS plate with dimension

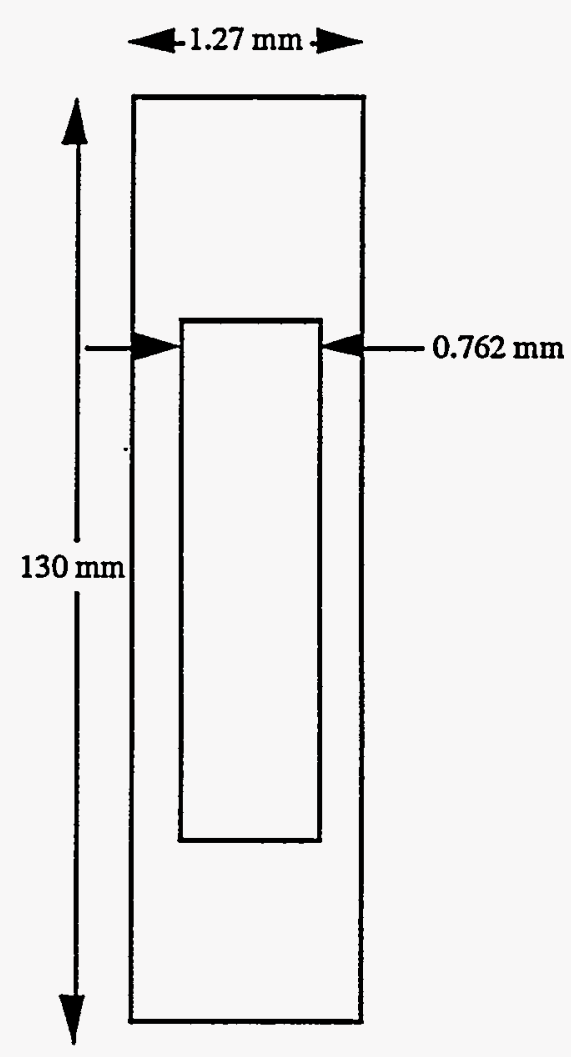

Profile of the ANS fuel plate with dimensions

Fig. 4. ANS fuel plate dimensions 
Table 2 shows the test and corresponding energy deposited.

Table 2. ANS fuel tests in NSSR facility

\begin{tabular}{|c|c|c|}
\hline $\begin{array}{c}\text { Test } \\
\text { ID }\end{array}$ & $\begin{array}{c}\text { Energy } \\
\text { Deposited } \\
\text { (KJ) }\end{array}$ & Notes \\
\hline $518-1$ & 3.3 & $\begin{array}{c}\text { Inadequate homogeneity - } \\
\text { plate developed cracks }\end{array}$ \\
\hline $518-2$ & 5.2 & $\begin{array}{c}\text { Inadequate homogeneity - } \\
\text { some melting }\end{array}$ \\
\hline $518-3$ & 3.5 & No failure \\
\hline $\mathbf{5 1 8 - 4}$ & 2.5 & No failure \\
\hline $\mathbf{5 1 8 - 5}$ & 5.66 & Melting occured \\
\hline
\end{tabular}

Summary of the test results will be outlined in the results section of this report.

\subsubsection{TREAT Energy Deposition Transients}

TREAT series of experiments were not as easy to simulate because the only information about the pulse width was given in terms of initial reactor period. The reactor period was used to determine the width of the pulse by estimating the pulse width at half maximum. Exponents in the Eq. (23) were determined for each transient

$$
q(t)=q_{o} K\left(t_{o}\right) t^{n}\left(e^{-\pi}\right)^{m} \quad 0<\mathrm{t}<\mathrm{t}_{0},
$$

where $q_{0}$ is the prompt fission energy deposited during the transient, $t_{0}$ is the duration of the pulse, and the normalization factor $\mathrm{K}\left(\mathrm{t}_{0}\right)$ is given by:

$$
K\left(t_{0}\right)=\frac{1}{\int_{0}^{t_{0}} t^{n}\left(e^{-\pi t}\right)^{m} d t},
$$

It is important to note that the Eq. (23) only approximates the temporal pulse shape. Numerical simulation of the tests performed for the ANS and JMTR fuel plate tests have revealed that for short transients, the thermal response is very sensitive to the shape of the transient. For longer transients the thermal response is not as sensitive.

The HFIR and SL-1 reactor fuel plate samples for the TREAT tests were dimensionally much smaller than the fuel tested in the NSRR reactor. Fig. 5 shows the dimension of the SL-1 fuel plate sample. The SL-1 fuel plate samples were also uncladded fuel plate samples. Fig. 6 shows the dimensions of the HFIR fuel plates used in the tests. The plates where again smaller in size than the ANS and JMTR plates but were cladded. Tables 3 and 4 display the information for different tests and the associated energy deposited in the fuel sample along with the pulse width for SL-1 and HFIR fuel plates respectively. 

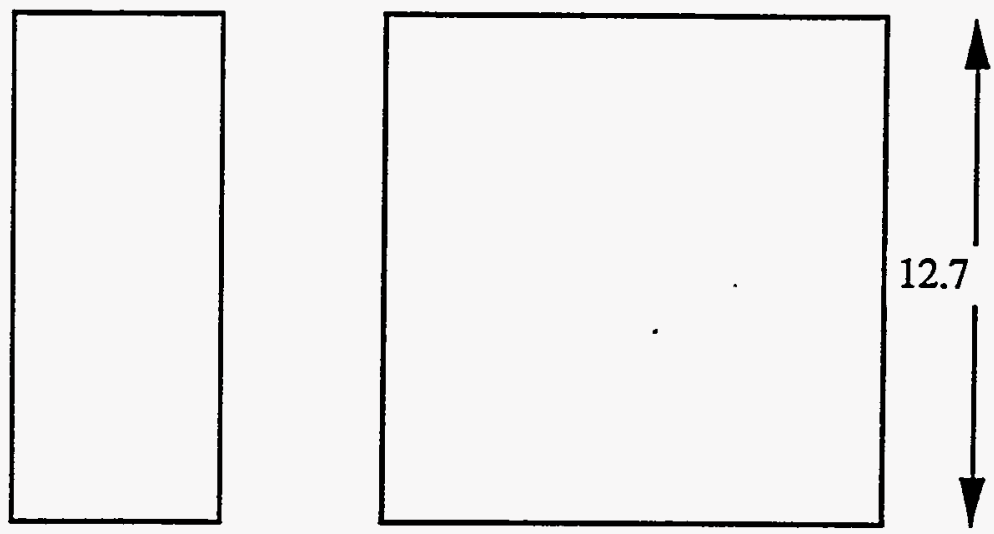

$12.7 \mathrm{~mm}$

$\longrightarrow 5 \mathrm{~mm}$

Fig. 5. Dimensions of the SL-1 fuel plate tested in treat facility.

Table 3. SL-1 fuel tests in TREAT facility

\begin{tabular}{|c|c|c|c|c|c|}
\hline \multirow{2}{*}{$\begin{array}{c}\text { Test } \\
\text { ID }\end{array}$} & \multicolumn{3}{|c|}{$\begin{array}{c}\text { Energy Deposited into unclad } \\
\text { SL-1 Reactor Fuel Plates }\end{array}$} & \multirow{2}{*}{ Notes } \\
\cline { 2 - 5 } & $\begin{array}{c}\text { KJ/g of } \\
\text { fuel }\end{array}$ & $\begin{array}{c}\text { KJ in the } \\
\text { fuel plate }\end{array}$ & $\begin{array}{c}\text { Reactor } \\
\text { Period } \\
\text { (ms) }\end{array}$ & $\begin{array}{c}\text { Pulse } \\
\text { Width } \\
\text { (ms) }\end{array}$ & \\
\hline CEN 114 & 1.21 & 3.150 & 112 & 925 & $\begin{array}{c}\text { melted and bulged retaining } \\
\text { original shape }\end{array}$ \\
\hline CEN 97 & 1.67 & 4.35 & 79 & 671 & melted into one globule \\
\hline CEN 121 & 1.98 & 5.148 & 79 & 671 & $\begin{array}{c}\text { Melted into one semi-circular } \\
\text { globule }\end{array}$ \\
\hline CEN 122 & 2.23 & 5.38 & 79 & 671 & Melted into one spherical globule \\
\hline CEN 123 & 2.23 & 5.29 & 79 & 671 & Melted into one spherical globule \\
\hline CEN 115 & 2.43 & 6.39 & 77 & 650 & Melted and fragmented \\
\hline CEN 116 & 2.8 & 7.25 & 62 & 530 & Melted and fragmented \\
\hline CEN 98 & 3.1 & 7.9 & 51 & 433 & $\begin{array}{c}\text { Melted and dispersed particles } \\
\text { welded to inner surfaces of } \\
\text { autoclave }\end{array}$ \\
\hline CEN 137 & 3.69 & 9.2 & 54 & 460 & Melted and fragmented \\
\hline CEN 99 & 4.29 & 10.76 & 50 & 425 & $\begin{array}{c}\text { Melted and dispersed particles } \\
\text { welded to inner surfaces of } \\
\text { autoclave }\end{array}$ \\
\hline CEN 138 & 5.78 & 15.68 & 41 & 330 & Melled and fragmented \\
\hline
\end{tabular}


Equations (23 and 24) were used for the HFIR. Table 4 shows the list of HFIR fuel plate tests performing in the TREAT facility.
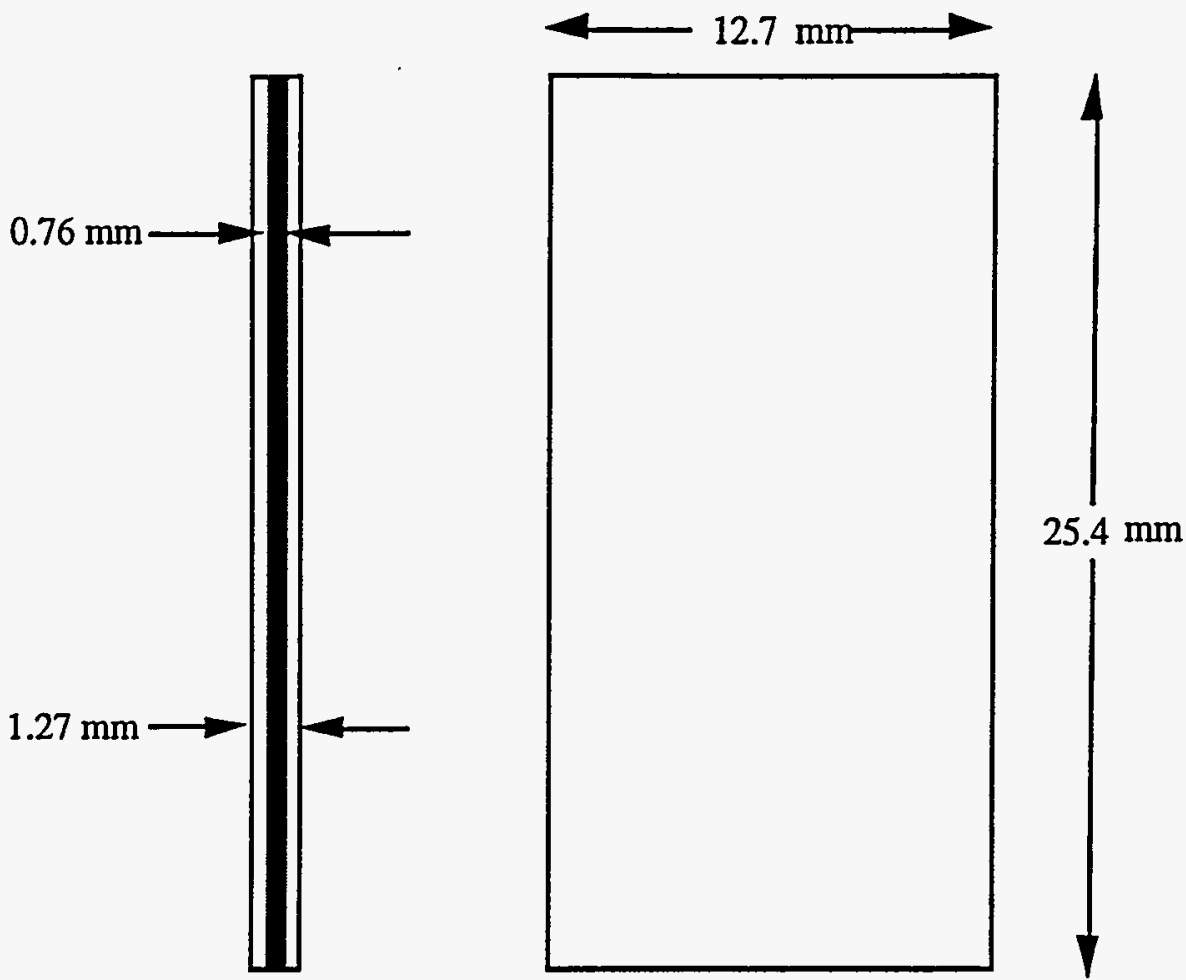

Fig.6 Dimensions of the HFIR fuel plate tested in the treat facility.

Table 4. General description of tests performed on the HFIR fuel in the TREAT facility.

\begin{tabular}{|c|c|c|c|c|c|}
\hline \multirow{2}{*}{$\begin{array}{c}\text { Test } \\
\text { ID }\end{array}$} & \multicolumn{3}{|c|}{ Energy Deposited into HFIR Reactor Fuel } & \multirow{2}{*}{ Notes } \\
\cline { 2 - 5 } & $\begin{array}{c}\text { Initial } \\
\text { Plates } \\
\text { therature of } \\
\text { coolant (K) }\end{array}$ & $\begin{array}{c}\text { KJ in the fuel } \\
\text { plate }\end{array}$ & $\begin{array}{c}\text { Reactor } \\
\text { Period (ms) }\end{array}$ & $\begin{array}{c}\text { Approximate } \\
\text { Pulse Width } \\
\text { (ms) }\end{array}$ & \\
\hline CEN 198 & 303 & 0.721 & 156 & 1291 & \\
\hline CEN 200 & 303 & 1.823 & 150 & 1252 & \\
\hline CEN 199 & 303 & 2.272 & 112 & 925 & \\
\hline CEN 201 & 303 & 2.306 & 10.3 & 85 & \\
\hline CEN 213 & 303 & 2.409 & 10.3 & 85 & \\
\hline CEN 204 & 303 & 3.521 & 112.1 & 925 & Fuel \\
\hline CEN 205 & 303 & 5.798 & 59 & 570 & \\
\hline CEN 210H & 393 & 1.921 & 116 & 959 & \\
\hline CEN 211H & 393 & 2.993 & 62.8 & 518 & \\
\hline CEN 212H & 393 & 4.874 & 65.8 & 543 & \\
\hline CEN 206H & 558 & 2.260 & 109 & 900 & \\
\hline CEN 207H & 558 & 3.592 & 107 & 883 & \\
\hline
\end{tabular}




\subsection{EXOTHERMIC ENERGY RELEASE FROM FUEL-AL REACTION}

Several research reactors use cermet-type fuels like $\mathrm{U}_{3} \mathrm{O}_{8}-\mathrm{Al}$ or $\mathrm{U}_{3} \mathrm{Si}_{2}-\mathrm{Al}$ mixtures. Such mixtures undergo a themitic reaction once the aluminum melts. The reaction rate varies with the

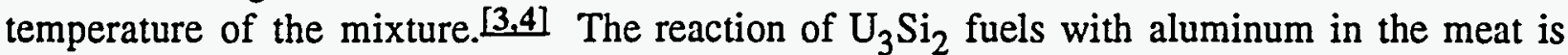
exothermic and releases anywhere between 0.3 and $0.35 \mathrm{MJ} / \mathrm{kg}$ of $\mathrm{U}_{3} \mathrm{Si}_{2}$, depending on the volume fraction of the fuel in the meat. The reaction begins at a very slow rate when aluminum reaches its melting temperature at $900 \mathrm{~K}$ and increases rapidly as the temperature increases. When fuel particles melt, the reaction rate is the fastest. The reaction of $\mathrm{U}_{3} \mathrm{O}_{8}$ fuels with aluminum in the meat is also exothermic and releases $0.75 \mathrm{MJ} / \mathrm{kg}$ of $\mathrm{U}_{3} \mathrm{O}_{8}$. The range of temperature when the energy release occurs for the $\mathrm{U}_{3} \mathrm{O}_{8}-\mathrm{Al}$ reaction is not the same as the temperature range for the $\mathrm{U}_{3} \mathrm{Si}_{2}$ - Al reaction. $\mathrm{U}_{3} \mathrm{O}_{8}$ releases energy in temperature bands. This effect will be described in Sect. 6.2.2. The difference in the energy release is primarily caused by the material properties of the fuel and aluminum. $\mathrm{U}_{3} \mathrm{Si}_{2}$ tends to behave as inter-metallic compound whereas $\mathrm{U}_{3} \mathrm{O}_{8}$ acts as a ceramic material embedded in the aluminum matrix.

The main problem with modeling the reaction rate process is that the rate of these reactions as a function of rate and magnitude of temperature changes are not well known; therefore, implementation of the energy deposition over a wrong time scale could significantly affect the predicted results.

The chemical reaction between fuel particle and aluminum is a diffusion controlled process that is highly temperature dependent. Section of the fuel meat is illustrated by Fig. 6. It shows that the $\mathrm{U}_{3} \mathrm{Si}_{2}$ fuel particles are dispersed in an aluminum filer material. $\mathrm{U}_{3} \mathrm{O}_{8}$ fuel is similarly dispersed in aluminum filer. When both aluminum and $\mathrm{U}_{3} \mathrm{Si}_{2}$ are in the solid state the diffusion between the two components is minimal. When aluminum melts, the reaction takes place over a period of many minutes ${ }^{\mathbf{3}}$ (this is a very large time scale compared to the fission pulse width that is approximately $10-80 \mathrm{~ms}$ for NSRR fuel tests and $100 \mathrm{~ms}$ to 1 second in duration for TREAT facility tests). It is also known that the reaction between the fuel particle and the aluminum in the meat is very rapid when $\mathrm{U}_{3} \mathrm{Si}_{2}$ particles begin to melt. $\mathrm{U}_{3} \mathrm{O}_{8}$ fuel exhibits the first exothermal reaction at the melting temperature of the aluminum. One could expect an extremely rapid and complete reaction to occur if the temperature exceeds the melting temperature of the fuel particles assuming sufficient aluminum is available. This rate would be governed by the diffusion of two liquids.

In general, diffusion of a material in a multi-component system is a complex preocess. There are four separate diffusion effects that can cause migration of material from one location to another and cause chemical reaction to take place. These diffusion mechanisms are given by Eq. (21).

$$
\mathrm{j}_{\mathrm{i}}=\mathrm{j}_{\mathrm{i}}^{\mathrm{x}}+\mathrm{j}_{\mathrm{i}}^{\mathrm{p}}+\mathrm{j}_{\mathrm{i}}^{\mathrm{g}}+\mathrm{j}_{\mathrm{i}}^{\mathrm{T}},
$$

where $j_{i}$ is the total net mass flux of component $i$, and superscripts $x, p, g$, and $T$ represent the components of diffusion by concentration gradient, diffusion by pressure gradient, diffusion induced by gravity, and diffusion caused by a temperature gradient.

$$
j_{i}^{x}=\frac{c^{2}}{\rho R T} \sum_{j=1}^{n} M_{i} M_{j} D_{i j}\left[x_{j} \sum_{\substack{k=j \\ k \neq j}}\left(\frac{\partial \bar{G}_{j}}{\partial x_{k}}\right)_{\substack{T, p, x_{k} \\ s \neq j, k}} \nabla x_{k}\right]
$$




$$
\begin{aligned}
& j_{i}^{p}=-\frac{c^{2}}{\rho R T} \sum_{j=1}^{n} M_{i} M_{j} D_{i j}\left[x_{j} M_{j}\left(\frac{\bar{V}_{j}}{M_{j}}-\frac{1}{\rho}\right) \nabla p\right], \\
& j_{i}^{g}=-\frac{c}{\rho R T} \sum_{j=1}^{n} M_{i} M_{j} D_{i j}\left[x_{j} M_{j}\left(g_{j}-\sum_{k=1}^{n} \frac{\rho_{k}}{\rho} g_{k}\right)\right], \\
& j_{i}^{T}=-D_{i}^{T} \nabla \ln T,
\end{aligned}
$$

where $G, V, M, \rho$, and c are partial molar free enthalpy (Gibbs free energy), volume, molar mass, universal gas constant, and speed of sound respectively.

To determine the reaction rate, i.e. energy release rate, the diffusion process has to be determined. This is a complex process and due to the limited data available to model the process, the method used to approximate the reaction rate did not use Eqs. (25-29). The method used to determine the reaction rate is empirical and it is outlined in the following section.

\subsubsection{Empirical Method of Determining Reaction Rates}

Reaction rate is expressed in terms of $f$, the total fraction of fuel particle that reacts with the aluminum, multiplied by the energy released by unit mass of the fuel given by Eq. 30 .

$$
\dot{\mathrm{Q}}=\mathrm{f}^{\prime}(\mathrm{t}) \mathrm{E} \text {, }
$$

where $Q$ is the energy release rate per unit mass of the fuel particle (W/kg), $E$ is the energy released per unit mass $(\mathrm{J} / \mathrm{kg})$, and $\mathrm{f}^{\prime}(\mathrm{t})$ is the rate of change of reacted fraction $(1 / \mathrm{s})$. Therefore, rate of change of reacted fraction of the fuel particle needs to be determined. To determine an empirical form of the equation, conditions need to be imposed on the equation. These conditions are:

1) At time equal to infinity the particle fully reacts under all conditions. Therefore, reacted fraction is equal to 1 and the rate of change of reacted fraction is equal to 0 .

$$
\begin{array}{r}
f(t \rightarrow \infty)=1 \\
f^{\prime}(t \rightarrow \infty)=0
\end{array}
$$

2) At time equal to zero, the reacted fraction is equal to zero and rate of change of reacted fraction is given by Eqs. (33 and 34).

$$
\begin{aligned}
& f(0)=0, \\
& f^{\prime}(0)=C\{T(t=0)\},
\end{aligned}
$$

where $\mathrm{C}$ is the initial fractional rate of change of reacted fuel. This parameter is temperature dependent.

3) As reaction progresses the diffusion through the newly formed layer will retard the reaction 
leading to slower reaction rates. Therefore, the presence of reacted material is assumed to increase the resistance to the diffusion and will retard the reaction rate.

$$
\mathrm{f}^{\prime}(\mathrm{t}) \propto\left\{\mathrm{C}_{1}-\mathrm{f}(\mathrm{t})\right\}
$$

Combining Eqns. (31), (32), and (35) results in $C_{1}$ being equal to 1 . This also satisfies the initial condition given by Eqns. (33) and (34).

$$
\mathrm{f}^{\prime}(\mathrm{t}) \propto\{1-\mathrm{f}(\mathrm{t})\}
$$

Removing a proportionality and replacing it with a reaction rate constant, results in Eq. (37).

$$
f^{\prime}(t)=\lambda(t)\{1-f(t)\}
$$

Therefore, the final equation is given by Eq. (37), where $\lambda$ is the effective rate coefficient $(1 / s)$. This model obeys the set of conditions such as: reacted fuel fraction at infinite time is equal to 1 and that the rate of change of the fuel fraction at that time is equal to zero. Depending on the behavior of the effective diffusion coefficient, the reacted fraction can be large or small during a pulse type transient. To model this type of reaction an empirical model was developed and a set of constants were determined using existing data.

The effective rate coefficient is modeled empirically. This approach consists of limiting the rate coefficient to very low values for temperatures below the melting temperature of the aluminum and limiting the peak value to the maximum expected rate coefficient when both fuel particles and aluminum are molten. First, a dimensionless temperature $\theta$ was defined as

$$
\theta(t)=\frac{T(t)-T m_{1}}{T m_{2}-T m_{1}}
$$

where $\operatorname{Tm}_{1}$ and $\mathrm{Tm}_{2}$ are melting temperature of the aluminum and melting temperature of the $\mathrm{U}_{3} \mathrm{Si}_{2}$ fuel particles respectively. The dimensionless form was chosen so that the argument is negative when temperature is below the melting temperature of the aluminum and positive form when the temperature is above the aluminum melting temperature. Since the reaction rate is small when aluminum is solid and large when both fuel and aluminum are molten, the large scale change was best modeled by some type of exponential function. Negative arguments of the exponential function are small and positive. Positive arguments of the exponential are large. It is also believed that the reaction rate will be stable and small when both fuel and aluminum are solid and large and stable when both materials are liquid. Therefore, an S - type temperature dependent curve should be imposed. This can be done using a hyperbolic tangent function. Illustrating the effect of these equations, for a given temperature in Fig. 7, the dimensionless temperature for the dominant reaction phase of the fuel is given by Fig. 8 . 


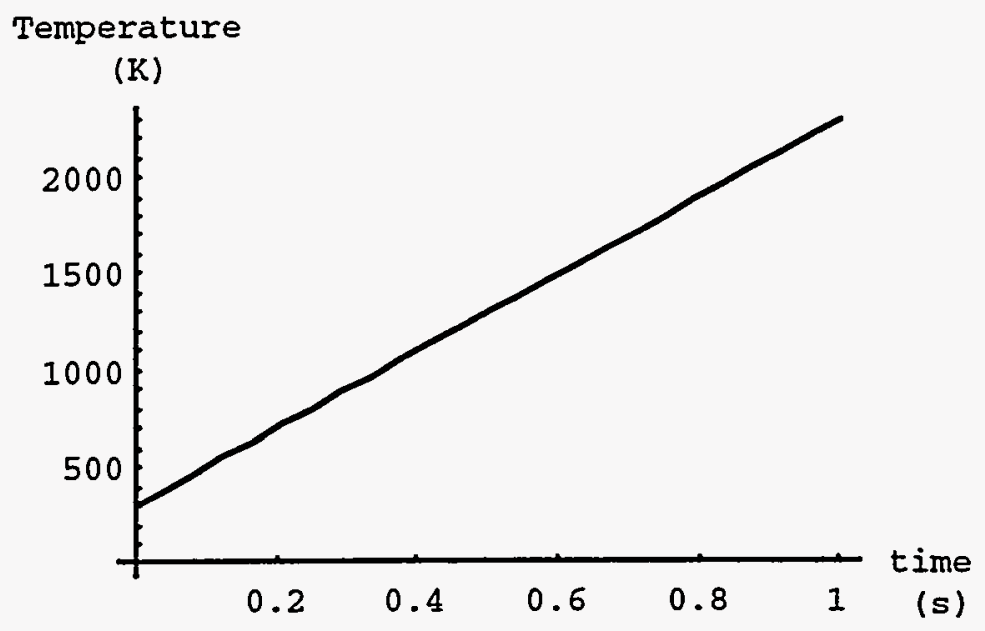

Fig. 7. Temperature profile used to illustrate the modeling approach.

$\theta(t)$

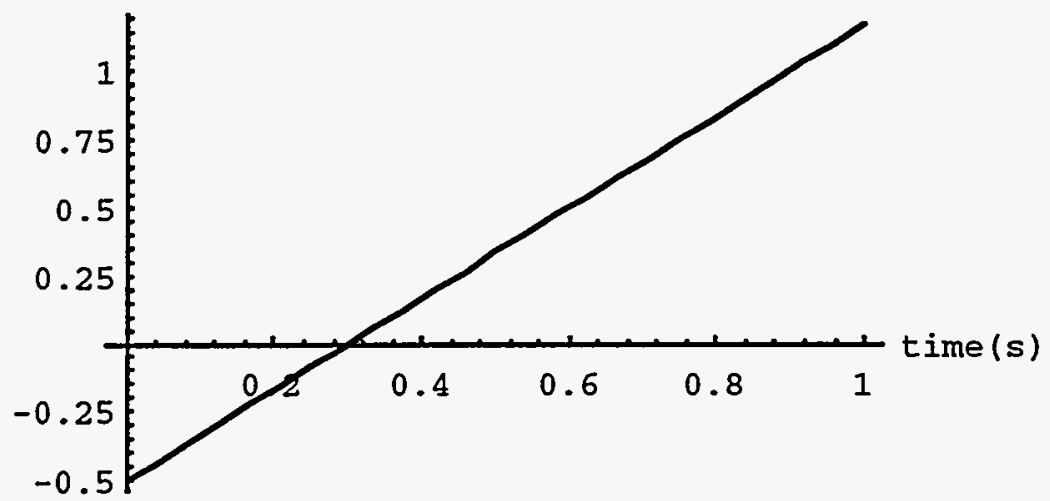

Fig. 8. Dimensionless temperature calculated using Eq. 38 . $\operatorname{Tanh}(\theta)$

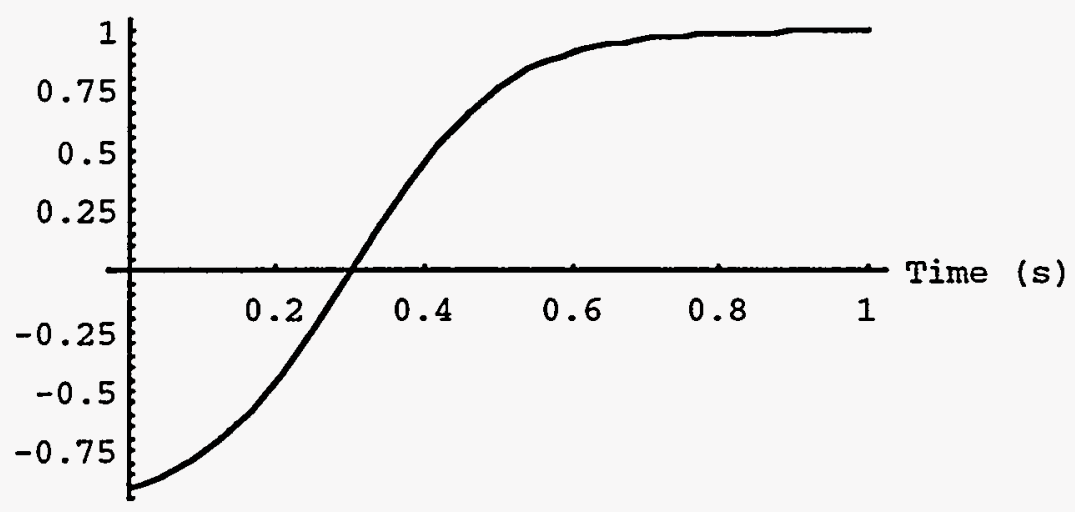

Fig. 9. Hyperbolic tangent of the dimensionless temperature multiplied by a constant $\mathbf{c 3}=3$.

The equation for reaction rate is : 


$$
\lambda(\theta)=c_{1} \operatorname{Exp}\left[c_{2} \tanh \left[c_{3} \theta\right]\right]
$$

where the constants $\mathrm{c} 1, \mathrm{c} 2$, and $\mathrm{c} 3$ are determined and presented in the next section.

To illustrate the effect of imposing Eq. (39) on the given dimensionless temperature profile, the constants were chosen to be: $10^{-4}, 15$, and 3 . With these constants, Fig. 10 is obtained.

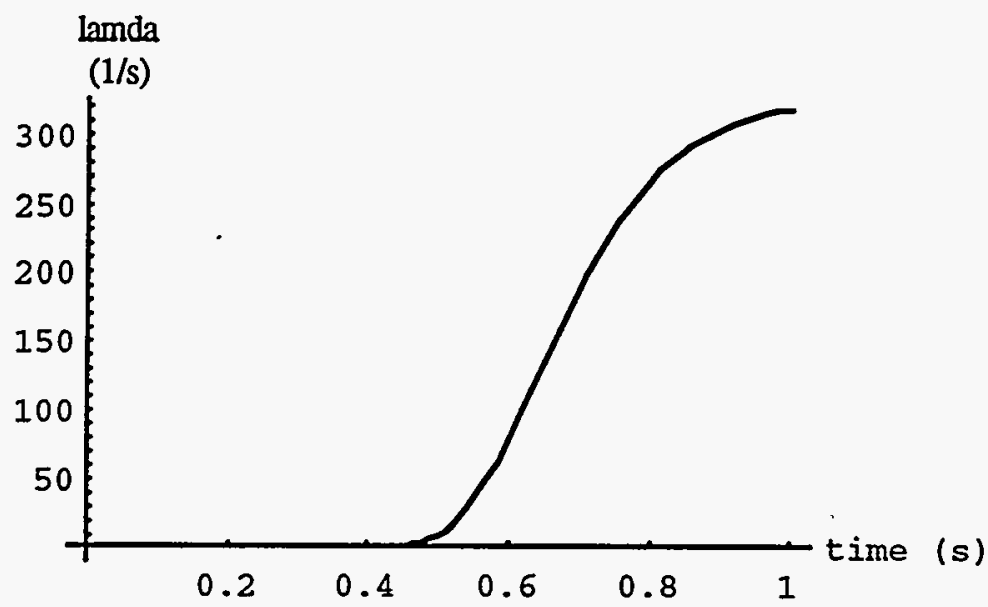

Fig. 10. Illustration of general shape of the reaction rate parameter.

Combination of values of $c_{1}$ and $c_{2}$ will determine the maximum and minimum reaction rates since the value of hyperbolic tangent is between -1 and 1 . Constant $c_{3}$ affects the slope of the hyperbolic tangent curve, affecting the sensitivity of the reaction coefficient to temperature. The next section shows the results of a parametric study relating diffusion parameter constants to the final reacted fraction.

\subsubsection{Effective Diffusion Coefficient for $\mathrm{U}_{3} \mathrm{Si}_{2}$}

There is a limited number of data points available for use with this model. Constant temperature data points at the melting point of aluminum are available along with the data from the several other transient tests. Data given in Table 5 are reported data given in terms of reacted fraction at a particular temperature and the time required to complete the reaction. The following procedure of determining the reaction rate constant assumes the rate is constant at a given temperature and that it varies with temperature. To obtain dimensionless temperature, the melting temperatures of the aluminum and particles are taken to be $T_{\text {melt1 }}=870 \mathrm{~K}$ and $T_{\text {melt2 }}=1973 \mathrm{~K}$, respectively. If the reaction is given by

$$
g^{\prime}(t)=\lambda(T)(1-g(t)),
$$

for a constant temperature, the fraction $\mathrm{g}$ is given by

$$
\begin{aligned}
g(t) & =1-e^{-\lambda(T) r}, \\
\lambda[T] & =\frac{-\ln \left[1-g\left[t_{r}\right]\right]}{t_{r}} .
\end{aligned}
$$


Table 5. Estimated reaction rate parameters for $\mathrm{U}_{3} \mathrm{Si}_{2}$ fuel

\begin{tabular}{|c|c|c|c|c|}
\hline $\begin{array}{c}\text { Temperature } \\
(\mathrm{K})\end{array}$ & $\begin{array}{c}\text { Dimensionless } \\
\text { Temperature }\end{array}$ & $\begin{array}{c}\text { Reacted } \\
\text { Fraction }\end{array}$ & Reaction time (s) & $\begin{array}{c}\text { Reaction rate } \\
\text { constant } \lambda\end{array}$ \\
\hline 300 & -0.45 & 0.9 & $8.6 \mathrm{e} 6$ & $2.6 \mathrm{e}-7$ \\
900 & 0 & 0.9 & 600.0 & 0.00384 \\
1400 & 0.384 & 0.6 & 1.0 & 0.916 \\
1973 & 1 & 0.9 & $5.0 \mathrm{e}-3$ & 460 \\
\hline
\end{tabular}

Plotting the data on a log based plot as shown in Fig. 11, and by an iterative process the coefficients $\mathrm{cl}, \mathrm{c2}$, and $\mathrm{c} 3$ in Eq. (39) are determined.

$$
\lambda(\theta)=c_{1} \operatorname{Exp}\left[c_{2} \tanh \left(c_{3} \theta\right)\right]
$$

Fig. 12 illustrates the effect of this modeling method on the total predicted energy for the 508 - 54 in NSRR reactor. More detailed evaluations can be found in appendix A where all the plots for each test show the fission and chemical energy deposited in the fuel sample. As it can be seen in Fig.12 the energy contribution from the chemical reaction tends to be a significant fraction of the fission energy that is deposited in the fuel sample.

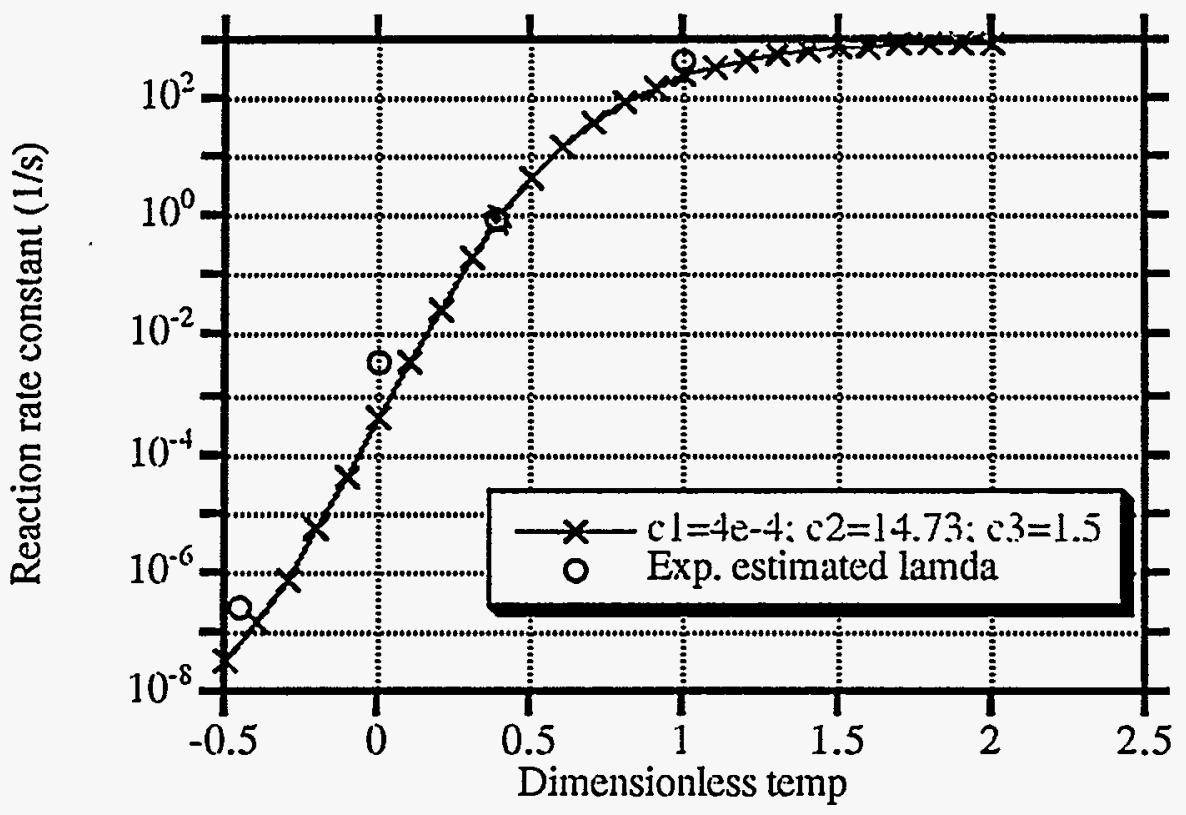

Fig. 11. Comparison of data points to the calculated reaction rate parameter. 


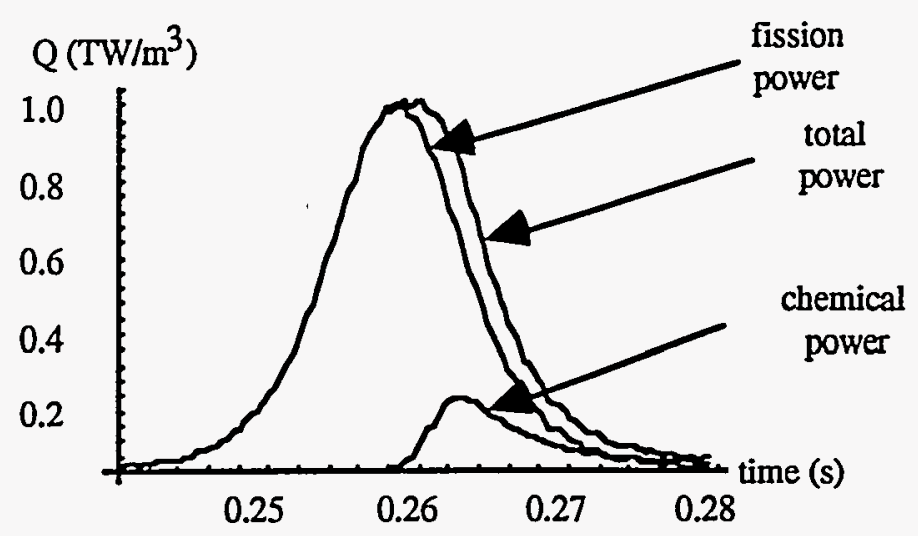

Fig. 12. Components of power density deposited in the fuel plate during a transient test.

\subsubsection{Effective Diffusion Coefficient for $\mathrm{U}_{3} \mathrm{O}_{8}$}

The major difference in which $\mathrm{U}_{3} \mathrm{O}_{8}$ and $\mathrm{U}_{3} \mathrm{Si}_{2}$ react with the aluminum lies in the temperatures at which the reaction takes place and the amount of energy released during the process. The energy released per unit mass of the $\mathrm{U}_{3} \mathrm{O}_{8}$ aluminum mixture is shown in Fig. 13 as a function of fuel aluminum composition.

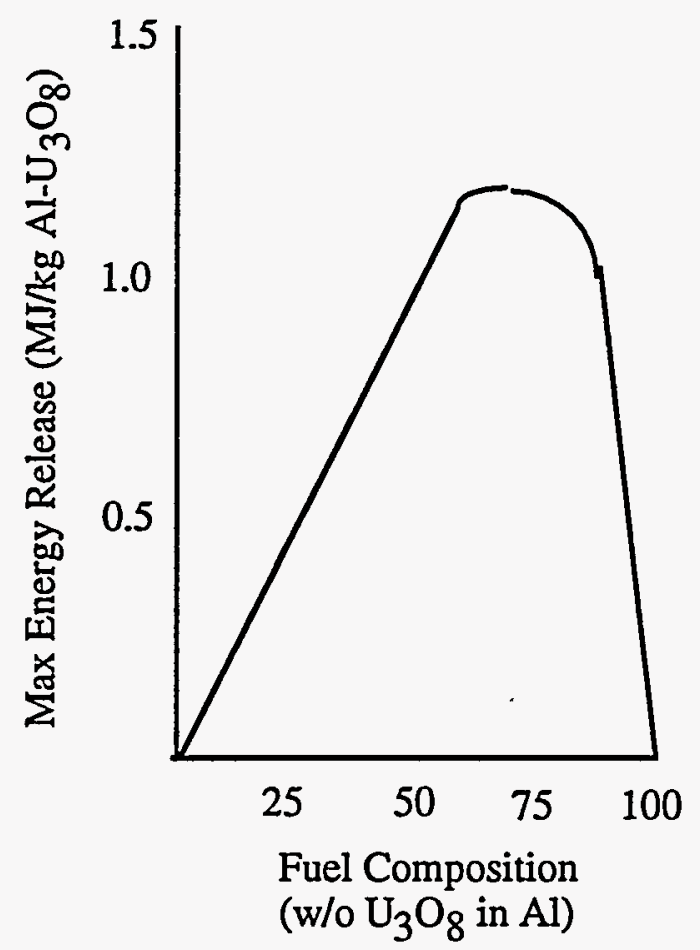

Fig. 13. Energy release as a function of $\mathrm{U}_{3} \mathrm{O}_{8}$ - aluminum mass fraction 
The temperatures at which the reactions take place are over several temperature ranges. First exotherm occurs at temperature close to the melting temperature of the aluminum, approximately $870 \mathrm{~K}$. The second exothermal reaction occurs close to $1220 \mathrm{~K}$. The last exothermal reaction is observed to occur between the $1400-1500 \mathrm{~K}$ temperature range. The onset temperature seems to be affected by the partial conversion of $\mathrm{U}_{3} \mathrm{O}_{8}$ to $\mathrm{U}_{4} \mathrm{O}_{9}$. For this we obtained,

$$
\begin{aligned}
& \lambda(T)=c_{1} \operatorname{Exp}\left[c_{2} \tanh \left[c_{3} \theta_{1}(T)\right]\right]+c_{1} \operatorname{Exp}\left[c_{2} \tanh \left[c_{3} \theta_{2}(T)\right]\right], \\
& \theta_{1}(T)=\frac{T-T_{m 1}}{T_{m 2}-T_{m 1}}, \\
& \theta_{2}(T)=\frac{T-T_{m 3}}{T_{m 4}-T_{m 3}},
\end{aligned}
$$

and $T_{m 1}, T_{m 2}, T_{m 3}$, and $T_{m 4}$ are ranges of temperatures where the chemical reaction occurs.

Taking the value of constants $c_{1}, c_{2}$, and $c_{3}$ in Eq. (44) to be $4.010^{-4}, 14.0$, and 1.1. and plotting Eq. 44 on Fig. 14 one can see that there is a similarity between the $\mathrm{U}_{3} \mathrm{Si}_{2}$ and $\mathrm{U}_{3} \mathrm{O}_{8}$.

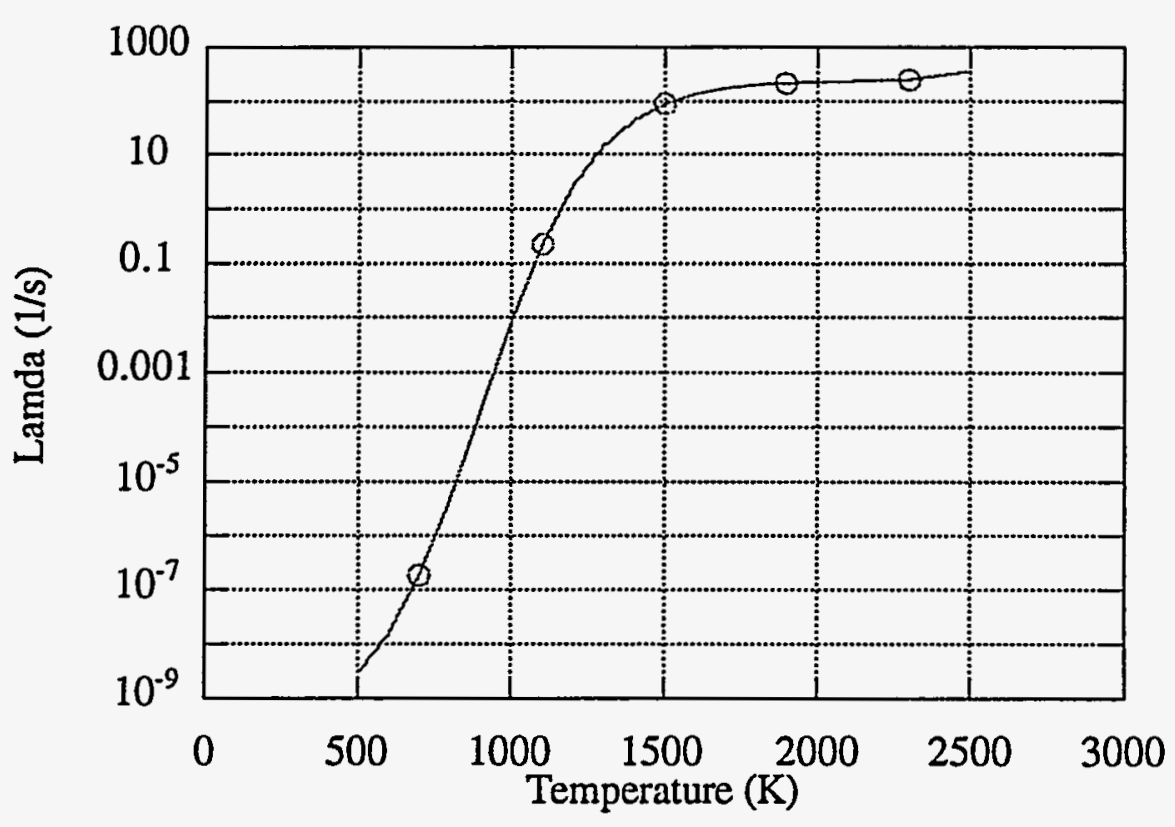

Fig. 14. Reaction rate parameter calculated for $\mathrm{U}_{3} \mathrm{O}_{8}$. 


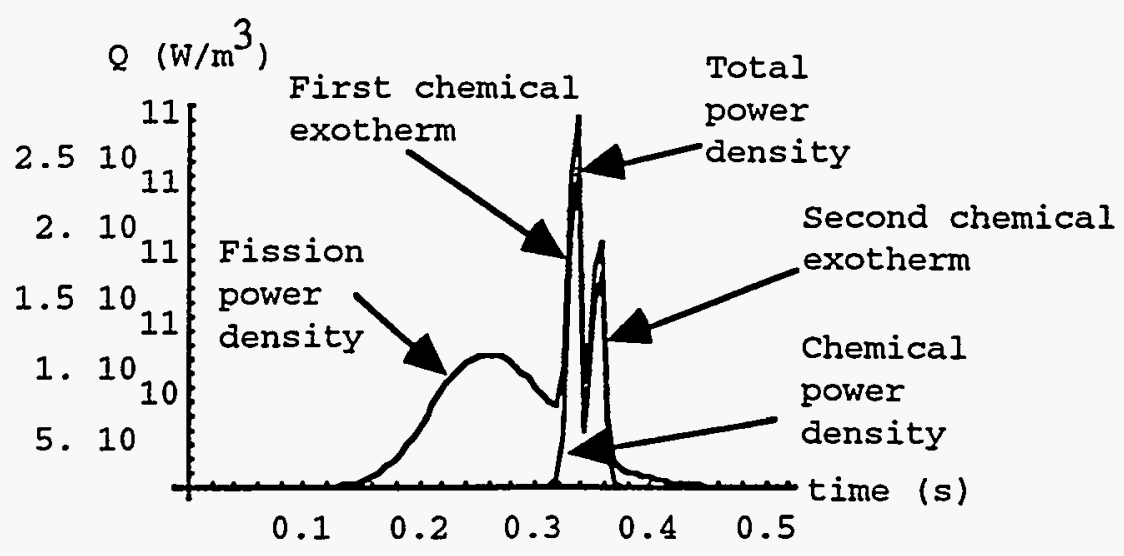

Fig.15 Calculated power deposition density into HFIR fuel plate test caused by fissioning and chemical reaction process during a TREAT test.

This is the same as for the fuel given by Fig. 12, Fig. 15 shows the calculated total power density deposited in the fuel plates during TREAT experiment CEN 211H. As it can be seen from the plot the fission power density is smaller than the predicted chemical energy. Chemical power is larger than the fission although it is much narrower. Despite the modeling uncertainty, this is a significant finding and underscores the importance and relevance of fuel - aluminum reactions. Two peaks are observed because the chemical reaction releases energy over two temperature ranges: one at $1200 \mathrm{~K}$ and the other at $1500 \mathrm{~K}$.

\subsection{ENERGY RELEASE FROM ALUMINUM-WATER REACTION}

The chemical oxidation phenomenon between aluminum and steam is very complex. The energy from its reaction was not included in the temperature predictions. The energy associated with this reaction is approximately $18 \mathrm{MJ} / \mathrm{kg}$. To estimate the error associated with neglect of the reactions, some physical examination of the phenomenological events occurring during the reaction needs to be performed. Two mechanisms by which aluminum oxidizes are vapor phase burning and steam diffusion through the solid/liquid aluminum oxide layer.[5] Fig - 16 illustrates the two effects.

When aluminum is at temperatures where aluminum vapor pressure is appreciable, evaporated aluminum chemically reacts with steam and burns away from the aluminum surface. For this reaction to sustain itself, there has to be steady supply of aluminum vapor and steam that feeds into the reaction. For that process to occur, energy from the reaction needs to be transferred to the aluminum surface. Part of this energy is then used for changing the phase of the aluminum from liquid to vapor.[5] The energy from the oxidation reaction is close to $18 \mathrm{MJ} / \mathrm{kg}$; however, the latent heat of vaporization of aluminum is $10.8 \mathrm{MJ} / \mathrm{kg}$. To sustain the reaction, $60 \%$ of the energy needs to be transferred to the aluminum surface. If an aluminum oxide layer is present on the surface, significant evaporation of aluminum will not occur until the aluminum oxide allows the aluminum vapor to pass though the oxide. This occurs when the temperature of the aluminum oxide reaches $2330 \mathrm{~K}$ (the melting temperature of the aluminum oxide).

The second phenomenon involves diffusive oxidation. When aluminum is in a cold solid state, a thin oxide film builds up rapidly. This oxide forms a protective layer that prevents further diffusion of steam or oxygen, and the reaction ends. The diffusion process is governed by the diffusivity of steam in the oxide layer. As the temperature increases, the diffusivity increases, allowing more steam to penetrate through the oxide layer. As the temperature is increased to the 
melting temperature of the oxide layer, the diffusion coefficient changes rapidly and allows steam to penetrate at a significantly higher rate than when the oxide layer is in the solid state. When aluminum oxide melts, significant chemical oxidation can take place. This oxidation continues until all the aluminum oxidizes or when the temperature of the aluminum oxide falls below solidification temperature. Solidification occurs when heat transfer from the surface exceeds the heat generation rate.

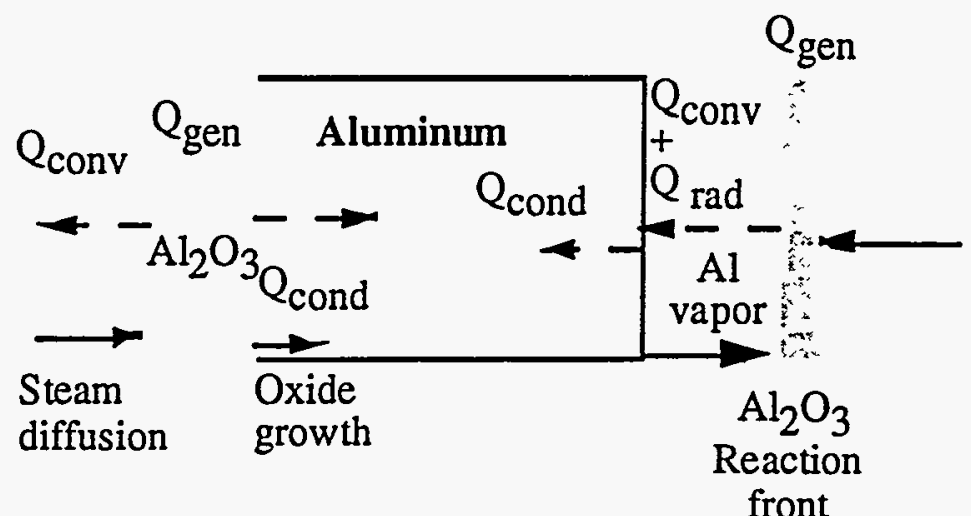

Diffusive oxidation
Vapor phase oxidation

\section{Fig. 16. Illustration of diffusive oxidation and vapor phase burning}

Under certain conditions aluminum ignition can occur at subcooled aluminum oxide temperatures.[5,6] This phenomenon seems to occur when the oxide layer is in a subcooled metastable liquid state and the aluminum surface-area-to-volume ratio is large. Due to the finite time associated with the growth of the aluminum oxide crystal, sufficient steam can diffuse and oxidize a large fraction of aluminum because of the large surface-area-to-volume ration. When the surface-area-to-volume ratio is small, the fraction of oxidized aluminum is also small. The condition that determines whether vapor phase burning or the diffusive oxidation process governs the reaction is not clear. It seems that the vapor phase burning will occur when significant aluminum vapor pressure is exerted. The diffusion-governed oxidation occurs when aluminum oxide is barely molten and diffusion of steam through the aluminum oxide layer is more likely than evaporation of aluminum. Both of these reactions clearly can become predominant at temperatures that are near or above the melting temperature of the aluminum oxide layer. Therefore, oxidation energy clearly becomes an important source when $2330 \mathrm{~K}$ is exceeded. As the following section shows, the available data confirms this effect. The uncertainty in the energy release rate is the main reason for not including the oxidation as the energy source in the analysis. To predict the energy release rate detailed phenomenological models need to be implemented. These models of fundamental processes are not currently available. As shown later by the predictions, most of the deviation in data originates when temperatures are around $2300 \mathrm{~K}$. 


\section{STRAIN RATE MODELING AND ANALYSIS FRAMEWORK}

follows:

Two key assumptions of the present work are noteworthy. These assumptions are as

1. The as-developed model represents the potential for acceleration and not the actual acceleration. The dynamic interaction between expansion and retention forces through material strength properties was not modeled.

2. Because of the insufficient knowledge base, the rate characteristics of the secondary sources of energy were not taken into account. The secondary source of energy not considered is the energy release from aluminum oxidation with steam.

\subsection{THE EFFECT OF NEGLECTING MATERIAL STRENGTH PROPERTIES}

In general, the material cohesive forces will reduce the strain rate and cumulative strain caused by the deposition of energy into a plate. The consequences of not taking into account the effect of material strength properties should therefore be quantified. During a heating transient four separate stages can be identified where material properties change and could influence the retention forces. The four stages are (1) solid, (2) slurry, (3) liquid, and (4) vapor. Restraining force depends on the state of the material.

When energy is deposited into the plate, the fuel changes from solid into liquid. Restraint in the solid is governed by elasticity of the material. The transition from solid to liquid is fuzzy because of eutectic formation. The melting point is not a single temperature but a range of temperatures. The cermet fuels seem to form a viscous slurry. During the slurry stage, it is not known whether the fuel will behave according to Newtonian or Bingham flow mechanism. When fluid properties exhibit non Newtonian behavior, the mixture may have solid like properties for a range of imposed shear stresses and exhibit linear Newtonian behavior past a critical shear stress. Some experimental evidence suggests that the cermet fuel in the plate/ tube geometry remains stiff (solid like) up to very high temperatures that are significantly beyond the melt temperatures of the pure aluminum.[3,4] Further deposition of energy causes full melting and collapse of the fuel plate. When in liquid form, the restraint is caused by the viscosity of the liquid. This restraint is significantly lower than the elasticity-based restraint. Further energy deposition leads to vaporization. Vapor states generally do not display any significant restraint.

The liquid and vapor stages provide very little resistance to flow when compared with the solid and slurry stages. Therefore, the only two stages where material strength effects have to be considered are solid and slurry. As will be shown in the examination of experimental data, dispersion is observed at very high temperatures. Material of the fuel exists only in liquid and vapor stages before dispersion. This means that neglecting material strength may not significantly affect the predicted strain rates during the important stages where dispersion is likely to occur.

\subsection{EFFECT OF FUEL IRRADIATION ON DISPERSION}

When fuel in a fuel plate fissions the uranium atom breaks up into two or more fission products. The break up the uranium atoms can cause changes in the physical properties of the fuel plate. The extent of the change directly depends on the fraction of fuel that has been converted from uranium to fission products. For $\mathrm{U}_{3} \mathrm{Si}_{2}$ fueled plates, fissioning causes minimal changes in the thermal performance of the fuel plate 15 . The change in thermal conductivity caused by the breakup of uranium is also affected by the swelling of the fuel particles. The swelling causes closure of preexisting voids and increases the contact between the fuel and aluminum. Specific 
heat capacity of the noble gases are not significantly different from the specific heat capacity of the silicide fuel. Therefore, the rate of change of temperature during a transient energy deposition is not expected to differ significantly. Table (6) illustrates the effect of irradiation on the material properties at various irradiation levels.

Table 6. Preliminary estimate of the material properties of irradiated silicide fuel plates under ambient conditions.

\begin{tabular}{|c|c|c|c|}
\hline Fuel type & $\begin{array}{c}\text { Burn-up } \\
(\%)\end{array}$ & $\begin{array}{c}\text { Thermal Conductivity } \\
(\mathrm{W} / \mathrm{m} / \mathrm{K})\end{array}$ & $\begin{array}{c}\text { Meat Density } \\
\mathrm{kg} / \mathrm{m}^{3}\end{array}$ \\
\hline ANS & 0 & 130 & 3547 \\
ANS & 50 & 136.5 & 3547 \\
ANS & 100 & 143 & 3547 \\
JMTR & 0 & 39.91 & 6550 \\
JMTR & 50 & 65.4 & 6550 \\
JMTR & 100 & 58 & 5960 \\
\hline
\end{tabular}

If the thermal response of irradiated fuel is very similar to the fresh fuel, the only way that the fuel can exhibit a different dispersion potential is if the volatile fission products vaporize and expand as a gas. The noble gas mass fraction for a fully irradiated fuel plate is $5.7 \% 15$. Such a small fraction at first glance may not have a significant effect however, if it converted to volume fraction in vapor state, the volume fraction is large. The vapor state density of volatile fission products such as iodine is approximately $11.27 \mathrm{~kg} / \mathrm{m}^{3}$ and xenon is $5.88 \mathrm{~kg} / \mathrm{m}^{3}$. This represents significant reduction in density when compared to the density of $\mathrm{U}_{3} \mathrm{Si}_{2}$ or $\mathrm{U}_{3} \mathrm{O}_{8}$ fuel with aluminum filler that has the density of several thousand $\mathrm{kg} / \mathrm{m}^{3}$ depending on the material and loading. The density of the volatile fission products could be higher because the surface tension effects or material properties compress the gas to higher than ambient pressures. This increases the effective density. Fig. 17 shows the effect of surface tension on the bubble pressure at various temperatures and radius of bubbles.

The effective volume fraction, $f_{\mathcal{V}}$, is determined by using the mass fraction, $f_{m}$, of the volatile fission products and multiplying the mass fraction by the fuel density, $\rho f$, and effective volatile fission product density $\rho_{f p g}$.

$$
f_{v}=\frac{f_{m} \rho_{f}}{f_{m} \rho_{f}+\left(1-f_{m}\right) \rho_{f p g}},
$$

using this expression Fig. 18 is obtained. It shows the relationship between the mass fraction and the volume fraction. 


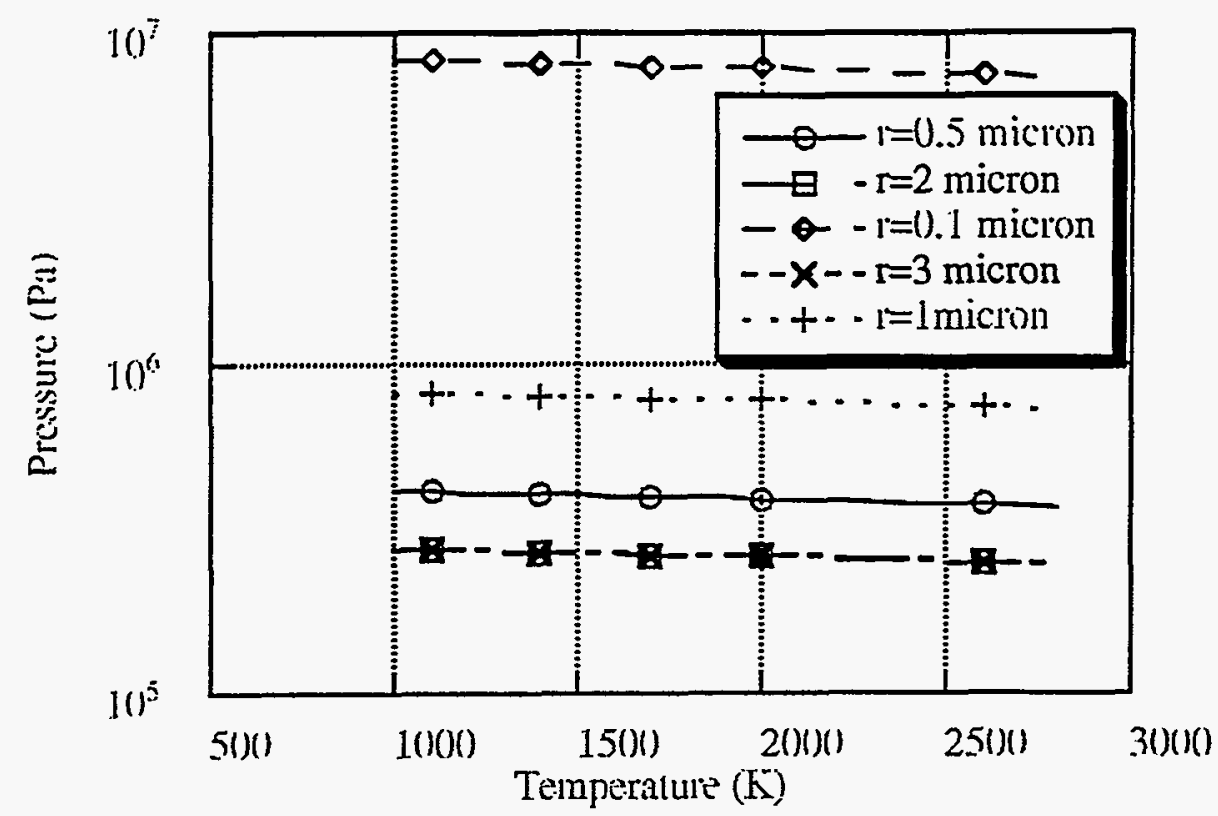

Fig. 17. The effect of aluminum surface tension on the internal pressure of gases trapped in spherical pockets.

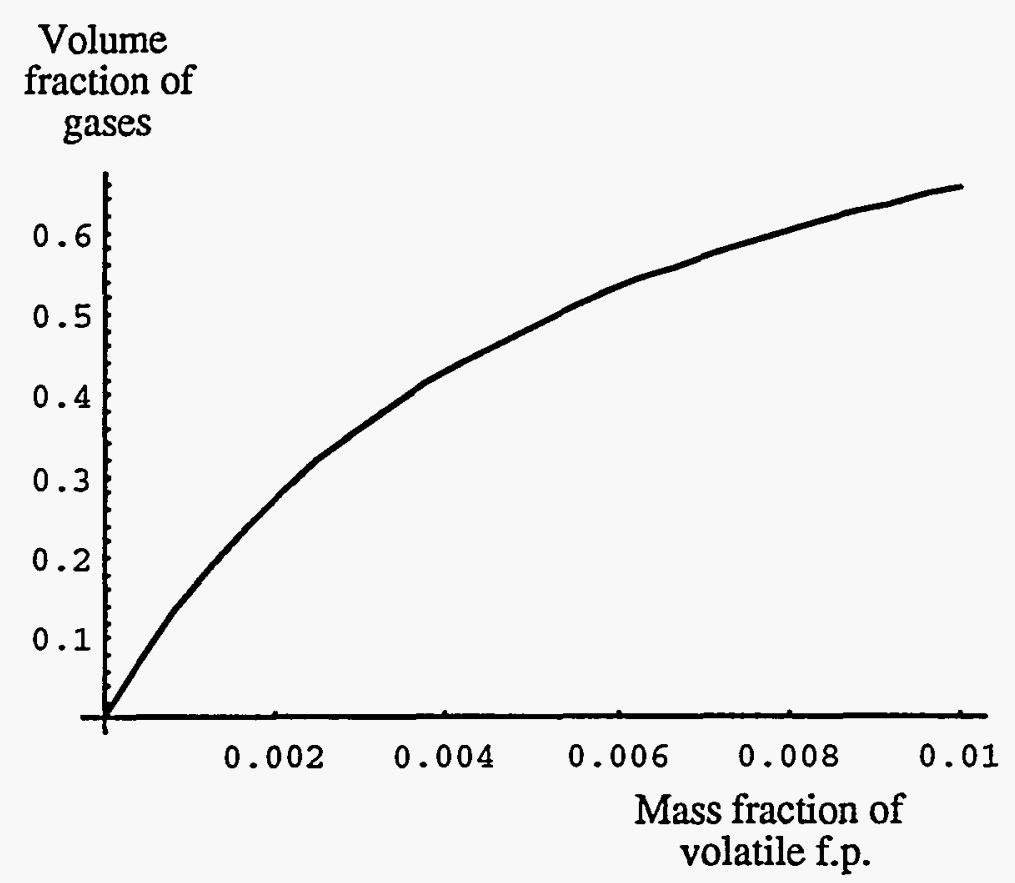

Fig. 18. Effective volume fraction for a given mass fraction of volatile fission products if the gas is allowed to expand to ambient pressure. 
If the density of the fission product gases is higher due to the compressive effects described earlier, then the curve should shift downward. It should be noted that the during slow heating of irradiated fuel, the swelling of irradiated fuel occurs when the material strength of the fuel plate decreases as the temperature approaches the melting temperature of the plate. At this temperature the material strength deteriorates significantly. The expansion model does not physically represent the reduction in material strength and expansion process caused by allowing the fission product gases to expand. Thus, the model does not perform well during this stage. To improve the model, the dynamic interaction between the bubble size, internal and external pressure, material properties have to be considered and modeled. To represent this aspect of physical phenomena models have to be developed. The current model represents a significant shortcoming for the irradiated fuel model.

Models with various gas fractions were evaluated to observe the differences in the fuel plate response. Figure 19 shows the response of the fuel plate during the JMTR test 508-53 transient with $1 \%$ effective gas volume presence.

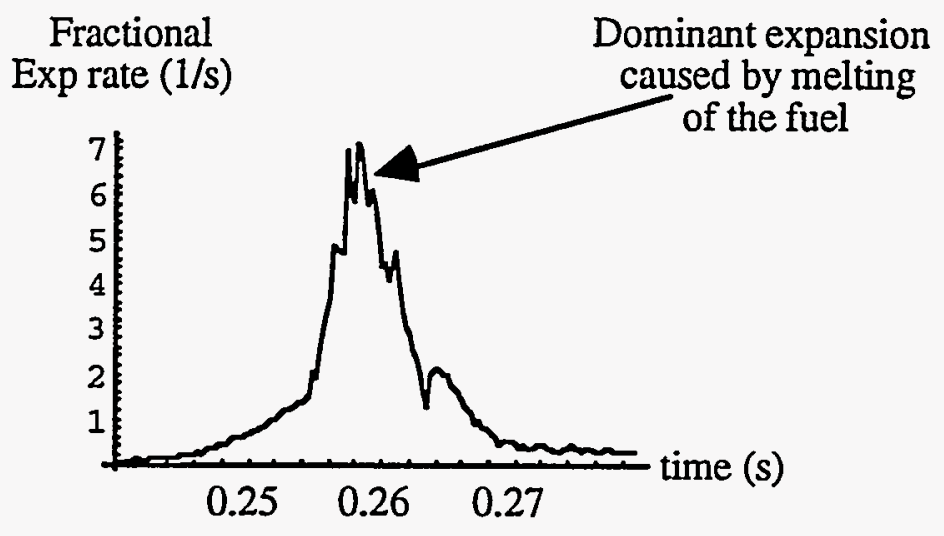

Fig. 19. Predicted strain rate for $1 \%$ effective gas volume fraction.

Figure 20 shows the result of the $25 \%$ effective gas volume fraction has on the expansion characteristics.

Fractional

Exp rate $(1 / s)$

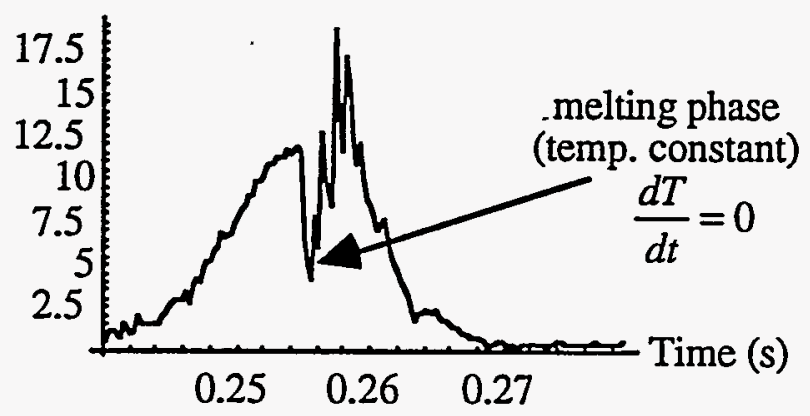

Fig. 20. Predicted strain rate for $25 \%$ effective gas volume fraction. 
Note that during the melting phase of the transient, the expansion rate of the gas phase is effectively zero. This causes the expansion rate during melting for the two examples of $1 \%$ and $25 \%$ gas volume fraction to be the same. When calculations for the various effective volume fractions are plotted on the peak strain rate against the effective volume fraction as given by Fig. 21 the behavior is linear. This means that the vapor dominates the expansion process if it is present in sufficient quantities.

The effect of noble gas on strain rate for JMTR fuel test 508-53

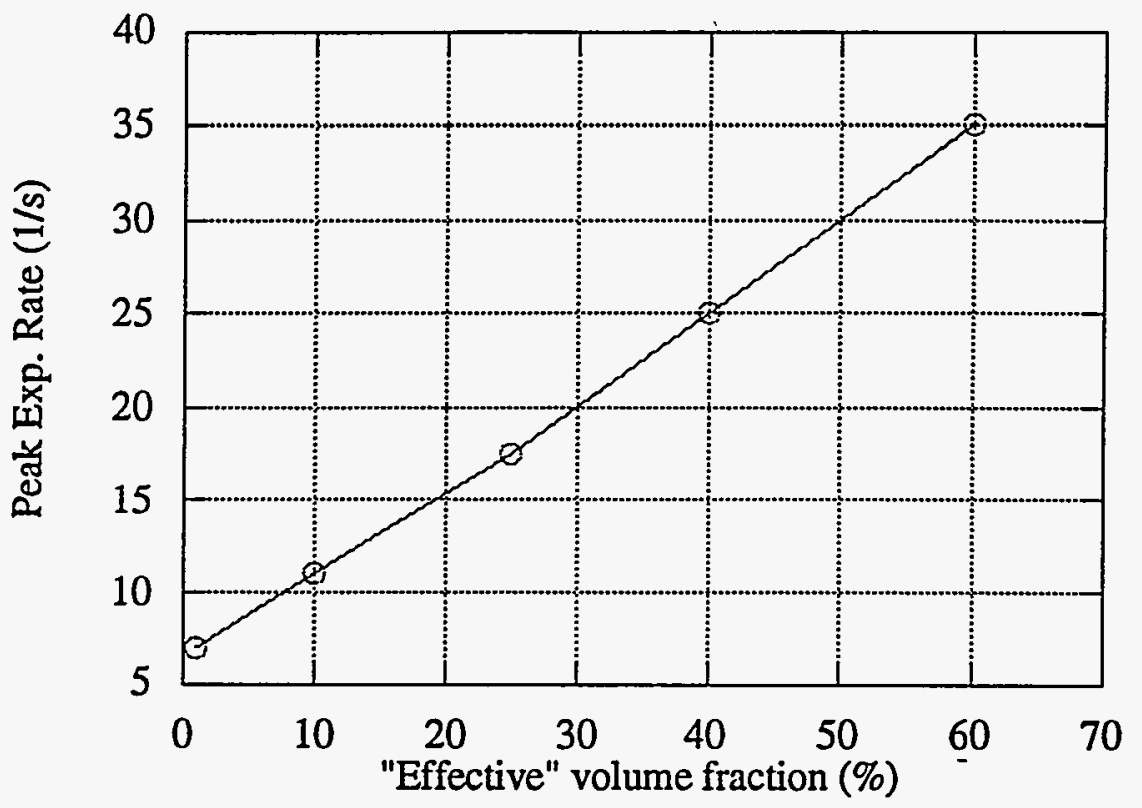

Fig. 21. The effect of effective volume fraction on the peak strain (expansion) rate.

The significant effect that the fission product gases have on the strain rate in the irradiated fuel plate shows that the gases play an important role in determining the onset of dispersion. Because significant physical effects such as bubble dynamics interaction with the solid and liquid material,

are lacking from the modeling framework, the uncertainty in the current model can not claim any significant break through in understanding of irradiated fuel dispersion. Data are required for model benchmarking, upgrading and validation

\subsection{SAMPLE MODEL RESULTS}

To illustrate the predictions of the model, the results from a sample transient evaluation are presented. These results compare the relative magnitudes of different effects. For this particular case, the energy is deposited over a $25 \mathrm{~ms}$ period into an ANS type of fuel. Figure 22 shows key parameters of interest for a sample transient. On the same figure, the cumulative expansion rate curve is given along with the individual curves representing sold/liquid expansion rate, expansion rate caused by melting, vaporization, and gas expansion along with the energy deposition curve. 
For this particular case the gas fraction inside the plate was chosen to be $5 \%$ of the plate volume.

As it can be seen from the figure, the expansion in the solid state is dominated by the gas expansion. As the plate begins to melt the plate transitions from solid to liquid state. Although the energy deposition rate when the plate fully melts is higher than when the plate starts melting, the larger expansion rate is caused by the larger coefficient of expansion for the liquid than the solid. For this particular case, after the plate melts the energy deposition rate decreases. The decrease in the rate is accompanied by a decrease in the strain rate. This continues until the plate reaches the vaporization temperature. When the vaporization temperatures are reached, the change in density associated with the vaporizing aluminum causes a large expansion rate.

It should be noted that the energy deposition for this particular example consists only of energy deposited from the fissioning process. Enegy contribution from the chemiocal reaction should alter the shape of the energy deposition rate curve.

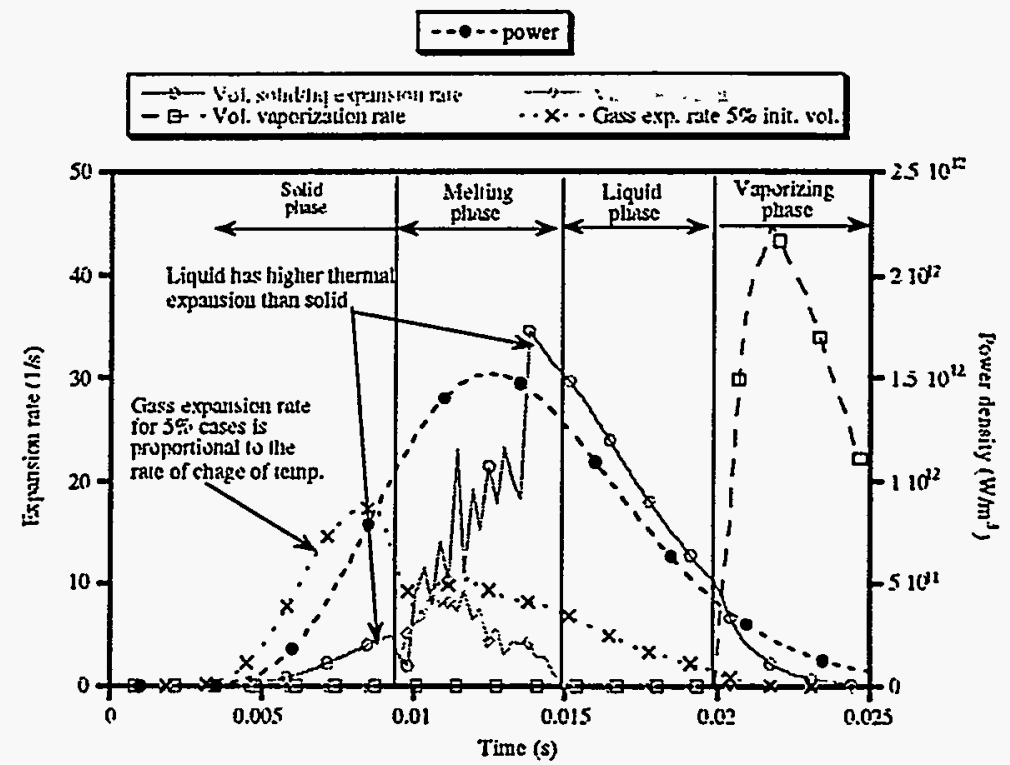

Fig. 22. Illustration of various expansion modes. 


\section{ANALYSIS OF EXPERIMENTAL RESULTS}

The experimental data for aluminum-based fuels performed in the TREAT facility in Idaho was examined. The types of plates tested were those from the High Flux Isotope Reactor (HFIR) and SL-1 reactor. Advanced Neutron Source (ANS) fuel plates are being tested in the Japan Atomic Energy Research Institute's (JEARI) NSRR facility in Japan. The NSRR results are not included as part of this work due to an incomplete data base. Some differences exist between the two facilities, producing variations in experimental conditions. One dominant difference is the duration of the neutron exposure. The TREAT facility pulse width varies between 0.3 and 1 second whereas the pulse width of the NSRR facility varies between 25 and 100 milliseconds. The amount of energy that can be deposited into a plate is a function of the neutron flux density and the duration of exposure.

Although the model has a term that accounts for the presence of fission products, the data with irradiated fuel plates is lacking. Irradiated fuel plate experiments will be performed in the NSRR facility in the future. The comparisons of the model with fission product model will be made when data become available.

\subsection{SL-1 FUEL TESTS IN TREAT}

SL-1 fuel plates were tested in the TREAT facility. $[8]$ SL-1 plate samples were U-Al alloy fuel without cladding. The dimensions of the test sample were $5.0 \mathrm{~mm} \times 12.7 \mathrm{~mm} \times 12.7 \mathrm{~mm}$. The fuel sample was an Al-U-Ni alloy that was composed of $81 \% \mathrm{Al}, 17 \% \mathrm{U}$, and $2 \% \mathrm{Ni}$. For energies deposited into the plate during the experiments, the peak computed strain rate vs. energy per unit mass of the plate was determined and plotted in Fig. 23. A comparison with the observed dispersion is also presented in the same plot. Experimental data found in the report for this particular set of experiments did not contain a break down in fragmented mass fraction. The report ${ }^{8}$ only reported whether fragmentation occurred or not. For this reason, the experimental data was presented in terms of being either as $0 \%$ or $100 \%$ fragmentation. The results indicate that the location where the slope of the strain rate curves changes is the location where the dispersion is likely to occur.

The experiments show that for all cases in which the energy deposition was greater than 2.3 MJ/kg, the plate dispersed. It was hoped that the prediction for dispersion would be represented by the point of inflection where the curve of peak strain rate as a function of energy begins to increase. The point of inflection where the strain rate begins to increase is $2.7 \mathrm{MJ} / \mathrm{kg}$. This represents a discrepancy between the point of inflection and the observed point where dispersion was observed. The test number CEN 115 was not in line with the predictions. To explain the discrepancy, the aluminum oxidation phenomenon was investigated. Figure 24 shows the peak computed surface temperature and the fraction of aluminum oxidation that took place as a function of the energy deposited. The peak temperature reached by nuclear heating alone in test CEN 115 was computed to be $2300 \mathrm{~K}$, which was sufficient to melt the oxide layer and allow oxidation to begin. For the CEN 115 test, the oxide melting temperature was reached during the period when nuclear heating was still taking place. Additional energy from oxidation was sufficient to raise the temperature of the fuel to the vaporization state and cause dispersion. This seems to indicate that energy from nuclear heating was supplemented by chemical oxidation to provide sufficient energy for the onset of vaporization. The chemical reaction phenomenon was not modeled; therefore, the strain rate is not representative of vaporization process. 


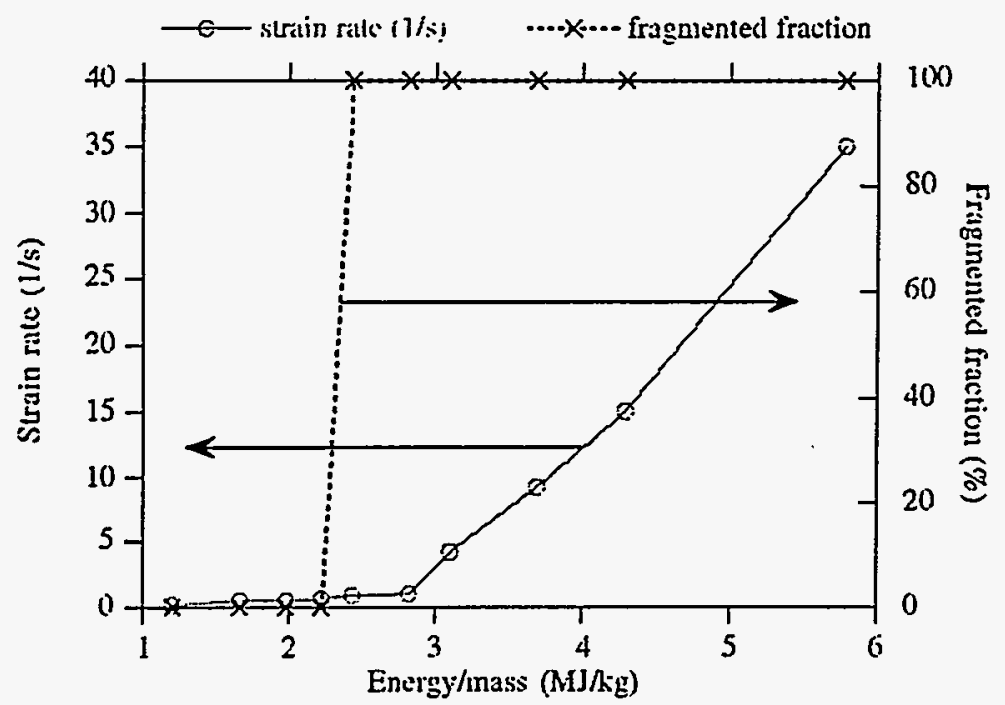

Fig. 23. Strain rate and fragmented fraction as a function of cumulative deposited energy for SL-1 fuel plate tests in the TREAT facility

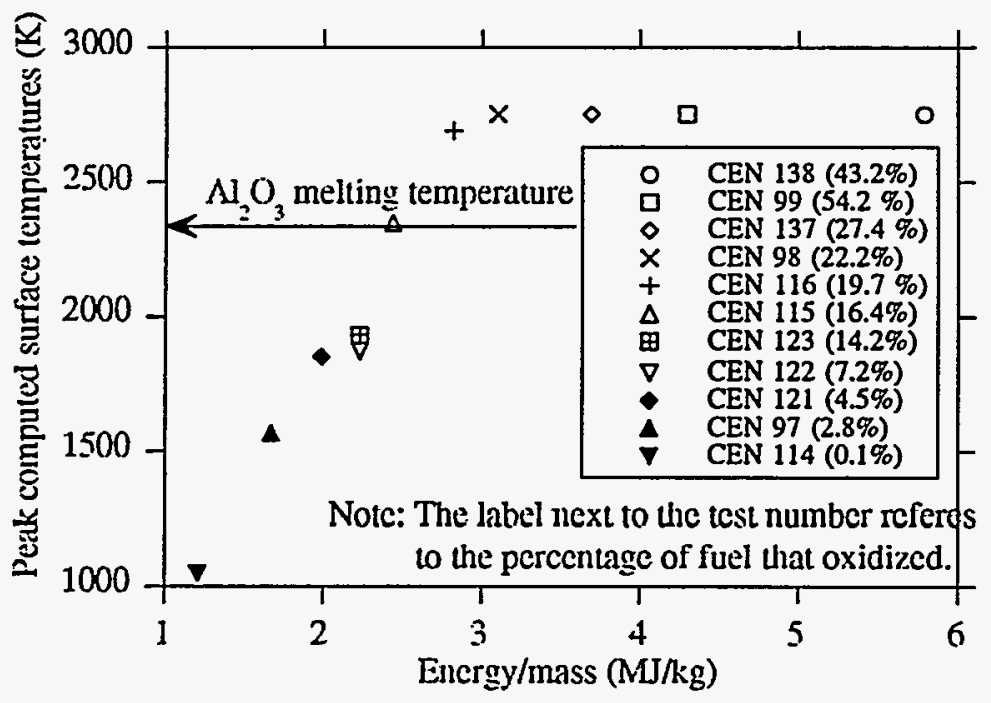

Fig. 24. Peak computed surface temperatures for different energy depositions in SL-1 fuel tests conducted in the TREAT facility. 


\subsection{HFIR FUEL TESTS IN TREAT}

HFIR fuel plates are made with $\mathrm{U}_{3} \mathrm{O}_{8}$ particles dispersed in an aluminum matrix.[8] HFIR fuel sample dimensions were $25.4 \mathrm{~mm} \times 12.7 \mathrm{~mm} \times 1.27 \mathrm{~mm}$. Composition by mass of the HFIR fuel is $59 \% \mathrm{Al}$ and $41 \% \mathrm{U}_{3} \mathrm{O}_{8}$. Similar to SL-1 tests, HFIR plates were subjected to neutron bursts in the TREAT facility. The initial fuel temperatures for the HFIR tests were $303 \mathrm{~K}$, $393 \mathrm{~K}$, and $558 \mathrm{~K}$. Since only two data points were tested with the initial temperature of $558 \mathrm{~K}$, they were not plotted in Figs. 25 and 26, but were included in Fig. 27. Sensitivity to initial temperatures is shown in Fig. 5 where strain rate was compared for the two initial temperatures. Comparison of the fragmented fraction with the strain rate for different energies appears in Fig. 26.

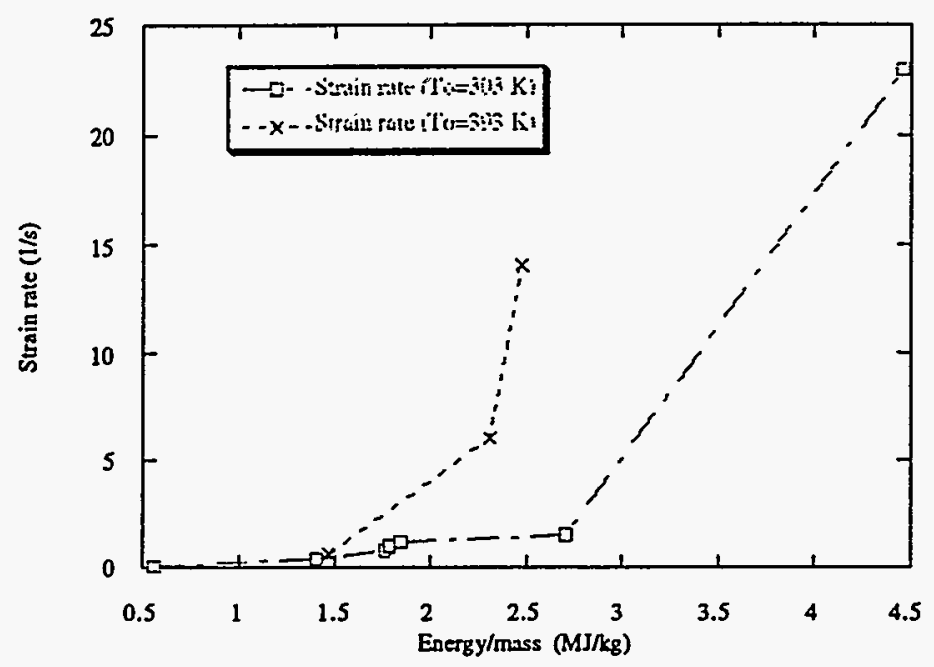

Fig. 25. Comparison of computed peak strain rate as a function of energy for different initial temperature

The results show that the HFIR and SL-1 fuel tests exhibit reasonable similarity in response to energy deposition. Just as in test CEN 115 with the SL-1 plates, CEN $211 \mathrm{H}$, and CEN 204 data fall into the category of dispersing without reaching vaporization temperature by nuclear heating alone. Figure 27 shows the peak computed temperature and measured oxidized fraction plotted against the deposited energy.

Both test points in question have significantly oxidized. The computed peak clad temperature from nuclear heating alone for both tests is above the oxide melting temperature. Therefore, just as observed with SL-1 fuel tests these two points are expected to use some of the oxidation energy to aid in reaching the vaporization state. 


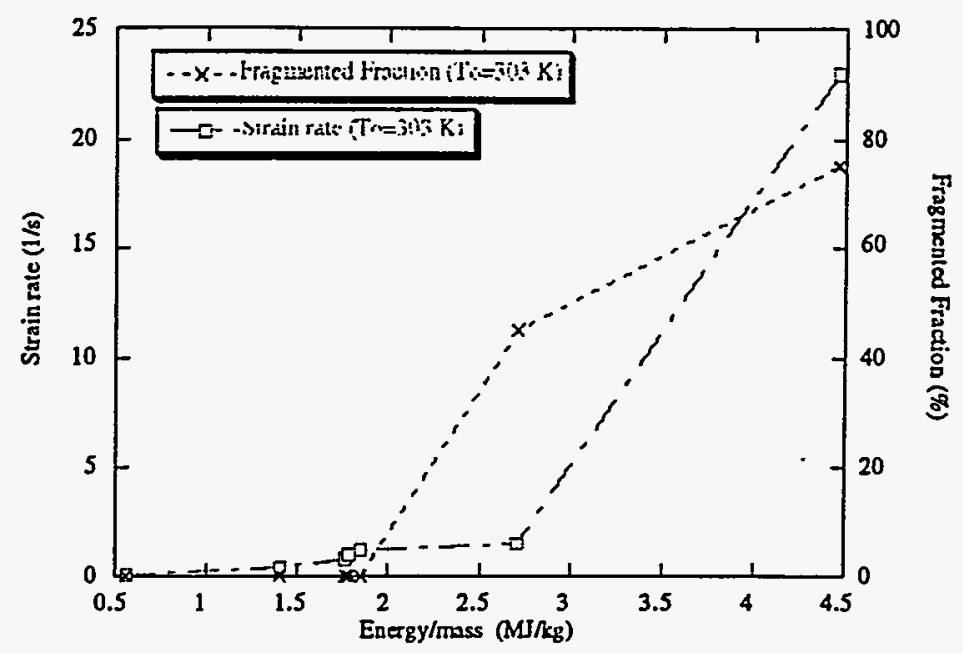

Fig. 26. Comparison of computed peak strain rate to experimentally measured fragmented fraction as a function of cumulative deposited energy

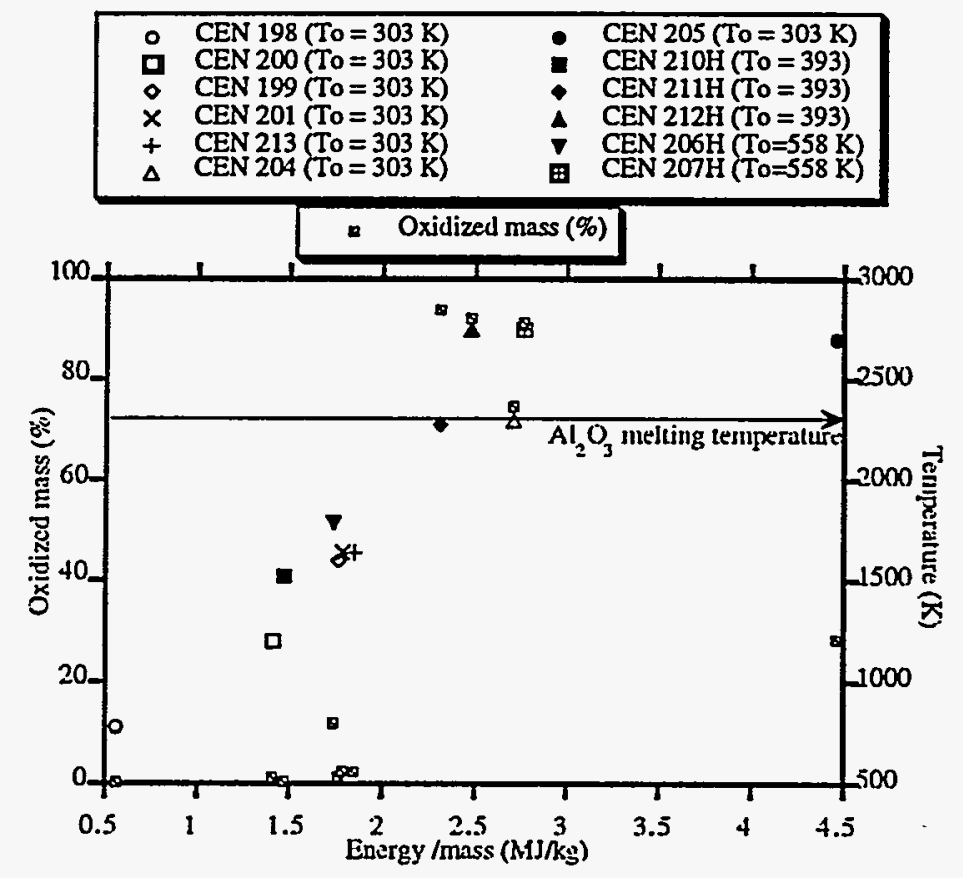

Fig. 27. Fraction of aluminum oxidation and peak computed temperatures for HFIR fuel tests as a function of energy deposition.

\subsection{JMTR FUEL PLATE TESTS IN NSRR}

This section summarizes the experimental results conducted in NSRR on JMTR fuel and analytical model simulating those tests. Six fuel plates were subjected to short duration pulse-type neutron exposure tests and are summarized in Table 7. Dimensions of the JMTR plates are given in 
the section 5.1.

Table 7. JMTR tests in NSRR facility

\begin{tabular}{|c|c|c|c|c|}
\hline $\begin{array}{c}\text { Test } \\
\text { ID }\end{array}$ & $\begin{array}{c}\text { Energy deposited } \\
\text { in JMTR } \\
\text { miniplate (kJ) }\end{array}$ & $\begin{array}{c}\text { Pulse base } \\
\text { width }\left(^{*}\right)\end{array}$ & $\begin{array}{c}\text { Calculated } \\
\text { Reacted Fuel } \\
\text { fraction (**) }\end{array}$ & Notes \\
\hline $\mathbf{5 0 8 - 5 1}$ & 7.74 & 60 & 0.02 & \\
\hline $\mathbf{5 0 8 - 5 2}$ & 9.17 & 45 & 0.14 & \\
\hline $\mathbf{5 0 8 - 5 3}$ & 10.81 & 40 & 0.85 & \\
\hline $\mathbf{5 0 8 - 5 4}$ & 12.25 & 40 & 1.0 & Melted fuel \\
\hline $\mathbf{5 0 8 - 5 5}$ & 13.71 & 40 & 1.0 & Melted fuel \\
\hline $\mathbf{5 0 8 - 5 6}$ & 16.05 & 30 & 1.0 & Fuel Dispersion \\
\hline
\end{tabular}

(*) Pulse base width is the width of the pulse at the base as opposed to the full width at half max.

${ }^{(* *)}$ Calculation based on modeling constants that were based on selected data points described in section 6 .

Each test was analyzed using two energy source models. The first energy source model consists of using only the fission heat source. As discussed earlier in the report, the shape of the energy deposition by fissioning of uranium was obtained from the neutron flux curve measured by the NSRR instruments. The second energy source model uses the combined fission heat source model and the chemical reaction model. As discussed earlier in the report, the mixture of $\mathrm{U}_{3} \mathrm{Si}_{2}$ fuel particles dispersed in aluminum when subjected to elevated temperatures exothermicaly react with each other releasing energy. The energy release rate model described in the earlier section was implemented into the dispersion model as a part of an energy source term. The total energy deposited in the fuel was based on the neutron flux measurements and the calculated chemical energy generation term. This section of the report summarizes the results of the dispersion model with and without the chemical energy release model implemented into the dispersion model.

The total amount of chemical energy that can be released is much smaller than the fission energy deposited during a test. Addition of that energy uniformly to the fission energy does not produce significant variations in temperature. This is caused by the diffusion of energy from the meat to the cladding lowering the overall temperature of the fuel plate. Also, relatively longer time allows energy to be transferred to the coolant resulting in lower temperature and related effects. However, if this energy is weighted so that is deposited at a crucial time, the effect is significantly more pronounced.

If the peak of chemical energy release coincides with the peak of fission energy deposition, then the combined energy significantly increases the peak power deposition. This increase in power causes the temperatures to increase further, increasing the chemical reaction rate and the energy release rate. If the chemical energy is deposited over a short time span, then the effect can be multiplying. Fig. 28 shows the effect of the additional energy produced by the chemical energy. 


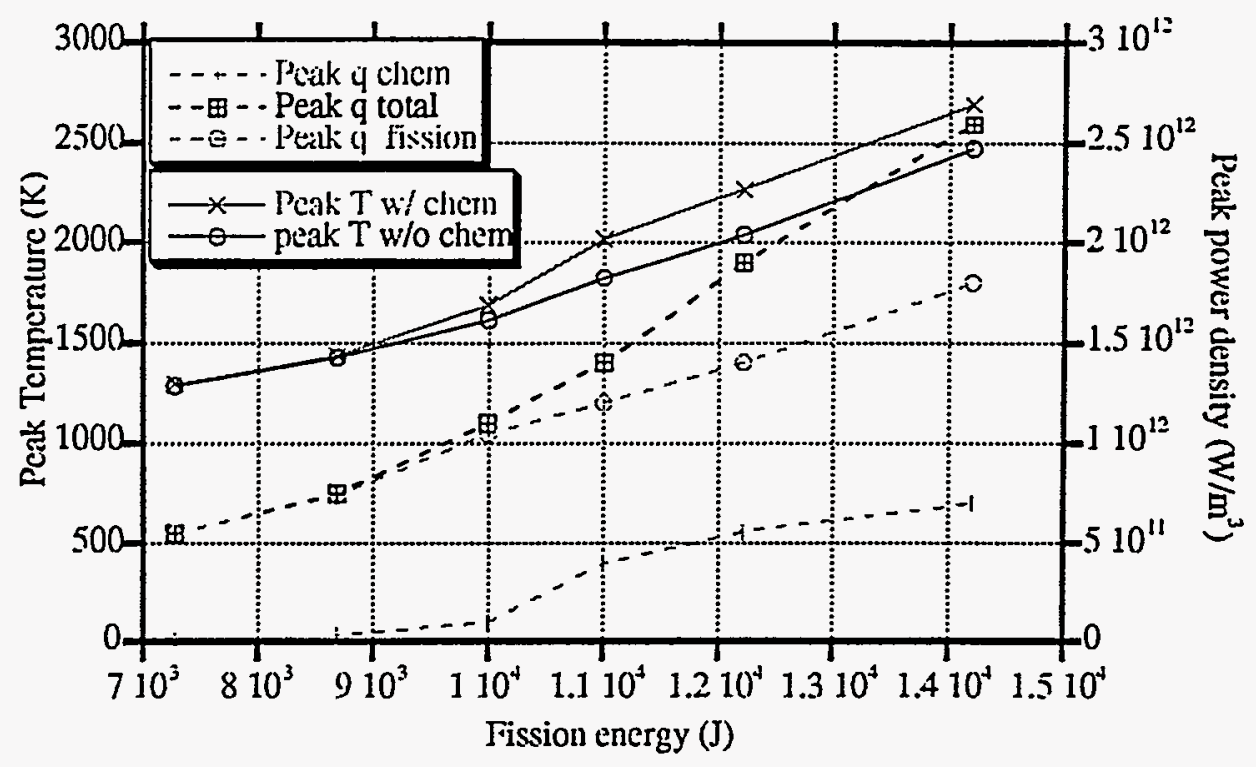

Fig. 28. Comparison of fission and chemical energy deposited for a given fission energy deposited and their corresponding temperatures.

At high fission energy depositions, supplemental energy from the chemical reaction tends to cause higher peak temperatures. For higher fission energy depositions ( $\mathrm{q}>10 \mathrm{~kJ})$, the peak temperature difference widens to $200 \mathrm{~K}$. It should be noted that for the largest energy deposition, the peak centerline temperature without chemical energy does not reach aluminum vaporization temperatures, whereas with the chemical energy deposition the vaporization temperature is reached. Since evaluations for HFIR and SL-1 tests indicate that vaporization location is the point of increase in the strain rate, not including the chemical energy in the JMTR analysis would under predict the temperature missing the vaporization point.

Strain rate curves with and without the chemical reaction are given by Fig. 29 . It can be seen that the increase in the strain rate is more dominant in the model that had a chemical energy deposition model implemented. The model without the chemical energy has a smooth increase in the strain rate, whereas the model with the chemical energy has a noticeable point of inflection. For low energy depositions, the difference in strain rates is minimal since the temperature reached by the fuel is not sufficiently high to cause the reaction to occur.

Because the energy deposition time scale for the NSRR facility is shorter than the thermal diffusion time of JMTR plates, the thermal energy does not escape form the fuel meat to the cladding during the energy deposition period. Because of this effect, large temperature gradients tend to exist for the JMTR tests. The large temperature gradients are reflected in the computed clad temperatures given by Fig. 30. As it is seen in the next section, ANS fuel plates have a higher meat thermal conductivity, allowing energy to be conducted to the clad faster and leading to lower temperature gradients. 


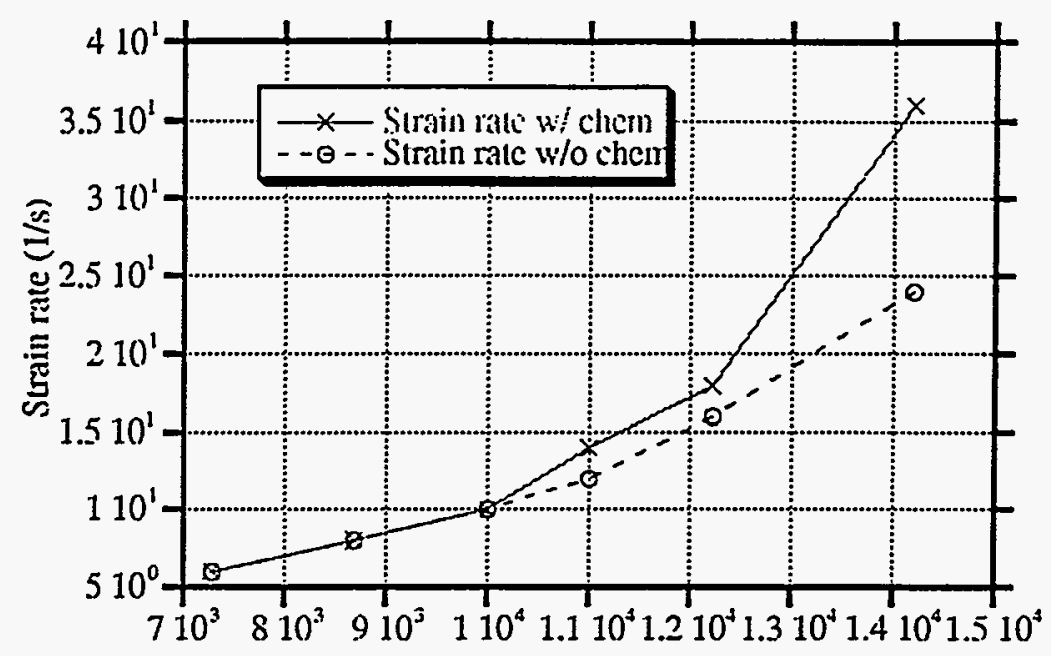

Fission energy (J)

Fig.29. Strain rate predicted by fission heating only and the combined fission heating and the fuel - aluminum chemical energy source.

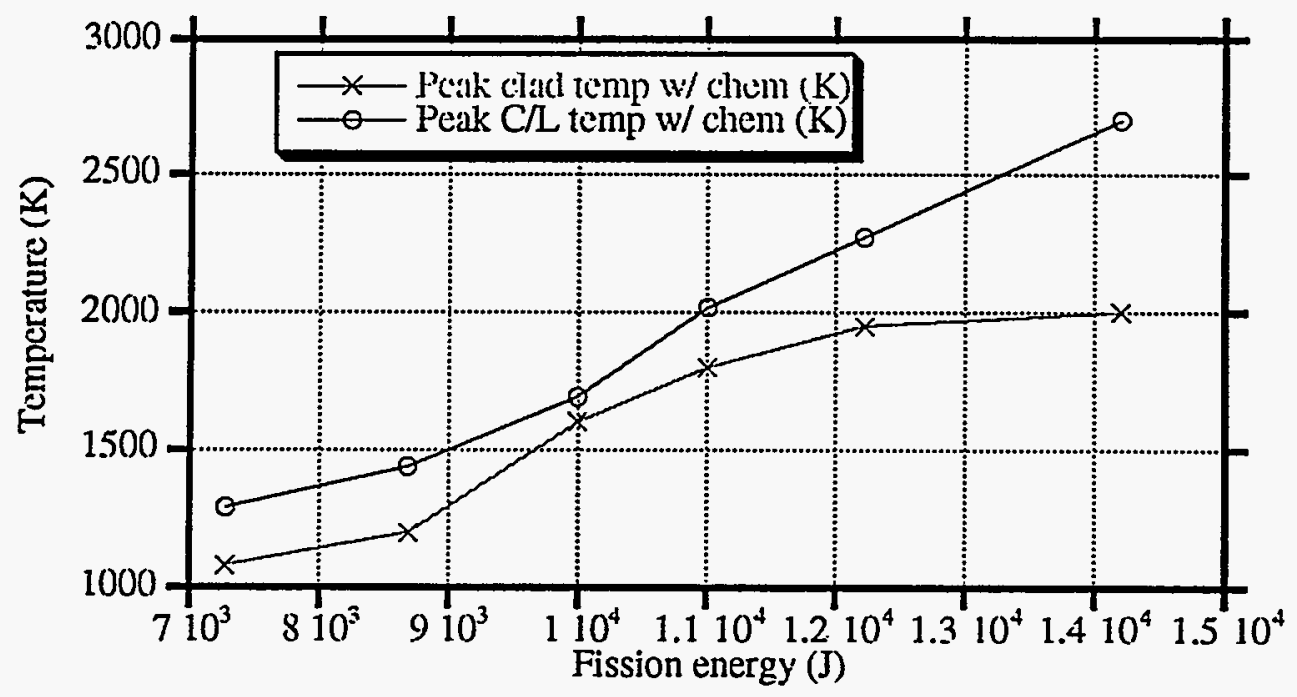

Fig 30. Peak center line and clad temperature for a given fission energy deposition with chemical energy model.

The issue of the aluminum - steam reaction can also be addressed in the test 508-56. Comparison of the peak fuel centerline temperature to the peak clad temperature shows that the clad temperature for the $508-56$ case never exceeds the $2300 \mathrm{~K}$. This temperature seems to be the onset of aluminum steam reaction. Therefore, the oxidation is not predicted for this test which is confirmed by the data from the experiment. This interpretation leads to the conclusion that for test 508-56 the principal reason behind the dispersion is the onset vaporization of the fuel meat.

As with SL-1 and the HFIR fuel tests, the onset of dispersion seems to be caused by the vaporization of the fuel meat. Next section discusses the ANS fuel plate tests. 


\subsection{ANS FUEL PLATE TESTS IN NSRR}

Tests performed in the NSRR Facility with the ANS fuel were not energetic enough to cause fuel dispersion. Fuel plate dimensions and energies deposited into the fuel plates are outlined in Section 5.1. Some of the fuel plates, tests 518-1 and 518-2 had large deviations in homogeneity. Hot spot induced thermal stresses caused the plates to become warped. Other more homogenous plates performed in a more expected manner. Since the experimental tests did not achieve dispersion, the next section will discuss predictions of dispersion using the current model. 


\section{PREDICTIONS OF ANS FUEL DISPERSION}

ANS fuel plates are composed of a fuel meat section sandwiched by aluminum cladding. [9] The fuel meat is $0.76 \mathrm{~mm}$ thick, and the cladding is $0.254 \mathrm{~mm}$ thick. Fuel meat is composed of uranium silicide particles dispersed in an aluminum matrix. The density of uranium silicide in the meat is $1400 \mathrm{~kg} / \mathrm{m}^{3}$. Based on a criteria deduced from comparison of the dispersion model with the TREAT experimental data, the model was used to predict the behavior of the ANS fuel. The criteria for dispersion is the location on the peak strain rate plot where the curve changes slope. The models and results are located in appendix D. Two types of plots resulted from the model. One plot shows the variation of strain rate with deposited energy in the plate over a 25-ms period per unit mass of the plate. This plot is given by Fig. 31. The second plot, Fig. 32, shows the variation of strain rate with a the varying duration for fixed cumulative energy deposited in the plate. Both Figs. 31 and 32 show a change in the slope of the strain rate curve.

When Fig. 31 is examined the expected dispersion energy is $\sim 2.7 \mathrm{MJ} / \mathrm{kg}$. This represents the total energy that is required, fission and fuel - aluminum chemical energy. This conclusion is valid as long as the aluminum oxidation chemical reaction does not occur. If a this chemical reaction occurs, then the threshold will be lower. If it is assumed that oxidation aids dispersion, with a constant $25 \mathrm{~ms}$ energy deposition period, the onset of oxidation will be achieved when energy deposition of $2.4 \mathrm{MJ} / \mathrm{kg}$ is exceeded.

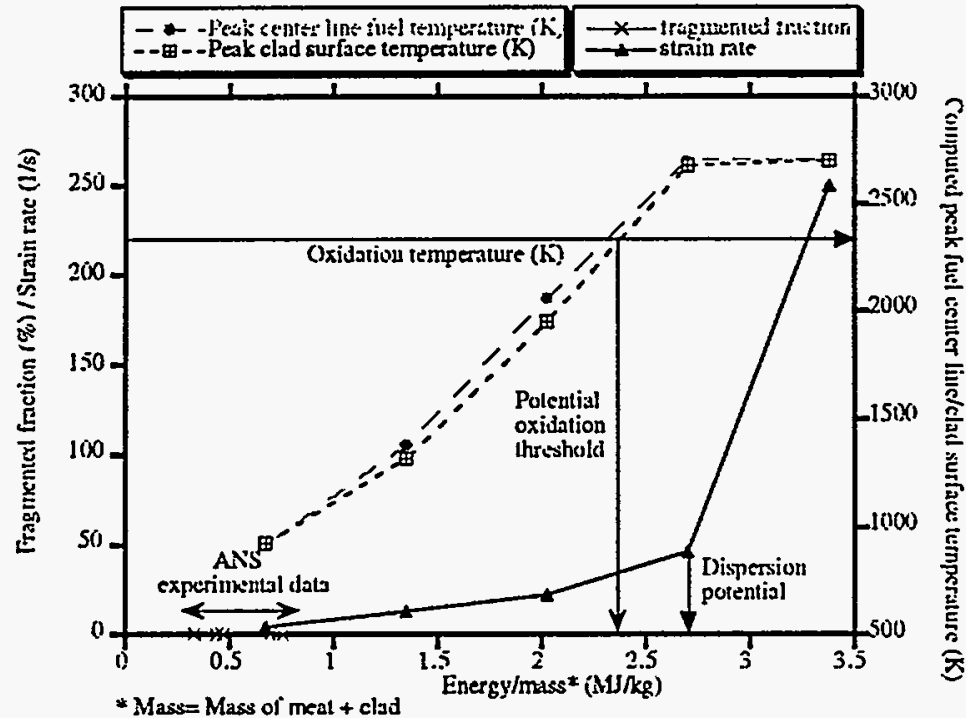

Fig. 31. Computed strain rate and temperature variation for ANS fuel (1.4 g/cc loading) as a function of deposited energy for a fixed $25 \mathrm{~ms}$ pulse width.

For the second case a fixed cumulative energy of $2.15 \mathrm{MJ} / \mathrm{kg}$ was used. For very short energy depositions, most of the deposited energy is used in raising the temperature of the fuel meat, and vaporization of the meat was achieved. For longer duration's, the energy spreads, and cumulative energy cannot raise the temperature of the entire plate to the vaporization temperatures, so the plate does not disperse. In other words, as the energy deposition duration is increased, the energy has time to diffuse, which results in a lower peak temperature of the meat. If dispersion 
criteria deduced earlier are applied, one can conclude that for $2.15 \mathrm{MJ} / \mathrm{kg}$ to disperse the plate the pulse width has to be shorter than 5 milliseconds. If oxidation is assumed to occur when clad temperatures exceed $2300 \mathrm{~K}$, the pulse width has to be anywhere between 12 and 27 milliseconds.

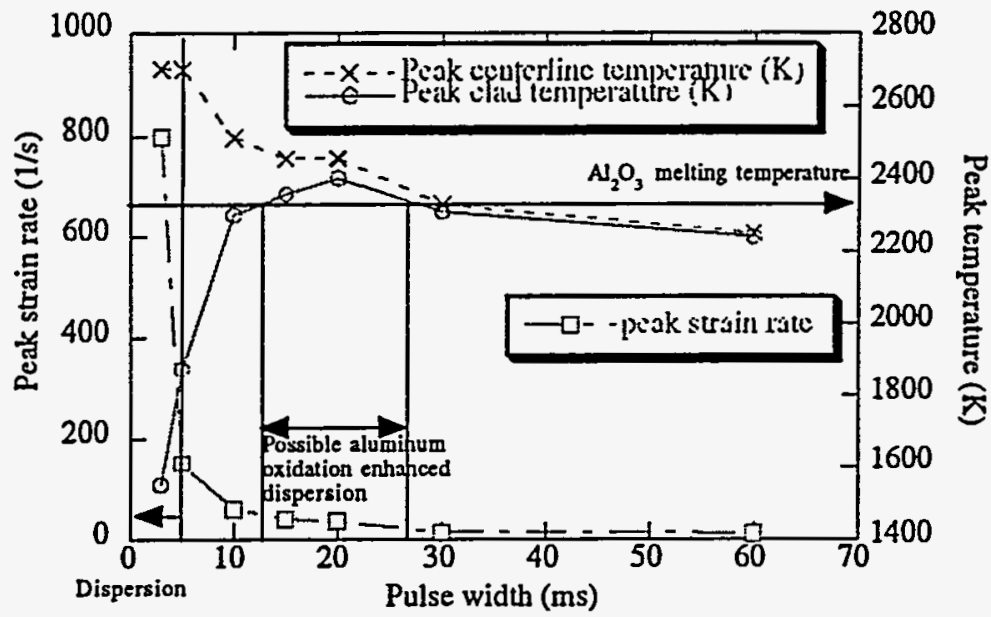

Fig. 32. Peak strain rate and peak temperatures as a function of pulse width for $2.15 \mathrm{MJ} / \mathrm{kg}$ energy deposition as a function of pulse width.

Experiments conducted with ANS mini plates in the NSRR facility in Japan have not been irradiated with a neutron flux that is sufficient to cause dispersion. All of the data gathered with the ANS fuel have been in the low energy range where dispersion did not occur.[2] The energies deposited in the ANS fuel varied between approximately 0.5 to $1.1 \mathrm{MJ} / \mathrm{kg}$ of fuel meat. As it can be seen from Fig. 31, when the mass of the clad is taken into account the apparent deposited energy is even lower. It should be noted that higher energies were sufficient to melt the fuel plates, but were significantly below the predicted threshold for dispersion of $2.4 \mathrm{MJ} / \mathrm{kg}$ for a 25 milliseconds exposure. 


\section{GENERAL OBSERVATIONS AND DISCUSSION}

The transient behavior of fuel and the effects of the fuel components can be difficult to visualize without the performance of a series of parametric evaluations. Parametric evaluations performed on the fuel plate showed that some parameters significantly affect the fuel heat-up behavior. Since heat-up behavior affects the expansion characteristics and dispersion, it is worthwhile to discuss some effects. Parameters that are controllable by design include plate thickness, fuel meat thickness, clad thickness, and meat composition. The parameter that affects the fuel behavior is the energy deposition transient. For a given energy deposition, the outcome varies significantly, depending on the input duration, as shown by the ANS fuel predictions.

The manufacturing method leaves a small volume of gases in the meat section of the fuel plate. During heat-up, the gas expands, potentially causing swelling. Meat composition affects the plate behavior by changing the meat thermal conductivity, heat capacity, and void fraction. Gases can also be generated by production of fission products during fuel burnup. This would lead to an increase in the strain rate due to the higher concentration of gas in the fuel at lower temperatures. Other effects of burnup include production of volatile isotopes. When volatiles melt and vaporize they have a more pronounced effect since the volume change associated with a phase change process is larger than gas expansion. This analysis tends to show that irradiated fuel is prone to dispersion under lower energy depositions. However, due to the lack of experimental data, this conclusion was not verified.

The additional effects that cause temperature profile variations are (1) the chemical reaction between the fuel and the aluminum that is, the extent of eutectic formed from the reaction under elevated temperatures; and (2) the melting temperature of the meat with the new eutectic. Thermal conductivity affects the transient performance of the fuel plate. Increasing the fuel loading reduces thermal conductivity in the fuel meat. Also, increasing the fuel loading reduces the specific heat capacity of the meat. The combination of these two parameters causes a more pronounced increase in temperature for a given constant volumetric energy deposition rate. The effect of meat and clad thickness on the transient behavior of the plate tends to affect the temperature distribution. For thinner meat and thicker cladding, the energy from the meat tends to diffuse out to the clad and cause the cladding to heat up. Since the specific heat of the cladding is higher than the specific heat of the meat, more energy is absorbed by the clad, thereby lowering the overall temperature. This is true if the energy is deposited over a longer period of time. If the energy deposition period is reduced, the effect can be reversed. For such cases, the fuel meat does not have sufficient time to transfer energy to the cladding. Therefore, the meat heats up faster to higher temperatures, reaching vaporization temperature with less energy.

Results show that reducing the thermal conductivity of the meat section increases the strain rate. The maximum strain rate corresponds to the adiabatic heat up of the fuel meat $(k=0)$. The strain rate increase is caused by a reduced transfer of thermal energy from the meat to the cladding; thus, the temperature increases faster than it would if the thermal conductivity was higher. The buildup of temperature causes other effects to become significant, such as: the expansion of gases, or the increase in melt or vaporization rate. Lower thermal conductivity of the meat can occur if fuel is not fabricated up to specifications. Nonhomogeneities in the fuel cause high and low concentrations of particles in the meat. High concentrations of fuel $\left(\mathrm{U}_{3} \mathrm{Si}_{2}\right)$ particles not only have lower thermal conductivity but also have lower specific heat capacity. Thus, increasing the concentration of fuel particles decreases both thermal conductivity and heat capacity of the meat. This causes the temperature of the meat during a transient to increase and possible strain rates to be higher than for the lower concentration case. This means that homogeneity of the fuel plates is very important and flawed production could cause premature failure of the plate. 


\section{SUMMARY AND CONCLUSION}

To summarize, a mathematical modeling framework was developed to predict the threshold of dispersion during heat-up transients for U-Al plate-type reactor fuels. The model centers on a determination of thermally induced strain rates that considers several physical phenomena. Exact closed form solution compared with a numerical model for an arbitrary simplified problem shows good agreement. Data from TREAT facility tests with SL-1 and HFIR fuel plate samples were analyzed to determine dispersion and rapid $\mathrm{Al}-\mathrm{H}_{2} \mathrm{O}$ reaction thresholds. Comparison of model predictions with the TREAT experiments produced a good agreement for the onset of dispersion. The study shows that the strain rate parameter displays a sharp increase coincident with the onset of material vaporization. Model predictions against the NSRR data taken with ANS reactor test samples indicate no onset of dispersion for the energies that were deposited. The NSRR data obtained so far with ANS miniplate samples corroborate this.

Overall, this work shows that the rate of energy deposition is just as important as the cumulative energy deposited in the fuel when one is trying to determine the dispersion potential during rapid transients. Strain rate as a method of determining the fragmentation characteristics predicts correctly overall trends. In this report, an empirically-based approach has been used to model exothermic fuel-aluminum reactions. Upon the melting of aluminum oxide, exothermic energy from an aluminum-steam chemical reaction is added to the fuel plate. However, for aluminum steam reactions modeling has yet to be put in place. To improve the model, a chemical energy deposition model needs to be implemented. For evaluating the criteria that should be used to determine the onset of dispersion, the energy deposition history needs to be taken into account. For slower transients, the temperature gradient in the fuel tends to be small. For such cases, when surface temperature of the clad exceeds the aluminum oxide melting temperature, dispersion should be assumed to follow. This is due to the onset of aluminum ignition with water. For rapid heat-up rates, the temperature gradients accross the plate thickness can be very large. For such cases, the meat vaporizes before the clad surface temperature reaches the melting temperature of the oxide layer. For this case, the vaporization of the meat triggers the onset of dispersion. 


\section{LITERATURE CITED}

1. M. E. Kipp et al., Experimental and Numerical Studies of High-Velocity Impact Fragmentation, Sandia Report SAND93-0773, 1993.

2. S. Navarro-Valenti et al., "Modeling and Analysis of Thermal - Hydraulic Response of Uranium-Aluminum Fuel Plates Under Transient Heatup Conditions", NURETH, Saratoga Springs, 1995.

3. J. L. Snelgrove et al., The Use of U3Si2 Dispersed in Aluminum in Plate-Type Fuel Elements For Research And Test Reactors, ANL/RERTR/TM-11, Argonne National Laboratory, Argonne, Illinois, 1987.

4. H. B. Peacock, Properties of U3O8 - Aluminum Cermet Fuel (U), WSRC-RP-89-981, Rev. 1, Westinghouse Savannah River Company, March 1990.

5. M. Epstein and H. K. Fauske, "On the Likelihood That Underwater Metal Ignition is a Vapor Phase Phenomena," Fauske \& Associates, Inc., 16W070 West 83rd Street, Burr Ridge, Illinois, 1990.

6. M. Epstein, "A Crystallization Theory of Underwater Aluminum Ignition", NURETH, Salt Lake City, Utah, 1992.

7. Chemical Engineering Division Summary Report, ANL-6687, Argonne National Laboratory, Argonne, Illinois, January, February, and March 1963.

8. Reactor Development Program Progress Report, ANL-7090, Argonne, Illinois, August 1965.

9. C. D. West, "The Advanced Neutron Source: A New Reactor -Based Facility for Neutron Research", Trans. Amer. Nuc. Soc., Vol. 61, 375, June 1990.

10. K.W. Childs, "Heating7.2b Multidimensional, Finite-Difference Heat Conduction Analysis", RSIC Peripheral Shielding Routine Collection. ORNL/TM-12262 (1993).

11. N. Ohnishi, and T. Inabe, Evaluation of Effective Energy Deposition in Test Fuel During Power Burst Experiment in NSRR, " J. Nucl. Sci. Tech., 19 528-542 (1982).

12. H. Kawamura, et. al.," Heat Transfer and DNB Heat Flux in Transient Boiling", 4th Intl. Heat Transfer Conference, Versailles (1970).

13. W.B. Hall, W.C. Harrison, "Transient Boiling of Water at Atmospheric Pressure", 3rd Intl. Heat Transfer Conference, Chicago, Vol.3 (1966).

14. S. Navarro-Valenti et. al., " Modeling and Analysis of Thermal-Hydraulic Responce of Uranium-Aluminum reactor Fuel Plates Under Transient Heatup Conditions ",

15 S. Navarro-Valenti et. al., " Effect of Pre-Irradiation on Thermal Behavior of Fuel Miniplates," Calc. Note SVN-10 July 1995. 


\section{APPENDIX A: MATHEMATICAL INPUT AND RESULTS FOR}

\section{JMTR PLATE TEST SIMULATIONS}

\section{1}

(*

THIS IS A REVISED DISPERSION MODEL THAT USES THE

TIME ENERGY DATA FROM THE EXPERIMENTS AND TEMPERATURE

DEPENDANT CHEMICAL REACTION RATES FUEL- ALUMINUM

This copy has chemical reaction rates included in the model

LAST UPDATED 4-19-95

Renormalized pulse width was used to a narrower band width.

*)

Print["Date last updated =",Date[];

Date last updated $=\{1995,4,21,8,39,3\}$

$\mathrm{l}=0.000635 ; \mathrm{m}=10 ; \mathrm{dx}=\mathrm{l} / \mathrm{m} ; \mathrm{n}=\mathrm{Round}[\mathrm{m} * .4] ;$ time $=0 ; \operatorname{Tinf}=300$;

volmeat $=2 * \mathrm{dx} * \mathrm{n} *\left(25^{*} 10^{\wedge}-3\right) *\left(70^{*} 10^{\wedge}-3\right)$;

$\operatorname{Do}[\mathrm{xx}[\mathrm{i}]=\mathrm{i} * \mathrm{dx}-\mathrm{dx} / 2,\{\mathrm{i}, 1, \mathrm{~m}\}]$;

$\mathrm{Tm}=900 . ; \mathrm{Tv}=2700$;

$\mathrm{Do}[\mathrm{To}[\mathrm{i}]=300 ; \mathrm{Tc}[\mathrm{i}]=300 ; \mathrm{xm}[\mathrm{i}]=0 ; \mathrm{xv}[\mathrm{i}]=0,\{\mathrm{i}, 1, \mathrm{~m}\}]$;

$\mathrm{k}[\mathrm{i}]:=39.91 / ; \mathrm{i}<=\mathrm{n} ; \quad(*$ assign $\mathrm{k}$ to the meat $*)$

$\mathrm{k}[\mathrm{i}]:=\mathrm{kcl}[\mathrm{To}[\mathrm{i}]] / ; \mathrm{i}>\mathrm{n} ; \quad(*$ assign $\mathrm{k}$ to the clad $*)$

rho[i]]:=6550.0 /; i $<=\mathrm{n} ;(*$ assign meat density $*$ )

rho[i] $]:=2700.0 \%$; $>n$; (* assign clad density $\left.{ }^{*}\right)$

$\mathrm{cp}[\mathrm{i}]:=\operatorname{cpcl}[\mathrm{To}[\mathrm{i}]] / ; \mathrm{i}>\mathrm{n} ; \quad(*$ assign clad cpecific heat $*)$

$\mathrm{cp}[\mathrm{i}] \mathrm{]}:=\operatorname{cpf}[\mathrm{To}[\mathrm{i}]] / ; \mathrm{i}<=\mathrm{n} ; \quad\left(*\right.$ assign meat cpecific heat $\left.{ }^{*}\right)$

htc=Interpolation $[\{\{150,13232\},\{350,13232\},\{410,14770\},\{726,12542\}$,

$\{776,11561\},\{1256,9924\},\{1458,1750\},\{1526,1729\},\{1556,800\}$, $\{5000,800\}\}$, InterpolationOrder- $>1]$;

$\mathrm{kcl}=$ Interpolation $[\{\{100,161\},\{400,177\},\{500,186\},\{600,193\}$,

$\{750,193\},\{850,193\},\{900,193\},\{930,193\}$,

$\{1200,84\},\{1300,84\},\{1500,84\},\{2000,84\},\{5000,84\}\}$,

InterpolationOrder $\rightarrow 1$ ];

cpcl=Interpolation $[\{\{100,878\},\{300,878\},\{366,942\},\{422,963\}$, $\{588,1034\},\{700,1067\},\{811,995\},\{1000,995\},\{2000,995\}$, $\{5000,995\}\}$, InterpolationOrder $->1]$;

cpf=Interpolation $[\{\{100,351\},\{300,351\},\{933,463\},\{1933,546\}$, $\{2500,546\},\{3500,546\},\{5000,546\}\}$, Interpolation Order->1];

hsf[i_]:=398000*fmal $/ ;$ i $<=$ n;

hfg[i] $:=10800000 *$ fmal $/ ; \mathrm{i}<=\mathrm{n}$; 


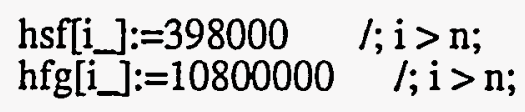

$151=$ ReadList["508.51",Number,RecordLists->True];

shape=Interpolation [151,InterpolationOrder $->1]$;

num=Part[Part[Position[151,Last[151]],1],1];

TimeBeg=Part[151[[1]],1]; TimeEnd=Part[151[[num]],1];

$\mathrm{cl}=\operatorname{Sum}[0.5 *(\operatorname{shape}[\operatorname{Part}[151[[i]], 1]]+\operatorname{shape}[\operatorname{Part}[151[[i+1]], 1]]) *$

(Part[151[[i+1]],1]-Part[151[[i]],1]), $\{\mathrm{i}, 200,500\}]$;

qs[qtot_time_]:=qtot*shape[time]/(volmeat*c1);

qtot $=7277$

${ }^{*}$ Functions : nrt - new reacted fraction

orf - old reacted fraction *)

$\operatorname{Tm} 1=863 ; \operatorname{Tm} 2=1970 ; \operatorname{Td}[\mathrm{i}]]=(\operatorname{To}[\mathrm{i}]-\operatorname{Tm} 1) /(\operatorname{Tm} 2-\operatorname{Tm} 1) ;$

lamda[i] $:=\left(4 * 10^{\wedge}-4\right) \mathrm{E}^{\wedge}\left(14.73 * \operatorname{Tanh}\left[1.8^{*} \mathrm{Td}[\mathrm{i}]\right]\right)$;

$\mathrm{z} 1\left[\mathrm{i}_{-}, \mathrm{dt}\right] \mathrm{R}=\mathrm{NDSolve}[\{\mathrm{RF}[\mathrm{t}]==$ lamda[i]-lamda[i] $* \mathrm{RF}[\mathrm{t}]$,

$\overline{R F}[0]==\operatorname{orf}[\mathrm{i}]\}, R F,\{t, 0, \mathrm{dt}\}$, AccuracyGoal $>15]$;

nrf[i_dt $]:=\operatorname{Part}[\mathrm{RF}[\mathrm{dt}] / \mathrm{zI}[\mathrm{i}, \mathrm{dt}], 1]$

frr[i] $]:=$ lamda[i]-lamda[i]*orf[i];

UpdateRF[dt_]:=Do[orf [i] $=\operatorname{nrf}[i, \mathrm{dt}],\{\mathrm{i}, 1, \mathrm{n}\}]$

qchem[i] $]:=w *$ frr $[i]$;

$\mathrm{q}\left[\mathrm{i} \_,\right.$time_qtot] $]:=\mathrm{qs}[\mathrm{qtot}, \mathrm{time}]+\mathrm{qchem}[\mathrm{i}] / \mathrm{i}<=\mathrm{n} ;{ }^{*}$ assign heat generation in the meat $\left.{ }^{*}\right)$

$\mathrm{q}[\mathrm{i}$, time, $\mathrm{qtot}]:=0 / ; \mathrm{i}>\mathrm{n} ; \quad(*$ assign heat generation in the clad $*)$

$\mathrm{bb}[\bar{i}]:=\mathrm{htc}[\mathrm{To}[\mathrm{m}]] / \mathrm{dx} / ; \mathrm{i}==\mathrm{m}$;

$\mathrm{bb}[\mathrm{i}]:=0 / ; \mathrm{i} !=\mathrm{m} ; \quad(*$ value for the heat transfer out of the plate $*)$

$\mathrm{k} 1[\mathrm{i}] \mathrm{]}:=(2 * \mathrm{k}[\mathrm{i}-1] * \mathrm{k}[\mathrm{i}] /(\mathrm{k}[\mathrm{i}-1]+\mathrm{k}[\mathrm{i}])) / \mathrm{dx} \mathrm{x}^{\wedge} / ; \mathrm{i} !=1$

$\mathrm{k} 1[\mathrm{i}]:=0 / ; \mathrm{i}=1$

$\mathrm{k} 2[\mathrm{i}] \mathrm{]}:=\mathrm{k} 1[\mathrm{i}]+\mathrm{k} 3[\mathrm{i}]$;

$\mathrm{k} 3[\mathrm{i}] \mathrm{]}:=(2 * \mathrm{k}[\mathrm{i}+1] * \mathrm{k}[\mathrm{i}] /(\mathrm{k}[\mathrm{i}+1]+\mathrm{k}[\mathrm{i}])) / \mathrm{dx} \wedge 2 / ; \mathrm{i} !=\mathrm{m}$

$\mathrm{k} 3[\mathrm{i}] \mathrm{]}:=0 / ; \mathrm{i}=\mathrm{m}$;

phase[i_]:=solid /; Tc[i] $<\mathrm{Tm}$;

phase[i] $:=$ liquid $/ ; \mathrm{Tc}[\mathrm{i}]<\mathrm{Tv} \& \& \mathrm{Tc}[\mathrm{i}]>=\operatorname{Tm} \& \& \mathrm{xm}[\mathrm{i}]>=0.85$;

phase[i] $:=$ vapor $/ ; \quad \operatorname{Tc}[i]>=\operatorname{Tv} \& \& \mathrm{xv}[\mathrm{i}]>1$;

phase[i] $]:=$ melting $/ ; \quad \operatorname{Tc}[\mathrm{i}]>=\operatorname{Tm} \& \& \times \mathrm{xm}[\mathrm{i}]<0.85$;

phase[i_]:= vaporizing $/ ; \quad T \mathrm{Tc}[\mathrm{i}]>=\mathrm{Tv} \& \& \mathrm{xv}[\mathrm{i}]<1 \& \& \mathrm{xv}[\mathrm{i}]>-0.01$;

$\operatorname{Tn}[\mathrm{i}] \mathrm{]}:=\mathrm{Tc}[\mathrm{i}] /$ phase[i] $=!=$ melting $\& \&$ phase[i] $=!=$ vaporizing;

$\operatorname{Tn}[\mathrm{i}]:=\mathrm{Tm} / ;$ phase[i] $==$ melting;

$\operatorname{Tn}[i]$ ] $=T v / ;$ phase[i] $===$ vaporizing ;

$\left.\mathrm{vv[i \_ j],dt]}\right]=\mathrm{k} 1[\mathrm{i}] / ; \mathrm{i}-1==\mathrm{j} \& \&$ phase[j]=!=melting \&\& phase[j]=!=vaporizing

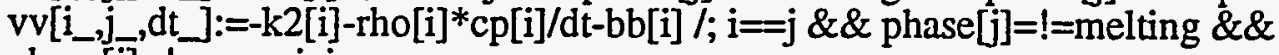
phase $[\bar{j}]=!=$ =vaporizing

$\mathrm{vv}\left[\mathrm{i}, \mathrm{j}_{-}, \mathrm{dt}\right] \mathrm{:}=\mathrm{k} 3[\mathrm{i}] / ; \mathrm{i}+1==\mathrm{j} \& \&$ phase[j]=!=melting \&\& phase[j]=!=vaporizing $\left.v v\left[i_{-},\right]_{-}, d t\right]:=0 / ; i !=j \& \& i-1 !=j \& \& i+1 !=j$;

$(* \ldots$

$\mathrm{vv}\left[\mathrm{i}_{3}, \mathrm{j}, \mathrm{dt}\right] \mathrm{l}=1 / \mathrm{i}=\mathrm{j} \quad \& \&$ phase[j]==melting;

$\mathrm{vv}\left[\mathrm{i}_{-} \mathrm{j}_{-}, \mathrm{dt}\right] \mathrm{]}:=0 / ; \mathrm{i}-1==\mathrm{j} \& \&$ phase[j]===melting;

$\left.\mathrm{vv}\left[\mathrm{i}_{-}, \mathrm{j}_{\mathrm{j}}, \mathrm{dt}\right] \mathrm{d}\right]=0 / ; \mathrm{i}+1=\mathrm{j} \& \&$ phase $[\mathrm{j}]===$ melting;

$\left.\mathrm{vv}\left[\mathrm{i}_{-}, \mathrm{j}_{\mathrm{H}}, \mathrm{dt}\right] \mathrm{t}\right]=1 / ; \mathrm{i}=\mathrm{j} \quad \& \&$ phase$[\mathrm{j}]==\mathrm{=}$ aporizing; 
$\mathrm{vv}\left[\mathrm{i}_{-} \mathrm{j}_{-}, \mathrm{dt}\right]:=0 / ; \mathrm{i}-1==\mathrm{j} \& \&$ phase[j]===vaporizing;

$\left.v v\left[i_{-}\right]_{-}, d t\right]:=0 / ; i+1==j \& \&$ phase[j]===vaporizing;

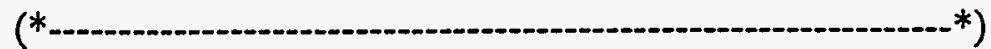

fli_dt_time_, qtot_]:= -q[i,time,qtot]-To[i] ${ }^{*}$ hho[i] ${ }^{*} \mathrm{cp}[\mathrm{i}] / \mathrm{dt}-\mathrm{bb}[\mathrm{i}] *$ Tinf $/$; phase[i]=!=melting \&\& phase $[\mathrm{i}]=!=$ =vaporizing;

f[i_,dt_time_,gtot_]:= Tm /; phase[i] =melting;

$\mathrm{f}\left[\mathrm{i}_{-}, \mathrm{dt}, \mathrm{time}, \mathrm{qtot}\right]:=\mathrm{Tv} / ;$ phase[i]==vaporizing;

Plot[shape[t],\{t,.24,0.32\},PlotRange->\{0,20\}]

-Graphics-

$\mathrm{TB}=.25 ; \mathrm{TE}=.31$;

RhoMeat=6500.;RhoAl=2700.;RhoU=12200.;

fval $=0.5$;

fvu=1-fval;

DenRat=(RhoU/RhoAl);

fmal $=0.212$;

fmu $=1$-fmal;

Echem $=350000.0$;

$\mathrm{ww}=\mathrm{E} \mathrm{chem}^{*} 5100$;

General::spell1:

Possible spelling error: new symbol name "fval" is similar to existing symbol "fmal".

time $=\mathrm{TB}$;

$\mathrm{Do}[\mathrm{To}[\mathrm{i}]=300 ; \mathrm{Tc}[\mathrm{i}]=300 ; \operatorname{xm}[\mathrm{i}]=0 ; \mathrm{xv}[\mathrm{i}]=0 ; \operatorname{orf}[\mathrm{i}]=0 ;,[\mathrm{i}, 1, \mathrm{~m}\}]$;

$\mathrm{dtt}[\mathrm{i}]]:=10 * \mathrm{dx} * \mathrm{dx} * \operatorname{rho}[\mathrm{i}] * \operatorname{cp}[\mathrm{i}] /(2 * \mathrm{k}[\mathrm{i}]) ;$

$\mathrm{dt}=\operatorname{Min}[\mathrm{Table}[\mathrm{dtt}[\mathrm{i}],\{\mathrm{i}, 1, \mathrm{~m}\}]]$;

$\mathrm{nt}=$ Floor $[(\mathrm{TE}-\mathrm{TB}) / \mathrm{dt}]-1$;

Print["dt= ",dt," nt= ",nt];

$\mathrm{dt}=0.000278413 \mathrm{nt}=214$

Do[

$s=$ Table[vv[i,j,dt],\{j,m $\},\{\mathrm{i}, \mathrm{m}\}]$;

sinv $=$ Inverse[s]; $(*$ invert the matrix $*)$

$\mathrm{qq}=$ Table[f[i,dt,time,qtot],\{i,m\}];

ans=sinv.qq;

$\operatorname{Do}[\mathrm{Tc}[\mathrm{i}]=$ ans $[[\mathrm{i}]]$;

If $\mathrm{bb}[\mathrm{i}] *(\mathrm{To}[\mathrm{m}]-\mathrm{Tinf})) * \mathrm{dt} /(\mathrm{rho}[\mathrm{i}] * \mathrm{hsf}[\mathrm{i}]) ; 0]$;

If $[$ phase $[\mathrm{i}]==$ =vaporizing, $\mathrm{xv}[\mathrm{i}]+=(\mathrm{k} 1[\mathrm{i}] * \mathrm{To}[\mathrm{i}-1]-\mathrm{k} 2[\mathrm{i}] * \mathrm{To}[\mathrm{i}]+\mathrm{k} 3[\mathrm{i}] * \mathrm{To}[\mathrm{i}+1]+\mathrm{q}[\mathrm{i}, \mathrm{time}, \mathrm{qtot}]-$ $\mathrm{bb}[\mathrm{i}] *(\mathrm{To}[\mathrm{m}]-\mathrm{Tinf})) * \mathrm{dt}(\mathrm{rho}[\mathrm{i}] * \mathrm{hfg}[\mathrm{i}]) ; 0]$;

$,\{\mathrm{i}, 1, \mathrm{~m}\}]$;

If $[$ Mod[numtimesteps, 5$]==0 \|$ numtimesteps $>=60$,

Print[numtimesteps," ",time," ",To[1]," ",xv[1]," ",phase[1]," ", 
q[1,time,qtot]," ",orf[1]," ",qs[qtot,time]," ",qchem[1]]];

$\mathrm{Do}[\mathrm{To}[\mathrm{i}]=\operatorname{Tn}[\mathrm{i}]$;

$\mathrm{xx1}[\mathrm{i}$,numtimesteps] $=\{$ time, $\mathrm{To}[\mathrm{i}]\}$;

$\mathrm{xx} 2[\mathrm{i}$,numtimesteps] $=\{$ time, $\mathrm{xm}[\mathrm{i}]\}$;

$\mathrm{xx} 3[\mathrm{i}$, numtimesteps] $=\{$ time, $\mathrm{xv}[\mathrm{i}]\}$;

$\mathrm{xx} 4[$ i,numtimesteps $]=\{$ time, $\operatorname{orf}[\mathrm{i}]\}$;

$\mathrm{xx5}[\mathrm{i}$, numtimesteps $]=\{$ time, $q[\mathrm{i}, \mathrm{time}, \mathrm{qtot}]\}$;

xx6[i,numtimesteps] $=\{$ time,qchem[i] $\}$;

$\operatorname{xx7[i,numtimesteps]}=\{$ time,qs[qtot,time $]\}$;

$,\{\mathrm{i}, 1, \mathrm{~m}\}]$;

To[i] $=\operatorname{Tn}[\mathrm{i}]$;

time $+=\mathrm{dt}$;

UpdateRF[dt];

, numtimesteps,1,nt\}];

Print[Finished];

$\begin{array}{llll}9 & -11 & 9\end{array}$

50.251114300 .3380 solid $1.50726101 .0468710 \quad 1.5072610 \quad 16.8081$ $9 \quad-11 \quad 9$

100.252506301 .0420 solid $2.59661102 .3633710 \quad 2.596611016 .9438$ $9 \quad-11 \quad 9$

150.253898301 .9750 solid $3.16824103 .6926310 \quad 3.1682410 \quad 17.1257$

$9 \quad-11 \quad 9$

200.25529303 .4420 solid $4.46902105 .0419310 \quad 4.4690210 \quad 17.4165$ $\begin{array}{llll}9 & -11 & 9\end{array}$

250.256682305 .1810 solid $6.20982106 .4148410 \quad 6.2098210 \quad 17.769$ $\begin{array}{llll}9 & -11 & 9\end{array}$

300.258074307 .9260 solid $8.8987410 \quad 7.8249810 \quad 8.8987410 \quad 18.343$

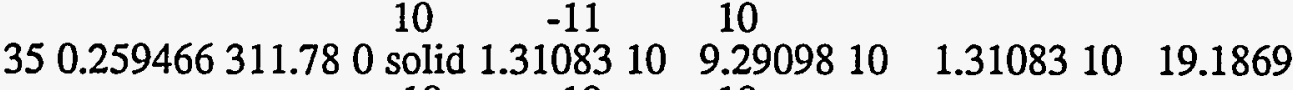

400.260858316 .8550 solid $1.8325210 \quad 1.083910 \quad 1.8325210 \quad 20.3703$ $\begin{array}{lll}10 & -10 & 10\end{array}$

450.26225323 .6680 solid $2.5104110 \quad 1.250610 \quad 2.510411022 .0992$ $\begin{array}{llll}10 & -10 & 10\end{array}$

500.263642332 .6110 solid $3.2254110 \quad 1.4341410 \quad 3.2254110 \quad 24.6411$ $\begin{array}{lll}10 & -10 & 10\end{array}$

$\begin{array}{llllll}550.265034345 .6550 \text { solid } 4.8778810 & 1.6448310 & 4.8778810 & 28.9979\end{array}$ $\begin{array}{llll}10 & -10 & 10\end{array}$

600.266426363 .7380 solid $6.6624710 \quad 1.9043210 \quad 6.6624710 \quad 36.6312$ $\begin{array}{lll}10 & -10 & 10\end{array}$

610.266705368 .158 0. solid $6.9907810 \quad 1.964910 \quad 6.9907810 \quad 38.8394$ $\begin{array}{lll}10 & -10 & 10\end{array}$

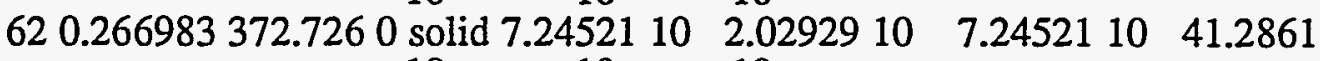
$\begin{array}{lll}10 & -10 & 10\end{array}$

630.267262377 .3510 solid $8.0977910 \quad 2.0978410 \quad 8.0977910 \quad 43.9477$ $\begin{array}{lll}10 & -10 & 10\end{array}$

640.26754382 .7070 solid $8.4439110 \quad 2.1715910 \quad 8.4439110 \quad 47.2814$ $\begin{array}{lll}10 & -10 & 10\end{array}$

650.267818388 .1820 solid $9.0238510 \quad 2.2511310 \quad 9.0238510 \quad 50.9952$ 10 $\begin{array}{lll}-10 & 10\end{array}$

660.268097394 .0310 solid $9.6641102 .3374410 \quad 9.664110 \quad 55.3385$ 


$$
\begin{array}{llll}
11 & -10 & 11
\end{array}
$$

670.268375400 .2990 solid $1.0271810 \quad 2.4317610 \quad 1.0271810 \quad 60.473$ $11 \quad-10$ 11

680.268654406 .9280 solid $1.09391102 .5354910 \quad 1.093911066 .5049$ $\begin{array}{lll}11 & -10 & 11\end{array}$ 690.268932413 .9610 solid $1.16569102 .650410 \quad 1.1656910 \quad 73.6695$ $11 \cdot-10 \quad 11$

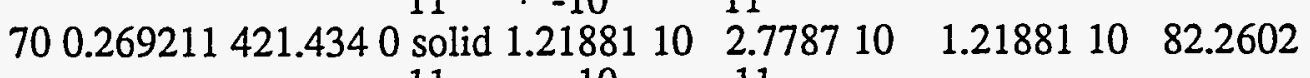
$11 \quad-10 \quad 11$

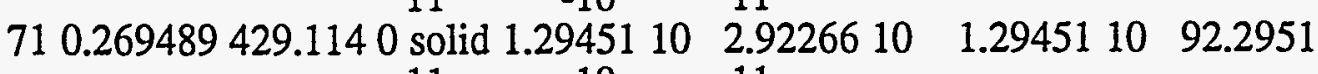
$11 \quad-10 \quad 11$

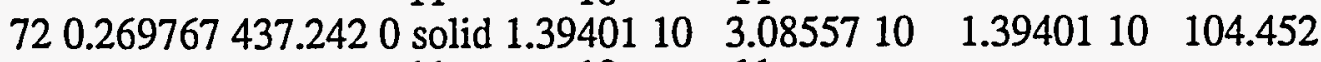
$11 \quad-10 \quad 11$

730.270046446 .0570 solid $1.4832610 \quad 3.2723110 \quad 1.4832610 \quad 119.72$ $\begin{array}{lll}11 & -10 & 11\end{array}$

740.270324455 .4060 solid $1.57189103 .4886610 \quad 1.5718910 \quad 138.711$ $\begin{array}{llll}11 & -10 & 11\end{array}$ 750.270603465 .250 solid $1.6524610 \quad 3.7420110 \quad 1.6524610 \quad 162.43$

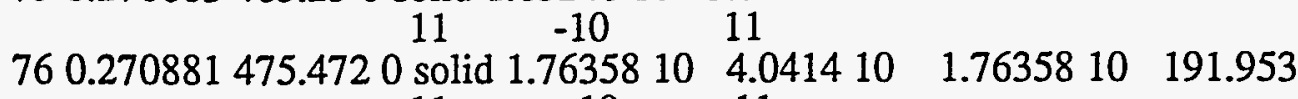

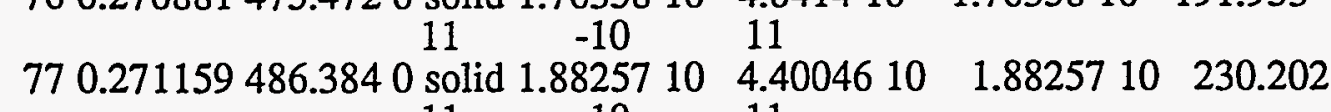

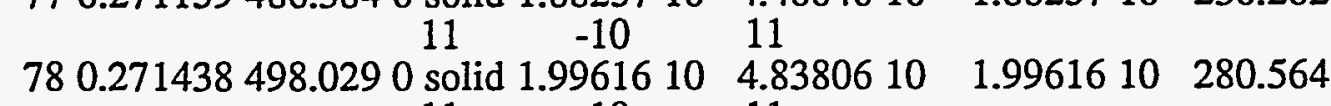
$\begin{array}{llll}11 & -10 & 11\end{array}$

790.271716510 .3050 solid $2.1116710 \quad 5.3795110 \quad 2.1116710 \quad 347.141$ $11 \quad-10 \quad 11$

800.271995523 .1930 solid $2.2227410 \quad 6.0598510 \quad 2.2227410 \quad 436.185$ $\begin{array}{lll}11 & -10 & 11\end{array}$

810.272273536 .6110 solid $2.3638410 \quad 6.9272110 \quad 2.3638410 \quad 556.097$ $\begin{array}{lll}11 & -10 & 11\end{array}$

$82 \quad 0.272551550 .8450$ solid $2.4758810 \quad 8.0558910 \quad 2.4758810 \quad 723.631$ $11 \quad-10 \quad 11$

830.27283565 .5450 solid $2.6600210 \quad 9.5462910 \quad 2.6600210 \quad 955.549$ $\begin{array}{llll}11 & -9 & 11\end{array}$

840.273108581 .4330 solid $2.7949210 \quad 1.1572810 \quad 2.7949210 \quad 1299.26$ $\begin{array}{llll}11 & -9 & 11\end{array}$

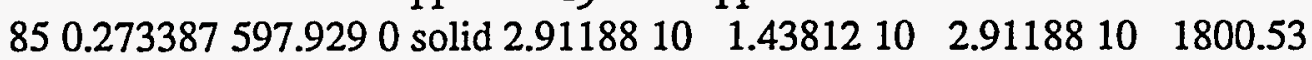

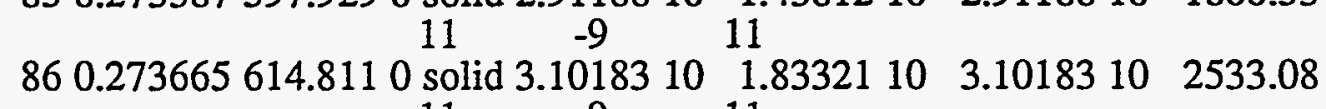

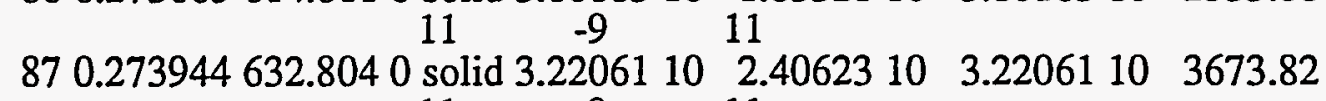
$\begin{array}{llll}11 & -9 & 11\end{array}$

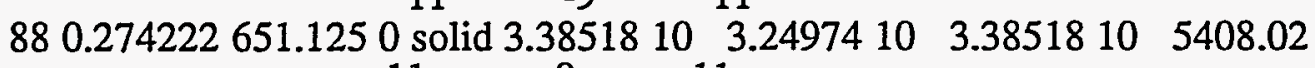
$\begin{array}{lll}11 & -9 & 11\end{array}$

890.2745670 .2190 solid $3.51628 \quad 10 \quad 4.5222410 \quad 3.5162810 \quad 8158.46$

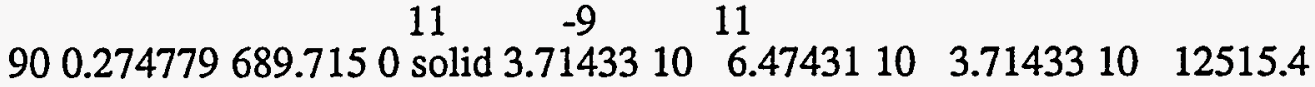

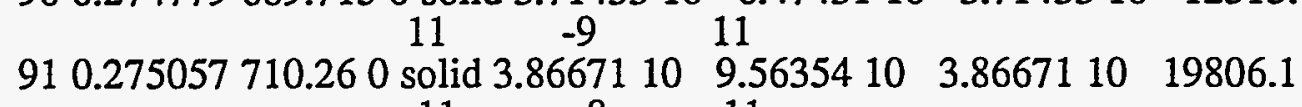

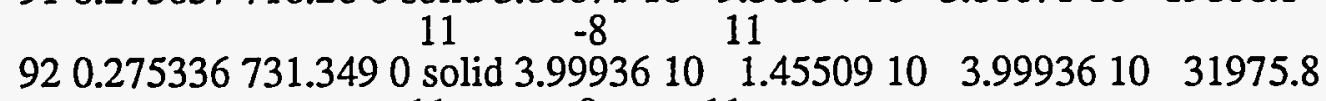
$\begin{array}{llll}11 & -8 & 11\end{array}$

930.275614752 .7620 solid $4.140510 \quad 2.2720410 \quad 4.140510 \quad 52376.9$ 
$\begin{array}{llll}11 & -8 & 11\end{array}$

940.275892774 .5730 solid $4.3204310 \quad 3.6310710 \quad 4.3204310 \quad 87132.6$

$\begin{array}{lll}11 & -8 & 11\end{array}$

950.276171797 .1450 solid $4.459310 \quad 5.9449510 \quad 4.459310148350$.

$\begin{array}{llll}11 & -8 & 11\end{array}$

960.276449820 .0570 solid 4.6111109 .93321104 .611110255700$.

$\begin{array}{lll}11 & -7 & 11\end{array}$

970.276728843 .4250 solid $4.7373610 \quad 1.69027104 .7373510446839$.

$\begin{array}{llll}11 & -7 & 11\end{array}$

980.277006867 .0040 solid $4.923710 \quad 2.91601104 .923710785859$.

$\begin{array}{llll}11 & -7 & 11\end{array}$

990.277284891 .3550 melting $5.0191410 \quad 5.11127105 .0191310$

6

1.4074510

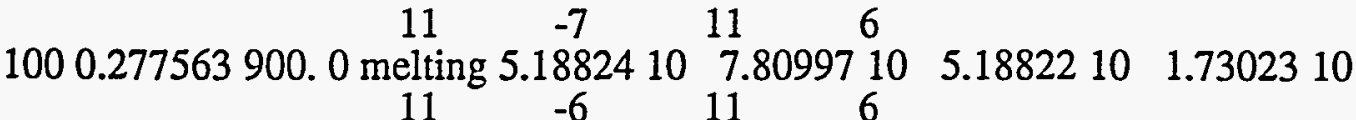
1010.277841900 .0 melting $5.2495110 \quad 1.0508710 \quad 5.2494910 \quad 1.7302310$ $\begin{array}{llll}11 & -6 & 11 & 6\end{array}$

1020.27812900 .0 liquid $5.2976210 \quad 1.3207410 \quad 5.297610 \quad 1.7302310$

$11 \quad-6 \quad 11 \quad 6$

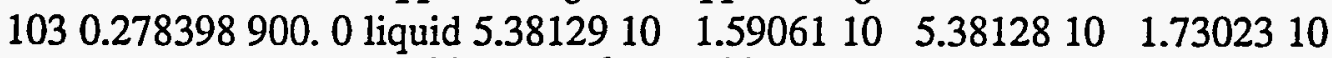

1040.278677926 .0560 liquid $5.4784310^{-6} \quad 2.0922110 \quad 5.478410$

3.2159410

1050.278955940 .0220 liquid $5.5561810 \quad 2.7900510 \quad 5.5561310$

6

4.4740910

1060.279233947 .6880 liquid $5.6048710 \quad 3.6259210 \quad 5.6048210$

6

5.3590410

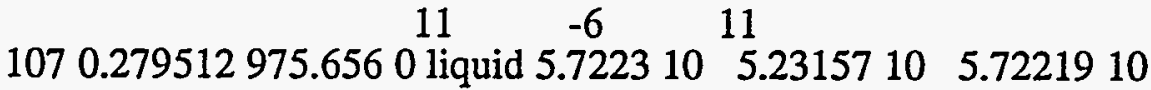

1.0294310

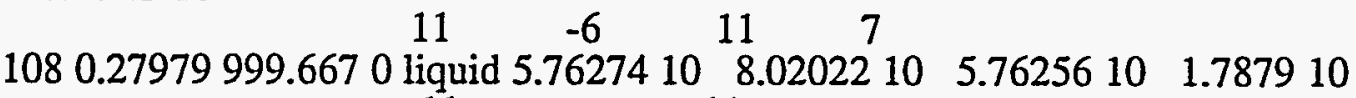
$11 \quad 11$

1090.2800691018 .510 liquid $5.7105810 \quad 0.00001229355 .710310$

2.7397410

1100.2803471041 .770 liquid $5.6535710^{11} 0.00001946585 .6531110$ 
4.5983810

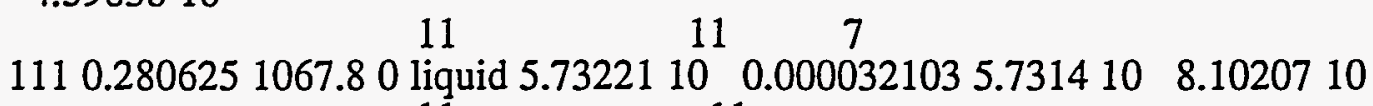
11 11

1120.2809041093 .020 liquid $5.714910 \quad 0.00005366555 .7135210$

8

1.3824310

$11 \quad 11$

1130.2811821115 .250 liquid $5.6707910 \quad 0.00008775985 .668610$

8

2.1858610

$11 \quad 11$

1140.2814611137 .150 liquid $5.5791610 \quad 0.0001406495 .5757710$

8

3.3908410

$11 \quad 11$

1150.2817391159 .070 liquid $5.4469610 \quad 0.0002216745 .4417610$

8

5.1945610

11

1160.2820181179 .530 liquid $5.3822310 \quad 0.0003408545 .3745910$

8

7.6405810

1111

1170.2822961198 .260 liquid $5.3096910 \quad 0.0005087875 .2989210$

9

1.0765810

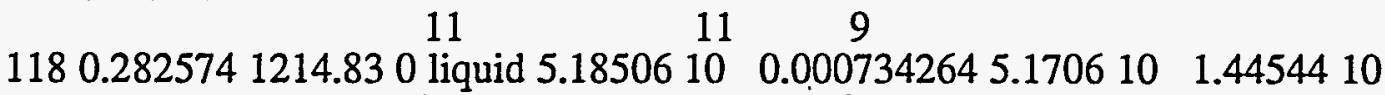
$11 \quad 11 \quad 9$

1190.2828531228 .720 liquid $5.029910 \quad 0.001021085 .0115110 \quad 1.8385810$ $11 \quad 11 \quad 9$

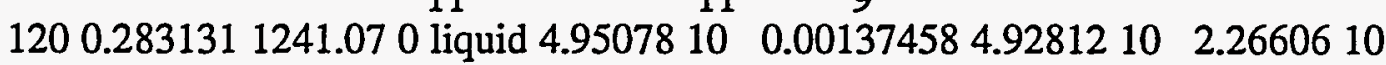
$11 \quad 11 \quad 9$

1210.283411252 .390 liquid $4.7942910 \quad 0.001801024 .76695102 .7334310$ $11 \quad 11 \quad 9$

1220.2836881261 .690 liquid $4.6719910 \quad 0.002297044 .6402103 .1793410$ 1230.2839661269 .660 liquid $4.5285310 \quad 0.002860414 .4924210 \quad 3.6109710$ $11 \quad 11 \quad 9$

1240.2842451276 .360 liquid $4.3539110 \quad 0.003486384 .3137910 \quad 4.0120310$

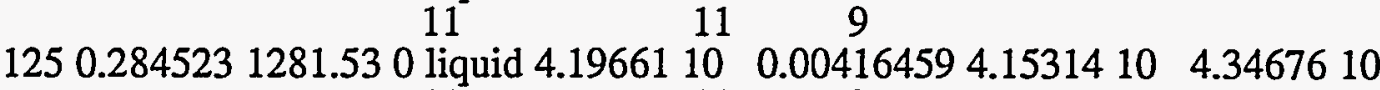

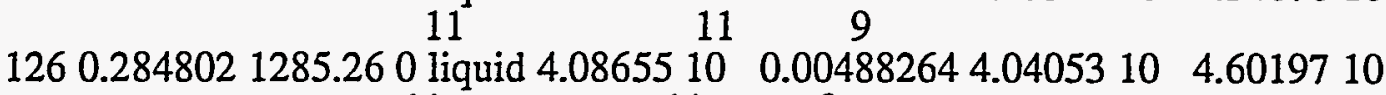
$11 \quad 11 \quad 9$

1270.285081288 .20 liquid $3.9159210 \quad 0.005633443 .867810 \quad 4.8118610$ $11 \quad 9$ 
1280.2853581290 .040 liquid $3.7191810 \quad 0.006405163 .6697210 \quad 4.9458310$

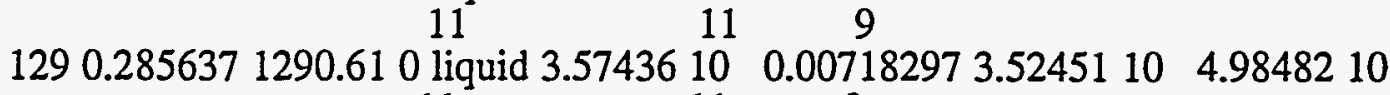
$\begin{array}{lllllll}130 & 0.2859151290 .30 \text { liquid } 3.46261 & 10 & 0.007956553 .41304 & 10 & 4.95777 & 10\end{array}$ $1310.2861941289 .35011 \quad 11$ 1310.2861941289 .350 liquid 3.2699210 9
0.00871832
9 1320.2864721287 .30 liquid $3.1277410 \quad 0.009455993 .0804710 \quad 4.7277210$ $11 \quad 11$ 1330.2867511284 .760 liquid 2.9765210 1340.2870291281 .610 liquid 2.8107310 $11 \quad 11$ 1350.2873071277 .650 liquid 2.6549910 1360.2875861272 .990 liquid 2.5464710 1370.2878641268 .11011 1370.2878641268 .110 liquid 2.4084210 1380.2881431262 .770 liquid 2.2787310 $11 \quad 11$ 1390.2884211257 .030 liquid 2.1583810 1400.2886991250 .95011 liquid 2.0284911 1400.2886991250 .950 liquid 2.0284910 1410.2889781244 .390 liquid 1.9033410 1420.2892561237 .490 liquid 1.8102711 1420.2892561237 .490 liquid 1.8102711 1430.2895351230 .720 liquid 1.6902910 $11 \quad 11$ 1440.2898131224 .060 liquid 1.5918410 1450.2900911217 .820 liquid 1.5010610 11 11 11 1460.290371212 .140 liquid 1.4355610 1470.2906481207 .210 liquid 1.3456410 1480.2909271202750 liquid $12471410^{11}$ 1490.2912051198 .610 liquid 1.1753610 $11 \quad 11$ 1500.2914841194 .920 liquid $1.0803410 \quad 0.01636271 .07037$ i0 9.9732510

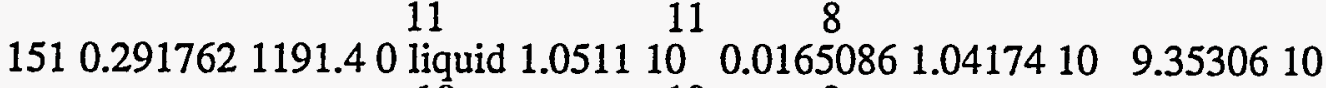
1520.292041188 .520 liquid 9.6533810 1530.2923191185 .720 liquid 9.1491410 $10 \quad 10$ 1540.2925971183 .220 liquid 8.5925310 $0.01016472 .9310910 \quad 4.5422510$ $0.01083922 .7675110 \quad 4.3227410$

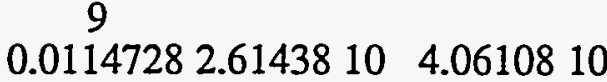
9 0.01206132 .50876103 .7716810 9
0.01260542 .3735410
9.4879410

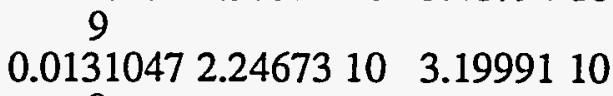
9
0.01355942 .1292410
9 2.9146110 $\begin{array}{ccc}9 & & \\ 0.0139708 & 2.0021210 & 2.6370410\end{array}$ $\begin{array}{ccc}0.01397082 .0021210 & 2.6370410 \\ 9 & \end{array}$ 0.01433961 .87969102 .3645310

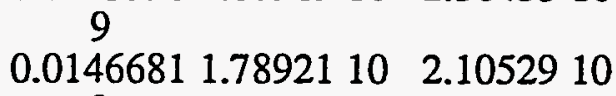
9 $0.01496071 .6715310 \quad 1.8761310$ $0.01522171 .5751110 \quad 1.672710$ 9
0.0154558
9 $1.4860510 \quad 1.5006410$ $\stackrel{9}{9} \begin{array}{lll}01566761.4219810 & 1.357910\end{array}$ 0.01566

$0.01586171 .333210 \quad 1.2441310$ 9

0.01604091 .23565101 .148810 9 $0.01620721 .164710 \quad 1.0662210$ 8 $\begin{array}{ccc}0.01650861 .0417410 & 9.3530610 \\ 8 & & \end{array}$ $0.0166479 .5646510 \quad 8.8731310$ 8
$0.01677859 .0648710 \quad 8.426610$ $\begin{array}{ccc}8 & & \\ 0.0169048 .5120710 \quad 8.0457510\end{array}$ 10 10 8 
1550.2928761180 .910 liquid $8.2428610 \quad 0.01702428 .1657810 \quad 7.7077610$ $10 \quad 10 \quad 8$

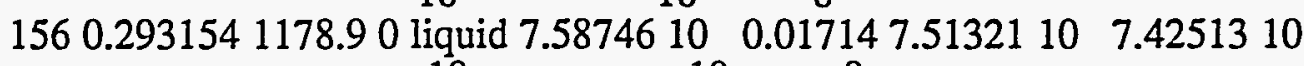
$10 \quad 10 \quad 8$

1570.2934321176 .880 liquid $6.9969610 \quad 0.01725166 .9254610 \quad 7.1499410$ $10 \quad 10$

1580.2937111174 .850 liquid 6.6890310 $10 \quad 10$

1590.2939891173 .030 liquid 6.3661910

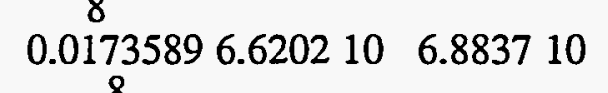
0.01735896 .620210
0.01746276 .893710 $0.01746276 .2996710 \quad 6.6518610$ $10 \quad 10$

1600.2942681171 .360 liquid 6.0098610 $10 \quad 10$

1610.2945461169 .770 liquid 5.6779710 $10 \quad 10$

1620.2948251168 .250 liquid 5.0136810

1630.2951031166 .480 liquid 4.8644610

$10 \quad 10$

1640.2953811164 .910 liquid 4.4048410 $10 \quad 10$

1650.295661163 .220 liquid $4.314310 \quad 0.01802244 .2590710 \quad 5.5230910$ $0.01756325 .9454110 \quad 6.4453310$ $0.01766085 .6154210 \quad 6.2545110$ 8 $0.01775564 .9529110 \quad 6.0771310$ $0.01784724 .8056910 \quad 5.8771510$ 8

$0.01793624 .3478110 \quad 5.7033910$ $10 \quad 10$

$\begin{array}{llcccc}166 & 0.2959381161 .730 \text { liquid } 3.7400610 & 0.01810613 .6863810 & 5.36812 & 10\end{array}$ $\begin{array}{lllll}1670.296217 & 1160.0 \text { liquid } 3.4974210 & 0.01818713 .445510 & 5.1927 & 10\end{array}$

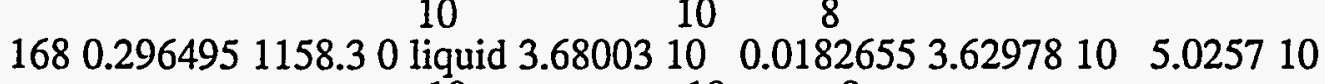
1690.2967731156 .980 liquid 3.4187810 $10 \quad 10$ 1700.2970521155 .640 liquid 3.0161210 $10 \quad 10$

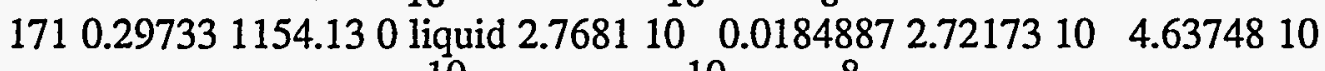
$10 \quad 10 \quad 8$

$\begin{array}{llllll}172 & 0.297609 & 1152.580 & \text { liquid } 3.0449310 & 0.01855892 .9999210 & 4.5007610\end{array}$ 1010

1730.2978871151 .450 liquid 2.6062510 $10 \quad 10$

1740.2981651150 .070 liquid 2.4230310 1750.2984441148 .680 liquid 2.1863310 1760.2987221147 .210 liquid 22162910 1760.2987221147 .210 liquid 2.2162910 1770.2990011145 .90 liquid 2.1677510 8
0.01862762 .5622210
8.4024310 8 $0.01869442 .3801710 \quad 4.2864310$

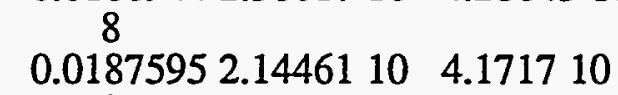
$\begin{array}{ccc}0.0187595 & 2.1446110 & 4.171710 \\ 0 & & \end{array}$ $0.01882272 .1757510 \quad 4.054110$ 0.01888442 .12824103 .9514310 $10 \quad 8$

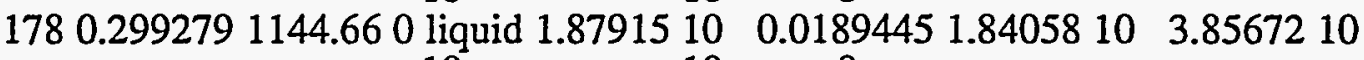
$10 \quad 10$ 1790.2995581143 .280 liquid 1.7762910 1800.2998361141 .910 liquid 1.9822910 $10 \quad 10$ 1810.3001141140 .810 liquid 1.7071610 10 10

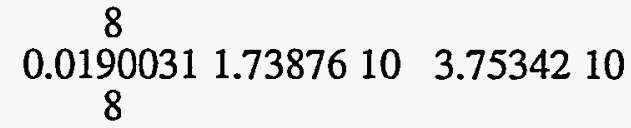
0.01906011 .94575103 .6536710 8
$0.01911581 .671410 \quad 3.575710$ 8 


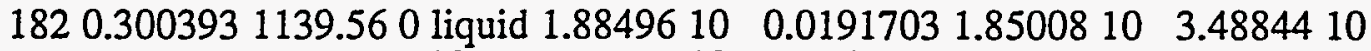
$10 \quad 10$

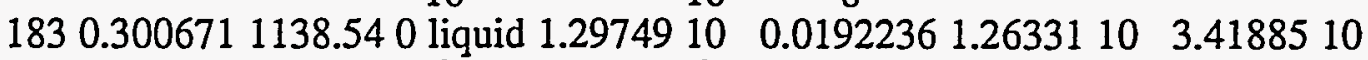
$10 \quad 10 \quad 8$

1840.300951137 .080 liquid $1.3736710 \quad 0.01927541 .3404510 \quad 3.3213110$

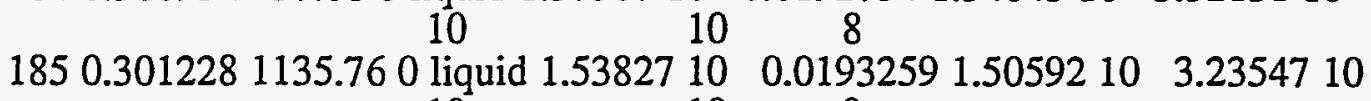

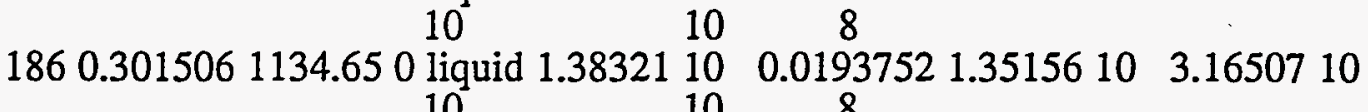

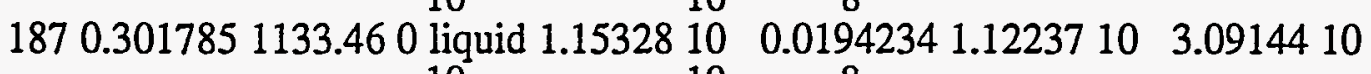
$10 \quad 10$

$\begin{array}{llllll}1880.3020631132 .140 \text { liquid } 1.1606710 & 0.01947041 .1305610 & 3.0107910\end{array}$ $\begin{array}{llllll}189 & 0.3023421130 .870 \text { liquid } 1.1415310 & 0.01951621 .1121710 & 2.93588 & 10\end{array}$ $10 \quad 10$

1900.302621129 .650 liquid $1.2113910 \quad 0.01956091 .1827410 \quad 2.8648310$

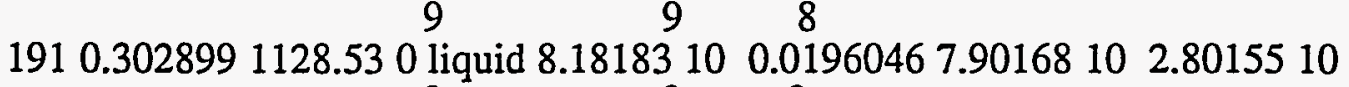

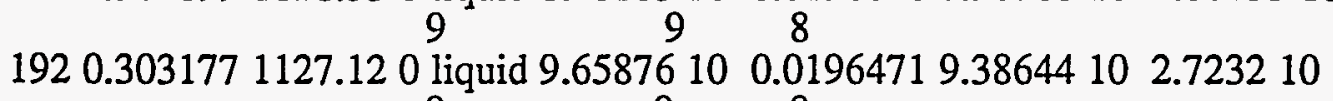

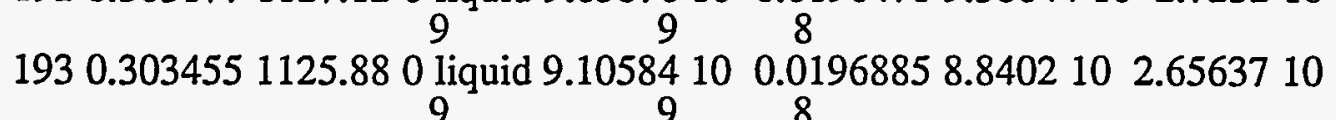
1940.3037341124 .640 liquid 9.84929100 .01972899 .5902102 .5908210

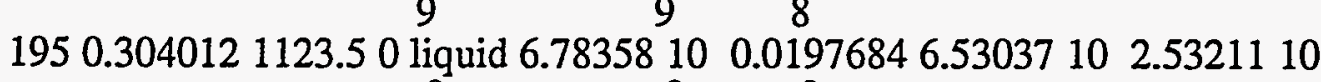

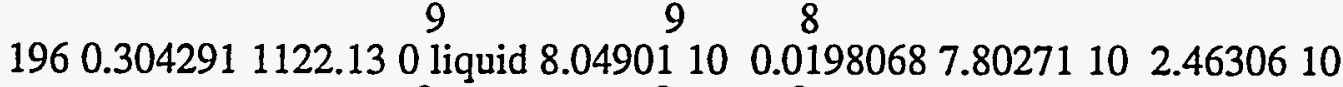

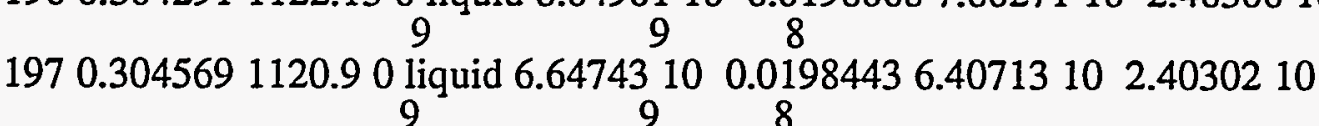

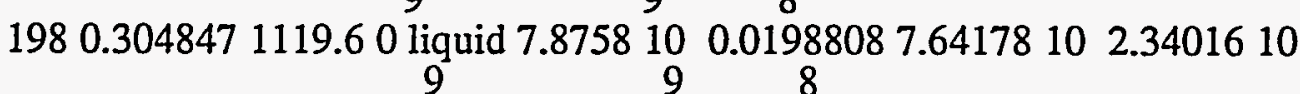

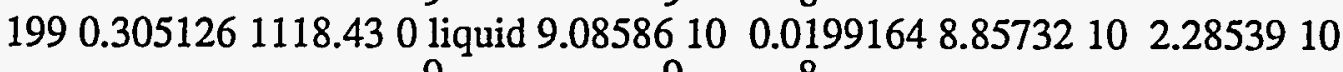
$\begin{array}{lllllll}200 & 0.3054041117 .390 & 9 & \text { liquid } 6.5005310 & 0.0199513 & 6.2767510 & 2.2378510\end{array}$

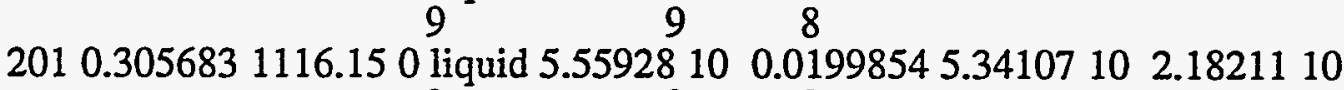

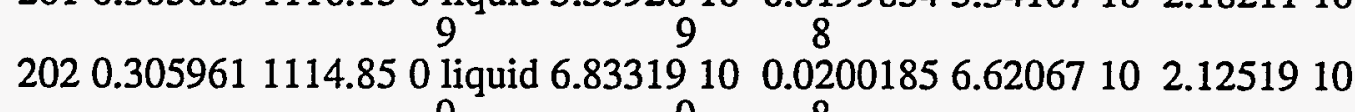

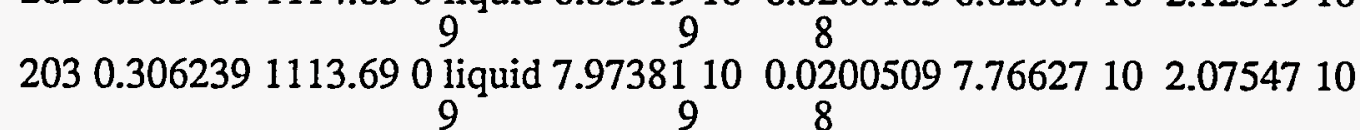
2040.3065181112 .650 liquid 5.72272100 .02008265 .51954102 .0318310 $9 \begin{array}{lll}9 & 8\end{array}$ 2050.3067961111 .430 liquid 2.36223100 .02011352 .16406101 .9816910 2060.3070751109 .930 liquid 5.55674100 .02014355 .36455101 .9219110

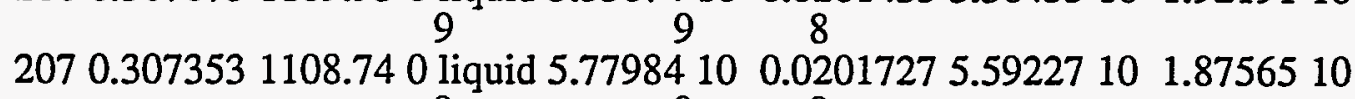

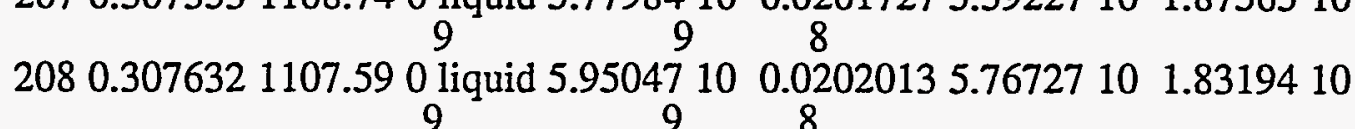


2090.307911106 .480 liquid 3.24404100 .02022923 .06501101 .7903410

2100.3081881105 .140 liquid 3.24748100 .02025643 .07332101 .741610

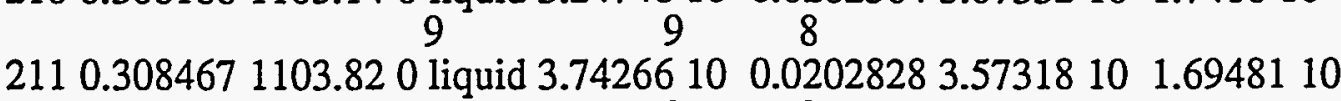

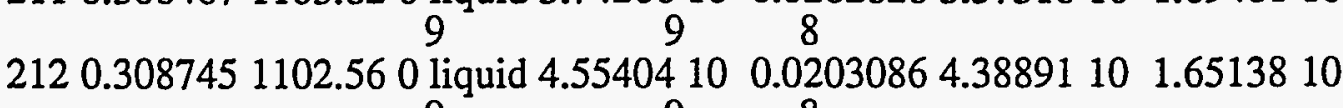

$\begin{array}{llccccc}213 & 0.309024 & 9 & 9 & 8 & & 9 \\ 1101.39 & 0 & \text { liquid } 5.1291210 & 0.02033374 .9679210 & 1.6119410\end{array}$

2140.3093021100 .290 liquid 5.06907100 .02035834 .91153101 .5754610

Finished

Tcoefsol $=2.25 * 10^{\wedge}-5$;

Tcoefliq $=1.17 * 10^{\wedge}-4$

(* TA - average temperature *)

ta[ts_]:= Sum[Part[xx1[node,ts],2],\{node, $1, \mathrm{~m}\}] / \mathrm{m}$;

$(*$ tr - Temperature time rate of change $*$ )

$\operatorname{tr}[$ node_ts_]:=Part[xx1[node,ts]-xx1[node,ts-1],2]/Part[xx1[node,ts]-xx1[node,ts-1],1];

(* tra - average rate of change of temp for the plate *)

$\operatorname{tra}\left[\mathrm{ts} \_\right]:=\operatorname{Sum}[\operatorname{tr}[$ node,ts], $\{$ node $, 1, \mathrm{~m}\}] / \mathrm{m}$;

(* expth - expansion thermal $\left.{ }^{*}\right)$

(* texprate - thermal expansion rate for the plate *)

expth[node_ts_]:=Tcoefsol*tr[node,ts] /; Part[xx1[node,ts],2]<Tm;

expth[node_ts_]:=Tcoefliq*tr[node,ts] /; Part[xx1[node,ts],2]>Tm \&\& Part[xx1[node,ts],2]<Tv;

expth[node_ts_]:=tr[node,ts]/ Part[xx1[node,ts],2]/; Part[xx1[node,ts],2]>Tv;

expth[node_,ts_]: $=0 \% \operatorname{Part}[\mathrm{xx} 1[$ node,ts],2] $===\mathrm{Tm}$;

expth[node_ts_]: $=0 / ; \operatorname{Part}[\mathrm{xx} 1[$ node,ts],2] $===\mathrm{Tv}$;

texprate[ts_]:=Sum[expth[node,ts],\{node, $1, \mathrm{~m}\}] / \mathrm{m}$;

$(*$ qm - quality of the melt *)

$(* \mathrm{mv}$ - quality of the vapor *)

qm[ts_]:=Sum[Part[xx2[node,ts],2], \{node, $1, \mathrm{~m}\}] / \mathrm{m}$;

qv[ts_]:=Sum[Part[xx3[node,ts],2], (node, $1, \mathrm{~m})] / \mathrm{m}$;

vfaln[i_]:=fval $/ ; \mathrm{i}<=\mathrm{n}$;

vfaln[i_]:=1 /; i $>$;

(* Fractional rate of change of volume due to various factors *)

(* ger - Gas Expansion Rate

(* VMR - Volumetric Melting Rate

(*VVR - Volumetric Vaporization Rate

(* VOFR - Volumetric Oxide Formation Rate

(* QMR - Quality Melt Rate

(* QVR - Quality Vaporization Rate

*)

$*$

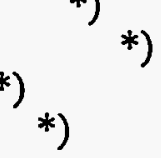

rhosolid=2700; rholiquid $=2500$; rhovapor $=1.0$;

DencRatLV=(1//rhovapor ${ }^{\wedge}(0.3)-1 /$ rholiquid $\left.^{\wedge}(0.3)\right) /\left(1 /\right.$ rholiquid $\left.^{\wedge}(0.3)\right)$;

DencRatSL $=\left(1 /\right.$ rholiquid^ $(0.3)-1 /$ rhosolid^$\left.^{\wedge}(0.3)\right) /\left(1 /\right.$ rhosolid $\left.^{\wedge}(0.3)\right)$;

qmr[node_ts_]:=Part[xx2[node,ts]-xx2[node,ts-1],2]/Part[xx2[node,ts]-xx2[node,ts-1],1];

qvr[node_ts]]:=Part[xx3[node,ts]-xx3[node,ts-1],2]/Part[xx3[node,ts]-xx3[node,ts-1],1];

$\operatorname{vmr}[$ ts_]:=Sum[DencRatSL*qmr[node,ts]*vfaln[node],\{node, $1, \mathrm{~m}\}] / \mathrm{m}$;

$\operatorname{vvr[ts]}]:=S u m\left[\right.$ DencRatLV*qvr[node,ts] ${ }^{*}$ vfaln[node], $\{$ node, $\left.1, \mathrm{~m}\}\right] / \mathrm{m}$; 
ger[ts_]:=Sum[ tr[node,ts]/ Part[xx1[node,ts],2], \{node,1,n\}]/m;

$\mathrm{ff}=0.01$;

TotalExpansionRate[ts_]:= (1-ff)*(vmr[ts]+vvr[ts]+texprate[ts] $)+\mathrm{ff} * \mathrm{ger}[\mathrm{ts}]$

IntegralTotExp[ts]]:=Sum[TotalExpansionRate[tt]*dt,\{tt,2,ts\}]

ListPlot[Table[\{Part[xx1[1,ts],1],TotalExpansionRate[ts]\},\{ts,2,nt $\}]$,

PlotJoined $\rightarrow$ True,

PlotRange->All,

AxesLabel-> $\{$ "time (s)","Fractional Exp rate (1/s)" $\}$ ]

ter $=1$;

(* ter total expansion *)

Do[ter*=(1+TotalExpansionRate[tt]*dt);

qwa $[\mathrm{tt}]=\{\operatorname{Part}[\mathrm{xx} 1[1, \mathrm{tt}], 1], \mathrm{ter}-1\}$

$,\{\mathrm{tt}, 2, \mathrm{nt}\}]$

ListPlot[Table[qwq[tt],\{tt,2,nt $\}]$,

PlotJoined $\rightarrow$ True,

PlotRange- $>$ All,

AxesLabel->\{"time (s)","Expanded fraction" $\}]$

Do[eff[ts] $=\{$ Part[xx1[1,ts],1],ta[ts],TotalExpansionRate[ts],Part[qwq[ts],2]\},\{ts,2,nt $\}]$;

ListPlot[Table[\{Part[xx1[1,ts],1],ta[ts]\},\{ts,2,nt $\}]$,

PlotJoined $\rightarrow$ True,

PlotRange->All,

AxesLabel->\{"time (s)","average temp (K)" $\}]$

-Graphics-

-Graphics-

-Graphics-

ListPlot[Table[\{Part[xx1[1,i],1],Part[xx1[1,i],2]\},\{i,1,nt\}],

PlotJoined $\rightarrow$ True,

PlotRange->All,

AxesLabel->\{"time (s)"," temp (K)"\}]

ListPlot[Table[\{Part[xx1[m,i],1],Part[xx1[m,i], 2$]\},\{\mathrm{i}, 1, \mathrm{nt}\}]$,

PlotJoined $\rightarrow$ True,

PlotRange- $>$ All,

AxesLabel->\{"time (s)"," temp (K)"\}]

-Graphics-

-Graphics- 
ListPlot[Table[\{Part[xx4[1,i],1],Part[xx4[1,i],2]\},\{i,1,nt $\}]$,

PlotJoined $\rightarrow>$ True,PlotRange->All,

AxesLabel->\{"time (s)"," fraction of fuel reacted" $\}]$;

szs1 $=$ ListPlot[Table[ $\{\operatorname{Part}[\mathrm{xx} 5[1, \mathrm{i}], 1], \operatorname{Part}[\mathrm{xx5}[1, \mathrm{i}], 2]\},\{\mathrm{i}, 1, \mathrm{nt}\}]$,

PlotJoined $\rightarrow$ True,PlotRange- $>$ All,

AxesLabel->\{ "time (s)"," Q fission (W/m^3)" $\}$ ];

szs2=ListPlot[Table[\{Part[xx6[1,i],1],Part[xx6[1,i],2]\},\{i,1,nt $\}]$,

PlotJoined $\rightarrow$ True,PlotRange $->$ All,

AxesLabel-> "time (s)"," $Q$ chemical $\left(\mathrm{W} / \mathrm{m}^{\wedge} 3\right)$ " $\left.\}\right]$;

szs3=ListPlot[Table[\{Part[xx7[1,i],1],Part[xx7[1,i],2]\},\{i,1,nt $\}]$,

PlotJoined $\rightarrow$ True,PlotRange- $>$ All,

AxesLabel-> "time (s)"," Q total (W/m^3)" \}];

Show[szs1,szs2,szs3]

-Graphics-

\section{2}

$(*$

THIS IS A REVISED DISPERSION MODEL THAT USES THE

TIME ENERGY DATA FROM THE EXPERIMENTS AND TEMPERATURE

DEPENDANT CHEMICAL REACTION RATES FUEL- ALUMINUM

This copy has chemical reaction rates included in the model

LAST UPDATED 4-19-95

Renormalized pulse width was used to a narrower band width.

*)

Print["Date last updated =",Date[];

Date last updated $=\{1995,5,1,16,44,46\}$

$\mathrm{l}=0.000635 ; \mathrm{m}=10 ; \mathrm{dx}=1 / \mathrm{m} ; \mathrm{n}=\mathrm{Round}[\mathrm{m} * 4] ;$ time $=0 ; \operatorname{Tinf}=300$;

volmeat $=2 * \mathrm{dx}^{*} \mathrm{n} *\left(25^{*} 10^{\wedge}-3\right) *\left(70^{*} 10^{\wedge}-3\right)$;

Do $[\mathrm{xx}[\mathrm{i}]=\mathrm{i} * \mathrm{dx}-\mathrm{dx} / 2,\{\mathrm{i}, 1, \mathrm{~m}\}] ; \mathrm{Tm}=900$; $\mathrm{Tv}=2700$;

$\mathrm{Do}[\mathrm{To}[\mathrm{i}]=300 ; \operatorname{Tc}[\mathrm{i}]=300 ; \mathrm{xm}[\mathrm{i}]=0 ; \mathrm{xv}[\mathrm{i}]=0,\{\mathrm{i}, 1, \mathrm{~m}\}]$;

$\mathrm{k}[\mathrm{i}] \mathrm{B}:=39.91 / ; \mathrm{i}<=\mathrm{n} ; \quad(*$ assign $\mathrm{k}$ to the meat $*)$

$\mathrm{k}[\mathrm{i}]]:=\mathrm{kcl}[\mathrm{To}[\mathrm{i}]] / ; \mathrm{i}>\mathrm{n} ; \quad$ (*assign $\mathrm{k}$ to the clad $*)$ 
rho[i_]:=6550.0/;i $<=\mathrm{n} ;\left({ }^{*}\right.$ assign meat density $\left.*\right)$

rho[i_]:= $2700.0 / ;$ i $>\mathrm{n} ;\left({ }^{*}\right.$ assign clad density $\left.{ }^{*}\right)$

$\mathrm{cp}[\mathrm{i}]$ ]:= $\operatorname{cpcl[To[i]]} / ;$ i $>\mathrm{n} ; \quad\left({ }^{*}\right.$ assign clad cpecific heat $\left.{ }^{*}\right)$

$\operatorname{cp}[\mathrm{i}]]:=\operatorname{cpf}[\mathrm{To}[\mathrm{i}]] / ; \mathrm{i}<=\mathrm{n} ; \quad(*$ assign meat cpecific heat $*$ )

htc=Interpolation $[\{\{150,13232\},\{350,13232\},\{410,14770\},\{726,12542\}$,

$\{776,11561\},\{1256,9924\},\{1458,1750\},\{1526,1729\},\{1556,800\}$,

$\{5000,800\}\}$, InterpolationOrder- $>1]$;

kcl=Interpolation[ $\{\{100,161\},\{400,177\},\{500,186\},\{600,193\}$,

$\{750,193\},\{850,193\},\{900,193\},\{930,193\}$,

$\{1200,84\},\{1300,84\},\{1500,84\},\{2000,84\},\{5000,84\}\}$,

InterpolationOrder- $>1]$;

cpcl=Interpolation $[\{\{100,878\},\{300,878\},\{366,942\},\{422,963\}$,

$\{588,1034\},\{700,1067\},\{811,995\},\{1000,995\},\{2000,995\}$,

$\{5000,995\}\}$,InterpolationOrder- $>1]$;

$\mathrm{cpf}=$ Interpolation $[\{\{100,351\},\{300,351\},\{933,463\},\{1933,546\}$, $\{2500,546\},\{3500,546\},\{5000,546\}\}$, InterpolationOrder->1];

hsf[i ]: $=398000 *$ fmal $/ ; \mathrm{i}<=\mathrm{n}$;

$\mathrm{hfg}[\mathrm{i}]:=10800000 * \mathrm{fmal} / ; \mathrm{i}<=\mathrm{n}$;

hsf [i_ $]:=398000 \quad$ l; i $>\mathrm{n}$;

hfg[i] $]:=10800000 \quad / ;$ i $>n$;

151=ReadList["508.52",Number,RecordLists $>$ True];

shape=Interpolation[151,InterpolationOrder $\rightarrow 1]$;

num=Part[Part[Position[151,Last[151]],1],1];

TimeBeg=Part[151[[1]],1]; TimeEnd=Part[151[[num]],1];

$\mathrm{c} 1=\operatorname{Sum}\left[0.5^{*}\right.$ (shape[Part[151[[i]],1]]+shape[Part[151[[i+1]],1]])*

(Part[151[[i+1]],1]-Part[151[[i]],1]),\{i,200,500\}];

qs[qtot_time_]:=qtot*shape[time]/(volmeat $\left.{ }^{*} \mathrm{c} 1\right)$;

qtot $=8 \overline{685}$;

(* Functions : nrt - new reacted fraction

orf - old reacted fraction *)

$\operatorname{Tm} 1=863 ; \operatorname{Tm} 2=1970 ; \operatorname{Td}[\mathrm{i}]$ :=(To[i]-Tm1)/(Tm2-Tm1);

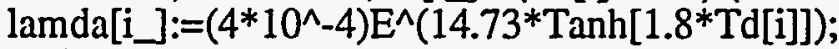

$z 1\left[i_{-}, d_{1}\right]:=N D S o l v e\left[\left\{R F^{\prime}[t]==\right.\right.$ lamda[i]-lamda[i] $* R F[t]$,

$\overrightarrow{R F}[0]==\operatorname{orf}[\mathrm{i}]\}, \mathrm{RF},\{\mathrm{t}, 0, \mathrm{dt}\}$, AccuracyGoal $\rightarrow$ 15];

$\mathrm{nrf}\left[\mathrm{i}_{\mathrm{i}}, \mathrm{dt}\right] \mathrm{C}=\mathrm{Part}[\mathrm{RF}[\mathrm{dt}] / . \mathrm{z} 1[\mathrm{i}, \mathrm{dt}], 1]$

frr[i] $:=$ lamda[i]-lamda[i]*orf[i];

UpdateRF[dt_]:=Do[orf [i] $=\operatorname{nrf}[i, d t],\{i, 1, n\}]$

qchem[i_]:=ww*frr[i];

$\mathrm{q}\left[\mathrm{i}_{-}, \mathrm{time}, \mathrm{qtot}\right]:=\mathrm{qs}[\mathrm{qtot}, \mathrm{time}]+\mathrm{qchem}[\mathrm{i}] / ; \mathrm{i}<=\mathrm{n} ;\left({ }^{*}\right.$ assign heat generation in the meat $\left.*\right)$

$\mathrm{q}[\mathrm{i}$, time_, $\mathrm{qtot}]:=0 / ; \mathrm{i}>\mathrm{n} ; \quad$ (* assign heat generation in the clad $*$ )

$\mathrm{bb}[\mathrm{i}]:=\mathrm{htc}[\mathrm{To}[\mathrm{m}]] / \mathrm{dx} / ; \mathrm{i}==\mathrm{m}$;

$\mathrm{bb}[\mathrm{i}] \mathrm{]}:=0 / ; \mathrm{i} !=\mathrm{m} ; \quad$ (* value for the heat transfer out of the plate $*$ )

$\mathrm{k} 1[\mathrm{i}] \mathrm{z}=(2 * \mathrm{k}[\mathrm{i}-1] * \mathrm{k}[\mathrm{i}] /(\mathrm{k}[\mathrm{i}-1]+\mathrm{k}[\mathrm{i}])) / \mathrm{dx} \mathrm{x}^{\wedge} / ; \mathrm{i} !=1$

$k 1[i]:=0 / ; i=1$ 
$\mathrm{k} 2[\mathrm{i}] \mathrm{i}=\mathrm{k} 1[\mathrm{i}]+\mathrm{k} 3[\mathrm{i}]$

$\mathrm{k} 3[\mathrm{i}]:=(2 * \mathrm{k}[\mathrm{i}+1] * \mathrm{k}[\mathrm{i}] /(\mathrm{k}[\mathrm{i}+1]+\mathrm{k}[\mathrm{i}])) / \mathrm{dx} \wedge 2 / ; \mathrm{i} !=\mathrm{m}$

$\mathrm{k} 3[\mathrm{i}]:=0 / ; \mathrm{i}=\mathrm{=m}$;

phase[i] $]:=$ solid $/ ; \mathrm{Tc}[\mathrm{i}]<\mathrm{Tm}$;

phase[i] : = liquid /; Tc[i] $<\operatorname{Tv} \& \& \operatorname{Tc}[\mathrm{i}]>=\operatorname{Tm} \& \& \mathrm{xm}[\mathrm{i}]>=0.85$;

phase[i $]:=$ vapor $/ ; \quad T c[i]>=T v \& \&$ xv[i] $>1$;

phase $[i]:=$ melting $/ ; \quad \operatorname{Tc}[i]>=\operatorname{Tm} \& \&$ xm $[i]<0.85$;

phase[i] $=$ vaporizing $/ ; \quad \operatorname{Tc}[\mathrm{i}]>=\mathrm{Tv} \& \& \mathrm{xv}[\mathrm{i}]<1 \& \& \mathrm{xv}[\mathrm{i}]>-0.01$;

$\operatorname{Tn}[\mathrm{i}] \mathrm{]}:=\mathrm{Tc}[\mathrm{i}] /$; phase $[\mathrm{i}]=!=$ melting $\& \&$ phase $[\mathrm{i}]=!=$ vaporizing;

$\operatorname{Tn}[i]$ : $=\operatorname{Tm} / ;$ phase $[i]===$ melting ;

$\operatorname{Tn}[\mathrm{i}]:=\mathrm{Tv} / ;$ phase[i] === vaporizing ;

$\mathrm{vv}\left[\mathrm{i}_{-} \mathrm{j}_{-}, \mathrm{dt}\right]:=\mathrm{k} 1[\mathrm{i}] / ; \mathrm{i}-1=\mathrm{j} \& \&$ phase$[\mathrm{j}]=!=$ melting $\& \&$ phase[j]=!=vaporizing

$v v\left[i_{-}, j_{1}, d t\right]:=-k 2[i]-r h o[i] * c p[i] / d t-b b[i] / ; i==j \& \&$ phase[j]=!=melting \&\&

phase $[\bar{j}]=!=$ =vaporizing

$\mathrm{vv}\left[\mathrm{i}_{-}, \mathrm{j}_{-}, \mathrm{dt}\right]:=\mathrm{k} 3[\mathrm{i}] / ; \mathrm{i}+1==\mathrm{j} \& \&$ phase $[\mathrm{j}]=!=$ melting $\& \&$ phase$[\mathrm{j}]=!=\mathrm{l}$ aporizing

$v v\left[i_{-}, j_{-}, d t\right]:=0 / ; i l=j \& \& i-1 !=j \& \& i+1 !=j$;

$(*-\ldots, j, \ldots$

$v v\left[i_{-}, j_{-}, d t\right]:=1 / ; i==j \quad \& \&$ phase[j] $===$ melting;

$v v\left[i_{-}, j_{-}, \mathrm{dt}\right]:=0 / ; \mathrm{i}-1==\mathrm{j} \& \&$ phase $[\mathrm{j}]===$ melting;

$v v\left[i_{-} j_{-}, \mathrm{dt}\right]:=0 / ; \mathrm{i}+1==\mathrm{j} \& \&$ phase $[\mathrm{j}]===$ melting;

$v v[i[, j, d t]:=1 / ; i==j$ \&\& phase $[j]===$ aporizing;

$\mathrm{vv}\left[\mathrm{i}, \mathrm{j}_{-}, \mathrm{dt}\right]:=0 / ; \mathrm{i}-1==\mathrm{j} \& \&$ phase $[\mathrm{j}]===$ vaporizing;

$v v\left[i_{-}, j_{-}, d t\right]:=0 / ; i+1=j \& \&$ phase $[j]===$ vaporizing;

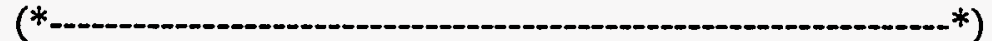

$\mathrm{f}\left[\mathrm{i}_{-}, \mathrm{dt}, \mathrm{time}, \mathrm{qtot}\right]:=-\mathrm{q}[\mathrm{i}, \mathrm{time}, \mathrm{qtot}]-\mathrm{To}[\mathrm{i}] *_{\mathrm{rho}}[\mathrm{i}] * \mathrm{cp}[\mathrm{i}] / \mathrm{dt}-\mathrm{bb}[\mathrm{i}] *$ Tinf $/$; phase[i] $=!=$ melting \&\& phase $[\overline{\mathrm{i}}]=$ !=vaporizing;

$\mathrm{f}[\mathrm{i}, \mathrm{dt}$,time_qtot_]:=Tm /; phase[i] ===melting;

$\mathrm{f}\left[\mathrm{i}_{-}, \mathrm{dt}, \mathrm{time}, \mathrm{qtot}\right]:=\mathrm{Tv} / ;$ phase[i] ==-=vaporizing;

Plot[shape[t], $\{t, .245,0.29\}$, PlotRange-> $>0,50\}]$

-Graphics-

$\mathrm{TB}=.245 ; \mathrm{TE}=.29$;

RhoMeat=6500.;RhoAl=2700.;RhoU=12200.;

fval $=0.5$;

fvu=1-fval;

DenRat $=(\mathrm{RhoU} / \mathrm{RhoAl})$;

fmal $=0.212$;

fmu=1-fmal;

Echem $=350000.0$;

$\mathrm{ww}=$ Echem $* 5100$;

time=TB;

$\operatorname{Do}[\mathrm{To}[\mathrm{i}]=300 ; \mathrm{Tc}[\mathrm{i}]=300 ; \mathrm{xm}[\mathrm{i}]=0 ; \mathrm{xv}[\mathrm{i}]=0 ; \operatorname{orf}[\mathrm{i}]=0 ;\{\mathrm{i}, 1, \mathrm{~m}\}]$;

$\mathrm{dtt}[\mathrm{i}]:=10 * \mathrm{dx} * \mathrm{dx} * \operatorname{rho}[\mathrm{i}] * \mathrm{cp}[\mathrm{i}] /(2 * \mathrm{k}[\mathrm{i}])$; 
$\mathrm{dt}=\mathrm{Min}[$ Table[dtt[i],\{i,1,m\}]];

$\mathrm{nt}=$ Floor$[(\mathrm{TE}-\mathrm{TB}) / \mathrm{dt}]-1$;

Print["dt= ",dt," nt= ",nt];

$\mathrm{dt}=0.000278413 \mathrm{nt}=160$

Do[

$s=$ Table[vv[i,j,dt],\{j,m\},\{i,m $\}]$

sinv=Inverse[s];(* invert the matrix *)

$q q=$ Table[f[i,dt,time, $q$ tot $],\{i, m\}]$;

ans=sinv.qq;

$\operatorname{Do}[\mathrm{Tc}[\mathrm{i}]=\mathrm{ans}[[\mathrm{i}]]$;

If $[$ phase[i] $===$ melting, $x m[i]+=(k 1[i] * T o[i-1]-k 2[i] * T o[i]+k 3[i] * T o[i+1]+q[i$, time,qtot $]-$ $\mathrm{bb}[\mathrm{i}] *(\mathrm{To}[\mathrm{m}]-\mathrm{Tinf}) * \mathrm{dt} /(\mathrm{rho}[\mathrm{i}] * \mathrm{hsf}[\mathrm{i}]) ;, 0]$;

If $[$ phase[i] $==$ =vaporizing, $x v[i]+=(k 1[i] * T o[i-1]-k 2[i] * T o[i]+k 3[i] * T o[i+1]+q[i, t i m e, q t o t]-$ $\mathrm{bb}[\mathrm{i}] *(\mathrm{To}[\mathrm{m}]-\operatorname{Tinf})) * \mathrm{dt} /(\mathrm{rho}[\mathrm{i}] * \mathrm{hfg}[\mathrm{i}]) ;, 0]$;

$,\{\mathrm{i}, 1, \mathrm{~m}\}]$;

If[Mod[numtimesteps,5] $==0$ II numtimesteps $>=60$,

Print[numtimesteps," ",time," ",To[1]," ",xv[1]," ",phase[1]," ", q[1,time,qtot]," ",orf[1]," ",qs[qtot,time]," ",qchem[1]]];

$\mathrm{Do}[\mathrm{To}[\mathrm{i}]=\operatorname{Tn}[\mathrm{i}]$;

xx1[i,numtimesteps] $=\{$ time, $T o[i]\}$;

$\mathrm{xx2}[\mathrm{i}$, numtimesteps] $=\{$ time, $\mathrm{xm}[\mathrm{i}]\}$;

$\mathrm{xx3}[\mathrm{i}$, numtimesteps] $=\{$ time, $\mathrm{xv}[\mathrm{i}]\}$;

$\mathrm{xx} 4[$ i, numtimesteps] $=\{$ time, $\operatorname{orf}[\mathrm{i}]\}$;

$\mathrm{xx}[$ [i,numtimesteps $]=\{$ time, $q[\mathrm{i}$, time, $q$ tot $]\}$;

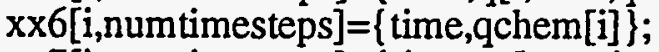

xx7[i,numtimesteps] $=\{$ time,qs[qtot,time] $\}$;

$,\{\mathrm{i}, 1, \mathrm{~m}\}]$;

To[i] $=\operatorname{Tn}[\mathrm{i}]$;

time $+=\mathrm{dt}$;

UpdateRF[dt];

, $\{$ numtimesteps,1,nt\}];

Print[Finished];

\section{$9 \quad-11 \quad 9$}

50.246114302 .2920 solid $7.34496101 .0609310 \quad 7.344961017 .188$

$\begin{array}{lll}10 & -11 & 10\end{array}$

100.247506306 .1660 solid $1.4093710 \quad 2.4372710 \quad 1.4093710 \quad 17.9724$

$\begin{array}{lll}10 & -11 & 10\end{array}$

150.248898311 .7480 solid $1.91851103 .8936810 \quad 1.9185110 \quad 19.1797$

$\begin{array}{lll}10 & -11 & 10\end{array}$

200.25029319 .9110 solid $2.6621610 \quad 5.4759810 \quad 2.6621610 \quad 21.1253$

$\begin{array}{llll}10 & -11 & 10\end{array}$

250.251682331 .3430 solid $3.6916410 \quad 7.2586110 \quad 3.6916410 \quad 24.2605$ $\begin{array}{lll}10 & -11 & 10\end{array}$

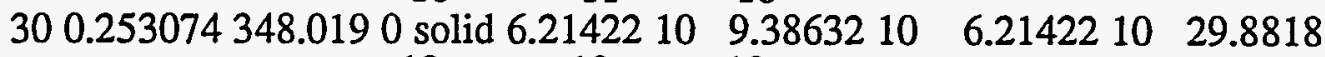
$\begin{array}{lll}10 & -10 & 10\end{array}$

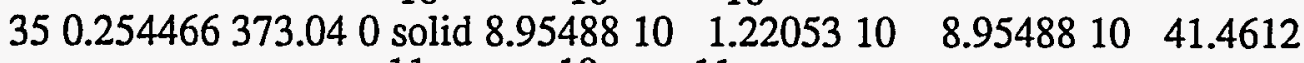
$\begin{array}{lll}11 & -10 & 11\end{array}$ 
400.255858408 .4320 solid $1.29610 \quad 1.6528810 \quad 1.29610 \quad 67.9674$ $\begin{array}{lll}11 & -10 & 11\end{array}$ 450.25725458 .0850 solid $1.87624102 .4856210 \quad 1.8762410 \quad 144.758$ $\begin{array}{llll}11 & -10 & 11\end{array}$

$\begin{array}{lllllll}50 & 0.258642526 .4030 \text { solid } 2.5935810 & 4.80081 & 10 & 2.59358 & 10 & 462.057\end{array}$

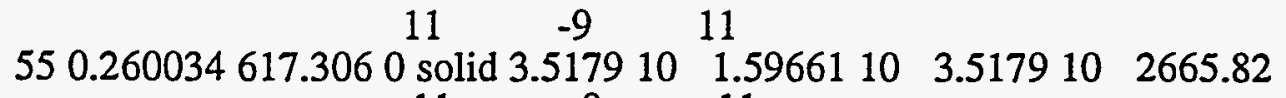

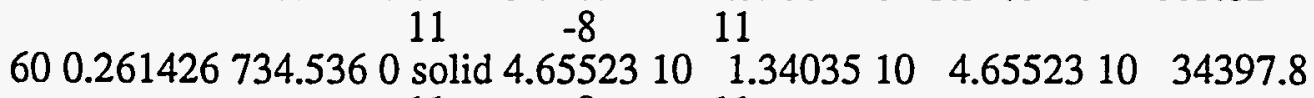
$\begin{array}{lll}11 & -8 & 11\end{array}$

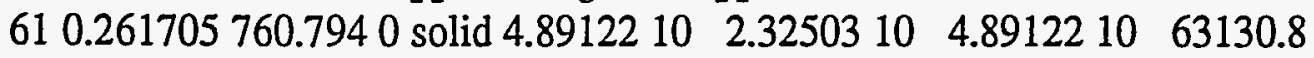
$\begin{array}{llll}11 & -8 & 11\end{array}$

620.261983788 .0020 solid $5.1580610 \quad 4.1891310 \quad 5.1580510119514$. $11 \quad-8 \quad 11$

630.262262816 .40 solid $5.39198107 .8446110 \quad 5.3919810234365$. $\begin{array}{lll}11 & -7 & 11\end{array}$

640.26254845 .6080 solid $5.6114310 \quad 1.5187810 \quad 5.6114310470795$.

650.262818875 .4490 melting $5.81675103 .0192510 \quad 5.8167410962004$.

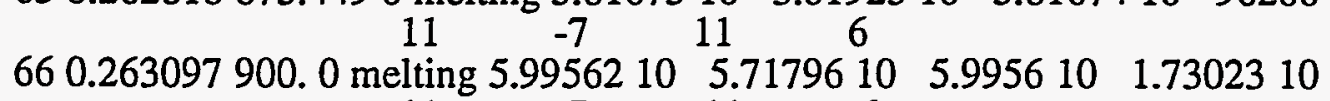

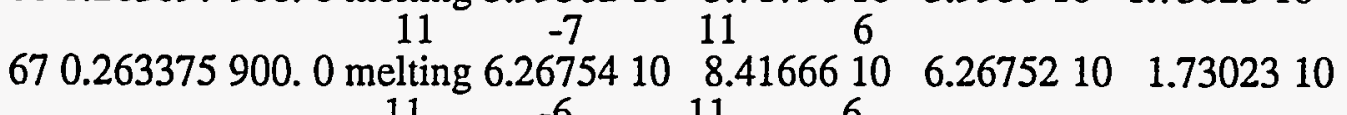

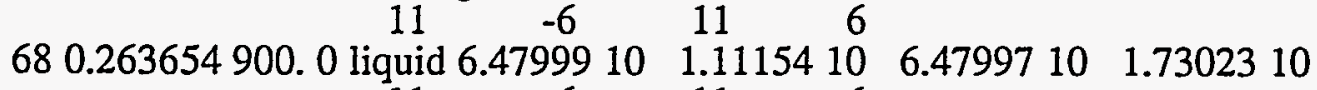

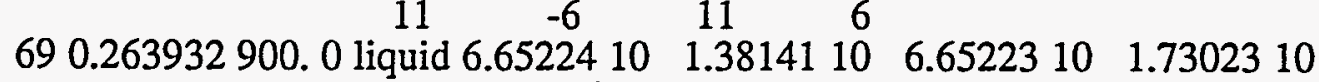

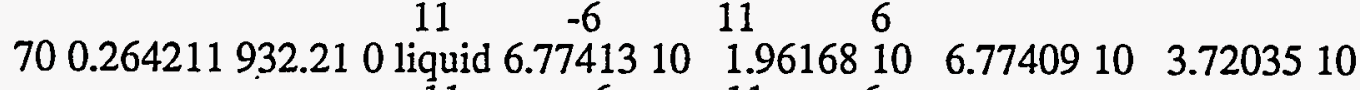

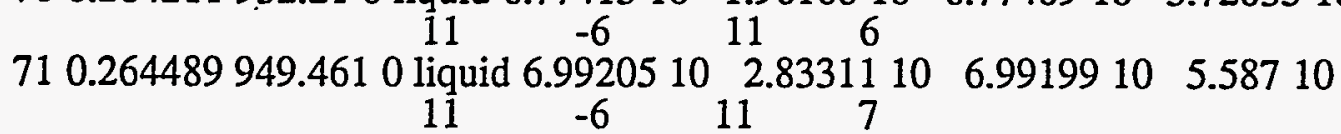

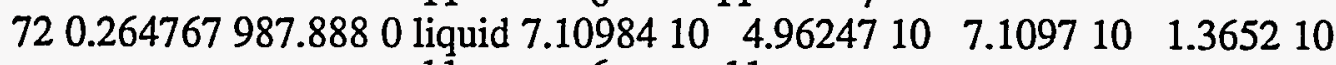
730.2650461019 .530 liquid $7.1823610 \quad 9.3341210 \quad 7.1820810$ 7

2.8028110

740.2653241044 .230 liquid $7.2919710 \quad 0.00001690557 .2914910$ $\stackrel{7}{4} 10$

750.2656031075 .510 liquid $7.4123410^{11} 0.00003180767 .4113810$ 9.7541610

760.2658811111 .540 liquid $7.3957410 \quad 0.00006342057 .3937210$ 2.0267810

$\begin{array}{lll}11 & 11 & 8\end{array}$ 


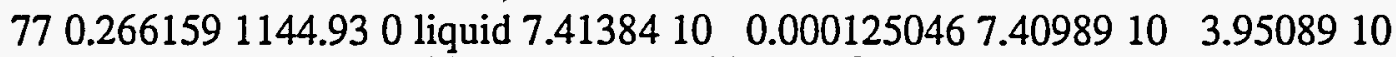
$11 \quad 11 \quad 8$

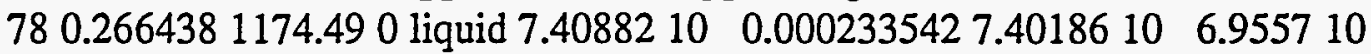
$11 \quad 11 \quad 9$

790.2667161203 .920 liquid $7.3967810 \quad 0.000419457 .3848610 \quad 1.191810$

800.2669951234 .190 liquid $7.3302710 \quad 0.00073447 .3100810 \quad 2.0189310$ $11 \quad 11 \quad 9$

810.2672731263 .180 liquid $7.2237110 \quad 0.001243017 .1911110 \quad 3.2600710$ $11 \quad 11 \quad 9$

820.2675511289 .430 liquid $7.176610 \quad 0.002010947 .1273910 \quad 4.9215610$ $11 \quad 11 \quad 9$

830.26783 1313. 0 liquid $7.048310 \quad 0.003102716 .97834106 .9958610$ $11 \quad 11 \quad 9$

840.2681081334 .740 liquid $6.913310 \quad 0.004590716 .81797109 .5329310$ $11 \quad 11 \quad 10$

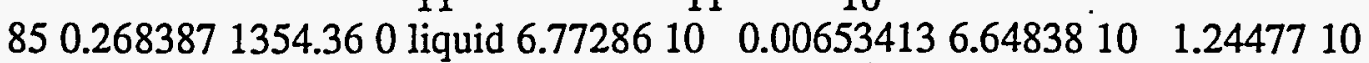
11 $11 \quad 10$

860.2686651371 .410 liquid $6.6183510 \quad 0.008961196 .4629310 \quad 1.5541710$

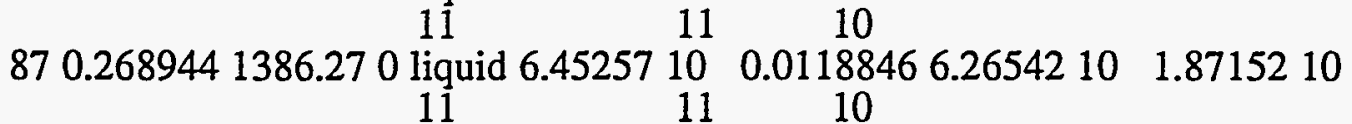

$\begin{array}{lllll}88 & 0.269222 & 1399.180 \text { liquid } 6.2770210 & 0.01530086 .0583810 & 2.1864810\end{array}$

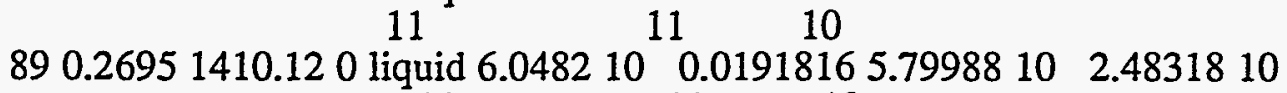
$\begin{array}{llllll}90 & 0.269779 & 1418.620 & 11 & 11 & 10 \\ \text { liquid } 5.86683 & 10 & 0.02345095 .593710 & 2.73122 & 10\end{array}$

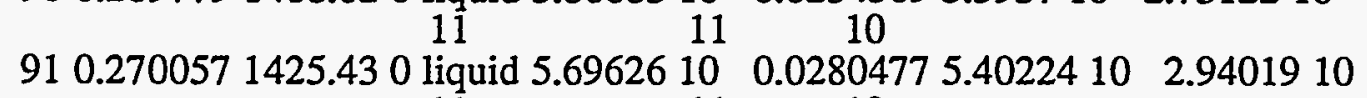

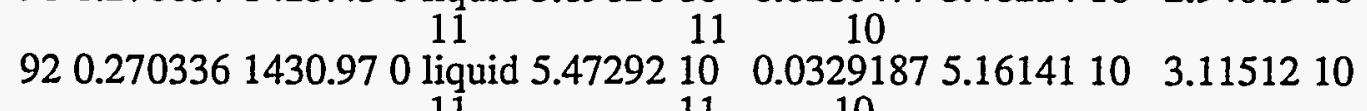
$\begin{array}{lllllll}93 & 0.270614 & 1434.890 \text { liquid } 5.2371310 & 0.03798284 .913310 & 3.23826 & 10\end{array}$ $11 \quad 11 \quad 10$

940.2708921437 .080 liquid $5.0301810 \quad 0.04314484 .7001210 \quad 3.3006110$ $11 \quad 11 \quad 10$

950.2711711438 .140 liquid $4.7645510 \quad 0.04833924 .4324210 \quad 3.3212710$ $11 \quad 11$

960.2714491437 .770 liquid $4.5438310 \quad 0.05348474 .2148310 \quad 3.2910$

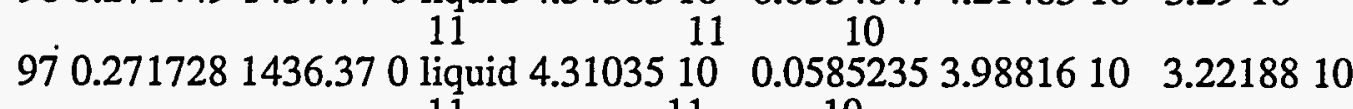
$\begin{array}{llllllll}98 & 0.272006 & 1433.84 & 0 \text { liquid } 4.06659 & 10 & 0.06339623 .75510 & 3.11599 & 10\end{array}$

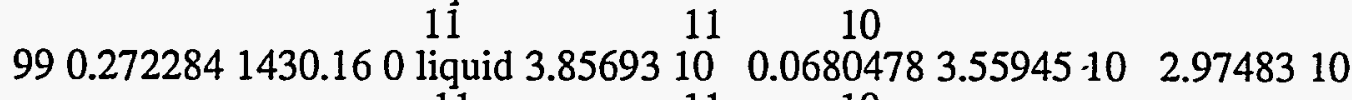
$11 \quad 11 \quad 10$ 1000.2725631425 .660 liquid $3.6245110 \quad 0.0724463 .34319102 .8131610$

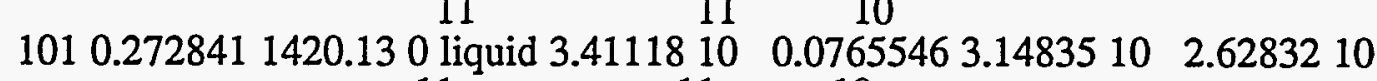
$11 \quad 11 \quad 10$ 1020.273121413 .70 liquid $3.1970410 \quad 0.08035032 .95419102 .4285410$

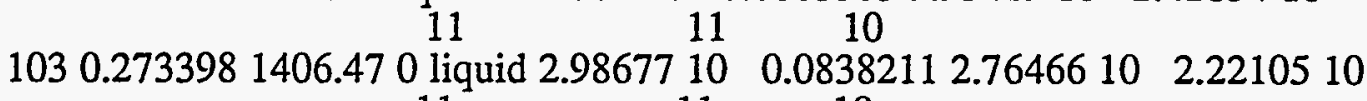
11 
1040.2736771398 .760 liquid $2.812210 \quad 0.08697272 .61048102 .0171310$ $11 \quad 11 \quad 10$

1050.2739551391 .170 liquid $2.6642610 \quad 0.08983492 .4810510 \quad 1.8321810$ $11 \quad 11 \quad 10$

1060.2742331384 .140 liquid $2.4589110 \quad 0.09244932 .2915410 \quad 1.6737210$ $11 \quad 11$

1070.2745121377 .290 liquid 2.2814910 11 11

1080.274791370 .860 liquid 2.1486210 11 11

1090.2750691365 .180 liquid 1.9700110 1100.2753471359 .740 liquid 18472711 1100.2753471359 .74011 1110.2756251354 .890 liquid 1.7167810 $11 \quad 11$ 1120.2759041350 .440 liquid 1.5952810 $11 \quad 11$ 1130.2761821346 .340 liquid 1.4823910 $11 \quad 11$

1140.2764611342 .540 liquid 1.4064510 1150.2767391339 .230 liquid 1.3126710 $1160.2770181336 .17011 \quad 11$ 1160.2770181336 .170 liquid 1.1884210 1170.2772961332 .990 liquid 1.1227711 $11 \quad 10$

1180.2775741330 .10 liquid 1.0548810 $10 \quad 10$

1190.2778531327 .420 liquid 9.8235610

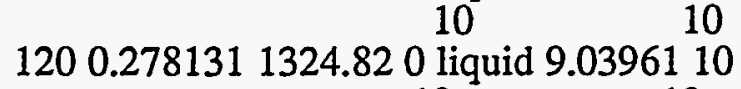
$10 \quad 10$

1210.278411322 .20 liquid 8.6331710

1220.2786881319 .840 liquid 7.6618810 $10 \quad 10$

1230.2789661317 .190 liquid 7.2379710 $10 \quad 10$

1240.2792451314 .70 liquid 6.8770610 1250.2795231312 .370 liquid 6.4441110 1060 1260.2798021310 .120 liquid 6.2622310 1270.280081308 .110 liquid 5.6492110

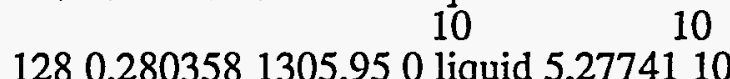
1280.2803581305 .950 liquid 5.2774110 1290.2806371303 .820 liquid 4.9220610 $10 \quad 10$

1300.2809151301 .720 liquid 4.7385610 10 10

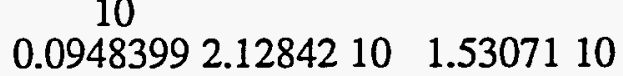
10

0.09703572 .00802101 .4060510 10

$0.099071 .8397310 \quad 1.3028110$ 10

$0.1009591 .7262610 \quad 1.2101310$ 10

$0.1027271 .6035510 \quad 1.1322410$ 10

$0.1043891 .4888310 \quad 1.0644710$ 10

0.1059581 .38189101 .0050210 9

$0.1074451 .3112110 \quad 9.5241710$ 9

0.1088631 .22182109 .0851110 9

0.110221 .10149108 .6931710

0.1115161 .03974108 .3028210 9

0.1127589 .75263107 .9613710 9

0.1139539 .05817107 .6539610 9

$0.1151038 .3029410 \quad 7.3666710$ 9

0.1162097 .92446107 .0871510

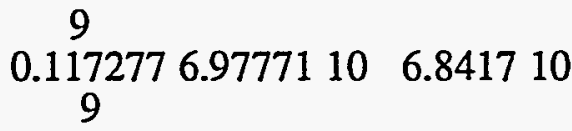

$0.1183036 .5802410 \quad 6.5773210$ 9

0.1192926 .24344106 .3361410

$0.1202475 .8323210 \quad 6.1179110$ 9

$0.1211695 .6709810 \quad 5.9124810$ 9

$0.1220645 .0757810 \quad 5.734310$ 9

0.122934 .72256105 .5485310 9

$0.1237684 .3849910 \quad 5.3706910$ 9

$0.124584 .2185810 \quad 5.1997810$ 9 
1310.2811941299 .760 liquid $4.425210 \quad 0.1253673 .9207110 \quad 5.0449610$ $10 \quad 10 \quad 9$

1320.2814721297 .820 liquid $4.03201100 .1261313 .5424610 \quad 4.8954210$ $10 \quad 10$

1330.2817511295 .810 liquid 3.5187910 $10 \quad 10$

1340.2820291293 .610 liquid 3.3559810 $10 \quad 10$

1350.2823071291 .510 liquid 3.4106810 $10 \quad 10$

1360.2825861289 .690 liquid 3.0178910 $10 \quad 10$

1370.2828641287 .740 liquid 2.6081310 $10 \quad 10$

1380.2831431285 .640 liquid 2.6707110 $10 \quad 10$

1390.2834211283 .780 liquid 2.5737810

1400.2836991282 .010 liquid 1.8554710 $10 \quad 10$

1410.2839781279 .790 liquid 2.1149410

1420.2842561277 .960 liquid 1.907210

1420.2842561277 .960 liquid 1.907210

1430.2845351276 .090 liquid 1.9272310 $10 \quad 10$

1440.2848131274 .390 liquid 1.8100210 10 9

1450.2850911272 .70 liquid 1.2073410 $10 \quad 10$

1460.285371270 .620 liquid 1.5769910 $10 \quad 9$

1470.2856481268 .980 liquid 1.3017210 $10 \quad 10$

1480.2859271267 .20 liquid 1.5294310 $10 \quad 9$

1490.2862051265 .720 liquid 1.2633410 $10 \quad 10$

1500.2864841264 .090 liquid 1.3642410 $10 \quad 9$

1510.2867621262 .640 liquid 1.2246210

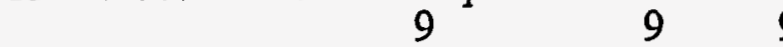

1520.287041261 .130 liquid 9.01229100 .1373766 .28802102 .7242710 $10 \quad 9 \quad 9$

1530.2873191259 .420 liquid $1.0036410 \quad 0.1377897 .38793102 .6484810$ 9909

1540.2875971257 .870 liquid 9.53533100 .1381926 .9541102 .5812310 $10 \quad 9 \quad 9$

1550.2878761256 .330 liquid $1.1923810 \quad 0.1385859 .40745102 .5163910$

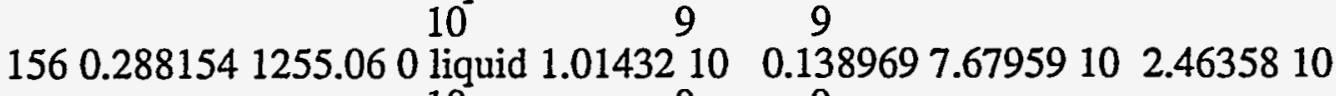
$10 \quad \begin{array}{lll}9 & 9\end{array}$ 1570.2884321253 .690 liquid 1.0178810 $10 \quad 9$

0.1393457 .77113102 .4076310 9 
1580.2887111252 .360 liquid $1.053310 \quad 0.1397128 .17833102 .3546610$

99

1590.2889891251 .10 liquid 8.42375100 .1400726 .11836102 .3053910

$9 \quad 9 \quad 9$

1600.2892681249 .690 liquid 8.53329100 .1404236 .28163102 .2516610

Finished

Tcoefsol $=2.25 * 10^{\wedge}-5$;

Tcoefliq $=1.17 * 10^{\wedge}-4$;

$(* \mathrm{TA}$ - average temperature *)

ta[ts_]:= Sum[Part[xx1[node,ts],2],\{node, $1, \mathrm{~m}\}] / \mathrm{m}$;

$(* \operatorname{tr}$ - Temperature time rate of change $*$ )

$\operatorname{tr}[$ node_ts_]:=Part[xx1[node,ts]-xx1[node,ts-1],2]/Part[xx1[node,ts]-xx1[node,ts-1],1];

(* tra - average rate of change of temp for the plate *)

tra[ts]:=Sum[tr[node,ts],\{node, $1, \mathrm{~m}\}] / \mathrm{m}$;

(* expth - expansion thermal *)

(* texprate - thermal expansion rate for the plate *)

expth[node_ts_]:=Tcoefsol $* \operatorname{tr}[$ node,ts] $/ ; \operatorname{Part}[\mathrm{xx} 1[$ node,ts],2] $<\mathrm{Tm}$;

expth[node_ts_]:=Tcoefliq*tr[node,ts] /; Part[xx1[node,ts],2] $>\operatorname{Tm} \& \& \operatorname{Part}[\mathrm{xx} 1[$ node,ts],2] $<\mathrm{Tv}$;

expth[node_ts_]:=tr[node,ts]/ Part[xx1[node,ts],2]/; Part[xx1[node,ts],2]>Tv;

expth[node,ts]: $=0 /$ Part[xx1[node,ts],2] $===\mathrm{Tm}$;

expth[node_ts] $:=0 / ; \operatorname{Part}[\mathrm{xx} 1[$ node,ts],2] $===\mathrm{Tv}$;

texprate[ts_]:=Sum[expth[node,ts], $\{$ node, $1, \mathrm{~m}\}] / \mathrm{m}$;

(* qm - quality of the melt *)

(* mv - quality of the vapor *)

qm[ts_]:=Sum[Part[xx2[node,ts],2],\{node, $1, \mathrm{~m}\}] / \mathrm{m}$;

$\mathrm{qv}[\mathrm{ts}]$ ]:=Sum[Part[xx3[node,ts],2], \{node, $1, \mathrm{~m}$ \}] $/ \mathrm{m}$;

vfaln[i_]:=fval $/ ; \mathrm{i}<=\mathrm{n}$;

vfaln[i] $]:=1 / ;$ i $>\mathbf{n}$;

(* Fractional rate of change of volume due to various factors *)

(* ger - Gas Expansion Rate

(* VMR - Volumetric Melting Rate

(*VVR - Volumetric Vaporization Rate

(* VOFR - Volumetric Oxide Formation Rate

(* QMR - Quality Melt Rate

(* QVR - Quality Vaporization Rate

rhosolid=2700; rholiquid=2500; rhovapor $=1.0$;

*)

$*)$

*)

*)

*)

*)

DencRatLV = (1/rhovapor ${ }^{\wedge}(0.3)-1 /$ rholiquid^$\left.^{\wedge}(0.3)\right) /\left(1 /\right.$ rholiquid^$\left.^{\wedge}(0.3)\right)$;

DencRatSL $=\left(1 /\right.$ rholiquid $^{\wedge}(0.3)-1 /$ rhosolid^$\left.^{\wedge}(0.3)\right) /\left(1 /\right.$ rhosolid $\left.^{\wedge}(0.3)\right)$;

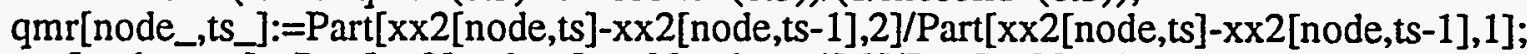

qvr[node_ts]]:=Part[xx3[node,ts]-xx3[node,ts-1],2]/Part[xx3[node,ts]-xx3[node,ts-1],1];

$\operatorname{vmr}[$ ts_]: $=$ Sum[DencRatSL*qmr[node,ts]*vfaln[node],\{node, $1, \mathrm{~m}\}] / \mathrm{m}$;

$\operatorname{vvr}[\operatorname{ts}]:=\operatorname{Sum}\left[\right.$ DencRatLV*qvr[node,ts] ${ }^{*}$ vfaln[node], $\{$ node, $\left.1, \mathrm{~m}\}\right] / \mathrm{m}$;

ger[ts_]:=Sum[tr[node,ts]/ Part[xx1[node,ts],2], \{node,1,n\}]/m;

$\mathrm{ff}=0.01$;

TotalExpansionRate[ts] $]:=(1-\mathrm{ff}) *(\mathrm{vmr}[\mathrm{ts}]+\mathrm{vvr}[\mathrm{ts}]+$ texprate[ts] $)+\mathrm{ff} * \mathrm{ger}[\mathrm{ts}]$

IntegralTotExp[ts_]:=Sum[TotalExpansionRate[tt]*dt,\{tt,2,ts\}]

ListPlot[Table[\{Part[xx1[1,ts],1],TotalExpansionRate[ts]\},\{ts,2,nt\}],

PlotJoined $\rightarrow$ True, 
PlotRange- $>$ All,

AxesLabel-> "time (s)","Fractional Exp rate (1/s)" $\}]$

ter $=1$;

(* ter total expansion *)

Do[ter* $=(1+$ TotalExpansionRate $[\mathrm{tt}] * \mathrm{dt})$;

$q w q[t t]=\{\operatorname{Part}[\mathrm{xx} 1[1, \mathrm{tt}], 1]$, ter -1$\}$

$,\{\mathrm{tt}, 2, \mathrm{nt}\}]$

ListPlot[Table[qwq[tt],\{tt,2,nt $\}]$,

PlotJoined $\rightarrow$ True,

PlotRange->All,

AxesLabel->\{"time (s)","Expanded fraction" $\}]$

Do[eff[ts] $=\{$ Part[xx1[1,ts],1],ta[ts],TotalExpansionRate[ts],Part[qwq[ts],2]\},\{ts,2,nt $\}]$;

ListPlot[Table[\{Part[xx1[1,ts],1],ta[ts]\},\{ts,2,nt $\}]$,

PlotJoined $\rightarrow$ True,

PlotRange->All,

AxesLabel->\{"time (s)","average temp (K)"\}]

-Graphics-

-Graphics-

-Graphics-

ListPlot[Table[\{Part[xx1[1,i],1],Part[xx1[1,i],2]\},\{i,1,nt $\}]$,

PlotJoined $\rightarrow$ True,

PlotRange- $>$ All,

AxesLabel->\{"time (s)"," temp (K)" $\}]$

ListPlot $[$ Table $[\{\operatorname{Part}[\mathrm{xx} 1[\mathrm{~m}, \mathrm{i}], 1], \operatorname{Part}[\mathrm{xx} 1[\mathrm{~m}, \mathrm{i}], 2]\},\{\mathrm{i}, 1, \mathrm{nt}\}]$,

PlotJoined $\rightarrow$ True,

PlotRange- $>$ All,

AxesLabel-> "time (s)"," temp (K)" \}]

-Graphics-

-Graphics-

bsb1[i] $]:=(\operatorname{Sum}[\operatorname{Part}[\mathrm{xx} 4[\mathrm{j}, \mathrm{i}], 2],\{\mathrm{j}, 1, \mathrm{n}\}]) / \mathrm{n}$;

bsb1[26]

bsb2[26] 
bsb1[i_]:=(Sum[Part $[\mathrm{xx} 4[\mathrm{j}, \mathrm{i}], 2],\{\mathrm{j}, 1, \mathrm{n}\}]) / \mathrm{n}$;

ListPlot[Table[\{Part[xx4[1,i],1],bsb1[i]\},\{i,1,nt $\}]$,

PlotJoined $->$ True,PlotRange- $>$ All,

AxesLabel-> ["time (s)"," fraction of fuel reacted" \}];

szs1=ListPlot[Table[\{Part $[\mathrm{xx} 5[1, \mathrm{i}], 1], \operatorname{Part}[\mathrm{xx} 5[1, \mathrm{i}], 2]\},\{\mathrm{i}, 1, \mathrm{nt}\}]$,

PlotJoined $\rightarrow$ True,PlotRange- $>$ All,

AxesLabel-> "time (s)"," Q fission (W/m^3)" \}];

szs2=ListPlot[Table[\{Part[xx6[1,i],1],Part[xx6[1,i],2]\},\{i,1,nt $\}]$,

PlotJoined $\rightarrow$ True,PlotRange- $>$ All,

AxesLabel-> ["time (s)"," Q chemical (W/m^3)" $\}$;

szs3=ListPlot[Table[\{Part [xx7[1,i],1],Part[xx7[1,i],2]\},\{i,1,nt $\}]$,

PlotJoined $\rightarrow$ True,PlotRange- $>$ All,

AxesLabel-> "time (s)", Q total (W/m^3)" $\}]$;

Show[szs1,szs2,szs3]

-Graphics-

\section{3}

(*

THIS IS A REVISED DISPERSION MODEL THAT USES THE

TMME ENERGY DATA FROM THE EXPERIMENTS AND TEMPERATURE

DEPENDANT CHEMICAL REACTION RATES FUEL- ALUMINUM

This copy has chemical reaction rates included in the model

LAST UPDATED 4-19-95

Renormalized pulse width was used to a narrower band width.

*)

Print["Date last updated =",Date[]];

Date last updated $=\{1995,5,2,9,53,2\}$ 
$\mathrm{l}=0.000635 ; \mathrm{m}=10 ; \mathrm{dx}=\mathrm{l} / \mathrm{m} ; \mathrm{n}=\mathrm{Round}[\mathrm{m} *$.4];time $=0 ; \operatorname{Tinf}=300$;

volmeat $=2 * \mathrm{dx}^{*} \mathrm{n}^{*}\left(25^{*} 10^{\wedge}-3\right) *\left(70^{*} 10^{\wedge}-3\right)$;

$\mathrm{Do}[\mathrm{xx}[\mathrm{i}]=\mathrm{i} * \mathrm{dx}-\mathrm{dx} / 2,\{\mathrm{i}, 1, \mathrm{~m}\}] ; \mathrm{Tm}=900 . ; \mathrm{Tv}=2700$.

$\operatorname{Do}[\mathrm{To}[\mathrm{i}]=300 ; \mathrm{Tc}[\mathrm{i}]=300 ; \mathrm{xm}[\mathrm{i}]=0 ; \mathrm{xv}[\mathrm{i}]=0,\{\mathrm{i}, 1, \mathrm{~m}\}]$;

$\mathrm{k}[\mathrm{i}] \mathrm{]}:=39.91 / ; \mathrm{i}<=\mathrm{n} ; \quad\left(*\right.$ assign $\mathrm{k}$ to the meat $\left.{ }^{*}\right)$

$\mathrm{k}[\mathrm{i}] \mathrm{i}=\mathrm{kcl}[\mathrm{To}[\mathrm{i}]] / ; \mathrm{i}>\mathrm{n} ; \quad(*$ assign $\mathrm{k}$ to the clad *)

rho[i_]:=6550.0/; i <=n; (* assign meat density *)

rho[i_]:=2700.0/; i $>\mathrm{n} ;\left({ }^{*}\right.$ assign clad density $\left.{ }^{*}\right)$

$\operatorname{cp}[\mathrm{i}]]:=\operatorname{cpcl}[\mathrm{To}[\mathrm{i}]] / ; \mathrm{i}>\mathrm{n} ; \quad\left({ }^{*}\right.$ assign clad cpecific heat $\left.*\right)$

$\operatorname{cp}[\mathrm{i}]]:=\operatorname{cpf}[\mathrm{To}[\mathrm{i}]] / ; \mathrm{i}<=\mathrm{n} ; \quad(*$ assign meat cpecific heat $*$ )

htc $=$ Interpolation $[\{150,13232\},\{350,13232\},\{410,14770\},\{726,12542\}$, $\{776,11561\},\{1256,9924\},\{1458,1750\},\{1526,1729\},\{1556,800\}$, $\{5000,800\}\}$,InterpolationOrder $->1]$;

$\mathrm{kcl}=$ Interpolation $[\{\{100,161\},\{400,177\},\{500,186\},\{600,193\}$, $\{750,193\},\{850,193\},\{900,193\},\{930,193\}$, $\{1200,84\},\{1300,84\},\{1500,84\},\{2000,84\},\{5000,84\}\}$,

InterpolationOrder->1];

cpcl=Interpolation $[\{\{100,878\},\{300,878\},\{366,942\},\{422,963\}$, $\{588,1034\},\{700,1067\},\{811,995\},\{1000,995\},\{2000,995\}$, $\{5000,995\}\}$, InterpolationOrder- $>1]$;

cpf $=$ Interpolation $[\{\{100,351\},\{300,351\},\{933,463\},\{1933,546\}$, $\{2500,546\},\{3500,546\},\{5000,546\}\}$,InterpolationOrder- $>1]$;

hsf[i_]: $=398000 *$ fmal $/ ; \mathrm{i}<=\mathrm{n}$;

hfg[i] $]:=10800000 *$ fmal $/ ; \mathrm{i}<=\mathrm{n}$;

hsf[i]]:=398000 /; i > n;

hfg[i_]: $=10800000 \quad / ;$ i $>$ n;

151=ReadList["508.53",Number,RecordLists->True];

shape=Interpolation [151,InterpolationOrder $->1]$;

num=Part[Part[Position[151,Last[151]],1],1];

TimeBeg=Part[151[[1]],1]; TimeEnd=Part[151[[num]],1];

$\mathrm{cl}=\operatorname{Sum}\left[0.5^{*}(\operatorname{shape}[\mathrm{Part}[151[[\mathrm{i}]], 1]]+\operatorname{shape}[\operatorname{Part}[151[[\mathrm{i}+1]], 1]]) *\right.$

(Part[151[[i+1]],1]-Part[151[[i]],1]), \{i,200,500\}];

qs[qtot_time_]:=qtot*shape[time]/(volmeat $\left.{ }^{*} \mathrm{c} 1\right)$;

qtot=9997;

${ }^{*}$ Functions : nrt - new reacted fraction

orf - old reacted fraction *)

$\operatorname{Tm} 1=863 ; \operatorname{Tm} 2=1970 ; \operatorname{Td}[\mathrm{i}] \mathrm{]}=(\operatorname{To}[\mathrm{i}]-\operatorname{Tm} 1) /(\operatorname{Tm} 2-\operatorname{Tm} 1)$;

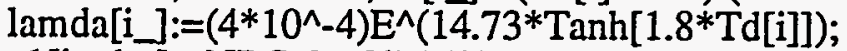

$\mathrm{zl}\left[\mathrm{i}_{-}, \mathrm{dt}\right] \mathrm{R}:=\mathrm{NDS}$ olve[ $\{\mathrm{RF}[\mathrm{t}]==$ lamda[i]-lamda[i] $* \mathrm{RF}[\mathrm{t}]$,

$\overline{R F}[0]==\operatorname{orf}[\mathrm{i}]\}, \mathrm{RF},\{\mathrm{t}, 0, \mathrm{dt}\}$, AccuracyGoal $>15]$;

nrf[i_,dt] $]:=\operatorname{Part}[\mathrm{RF}[\mathrm{dt}] / \mathrm{zl}[\mathrm{i}, \mathrm{dt}], 1]$

frr[i_]:=lamda[i]-lamda[i]*orf[i];

UpdateRF[dt_]:=Do[orf [i] $=\operatorname{nrf}[\mathrm{i}, \mathrm{dt}],\{\mathrm{i}, 1, \mathrm{n}\}]$

qchem[i] $]:=w w^{*} \operatorname{frr}[\mathrm{i}]$; 
$\mathrm{q}\left[\mathrm{i}\right.$, time_qtot_]:=qs[qtot,time]+qchem[i] $/ \mathrm{i}<=\mathrm{n} ;\left(^{*}\right.$ assign heat generation in the meat *) $\mathrm{q}\left[\mathrm{i}_{-}, \mathrm{time}, \mathrm{qtot}\right]:=0 / ; \mathrm{i}>\mathrm{n} ; \quad$ (* assign heat generation in the clad ${ }^{*}$ )

$\mathrm{bb}[\overline{\mathrm{i}}] \mathrm{:}=\mathrm{htc}[\mathrm{To}[\mathrm{m}]] / \mathrm{dx} / ; \mathrm{i}==\mathrm{m}$;

$\mathrm{bb}[\mathrm{i}]:=0 / ; \mathrm{i} !=\mathrm{m} ; \quad(*$ value for the heat transfer out of the plate $*)$

$\mathrm{k} 1[\mathrm{i}] \mathrm{i}=(2 * \mathrm{k}[\mathrm{i}-1] * \mathrm{k}[\mathrm{i}] /(\mathrm{k}[\mathrm{i}-1]+\mathrm{k}[\mathrm{i}])) / \mathrm{dx} \mathrm{x}^{\wedge} / ; \mathrm{i} !=1$

$\mathrm{k} 1[\mathrm{i}]:=0 / ; \mathrm{i}=1$

$\mathrm{k} 2[\mathrm{i}] \mathrm{]}=\mathrm{k} 1[\mathrm{i}]+\mathrm{k} 3[\mathrm{i}]$

$\mathrm{k} 3[\mathrm{i}]:=(2 * \mathrm{k}[\mathrm{i}+1] * \mathrm{k}[\mathrm{i}] /(\mathrm{k}[\mathrm{i}+1]+\mathrm{k}[\mathrm{i}])) / \mathrm{dx} \wedge 2 / ; \mathrm{i} !=\mathrm{m}$

$\mathrm{k} 3[\mathrm{i}]:=0 / ; \mathrm{i}==\mathrm{m}$;

phase[i]]:= solid /; Tc[i] $<\mathrm{Tm}$;

phase[i] $:=$ liquid $/ ; \mathrm{Tc}[\mathrm{i}]<\mathrm{Tv} \& \& \mathrm{Tc}[\mathrm{i}]>=\operatorname{Tm} \& \& \mathrm{xm}[\mathrm{i}]>=0.85$;

phase[i] $]:=$ vapor $/ ; \quad \mathrm{Tc}[\mathrm{i}]>=\mathrm{Tv} \& \& \mathrm{xv}[\mathrm{i}]>1$;

phase[i]:= melting $/ ; \quad \mathrm{Tc}[\mathrm{i}]>=\mathrm{Tm} \& \& \mathrm{xm}[\mathrm{i}]<0.85$;

phase[i] $:=$ vaporizing $/ ; \quad$ Tc $[\mathrm{i}]>=\mathrm{TV} \& \& \mathrm{xv}[\mathrm{i}]<1 \& \& \mathrm{xv}[\mathrm{i}]>-0.01$;

$\operatorname{Tn}[\mathrm{i}]:=\mathrm{Tc}[\mathrm{i}] / ;$ phase[i] =!= melting \&\& phase[i] =!= vaporizing;

$\operatorname{Tn}[\mathrm{i}] \mathrm{]}:=\operatorname{Tm} / ;$ phase $[\mathrm{i}]==$ melting;

$\operatorname{Tn}[\mathrm{i}] \mathrm{]}:=\mathrm{Tv} / ;$ phase[i] === vaporizing ;

$\mathrm{vv}[\mathrm{i}, \mathrm{j}, \mathrm{dt}]:=\mathrm{k} 1[\mathrm{i}] / ; \mathrm{i}-1==\mathrm{j} \& \&$ phase[j]=!=melting \&\& phase[j]=!=vaporizing

$v v[i, j, d t]]:=-k 2[\mathrm{i}]-\mathrm{rho}[\mathrm{i}] * \mathrm{cp}[\mathrm{i}] / \mathrm{dt}-\mathrm{bb}[\mathrm{i}] / ; \mathrm{i}==\mathrm{j} \& \&$ phase[j] $=!=$ melting \& \&

phase $[\hat{j}]=!=$ vaporizing

$\mathrm{vv}\left[\mathrm{i}, \mathrm{j}_{-}, \mathrm{dt}\right]:=\mathrm{k} 3[\mathrm{i}] / ; \mathrm{i}+1=\mathrm{j} \& \&$ phase $[\mathrm{j}]=!=$ melting $\& \&$ phase $[\mathrm{j}]=!=$ vaporizing

$v v\left[i_{-} j_{-}, d t\right]:=0 / ; i !=j \& \& \mathrm{i}-1 !=j \& \& \mathrm{i}+1 !=\mathrm{j}$;

vv[i,j,dt]:=1 /; i=-j \&\& phase[j]==melting;

$\mathrm{vv}\left[\mathrm{i}_{-}, \mathrm{j}_{-}, \mathrm{dt}\right] \mathrm{d}:=0 / ; \mathrm{i}-1==\mathrm{j} \& \&$ phase $[\mathrm{j}]===$ melting;

$v v\left[i_{-} j_{-}, \mathrm{dt}\right]:=0 / ; \mathrm{i}+1==\mathrm{j} \& \&$ phase $[\mathrm{j}]===$ melting;

$v v\left[i_{-}, j_{-}, d t\right]:=1 / ; i==j$ \&\& phase[j]==-vaporizing;

$\left.\left.v v\left[i_{-},\right]_{-}, d t\right]\right]:=0 / ; i-1==j \& \&$ phase $[\mathrm{j}]==$ =vaporizing;

$\left.v v\left[i_{-},\right]_{-}, \mathrm{dt}\right]:=0 / ; \mathrm{i}+1=\mathrm{j} \& \&$ phase $[\mathrm{j}]==$ =vaporizing;

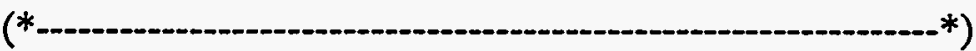

$\mathrm{f}[\mathrm{i}, \mathrm{dt}$, time_qtot $]:=-\mathrm{q}[\mathrm{i}, \mathrm{time}, \mathrm{qtot}]-\mathrm{To}[\mathrm{i}] *$ rho[i] $* \mathrm{cp}[\mathrm{i}] / \mathrm{dt}-\mathrm{bb}[\mathrm{i}] *$ Tinf $/ ;$ phase[i]=!=melting \&\& phase [i] $]=$ !=vaporizing;

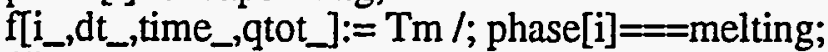

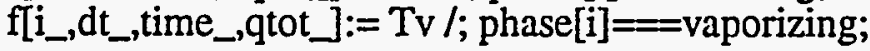

Plot[shape $[t],\{t, .240,0.28\}, P$ lotRange- $>\{0,100\}]$

$\mathrm{TB}=0.240 ; \mathrm{TE}=0.28$;

-Graphics-

RhoMeat=6500.;RhoAl=2700.;RhoU =12200;

fval=0.5;

fvu=1-fval;

DenRat $=(\mathrm{RhoU} / \mathrm{RhoAl})$;

fmal $=0.212$;

$\mathrm{fmu}=1-\mathrm{fmal}$;

Echem =350000.0; 
$w w=E$ chem $* 5100$;

General::spell1:

Possible spelling error: new symbol name "fval" is similar to existing symbol "fmal".

time $=\mathrm{TB}$;

Do[To[i] $=300 ; \operatorname{Tc}[\mathrm{i}]=300 ; \operatorname{xm}[\mathrm{i}]=0 ; \operatorname{xv}[\mathrm{i}]=0 ; \operatorname{orf}[\mathrm{i}]=0 ;\{\mathrm{i}, 1, \mathrm{~m}\}]$;

$\mathrm{dtt}[\mathrm{i}] \mathrm{i}:=10 * \mathrm{dx}^{*} \mathrm{dx} * \mathrm{rho}[\mathrm{i}] * \mathrm{cp}[\mathrm{i}] /(2 * \mathrm{k}[\mathrm{i}])$;

$\mathrm{dt}=\operatorname{Min}[\mathrm{Table}[\mathrm{dtt}[\mathrm{i}],\{\mathrm{i}, 1, \mathrm{~m}\}]]$;

$\mathrm{nt}=$ Floor$[(\mathrm{TE}-\mathrm{TB}) / \mathrm{dt}]-1$;

Print ["dt= ",dt," nt= ",nt];

$\mathrm{dt}=0.000278413 \mathrm{nt}=142$

Do[

$s=$ Table[vv[i,j,dt],\{j,m $\},\{\mathrm{i}, \mathrm{m}\}]$;

sinv=Inverse $[\mathrm{s}] ;\left({ }^{*}\right.$ invert the matrix *)

$\mathrm{qq}=$ Table[f[i,dt,time,qtot], $\{\mathrm{i}, \mathrm{m}\}]$;

ans=sinv.qq;

$\mathrm{Do}[\mathrm{Tc}[\mathrm{i}]=\mathrm{ans}[[\mathrm{i}]]$;

If $[$ phase[i] $===$ melting, $\quad x m[i]+=(k 1[i] * T o[i-1]-k 2[i] * T o[i]+k 3[i] * T o[i+1]+q[i$, time,qtot $]-$ bb[i]*(To[m]-Tinf $) * d t /($ rho[i] $* h s f[i]) ; 0]$;

If phase[i] $===$ vaporizing, $x v[i]+=(k 1[i] * \operatorname{To}[i-1]-k 2[i] * T o[i]+k 3[i] * T o[i+1]+q[i, t i m e, q t o t]-$ $\mathrm{bb}[\mathrm{i}] *(\operatorname{To}[\mathrm{m}]-\operatorname{Tinf})) * \mathrm{dt} /(\mathrm{rho}[\mathrm{i}] * \mathrm{hfg}[\mathrm{i}]) ; 0]$;

$,\{\mathrm{i}, 1, \mathrm{~m}\}]$;

If $[$ Mod[numtimesteps,5] $==0 \|$ numtimesteps $>=60$,

Print[numtimesteps," ",time," ",To[1]," ",xv[1]," ",phase[1]," ", q[1,time,qtot]," ",orf[1]," ",qs[qtot,time]," ",qchem[1]]];

$\mathrm{Do}[\mathrm{To}[\mathrm{i}]=\operatorname{Tn}[\mathrm{i}]$

xx1[i,numtimesteps] $=\{$ time,To[i] $\}$;

$\mathrm{xx} 2[\mathrm{i}$, numtimesteps] $=\{$ time, $\mathrm{xm}[\mathrm{i}]\}$;

$\mathrm{xx3}[\mathrm{i}$, numtimesteps] $=\{$ time, $\mathrm{xv}[\mathrm{i}]\}$;

$\mathrm{xx} 4[\mathrm{i}$,numtimesteps] $=\{$ time, orf $[\mathrm{i}]\}$;

$\mathrm{xx} 5[$ i, numtimesteps] $=\{$ time, $\mathrm{q}[\mathrm{i}, \mathrm{time}, \mathrm{qtot}]\}$

xx6[i,numtimesteps] $=\{$ time,qchem[i] $\}$;

$\mathrm{xx} 7[\mathrm{i}$, numtimesteps] $=\{$ time,qs[qtot,time] ;

$,\{\mathrm{i}, 1, \mathrm{~m}\}]$;

To[i] $=\operatorname{Tn}[\mathrm{i}]$;

time $+=\mathrm{dt}$;

UpdateRF[dt];

, numtimesteps, $1, \mathrm{nt}\}]$;

Print[Finished];

$$
10 \quad-11 \cdot 10
$$

50.241114305 .3980 solid $1.3577310 \quad 1.0861210 \quad 1.3577310 \quad 17.8136$ $\begin{array}{llll}10 & -11 & 10\end{array}$

100.242506311 .8970 solid $2.7616810 \quad 2.5385810 \quad 2.7616810 \quad 19.2134$ $\begin{array}{llll}10 & -11 & 10\end{array}$

150.243898321 .9660 solid $2.9917310 \quad 4.1512710 \quad 2.9917310 \quad 21.6514$ 


\section{$10 \quad-11 \quad 10$}

200.24529334 .5120 solid $5.0422510 \quad 5.9880310 \quad 5.0422510 \quad 25.2253$

$$
\begin{array}{llll}
10 & -11 & 10
\end{array}
$$

250.246682354 .5550 solid $7.2532410 \quad 8.2764610 \quad 7.2532410 \quad 32.4944$

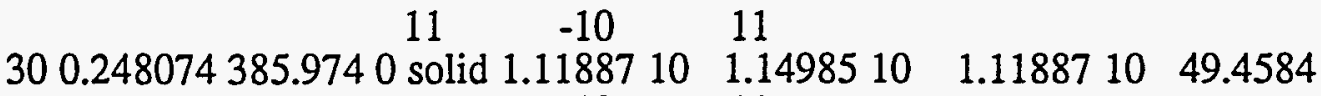

$\begin{array}{llllllll}350.249466433 .632 & 0 \text { solid } 1.71017 & 10 & 1.72949 & 10 & 1.71017 & 10 & 98.8429\end{array}$

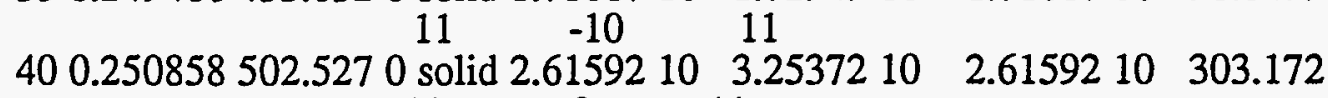
$\begin{array}{llll}11 & -9 & 11\end{array}$

450.25225601 .0120 solid $3.7915710 \quad 1.0996610 \quad 3.7915710 \quad 1915.26$ $11 \quad-8 \quad 11$

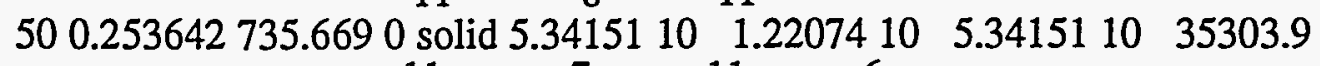
$\begin{array}{lllll}11 & -7 & 11 & 6\end{array}$

$\begin{array}{llllll}550.255034900 .0 \text { melting } 7.0628910 & 5.0915510 & 7.0628810 & 1.7302310\end{array}$ $11 \quad-6 \quad 11 \quad 6$

600.256426960 .5730 liquid $8.6570710 \quad 3.1242110 \quad 8.65710 \quad 7.2477810$ $11 \quad-6 \quad 11 \quad 7$

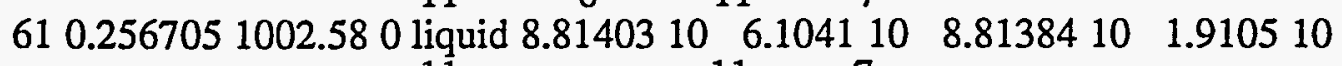

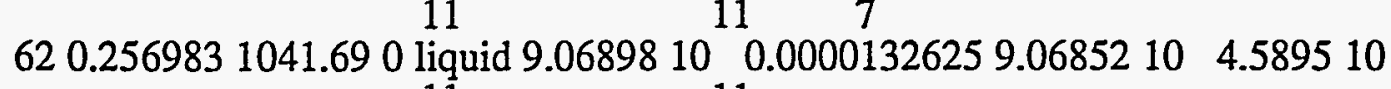
11 11

630.2572621074 .610 liquid $9.1869110 \quad 0.00002788219 .1859710$

7

9.3730510

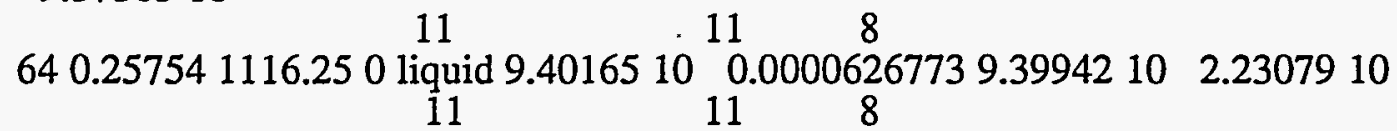

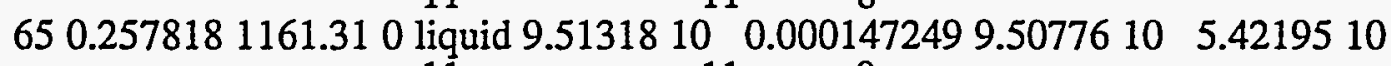
660.2580971204 .460 liquid $9.5098210 \quad 0.0003349789 .4977810 \quad 1.2034810$

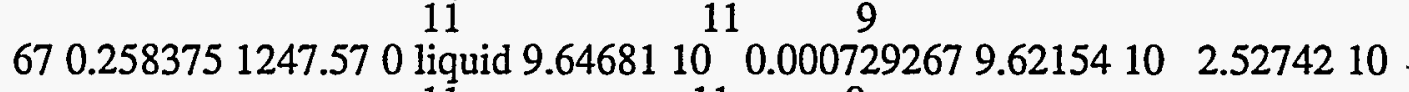
$1 \overline{1} \quad 11 \quad 9$

680.2586541292 .360 liquid $9.6019110 \quad 0.001532739 .5504210 \quad 5.1491710$

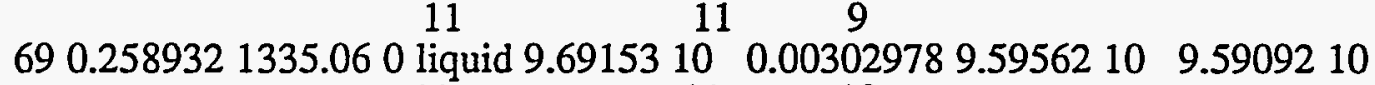
$11 \quad 11 \quad 10$

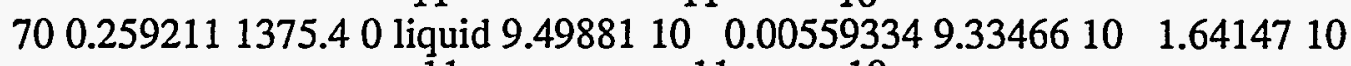
$11 \quad 11 \quad 10$

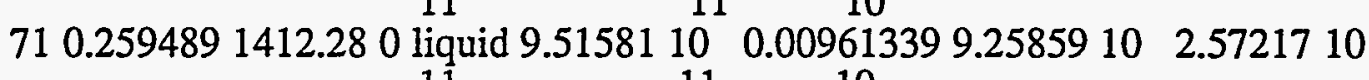
$11 \quad 11 \quad 10$

$\begin{array}{llllll}72 & 0.2597671447 .050 \text { liquid } 9.5897310 & 0.01554039 .2108710 & 3.78853 & 10\end{array}$ $11 \quad 11 \quad 10$

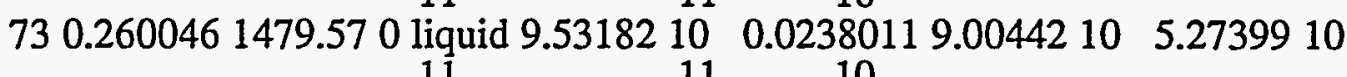
11 11

740.2603241509 .250 liquid $9.3928210 \quad 0.03469538 .6982610 \quad 6.9455410$ $11 \quad 11$

$\begin{array}{lllll}750.260603 & 1535.810 \text { liquid } 9.3029510 & 0.0483538 .4335310 & 8.6941410\end{array}$

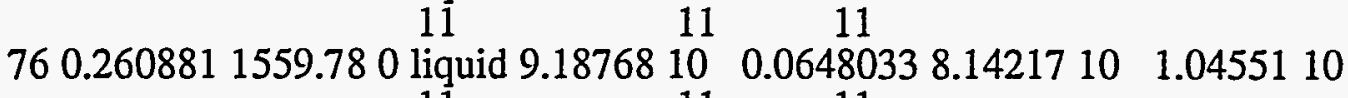
$11 \quad 11 \quad 11$ 
770.2611591581 .740 liquid 9.0765710 11

11

780.2614381602 .080 liquid 8.9623210 11

790.2617161620 .690 liquid 8.7459810

11 11

800.2619951636 .860 liquid 8.5284110 $11 \quad 11$

810.2622731650 .830 liquid 8.2739710 $11 \quad 11$

820.2625511662 .530 liquid 8.0538610 $11 \quad 11$

830.262831672 .520 liquid 7.7456210

840.2631081680 .360 liquid 7.3399210 $11 \quad 11$

850.2633871685 .530 liquid 7.0033810

$860.263665168876011 \quad 11$

860.2636651688 .760 liquid 6.6734210 $11 \quad 11$

870.2639441690 .360 liquid 6.2496510 11 . 11

880.2642221690 .010 liquid 5.9351710 $11 \quad 11$

890.26451689 .120 liquid 5.4850910

900.2647791686 .950 liquid 5.2264110 $11 \quad 11$

910.2650571685 .220 liquid 4.8013110 $11 \quad 11$

920.2653361682 .650 liquid 4.4722410 $11 \quad 11$

930.2656141679 .970 liquid 4.2536510 $11 \quad 11$

940.2658921677 .960 liquid 3.9235610

9502661711675.56011

950.2661711675 .560 liquid 3.6506810

9602664491673.0901111

960.2664491673 .090 liquid 3.4512110 $11 \quad 11$

970.2667281670 .970 liquid 3.1986110 $11 \quad 11$

980.2670061668 .630 liquid 2.9215110 $11 \quad 11$

990.2672841665 .740 liquid 2.8350710

1000.2675631663 .720 liquid 2.5810810 $11 \quad 11$

1010.2678411661 .120 liquid 2.4553210 $11 \quad 11$

1020.268121658 .870 liquid 2.2878810 $11 \quad 11$

1030.2683981656 .550 liquid 2.0721410
$0.08401037 .8578810 \quad 1.2186910$ 11

$0.1058797 .5770910 \quad 1.3852310$ 11

$0.1302037 .2079410 \quad 1.5380410$ 11

$0.1565616 .8643710 \quad 1.6640410$ 11

$0.1845086 .5122410 \quad 1.7617410$ 11

$0.2135476 .2256110 \quad 1.8282510$ 11

$0.2432725 .8763910 \quad 1.8692310$ 11

$0.2732075 .4591310 \quad 1.8807910$ 11

$0.3028195 .1440910 \quad 1.8592910$ 11

$0.3317464 .857910 \quad 1.8155310$ 11

$0.359724 .494210 \quad 1.7554610$ 11

$0.3864724 .2563810 \quad 1.6787810$ 11

0.411983 .88421101 .6008810 11

0.436133 .7103101 .5161110 11

$0.4590643 .361310 \quad 1.4410$ 11

$0.4807453 .1104410 \quad 1.3618110$ 11

$0.501242 .9659410 \quad 1.2877210$ 11

$0.52072 .7006510 \quad 1.2229110$ 11

$0.5391412 .4913910 \quad 1.1592910$ 11

$0.5566192 .3522310 \quad 1.0989810$ 11

$0.5732252 .1541610 \quad 1.0444510$ 10

$0.5889881 .9297710 \quad 9.9174310$ 10

0.603911 .89599109 .3907610 10

$0.6181171 .6867910 \quad 8.9428210$ 10

0.63161 .60636108 .4895910 10

$0.6444291 .4798610 \quad 8.0802310$ 10

0.6566371 .30309107 .6905110 10 
1040.2686771653 .70 liquid $1.8442910 \quad 0.6682191 .1143910 \quad 7.2990210$ $\begin{array}{lll}11 & 11 & 10\end{array}$

1050.2689551650 .170 liquid $1.7546610 \quad 0.6791671 .0644810 \quad 6.9018410$ $11 \quad 11 \quad 10$

1060.2692331647 .040 liquid $1.7205510 \quad 0.6895471 .0659810 \quad 6.5457710$ $11 \quad 11$

1070.2695121644 .690 liquid $1.6424210 \quad 0.6994421 .0182510 \quad 6.2417110$ $11 \quad 10 \quad 10$

1080.269791642 .70 liquid $1.5636510 \quad 0.70899 .668910 \quad 5.9676410$ $11 \quad 10 \quad 10$

1090.2700691641 .0 liquid $1.3645410 \quad 0.7179627 .9273310 \quad 5.7180910$ $11 \quad 10 \quad 10$

1100.2703471638 .570 liquid $1.2708210 \quad 0.7266047 .2532410 \quad 5.45510$ $11 \quad 10 \quad 10$

1110.2706251636 .220 liquid $1.2134410 \quad 0.7348556 .9255710 \quad 5.2088410$ $11 \quad 10 \quad 10$

1120.2709041634 .210 liquid $1.0946210 \quad 0.7427525 .95968104 .9865610$ $11 \quad 10 \quad 10$

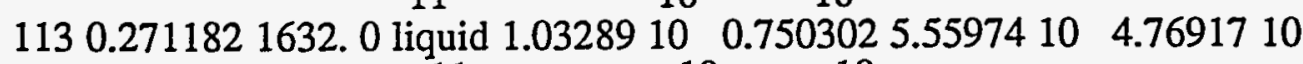

1130.2711821632 .01 quid $1.0328910 \quad 10$

1140.2714611630 .020 liquid $1.0110810 \quad 0.7575365 .54114104 .5697110$ $10 \quad 10$

1150.2717391628 .550 liquid 9.9029610 $10 \quad 10$

1160.2720181627 .560 liquid 9.2641910 $10 \quad 10$

1170.2722961626 .640 liquid $8.5458910 \quad 0.7776834 .4507910 \quad 4.095110$ $1180.2725741625 .7010 \quad 10 \quad 10$

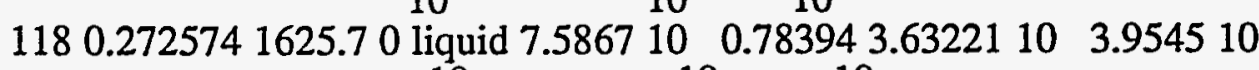

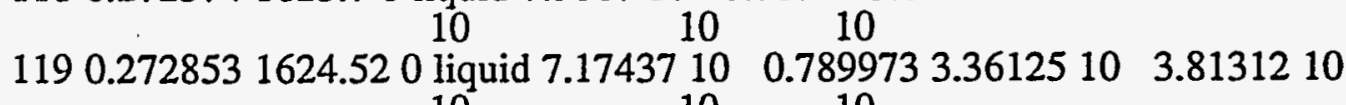
$10 \quad 10$

1200.2731311623 .510 liquid 6.3595210 $10 \quad 10$ 1210.273411622 .320 liquid $6.309310 \quad 0.8014152 .7579510 \quad 3.5513410$ $10 \quad 10$ 1220.2736881621 .550 liquid $6.5786610 \quad 0.8068493 .1428810 \quad 3.4357810$ $10 \quad 10$

1230.2739661621 .410 liquid 6.5663310 $10 \quad 10$

1240.2742451621 .640 liquid 6.7060310 $10 \quad 10$

1250.2745231622 .320 liquid 5.8550510 $10 \quad 10$

1260.2748021622 .620 liquid 5.323410

1270.275081622 .760 liquid 4.9902110

$10 \quad 10$

1280.2753581622 .90 liquid 5.0926410

1290.2756371623 .380 liquid 4.7750310 $10 \quad 10$

1300.2759151623 .840 liquid 4.22691 10

$0.7644925 .508210 \quad 4.3947610$

0.7712035 .02339104 .2407910 10

$\begin{array}{ccc}10 & & \\ 0.7957982 .67773 & 30 & 3.6817910\end{array}$ $\begin{array}{lll}10 & 1057982.6777310 & 3.6817910\end{array}$ 10

0.812133 .22762103 .3387110 $\begin{array}{ccc}10 & & \\ 0.8172743 .4535610 & 3.2524710\end{array}$

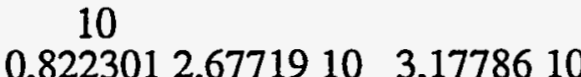
10

$0.8271992 .2269210 \quad 3.0964810$ 10

0.8319671 .97616103 .0140510 10

$0.8366082 .1589210 \quad 2.9337110$ 10

0.8411351 .9132102 .8618310 10

$0.845551 .4359610 \quad 2.7909510$ 10 
1310.2761941624 .060 liquid 3.8269710 $10 \quad 10$

1320.2764721624 .180 liquid 4.1366410 $10 \quad 10$

1330.2767511624 .740 liquid 4.7220110 10 10

1340.2770291625 .950 liquid 4.0207910 10 10

1350.2773071626 .750 liquid 3.5498610 10

1360.2775861627 .320 liquid 3.2912110 10 10

1370.2778641627 .820 liquid 3.4163610 10 10

1380.2781431628 .560 liquid 3.3890310 $10 \quad 9$

1390.2784211629 .40 liquid 2.8710410 $10 \quad 9$

1400.2786991629 .940 liquid 2.930310

1410.2789781630 .650 liquid 3.3942610 10 10

1420.2792561631 .830 liquid 3.4707810 Finished

Tcoefsol $=2.25 * 10^{\wedge}-5$;

Tcoefliq $=1.17 * 10^{\wedge}-4$;

(*TA - average temperature *)

ta[ts_]:= Sum[Part[xx1[node,ts],2], \{node, $1, \mathrm{~m}\}] / \mathrm{m}$;

(*tr - Temperature time rate of change $*$ )

$\operatorname{tr}[$ node_ts_]:=Part[xx1[node,ts]-xx1[node,ts-1],2]/Part[xx1[node,ts]-xx1[node,ts-1],1];

(* tra - average rate of change of temp for the plate*)

tra[ts_]:=Sum[tr[node,ts],\{node, $1, \mathrm{~m}\}] / \mathrm{m}$;

(* expth - expansion thermal *)

(* texprate - thermal expansion rate for the plate $\left.{ }^{*}\right)$

expth[node_ts_]:=Tcoefsol*tr[node,ts] $/ ; \operatorname{Part}[\mathrm{xx} 1[$ node,ts],2] $<\mathrm{Tm}$; expth[node_ts_]:=Tcoefliq*tr[node,ts] /; Part[xx1[node,ts],2] $>\operatorname{Tm} \& \&$ Part[xx1[node,ts],2]<Tv; expth[node_ts_]:=tr[node,ts]/ Part[xx1[node,ts],2]/; Part[xx1[node,ts],2]>Tv; expth[node_ts_]:=0/;Part[xx1[node,ts],2] ===Tm; expth[node_ts_]:=0/; Part[xx1[node,ts],2]===Tv;

texprate[ts_]:=Sum[expth[node,ts],\{node, $1, \mathrm{~m}\}] / \mathrm{m}$;

(* qm - quality of the melt *)

$(* \mathrm{mv}$ - quality of the vapor $*$ )

$\mathrm{qm}[\mathrm{ts}] \mathrm{:}=\operatorname{Sum}[\operatorname{Part}[\mathrm{xx} 2[$ node,ts],2],\{node, $1, \mathrm{~m}\}] / \mathrm{m}$;

qv[ts_]:=Sum[Part[xx3[node,ts],2], \{node, $1, \mathrm{~m}\}] / \mathrm{m}$;

vfaln[i_]:=fval $/ ; \mathrm{i}<=\mathrm{n}$;

vfaln[i_]:=1 $/ ;$ i $>$ n ;

(* Fractional rate of change of volume due to various factors $*$ )

(* ger - Gas Expansion Rate

*) 
(* VMR - Volumetric Melting Rate

(* VVR - Volumetric Vaporization Rate

(* VOFR - Volumetric Oxide Formation Rate

* QMR - Quality Melt Rate

(* QVR - Quality Vaporization Rate

rhosolid =2700; rholiquid=2500; rhovapor $=1.0$;

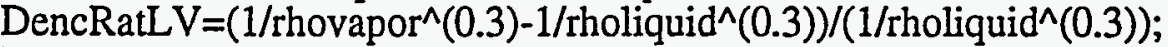

DencRatSL $=\left(1 /\right.$ rholiquid $^{\wedge}(0.3)-1 /$ rhosolid^$\left.^{\wedge}(0.3)\right) /(1 /$ rhosolid^$(0.3))$;

qmr[node_ts_]:=Part[xx2[node,ts]-xx2[node,ts-1],2]/Part[xx2[node,ts]-xx2[node,ts-1],1]; qvr[node_ts_]:=Part[xx3[node,ts]-xx3[node,ts-1],2]/Part[xx3[node,ts]-xx3[node,ts-1],1];

$\operatorname{vmr}[\mathrm{ts}]$ : =Sum[DencRatSL*qmr[node,ts]*vfaln[node],\{node, $1, \mathrm{~m}\}] / \mathrm{m}$;

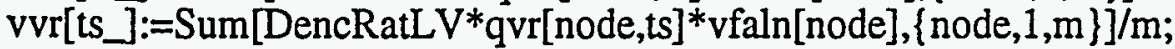

ger[ts_]:=Sum[ tr[node,ts]/ Part[xx1[node,ts],2], \{node,1,n\}]/m;

$\mathrm{ff}=0.01$;

TotalExpansionRate[ts_]:=(1-ff)*(vmr[ts] +vvr[ts]+texprate[ts] $)+f f * g e r[t s]$

IntegralTotExp[ts_]:=Sum[TotalExpansionRate[tt]*dt,\{tt,2,ts\}]

ListPlot[Table[\{Part[xx1[1,ts],1],TotalExpansionRate[ts]\},\{ts,2,nt\}],

PlotJoined $\rightarrow$ True,

PlotRange- $>$ All,

AxesLabel->\{"time (s)","Fractional Exp rate (1/s)" $\}$ ]

ter=1;

(* ter total expansion *)

Do[ter* $=\left(1+\right.$ TotalExpansionRate[t] $\left.{ }^{*} \mathrm{dt}\right)$;

qwq $[\mathrm{tt}]=\{\operatorname{Part}[\mathrm{xx} 1[1, \mathrm{tt}], 1]$, ter -1$\}$

$,\{\mathrm{tt}, 2, \mathrm{nt}\}]$

ListPlot[Table[qwq[tt],\{tt,2,nt\}],

PlotJoined $\rightarrow$ True,

PlotRange->All,

AxesLabel->\{"time (s)","Expanded fraction" $\}]$

Do[eff[ts] $=\{$ Part[xx1[1,ts],1],ta[ts],TotalExpansionRate[ts],Part[qwq[ts],2]\},\{ts,2,nt $\}]$;

ListPlot[Table[\{Part[xx1[1,ts],1],ta[ts]\},\{ts,2,nt\}],

PlotJoined $\rightarrow$ True,

PlotRange->All,

AxesLabel->\{"time (s)","average temp (K)" $\}]$

-Graphics-

-Graphics-

-Graphics-

bsb1[i]]:=(Sum[Part[xx4[j,i],2],\{j,1,n\}])/n;

ListPlot[Table[\{Part[xx4[1,i],1],bsb1[i]\},\{i,1,nt\}],

PlotJoined $\rightarrow$ True,PlotRange- $>$ All,

AxesLabel->\{ "time (s)"," fraction of reacted fuel" \}];

ListPlot[Table[\{Part[xx1[1,i],1],Part[xx1[1,i],2]\},\{i,1,nt\}], 
PlotJoined $\rightarrow$ True,

PlotRange- $>$ All,

AxesLabel-> "time (s)"," temp (K)" \}]

ListPlot[Table[\{Part[xx1[m,i],1],Part $[\mathrm{xx} 1[\mathrm{~m}, \mathrm{i}], 2]\},\{\mathrm{i}, 1, \mathrm{nt}\}]$,

PlotJoined $\rightarrow>$ True,

PlotRange->All,

AxesLabel->\{ "time (s)"," temp (K)" \}]

szs1 $=\operatorname{ListPlot}[$ Table $[\{\operatorname{Part}[\mathrm{xx5}[1, \mathrm{i}], 1], \operatorname{Part}[\mathrm{xx} 5[1, \mathrm{i}], 2]\},\{\mathrm{i}, 1, \mathrm{nt}\}]$,

PlotJoined $->$ True,PlotRange- $>$ All,

AxesLabel-> "time (s)"," Q fission (W/m^3)" \}];

szs2=ListPlot[Table[\{Part[xx6[1,i],1],Part[xx6[1,i],2]\},\{i,1,nt $\}]$,

PlotJoined $\rightarrow$ True,PlotRange $\rightarrow$ All,

AxesLabel-> "time (s)"," Q chemical (W/m^3)" $\}$;

szs3=ListPlot[Table[\{Part[xx7[1,i],1],Part[xx7[1,i],2]\},\{i,1,nt $\}]$,

PlotJoined $\rightarrow$ True,PlotRange- $>$ All,

AxesLabel-> "time (s)"," Q total (W/m³)" $\}$ ];

Show[szs1,szs2,szs3]

-Graphics-

-Graphics-

-Graphics-

(*

THIS IS A REVISED DISPERSION MODEL THAT USES THE

TIME ENERGY DATA FROM THE EXPERIMENTS AND TEMPERATURE

DEPENDANT CHEMICAL REACTION RATES FUEL- ALUMINUM

This copy has chemical reaction rates included in the model

LAST UPDATED 4-19-95

Renormalized pulse width was used to a narrower band width. 
*)

Print["Date last updated =",Date[];

Date last updated $=\{1995,5,2,10,6,51\}$

$\mathrm{l}=0.000635 ; \mathrm{m}=10 ; \mathrm{dx}=1 / \mathrm{m} ; \mathrm{n}=\mathrm{R}$ ound $\left[\mathrm{m}^{*} .4\right] ;$ time $=0 ; \operatorname{Tinf}=300$;

volmeat $=2 * d x^{*} n^{*}\left(25 * 10^{\wedge}-3\right) *\left(70 * 10^{\wedge}-3\right)$;

$\operatorname{Do}[\mathrm{xx}[\mathrm{i}]=\mathrm{i} * \mathrm{dx}-\mathrm{dx} / 2,\{\mathrm{i}, 1, \mathrm{~m}\}] ; \mathrm{Tm}=900 . ; \mathrm{Tv}=2700$;

$\mathrm{Do}[\mathrm{To}[\mathrm{i}]=300 ; \mathrm{Tc}[\mathrm{i}]=300 ; \mathrm{xm}[\mathrm{i}]=0 ; \mathrm{xv}[\mathrm{i}]=0,\{\mathrm{i}, 1, \mathrm{~m}\}]$;

$\mathrm{k}[\mathrm{i}]:=39.91 / ; \mathrm{i}<=\mathrm{n} ; \quad$ (* assign $\mathrm{k}$ to the meat $\left.{ }^{*}\right)$

$\mathrm{k}[\mathrm{i}]:=\mathrm{kcl}[\mathrm{To}[\mathrm{i}]] / ; \mathrm{i}>\mathrm{n} ; \quad(*$ assign $\mathrm{k}$ to the clad $*$ )

rho[i] $]:=6550.0 / ; \mathrm{i}<=\mathrm{n} ;\left({ }^{*}\right.$ assign meat density $*$ )

rho[i] $]:=2700.0 / ;$ i $>n$; (* assign clad density $\left.{ }^{*}\right)$

$\mathrm{cp}[\mathrm{i}]:=\operatorname{cpcl}[\mathrm{To}[\mathrm{i}]] / ; \mathrm{i}>\mathrm{n} ; \quad{ }^{*}$ assign clad cpecific heat $\left.*\right)$

$\mathrm{cp}[\mathrm{i}]:=\operatorname{cpf}[\mathrm{To}[\mathrm{i}]] / ; \mathrm{i}<=\mathrm{n} ; \quad\left(*\right.$ assign meat cpecific heat $\left.{ }^{*}\right)$

htc $=$ Interpolation $[\{\{150,13232\},\{350,13232\},\{410,14770\},\{726,12542\}$, $\{776,11561\},\{1256,9924\},\{1458,1750\},\{1526,1729\},\{1556,800\}$, $\{5000,800\}\}$,Interpolation Order $->1]$;

$\mathrm{kcl}=$ Interpolation $[\{\{100,161\},\{400,177\},\{500,186\},\{600,193\}$,

$\{750,193\},\{850,193\},\{900,193\},\{930,193\}$,

$\{1200,84\},\{1300,84\},\{1500,84\},\{2000,84\},\{5000,84\}\}$,

Interpolation Order $->1]$;

cpcl=Interpolation $[\{\{100,878\},\{300,878\},\{366,942\},\{422,963\}$,

$\{588,1034\},\{700,1067\},\{811,995\},\{1000,995\},\{2000,995\}$,

$\{5000,995\}\}$,InterpolationOrder $->1\}$;

$\mathrm{cpf}=$ Interpolation $[\{\{100,351\},\{300,351\},\{933,463\},\{1933,546\}$, $\{2500,546\},\{3500,546\},\{5000,546\}\}$,InterpolationOrder- $>1]$;

hsf[i_]:=398000*fmal $/ ; \mathrm{i}<=\mathrm{n}$;

hfg[i]:=10800000*fmal /; i <= n;

hsf[i_]:=398000 /; i $>$ n;

hfg[i] $]=10800000 \quad / ;$ i $>$ n;

151=ReadList["508.54",Number,RecordLists->True];

shape=Interpolation[151,InterpolationOrder $>1$ ];

num $=$ Part[Part[Position[151,Last[151]],1],1];

TimeBeg=Part[151[[1]],1]; TimeEnd=Part[151[[num]],1];

$\mathrm{cl}=\operatorname{Sum}\left[0.5^{*}\right.$ (shape[Part[151[[i]],1]]+shape[Part[151[[i+1]],1]])*

(Part[151[[i+1]],1]-Part[151[[i]]],1]),\{i,200,500\}];

qs[qtot_time]:=qtot*shape[time]/(volmeat*c1);

qtot=1 1006;

(* Functions : nrt - new reacted fraction

orf - old reacted fraction $*$ )

$\operatorname{Tm} 1=863 ; \operatorname{Tm} 2=1970 ; \operatorname{Td}\left[\mathrm{i}_{1}\right]:=(\operatorname{To}[\mathrm{i}]-\operatorname{Tm} 1) /(\operatorname{Tm} 2-\operatorname{Tm} 1) ;$

lamda[i_]: $=\left(4 * 10^{\wedge}-4\right) \mathrm{E}^{\wedge}(14.73 * \operatorname{Tanh}[1.8 * \mathrm{Td}[\mathrm{i}]])$;

$z 1\left[i_{\text {,dt }}\right]:=N D S o l v e\left[\left(\mathrm{RF}^{\prime}[\mathrm{t}]==\right.\right.$ lamda[i]-lamda $[\mathrm{i}] * \mathrm{RF}[\mathrm{t}]$,

$\overrightarrow{R F}[0]==0 r f[i]\}, R F,\{t, 0, d t\}$, AccuracyGoal $->15]$; 
$\operatorname{nrf}\left[\mathrm{i}_{-}, \mathrm{dt}\right] \mathrm{d}=\mathrm{Part}[\mathrm{RF}[\mathrm{dt}] / . \mathrm{z} 1[\mathrm{i}, \mathrm{dt}], 1]$

frr[i] ]:=lamda[i]-lamda[i]*orf[i];

UpdateRF[dt_]:=Do[orf[i] $=\operatorname{nrf}[i, \mathrm{dt}],\{\mathrm{i}, 1, \mathrm{n}\}]$

qchem[i_]:=wW*frr[i];

$\mathrm{q}\left[\mathrm{i}\right.$, time_,qtot_]:=qs[qtot,time]+qchem[i] $/ ; \mathrm{i}<=\mathrm{n} ;\left(^{*}\right.$ assign heat generation in the meat $*$ )

q[i_time_qtot_ $]:=0 / ; \mathrm{i}>\mathrm{n} ; \quad$ (* assign heat generation in the clad *)

$\mathrm{bb}[\overline{\mathrm{i}}]:=\mathrm{htc}[\mathrm{To}[\mathrm{m}]] / \mathrm{dx} / ; \mathrm{i}==\mathrm{m}$;

$\mathrm{bb}[\mathrm{i}] \mathrm{]}:=0 / ; \mathrm{i} !=\mathrm{m} ; \quad(*$ value for the heat transfer out of the plate $*)$

$\mathrm{k} 1[\mathrm{i}] \mathrm{]}:=(2 * \mathrm{k}[\mathrm{i}-1] * \mathrm{k}[\mathrm{i}] /(\mathrm{k}[\mathrm{i}-1]+\mathrm{k}[\mathrm{i}])) / \mathrm{dx} \mathrm{x}^{\wedge} 2 / \mathrm{i} !=1$

$\mathrm{k} 1[\mathrm{i}] \mathrm{i}:=0 / ; \mathrm{i}=1$

$\mathrm{k} 2[\mathrm{i}] \mathrm{]}:=\mathrm{k} 1[\mathrm{i}]+\mathrm{k} 3[\mathrm{i}]$

$\mathrm{k} 3[\mathrm{i}] \mathrm{]}:=(2 * \mathrm{k}[\mathrm{i}+1] * \mathrm{k}[\mathrm{i}] /(\mathrm{k}[\mathrm{i}+1]+\mathrm{k}[\mathrm{i}])) / \mathrm{dx} \mathrm{x}^{\wedge} / ; \mathrm{i} !=\mathrm{m}$

$\mathrm{k} 3[\mathrm{i}] \mathrm{]}:=0 / \mathrm{i}=\mathrm{m}$;

phase[i_]:= solid $/$; $\mathrm{Tc}[\mathrm{i}]<\mathrm{Tm}$;

phase[i] $:=$ liquid $/ ; \mathrm{Tc}[\mathrm{i}]<\mathrm{Tv} \& \& \mathrm{Tc}[\mathrm{i}]\rangle=\mathrm{Tm} \& \& \mathrm{xm}[\mathrm{i}]\rangle=0.85$;

phase[i] $:=$ vapor $/ ; \quad \operatorname{Tc}[i]>=\mathrm{TV} \& \& \mathrm{xv}[\mathrm{i}]>1$;

phase $[\mathrm{i}] \mathrm{]}:=$ melting $/ ; \quad \operatorname{Tc}[\mathrm{i}]>=\mathrm{Tm} \& \& \mathrm{xm}[\mathrm{i}]<0.85$;

phase[i] $]:=$ vaporizing $/ ; \quad \operatorname{Tc}[\mathrm{i}]>=\operatorname{Tv} \& \& \mathrm{xv}[\mathrm{i}]<1 \& \& \mathrm{xv}[\mathrm{i}]>-0.01$;

$\operatorname{Tn}[\mathrm{i}]$ ]:=Tc[i] $/ ;$ phase[i] $=!=$ melting \& \& phase[i] $=!=$ vaporizing;

$\operatorname{Tn}\left[i_{i}\right]:=\operatorname{Tm} / ;$ phase [i] $===$ melting ;

$\operatorname{Tn}[i]$ ] $=\operatorname{Tv} / ;$ phase[i] $===$ vaporizing ;

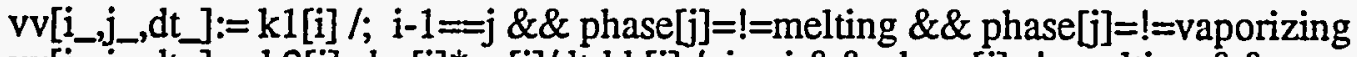
$\mathrm{vv}\left[\mathrm{i}_{\mathrm{i}}, \mathrm{j}, \mathrm{dt}\right] \mathrm{]}:=-\mathrm{k} 2[\mathrm{i}]-\mathrm{rho}[\mathrm{i}] * \mathrm{cp}[\mathrm{i}] / \mathrm{dt}-\mathrm{bb}[\mathrm{i}] / ; \mathrm{j}=\mathrm{j} \& \&$ phase[j]=!=melting \&\& phase[j] $=!=$ =vaporizing

$\mathrm{vv}[\mathrm{i}, \mathrm{j}, \mathrm{dt}]:=\mathrm{k} 3[\mathrm{i}] / ; \mathrm{i}+1=\mathrm{j} \& \&$ phase[j]=!=melting \&\& phase[j]=!=vaporizing

$v v\left[i_{-}, j_{-}, d t\right]:=0 / ; i !=j \& \& \mathrm{i}-1 !=j \& \& \mathrm{i}+1 !=j$;

$\left(*-j,{ }_{-1}\right.$

$v v\left[i_{-}, j_{-}, d_{1}\right]:=1 / ; \mathrm{i}==\mathrm{j} \quad \& \&$ phase[j] $===$ melting;

$\mathrm{vv}[\mathrm{i}, \mathrm{j}, \mathrm{dt}] \mathrm{l}:=0 / ; \mathrm{i}-1==\mathrm{j} \& \&$ phase $[\mathrm{j}]===$ melting;

$v v\left[i_{-}, j_{-}, d t\right][=0 / ; i+1==j \& \&$ phase $[j]===$ melting;

$\left.\mathrm{vv}\left[\mathrm{i}_{1}, \mathrm{j}_{-}, \mathrm{dt}\right] \mathrm{d}\right]=1 / ; \mathrm{i}==\mathrm{j} \quad \& \&$ phase$[\mathrm{j}]===\mathrm{vaporizing}$

$\mathrm{vv}\left[\mathrm{i}_{-} \mathrm{j}_{-}, \mathrm{dt}\right] \mathrm{d}:=0 / ; \mathrm{i}-1==\mathrm{j} \& \&$ phase$[\mathrm{j}]===$ vaporizing;

$\mathrm{vv}\left[\mathrm{i}_{-} \mathrm{j}_{-}, \mathrm{dt}\right] \mathrm{d}:=0 / ; \mathrm{i}+1==\mathrm{j} \& \&$ phase$[\mathrm{j}]===$ vaporizing;

$(*-\ldots$

$\mathrm{f}[\mathrm{i}, \mathrm{dt}, \mathrm{time}, \mathrm{qtot}]:=-\mathrm{q}[\mathrm{i}, \mathrm{time}, \mathrm{qtot}]-\mathrm{To}[\mathrm{i}]{ }^{*} \mathrm{rho}[\mathrm{i}] * \mathrm{cp}[\mathrm{i}] / \mathrm{dt}-\mathrm{bb}[\mathrm{i}] *$ Tinf $/ ;$ phase[i] $=!=$ melting \& \& phase $[\overline{\mathrm{i}}]=$ !=vaporizing;

$\mathrm{f}\left[\mathrm{i}_{\text {,dt_time_, }} \mathrm{qtot}\right]:=\mathrm{Tm} / ;$ phase[i] $===$ melting;

$\mathrm{f}\left[\mathrm{i}_{-}, \mathrm{dt}, \mathrm{time}, \mathrm{qtot}\right]:=\mathrm{Tv} /$; phase[i]===vaporizing;

$\mathrm{TB}=0.230 ; \mathrm{TE}=0.27$;

Plot[shape[t],\{t,TB,TE $\},$ PlotRange- $>\{0,100\}]$

-Graphics-

RhoMeat=6500.;RhoAl=2700.;RhoU=12200.; 
fval $=0.5$;

fvu=1-fval;

DenRat=(RhoU/RhoAl);

fmal $=0.212$;

fmu $=1$-fmal;

Echem $=350000.0$

$\mathrm{ww}=\mathrm{E}$ chem $* 5100$;

time $=\mathrm{TB}$;

$\mathrm{Do}[\mathrm{To}[\mathrm{i}]=300 ; \mathrm{Tc}[\mathrm{i}]=300 ; \mathrm{xm}[\mathrm{i}]=0 ; \mathrm{xv}[\mathrm{i}]=0 ; \operatorname{orf}[\mathrm{i}]=0 ;,[\mathrm{i}, 1, \mathrm{~m}\}]$;

$\mathrm{dtt}[\mathrm{i}] \mathrm{i}=10 * \mathrm{dx} * \mathrm{dx} * \mathrm{rho}[\mathrm{i}] * \mathrm{cp}[\mathrm{i}] /(2 * \mathrm{k}[\mathrm{i}])$;

$\mathrm{dt}=\operatorname{Min}[$ Table[dtt[i], $\{\mathrm{i}, 1, \mathrm{~m}\}]]$;

$\mathrm{nt}=$ Floor$[(\mathrm{TE}-\mathrm{TB}) / \mathrm{dt}]-1$;

Print["dt= ",dt," nt= ",nt];

$\mathrm{dt}=0.000278413 \mathrm{nt}=142$

Do[

$s=$ Table[vv[i,j,dt],\{j,m $\},\{\mathrm{i}, \mathrm{m}\}]$;

sinv=Inverse[s]; $; *$ invert the matrix *)

$\mathrm{qq}=$ Table[f[i,dt,time,qtot], $\{\mathrm{i}, \mathrm{m}\}]$;

ans $=$ sinv.qq;

Do[Tc[i] $=$ ans[[i]];

If $[$ phase[i] $===$ melting, $\quad x m[i]+=(k 1[i] * T o[i-1]-k 2[i] * T o[i]+k 3[i] * T o[i+1]+q[i$,time,qtot $]-$ bb[i]*(To[m]-Tinf) $) * d t /($ rho[i] $*$ hsf[i] $) ; 0]$;

If $[$ phase[i] $===$ vaporizing, $x v[i]+=(k 1[i] * T o[i-1]-k 2[i] * T o[i]+k 3[i] * T o[i+1]+q[i, t i m e, q t o t]-$ $\mathrm{bb}[\mathrm{i}] *(\mathrm{To}[\mathrm{m}]-\mathrm{Tinf})) * \mathrm{dt}(\mathrm{rho}[\mathrm{i}] * \mathrm{hfg}[\mathrm{i}]) ; 0]$;

$,\{\mathrm{i}, 1, \mathrm{~m}\}]$;

If[Mod[numtimesteps,5] $==0 \|$ numtimesteps $>=60$,

Print[numtimesteps," ",time," ",To[1]," ",xv[1]," ",phase[1]," ",

q[1,time,qtot]," ",orf[1]," ",qs[qtot,time]," ",qchem[1]]];

$\mathrm{Do}[\mathrm{To}[\mathrm{i}]=\operatorname{Tn}[\mathrm{i}]$;

xxl[i,numtimesteps] $=\{$ time, $T o[i]\}$;

$\mathrm{xx} 2[\mathrm{i}$, numtimesteps] $=\{$ time, $\mathrm{xm}[\mathrm{i}]\}$;

$\mathrm{xx3}[\mathrm{i}$, numtimesteps] $=\{$ time, $\mathrm{xv}[\mathrm{i}]\}$;

$\mathrm{xx} 4[\mathrm{i}$, numtimesteps $]=\{$ time, orf $[\mathrm{i}]\}$;

$\mathrm{xx} 5[\mathrm{i}$, numtimesteps] $=\{$ time, $\mathrm{q}[\mathrm{i}, \mathrm{time}, \mathrm{qtot}]\}$;

$\mathrm{xx} 6[\mathrm{i}$, numtimesteps] $=\{$ time,qchem[i] $\}$;

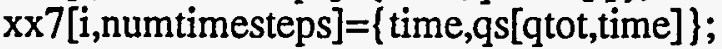

$,\{\mathrm{i}, 1, \mathrm{~m}\}]$;

To[i] $=\operatorname{Tn}[\mathrm{i}]$;

time $+=\mathrm{dt}$;

UpdateRF[dt];

, numtimesteps,1,nt\}];

Print[Finished];

$\begin{array}{lll}9 & -11 & 9\end{array}$

50.231114302 .0260 solid $5.91789101 .0625510 \quad 5.9178910 \quad 17.1356$

$\begin{array}{llll}10 & -11 & 10\end{array}$

100.232506305 .4760 solid $1.18493102 .4241110 \quad 1.1849310 \quad 17.8296$ 
$\begin{array}{lll}10 & -11 \quad 10\end{array}$

150.233898309 .3770 solid $1.8898410 \quad 3.860410 \quad 1.8898410 \quad 18.6554$ $\begin{array}{lll}10 & -11 & 10\end{array}$

200.23529317 .2830 solid $2.6237110 \quad 5.3938510 \quad 2.6237110 \quad 20.4742$ $\begin{array}{lll}10 & -11 & 10\end{array}$

250.236682330 .4940 solid $4.4152710 \quad 7.1424710 \quad 4.4152710 \quad 24.0094$ $10 \quad-11 \quad 10$

300.238074350 .5680 solid $6.7252310 \quad 9.2928310 \quad 6.7252310 \quad 30.8704$ $11 \quad-10 \quad 11$

350.239466382 .0020 solid $1.1928910 \quad 1.2351910 \quad 1.1928910 \quad 46.8267$ $\begin{array}{lll}11 & -10 & 11\end{array}$

400.240858434 .6920 solid $1.8403710 \quad 1.8082110 \quad 1.8403710 \quad 100.454$ $11 \quad-10 \quad 11$

450.24225514 .750 solid $2.9902410 \quad 3.5597210 \quad 2.9902410 \quad 375.374$ $\begin{array}{lll}11 & -9 & 11\end{array}$

500.243642634 .940 solid $4.6145610 \quad 1.7135710 \quad 4.6145610 \cdot 3841.67$ $\begin{array}{llll}11 & -8 & 11\end{array}$

550.245034804 .5170 solid $6.8141210 \quad 4.8698510 \quad 6.8141110 \quad 176684$. $\begin{array}{llll}11 & -6 & 11 & 6\end{array}$

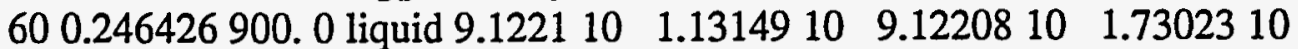
$\begin{array}{lll}11 & -6 & 11\end{array}$

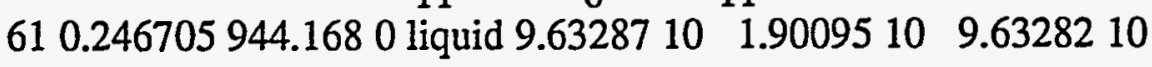

$$
\begin{gathered}
6 \\
4.9332610
\end{gathered}
$$

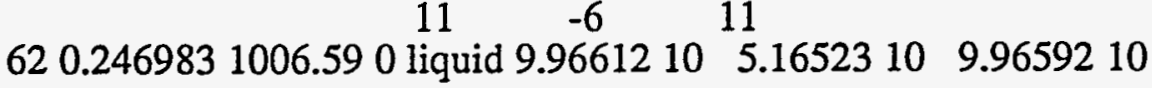

\subsection{0}

630.2472621056 .010 liquid $1.0424510^{12} 0.00001495951 .0423810$

\subsection{0}

$12 \quad 12 \quad 8$

640.247541096 .330 liquid $1.0714910 \quad 0.00003806191 .0713510 \quad 1.4811510$ $12 \quad 12 \quad 8$

650.2478181146 .350 liquid $1.1068310 \quad 0.0001014291 .1064210 \quad 4.0625410$ $12 \quad 12 \quad 9$

660.2480971200 .560 liquid $1.1225510 \quad 0.00027651 .1214310 \quad 1.1223410$

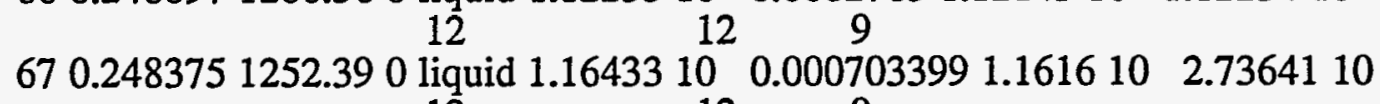
$12 \quad 12 \quad 9$

680.2486541307 .370 liquid $1.1783310 \quad 0.001709921 .1718810 \quad 6.4498910$ $12 \quad 12 \quad 10$

690.2489321363 .590 liquid $1.1995210 \quad 0.003912781 .1854110 \quad 1.4107710$ $12 \quad 12 \quad 10$

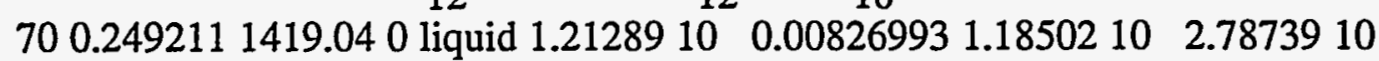
$12 \quad 12 \quad 10$

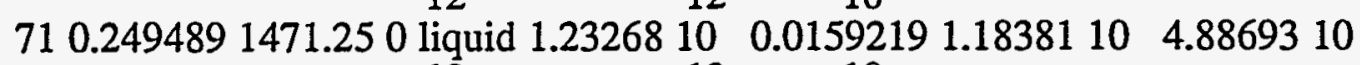

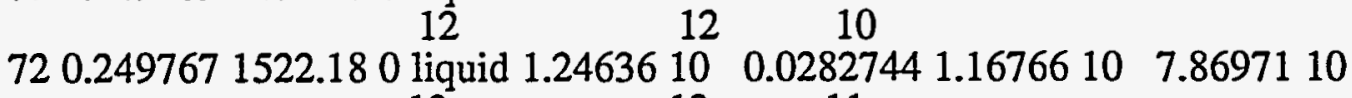
$\begin{array}{lll}12 & 12 & 11\end{array}$ 
730.2500461570 .60 liquid $1.2707110 \quad 0.04658461 .1544310 \quad 1.1627910$ $12 \quad 12 \quad 11$

$\begin{array}{llll}740.2503241617 .440 \text { liquid } 1.2955610 & 0.07194831 .1351210 & 1.6043310\end{array}$ 750.2506031662 .740 liquid 1.3075810 $12 \quad 12$ 760.2508811705 .360 liquid 1.3236810 $770.2511591746 .12 \quad 12$ 770.2511591746 .470 liquid 1.3408810 12 11 780.2514381786 .750 liquid 1.3315110 12 11

790.2517161824 .560 liquid $1.3139910 \quad 0.3055669 .550310 \quad 3.589610$ $12 \quad 11 \quad 11$

800.2519951859 .80 liquid $1.284310 \quad 0.3664269 .1173310 \quad 3.7257110$ 1211 810.2522731892 .040 liquid 1.2414310 820.2525511920 .8801211 820.2525511920 .880 liquid 1.1940910 $\begin{array}{llllllll}83 & 0.25283 & 1946.610 \text { liquid } 1.1229410 & 0.5458157 .748710 & 3.48072 & 10\end{array}$ 840.2531081967 .760 liquid 1.0543710 11 850.2533871984 .760 liquid 9.7511510 860.2536651997 .060 liquid 9.0315310 $1 \overline{1} 11$ 870.2539442005 .730 liquid 8.3023810 $11 \quad 11$ 880.2542222011 .220 liquid 7.5669310 $11 \quad 11$

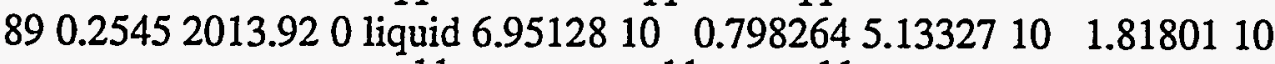
900.2547792015 .020 liquid 6.2578510 11 11 910.2550572013 .980 liquid 5.7397410 $920255336201213011 \quad 11$ 920.2553362012 .130 liquid 5.1700910 930.2556142008 .950 liquid 4.7038811 $11 \quad 11$ 940.2558922005 .060 liquid 4.2984910 950.2561712000 .75011 11 11 950.2561712000 .750 liquid 3.8908410 960.2564491995 .810 liquid 3.5432610 11 11 970.2567281990 .550 liquid $3.22610 \quad 0.9330712 .6536910 \quad 5.7230710$

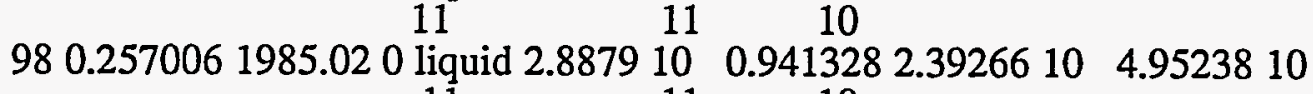

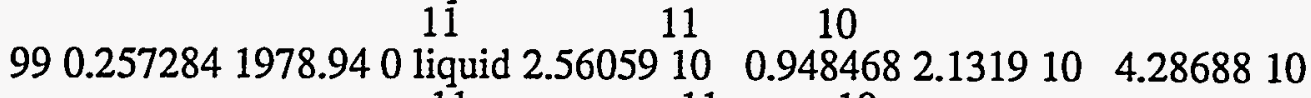
$\begin{array}{lll}11 & 11 & 10\end{array}$ 
1000.2575631972 .260 liquid $2.3324810 \quad 0.9546451 .9612610 \quad 3.7121110$ $11 \quad 11$

1010.2578411965 .650 liquid 2.1888310 1020.258121959 .640 liquid 1.8964210 1030.2583981952 .98011 11 11 1030.2583981952 .980 liquid 1.785210 1040.2586771946 .970 liquid 1.5732810 $11 \quad 11$ 1050.2589551940 .750 liquid 1.3718810 $11 \quad 11$ 1060.2592331934 .30 liquid 1.2707510 $11 \quad 11$ 1070.2595121928 .330 liquid 1.194310 $11 \quad 11$ 1080.259791922 .950 liquid 1.1399810 $10 \quad 10$ 1090.2600691918 .230 liquid 9.3710810 $10 \quad 10$ 1100.2603471912 .940 liquid 8.5434710 $10 \quad 10$ 1110.2606251907 .960 liquid 8.0548510 $10 \quad 10$ 1120.2609041903 .480 liquid 7.1990910 $10 \quad 10$ 1130.2611821899 .160 liquid 7.194710 1140.2614611895 .590 liquid 6.1489410 1010 1150.2617391891 .90 liquid 5.2087810 $10 \quad 10$

1160.2620181888 .120 liquid 5.3240510 $10 \quad 10$

1170.2622961885 .040 liquid 4.7181710 $10 \quad 10$

1180.2625741882 .040 liquid 4.4338210 $10 \quad 10$

1190.2628531879 .320 liquid 3.5237710 $10 \quad 10$

1200.2631311876 .370 liquid 3.6823710 $10 \quad 10$

1210.263411873 .980 liquid 2.6492710 $10 \quad 10$ 1220.2636881871 .20 liquid 3.0123610 $10 \quad 10$ 1230.2639661869 .080 liquid 2.8545710 $10 \quad 10$

1240.2642451867 .180 liquid 2.1857210 1250.2645231865 .080 liquid 2.8984410 1260.2648021863 .820 liquid 1.5218610 $10 \quad 10$

10

$0.9599981 .8667710 \quad 3.2205410$ 10

0.9646521 .61614102 .8027710 10

0.9686991 .54125102 .439510 10

0.9722291 .36025102 .1303410 10

$0.9753131 .1856410 \quad 1.8623910$ 10

$0.9780081 .1077510 \quad 1.6299710$ 10

0.9803721 .05123101 .4307110 10

0.9824521 .01401101 .2596910 10

$0.9842878 .2584110 \quad 1.1126710$ 9

$0.9859077 .5608210 \quad 9.8264310$ 9
$0.9873397 .1850710 \quad 8.6977810$ 9

0.988616 .4271107 .7199110 9

$0.9897396 .5083610 \quad 6.8634710$ $0.9907455 .5367110 \quad 6.1223210$ 9 $0.9916434 .6622810 \quad 5.4649410$ 9
$0.9924444 .8358410 \quad 4.882110$ 9

$0.9931624 .2806810 \quad 4.3748510$ 9

0.9938064 .04135103 .9247110 9

$0.9943843 .1710710 \quad 3.5269510$ 9

0.9949043 .36539103 .1697710 9

0.9953722 .36366102 .8560310 9 0.9957932 .75516102 .5720510 9
0.9961732 .6222810
9 2.3229110 9 0.9965171 .97566102 .1006710

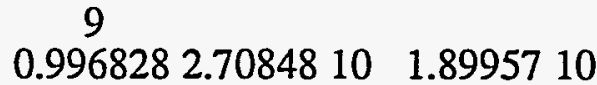
9 $0.997111 .3495210 \quad 1.7233510$ 9 
1270.265081861 .760 liquid $2.3784210 \quad 0.9973652 .2224110 \quad 1.5601210$ $10 \quad 10$

1280.2653581860 .610 liquid 1.4743110 10 10

1290.2656371858 .980 liquid 1.7054410 10 10 1300.2659151857 .740 liquid 1.8133410 10 9

1310.2661941856 .780 liquid 1.0994710 9 $0.9975971 .3325810 \quad 1.417310$

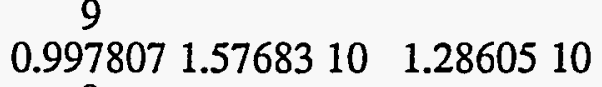
$\begin{array}{ccc}9 & & \\ 0.997998 & 1.6964410 & 1.1689810\end{array}$ 9 0.9981729 .93083101 .063910 $10 \quad 10 \quad 8$

1320.2664721855 .430 liquid $1.5748510 \quad 0.998331 .47811109 .6736510$ $10 \quad 10$

1330.2667511854 .620 liquid 1.4366310 $10 \quad 10$

1340.2670291853 .840 liquid 1.2923910 $10 \quad 10$

1350.2673071853 .080 liquid $1.1220410 \quad 0.9987241 .0487810 \quad 7.3260710$ 9 9 8

1360.2675861852 .30 liquid 5.27007100 .9988344 .60195106 .6811810 $10 \quad 10$

1370.2678641851 .180 liquid 1.4209510 $10 \quad 10$

1380.2681431850 .860 liquid 1.0609910 $10 \quad 10$

1390.2684211850 .350 liquid 1.1765310 $10 \quad 10$

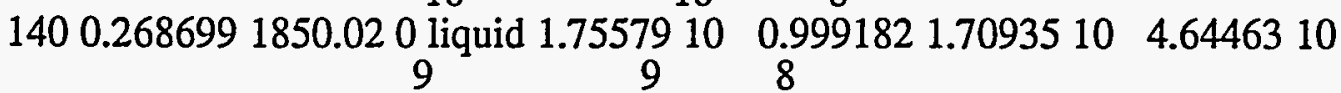

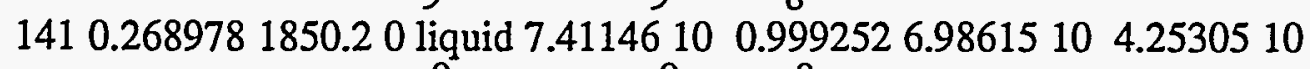

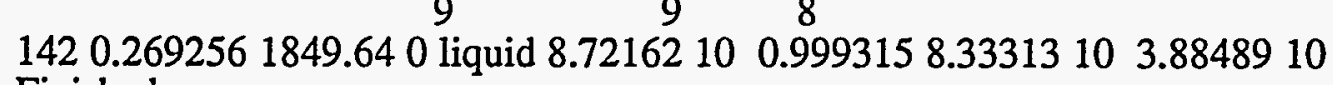
Finished

Tcoefsol $=2.25 * 10^{\wedge}-5$;

Tcoefliq $=1.17 * 10^{\wedge}-4$

(* TA - average temperature *)

ta[ts]: = Sum[Part[xx1[node,ts],2], \{node, $1, \mathrm{~m}\}] / \mathrm{m}$;

$(*$ tr - Temperature time rate of change $*$ )

$\operatorname{tr}[$ node_ts_]:=Part[xx1[node,ts]- $\mathrm{xx} 1$ [node,ts-1],2]/Part[xx1[node,ts]-xx1[node,ts-1],1];

(* tra - average rate of change of temp for the plate *)

tra[ts] $:=S u m[\operatorname{tr}[$ node, $t s],\{$ node, $1, \mathrm{~m}\}] / \mathrm{m}$;

(* expth - expansion thermal *)

(* texprate - thermal expansion rate for the plate *)

expth[node_ts_]: =Tcoefsol $*$ tr[node,ts] /; Part[xx1[node,ts],2]<Tm;

expth[node_ts_]:=Tcoefliq*tr[node,ts] /; Part[xx1[node,ts],2] $>\operatorname{Tm} \& \& \operatorname{Part}[\mathrm{xx} 1[$ node,ts],2]<Tv;

expth[node_,ts_]:=tr[node,ts] / Part[xx1[node,ts],2]/; Part[xx1[node,ts],2]>Tv;

expth[node_ts] $:=0 / ; \operatorname{Part}[\mathrm{xx} 1[$ node,ts],2] $===\mathrm{Tm}$;

expth[node_ts] $:=0 / ;$ Part[xx1[node,ts],2]==Tv;

texprate[ts_]:=Sum[expth[node,ts],\{node, $1, \mathrm{~m}\}] / \mathrm{m}$;

$(*$ qm - quality of the melt $*)$

$(* \mathrm{mv}$ - quality of the vapor *) 
qm[ts_]:=Sum[Part[xx2[node,ts],2],\{node, $1, \mathrm{~m}\}] / \mathrm{m}$;

$\mathrm{qv}\left[\mathrm{ts} \_\right]:=\operatorname{Sum}[\operatorname{Part}[\mathrm{xx} 3[$ node,ts],2],\{node, $1, \mathrm{~m}\}] / \mathrm{m}$;

vfaln[i_]:=fval $/ ; \mathrm{i}<=\mathrm{n}$;

vfaln $[\mathrm{i}] \mathrm{]}:=1 / ; \mathrm{i}>\mathrm{n}$;

(* Fractional rate of change of volume due to various factors *)

(* ger - Gas Expansion Rate

(* VMR - Volumetric Melting Rate

(* VVR - Volumetric Vaporization Rate

(* VOFR - Volumetric Oxide Formation Rate

(* QMR - Quality Melt Rate

(* QVR - Quality Vaporization Rate

*)

*)

*)

*)

*)

rhosolid $=2700$; rholiquid $=2500$; rhovapor $=1.0$;

DencRatLV $=\left(1 /\right.$ rhovapor $^{\wedge}(0.3)-1 /$ rholiquid $\left.^{\wedge}(0.3)\right) /\left(1 /\right.$ rholiquid $\left.^{\wedge}(0.3)\right)$;

DencRatSL $=\left(1 /\right.$ rholiquid^ $(0.3)-1 /$ rhosolid^$\left.^{\wedge}(0.3)\right) /(1 /$ rhosolid^ $(0.3))$;

qmr[node_ts_]:=Part[xx2[node,ts]-xx2[node,ts-1],2]/Part[xx2[node,ts]-xx2[node,ts-1],1];

qvr[node_ts_]:=Part[xx3[node,ts]-xx3[node,ts-1],2]/Part[xx3[node,ts]-xx3[node,ts-1],1];

$\operatorname{vmr}\left[t_{s}\right]$ : =Sum[DencRatSL*gmr[node, $\left.t s\right] *$ vfaln[node],\{node, $\left.\left.1, \mathrm{~m}\right\}\right] / \mathrm{m}$;

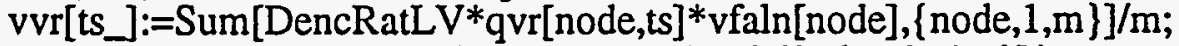

ger[ts_]:=Sum[ tr[node,ts]/ Part[xx1[node,ts],2], \{node, $1, \mathrm{n}\}] / \mathrm{m}$;

$\mathrm{ff}=0.01$;

TotalExpansionRate[ts $]:=(1-\mathrm{ff}) *(\mathrm{vmr}[\mathrm{ts}]+\mathrm{vvr}[\mathrm{ts}]+$ texprate$[\mathrm{ts}])+\mathrm{ff} * \mathrm{ger}[\mathrm{ts}]$

IntegralTotExp[ts_]:=Sum[TotalExpansionRate[tt]*dt,\{tt,2,ts\}]

ListPlot[Table [\{Part[xx1[1,ts],1],TotalExpansionRate[ts]\},\{ts,2,nt $\}]$,

PlotJoined $\rightarrow$ True,

PlotRange- $>$ All,

AxesLabel->\{"time (s)","Fractional Exp rate (1/s)" $\}]$

ter $=1$;

(* ter total expansion *)

Do[ter*=(1+TotalExpansionRate[tt]*dt);

qwq $[t t]=\{\operatorname{Part}[\mathrm{xx} 1[1, \mathrm{tt}], 1]$, ter -1$\}$

$,\{\mathrm{tt}, 2, \mathrm{nt}\}]$

ListPlot[Table[qwq[tt],\{tt,2,nt\}],

PlotJoined $\rightarrow$ True,

PlotRange->All,

AxesLabel $>\{$ "time (s)","Expanded fraction" $\}]$

Do[eff[ts] $=\{$ Part [xx1[1,ts],1],ta[ts],TotalExpansionRate[ts],Part[qwq[ts],2] $\},\{$ ts,2,nt $\}]$;

ListPlot[Table[\{Part[xx1[1,ts],1],ta[ts]\},\{ts,2,nt $\}]$,

PlotJoined $\rightarrow$ True,

PlotRange- $>$ All,

AxesLabel->\{"time (s)","average temp (K)"\}]

-Graphics-

-Graphics- 
-Graphics-

$\operatorname{bsb1}[\mathrm{i}]:=(\operatorname{Sum}[\operatorname{Part}[\mathrm{xx} 4[\mathrm{j}, \mathrm{i}], 2],\{\mathrm{j}, 1, \mathrm{n}\}]) / \mathrm{n}$;

ListPlot[Table[\{Part[xx4[1,i],1],bsb1[i] $\},\{\mathrm{i}, 1, \mathrm{nt}\}]$,

PlotJoined $\rightarrow$ True,PlotRange- $>$ All,

AxesLabel->\{ "time (s)"," fraction of reacted fuel" $\}$ ];

ListPlot[Table[\{Part[xx1[1,i],1],Part[xx1[1,i],2] $\left.\}^{\prime},\{\mathrm{i}, 1, \mathrm{nt}\}\right]$,

PlotJoined $\rightarrow$ True,

PlotRange- $>$ All,

AxesLabel-> "time (s)"," temp (K)" \}]

ListPlot[Table[\{Part[xx1[m,i],1],Part[xx1[m,i],2]\},\{i,1,nt $\}]$,

PlotJoined $\rightarrow$ True,

PlotRange- $>$ All,

AxesLabel-> "time (s)"," temp (K)" \}]

szs1 $=$ ListPlot $[$ Table $[\{\operatorname{Part}[\mathrm{xx5}[1, \mathrm{i}], 1], \operatorname{Part}[\mathrm{xx} 5[1, \mathrm{i}], 2]\},\{\mathrm{i}, 1, \mathrm{nt}\}]$,

PlotJoined $\rightarrow$ True,PlotRange- $>$ All,

AxesLabel-> "time (s)"," Q fission (W/m^3)" $\}$;

szs2=ListPlot[Table[\{Part[xx6[1,i],1],Part[xx6[1,i],2]\},\{i,1,nt $\}]$,

PlotJoined $->$ True,PlotRange- $>$ All,

AxesLabel->\{"time (s)"," Q chemical (W/m^3)" \}];

szs3=ListPlot[Table[ $\{\operatorname{Part}[\mathrm{xx} 7[1, \mathrm{i}], 1], \operatorname{Part}[\mathrm{xx} 7[1, \mathrm{i}], 2]\},\{\mathrm{i}, 1, \mathrm{nt}\}]$,

PlotJoined $\rightarrow$ True,PlotRange- $>$ All,

AxesLabel-> "time (s)"," Q total (W/m^3)" $\}$;

Show[szs1,szs2,szs3]

-Graphics-

-Graphics-

-Graphics- 
(*

THIS IS A REVISED DISPERSION MODEL THAT USES THE

TIME ENERGY DATA FROM THE EXPERIMENTS AND TEMPERATURE

DEPENDANT CHEMICAL REACTION RATES FUEL- ALUMNUM

This copy has chemical reaction rates included in the

model

LAST UPDATED 4-19-95

*)

Renormalized pulse width was used to a narrower band width.

Print["Date last updated =",Date[];

Date last updated $=\{1995,5,2,10,6,51\}$

$\mathrm{l}=0.000635 ; \mathrm{m}=10 ; \mathrm{dx}=1 / \mathrm{m} ; \mathrm{n}=\mathrm{R}$ ound $\left[\mathrm{m}^{*} .4\right] ;$ time $=0 ; \operatorname{Tinf}=300$;

volmeat $=2 * \mathrm{dx}^{*} \mathrm{n} *\left(25 * 10^{\wedge}-3\right) *\left(70^{*} 10^{\wedge}-3\right)$;

$\mathrm{Do}\left[\mathrm{xx}[\mathrm{i}]=\mathrm{i}^{*} \mathrm{dx}-\mathrm{dx} / 2,\{\mathrm{i}, 1, \mathrm{~m}\}\right] ; \mathrm{Tm}=900 . ; \mathrm{Tv}=2700$;

$\operatorname{Do}[\mathrm{To}[\mathrm{i}]=300 ; \mathrm{Tc}[\mathrm{i}]=300 ; \mathrm{xm}[\mathrm{i}]=0 ; \mathrm{xv}[\mathrm{i}]=0,\{\mathrm{i}, 1, \mathrm{~m}\}]$;

$\mathrm{k}[\mathrm{i}] \mathrm{]}:=39.91 / ; \mathrm{i}<=\mathrm{n} ; \quad\left({ }^{*}\right.$ assign $\mathrm{k}$ to the meat $\left.*\right)$

$\mathrm{k}[\mathrm{i}]:=\mathrm{kcl}[\mathrm{To}[\mathrm{i}]] /$ i $>\mathrm{n} ; \quad$ (* assign $\mathrm{k}$ to the clad *)

rho[i_]: $=6550.0 / ;$ i $<=\mathrm{n} ;\left({ }^{*}\right.$ assign meat density $\left.*\right)$

rho[i] $]:=2700.0 / ; \mathrm{i}>\mathrm{n} ;\left(^{*}\right.$ assign clad density $\left.{ }^{*}\right)$

$\operatorname{cp}[\mathrm{i}] \mathrm{i}=\operatorname{cpcl}[\mathrm{To}[\mathrm{i}]] / ; \mathrm{i}>\mathrm{n} ; \quad(*$ assign clad cpecific heat $*)$

$\operatorname{cp}[i]]:=\operatorname{cpf}[\mathrm{To}[\mathrm{i}]] / ; \mathrm{i}<=\mathrm{n} ; \quad\left(*\right.$ assign meat cpecific heat $\left.{ }^{*}\right)$

htc $=$ Interpolation $[\{\{150,13232\},\{350,13232\},\{410,14770\},\{726,12542\}$,

$\{776,11561\},\{1256,9924\},\{1458,1750\},\{1526,1729\},\{1556,800\}$,

$\{5000,800\}\}$,InterpolationOrder $->1]$;

$\mathrm{kcl}=$ Interpolation $[\{\{100,161\},\{400,177\},\{500,186\},\{600,193\}$,

$\{750,193\},\{850,193\},\{900,193\},\{930,193\}$,

$\{1200,84\},\{1300,84\},\{1500,84\},\{2000,84\},\{5000,84\}\}$,

InterpolationOrder $\rightarrow 1$; ;

cpcl=Interpolation $[\{\{100,878\},\{300,878\},\{366,942\},\{422,963\}$, $\{588,1034\},\{700,1067\},\{811,995\},\{1000,995\},\{2000,995\}$,

$\{5000,995\}\}$,InterpolationOrder- $>1]$;

cpf $=$ Interpolation $[\{\{100,351\},\{300,351\},\{933,463\},\{1933,546\}$, $\{2500,546\},\{3500,546\},\{5000,546\}\}$, InterpolationOrder- $>1]$;

hsf[i] $:=398000 * \mathrm{fmal} / ; \mathrm{i}<=\mathrm{n}$;

hfg[i] $]:=10800000 * \mathrm{fmal} / ; \mathrm{i}<=\mathrm{n}$;

hsf [i] $]:=398000 \quad l ; \mathrm{i}>\mathrm{n}$;

$\mathrm{hfg}[\mathrm{i}]:=10800000 \quad / ; \mathrm{i}>\mathrm{n}$;

151=ReadList["508.55",Number,RecordLists->True];

shape=Interpolation[151,InterpolationOrder $->1]$;

num=Part[Part[Position[151,Last[151]],1],1];

TimeBeg=Part[151[[1]],1]; TimeEnd=Part[151[[num]],1];

$\mathrm{cl}=\operatorname{Sum}[0.5 *$ (shape[Part[151[[i]],1]]+shape[Part[151[[i+1]],1]])*

(Part[151[[i+1]],1]-Part[151[[i]],1]), \{i,200,500\}];

qs[qtot_time_]:=qtot*shape[time]/(volmeat*c1); 
qtot=12218;

(* Functions : nrt - new reacted fraction

orf - old reacted fraction *)

$\operatorname{Tm} 1=863 ; \operatorname{Tm} 2=1970 ; \operatorname{Td}\left[\mathrm{i}_{1}\right]:=(\operatorname{To}[\mathrm{i}]-\operatorname{Tm} 1) /(\operatorname{Tm} 2-\operatorname{Tm} 1)$;

lamda[i_]:=(4*10^-4) $\mathrm{E}^{\wedge}\left(14.73^{*} \mathrm{Tanh}\left[1.8^{*} \mathrm{Td}[\mathrm{i}]\right]\right) ;$

$\mathrm{z} 1\left[\mathrm{i}_{-}, \mathrm{dt}\right] \mathrm{f}:=\mathrm{NDS}$ olve[ $[$ RF' $[\mathrm{t}]==\mathrm{lamda}[\mathrm{i}]-\mathrm{lamda}[\mathrm{i}] * \mathrm{RF}[\mathrm{t}]$,

$\mathrm{RF}[0]==\operatorname{orf}[\mathrm{i}]\}, \mathrm{RF},\{\mathrm{t}, 0, \mathrm{dt}\}$, AccuracyGoal- $>15]$;

nrf[i_dt_]:=Part[RF[dt]/.z1[i,dt],1]

frr[i] $]:=\operatorname{lamda}[\mathrm{i}]$-lamda[i] ${ }^{*}$ orf[i];

UpdateRF[dt_]:=Do[orf $[\mathrm{i}]=\mathrm{nrf}[\mathrm{i}, \mathrm{dt}],\{\mathrm{i}, 1, \mathrm{n}\}]$

qchem[i] $:=w w^{*}$ frr $[\mathrm{i}]$;

$\mathrm{q}[\mathrm{i}$, time_qtot $]:=\mathrm{qs}[\mathrm{qtot}, \mathrm{time}]+\mathrm{qchem}[\mathrm{i}] / \mathrm{i}<=\mathrm{n} ;(*$ assign heat generation in the meat *)

$\mathrm{q}[\mathrm{i}$, time_qtot $]:=0 \mathrm{l} ; \mathrm{i}>\mathrm{n} ; \quad$ (* assign heat generation in the clad *)

$\mathrm{bb}[\mathrm{i}] \mathrm{i}=\mathrm{htc}[\mathrm{To}[\mathrm{m}]] / \mathrm{dx} / ; \mathrm{i}==\mathrm{m}$;

$b b[i]:=0 / ; i !=m ; \quad(*$ value for the heat transfer out of the plate *)

$\mathrm{k} 1[\mathrm{i}] \mathrm{]}:=(2 * \mathrm{k}[\mathrm{i}-1] * \mathrm{k}[\mathrm{i}] /(\mathrm{k}[\mathrm{i}-1]+\mathrm{k}[\mathrm{i}])) / \mathrm{dx} \mathrm{x}^{\wedge} / ; \mathrm{i} !=1$

$\mathrm{k} 1[\mathrm{i}] \mathrm{]}:=0 / ; \mathrm{i}==1$

$\mathrm{k} 2[\mathrm{i}] \mathrm{]}:=\mathrm{k} 1[\mathrm{i}]+\mathrm{k} 3[\mathrm{i}]$;

$\mathrm{k} 3[\mathrm{i}] \mathrm{]}:=(2 * \mathrm{k}[\mathrm{i}+1] * \mathrm{k}[\mathrm{i}] /(\mathrm{k}[\mathrm{i}+1]+\mathrm{k}[\mathrm{i}])) / \mathrm{dx} \mathrm{x}^{\wedge} / ; \mathrm{i} !=\mathrm{m}$

$\mathrm{k} 3\left[\mathrm{i}_{-}\right]:=0 / ; \mathrm{i}==\mathrm{m}$;

phase[i $]:=$ solid /; Tc[i] $<\mathrm{Tm}$;

phase[i]:= liquid /; Tc[i] < Tv \&\& Tc[i] > $=\operatorname{Tm} \& \&$ xm[i] $>=0.85$;

phase[i] $:=$ vapor $/ ; \quad \mathrm{Tc}[\mathrm{i}]>=\mathrm{Tv} \& \& \mathrm{xv}[\mathrm{i}]>1$;

phase $[i]:=$ melting $/ ; \quad \operatorname{Tc}[i]>=\operatorname{Tm} \& \&$ xm $[i]<0.85$;

phase[i] := vaporizing $/ ; \quad T c[i]>=T v \& \& \mathrm{xv}[\mathrm{i}]<1 \& \& \mathrm{xv}[\mathrm{i}]>-0.01$;

$\operatorname{Tn}[\mathrm{i}]:=\mathrm{Tc}[\mathrm{i}] /$; phase $[\mathrm{i}]=!=$ melting \& \& phase[i] =!= vaporizing;

$\operatorname{Tn}[i]:=\operatorname{Tm} / ;$ phase $[i]==$ melting ;

$\operatorname{Tn}[i]$ : $=\operatorname{Tv} / ;$ phase[i] === vaporizing ;

$\mathrm{vv}\left[\mathrm{i}, \mathrm{j}_{-}, \mathrm{dt}\right]:=\mathrm{k} 1[\mathrm{i}] / ; \mathrm{i}-1==\mathrm{j} \& \&$ phase[j] $=!=$ melting \&\& phase[j] =!=vaporizing

$v v\left[i_{-}, j_{,}, \mathrm{dt}\right]:=-k 2[\mathrm{i}]-\mathrm{rho}[\mathrm{i}] * \mathrm{cp}[\mathrm{i}] / \mathrm{dt}-\mathrm{bb}[\mathrm{i}] / ; \mathrm{i}==\mathrm{j} \& \&$ phase[j] $=!=$ melting \&\&

phase $[\mathrm{j}]=!=$ vaporizing

$\mathrm{vv}\left[\mathrm{i}_{-} \mathrm{j}_{-}, \mathrm{dt}\right]:=\mathrm{k} 3[\mathrm{i}] / ; \mathrm{i}+1==\mathrm{j} \& \&$ phase $[\mathrm{j}]=!=$ melting \&\& phase $[\mathrm{j}]=!=$ vaporizing

$v v\left[i_{-} j_{-}, d t\right]:=0 / ; i !=j \& \& i-1 !=j \& \& i+1 !=j$;

$\left(*-\cdots j,{ }^{*}\right.$

$\mathrm{vv}\left[\mathrm{i}_{-} \mathrm{j}_{-}, \mathrm{dt}\right]:=1 / ; \mathrm{i}==\mathrm{j} \quad \& \&$ phase[j] $===$ melting;

$v v\left[i_{1}, j_{-}, d t\right]:=0 / ; i-1==j \& \&$ phase $[j]===$ melting;

$v v[i, j, d t]:=0 / ; i+1==j \& \&$ phase $[j]===$ melting;

$\mathrm{vv}[\mathrm{i}, \mathrm{j}, \mathrm{dt}]:=1 / ; \mathrm{i}==\mathrm{j} \quad \& \&$ phase $[\mathrm{j}]===$ =vaporizing;

$v v\left[i, j_{-}, \mathrm{dt}\right]:=0 / ; \mathrm{i}-1==\mathrm{j} \& \&$ phase $[\mathrm{j}]===$ vaporizing;

$v v\left[i_{-}, j_{-}, d t\right]:=0 / ; i+1==j \& \&$ phase $[j]==$ =vaporizing;

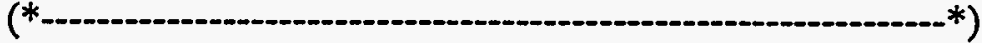

$\mathrm{f}\left[\mathrm{i}, \mathrm{dt}\right.$, time_qtot_]:= -q[i,time,qtot]-To[i]*rho[i]*cp[i]/dt - bb[i] $*^{\prime}$ Tinf $/ ;$ phase[i] $=!=$ melting \&\& phase $[\bar{i}]=!=$ =vaporizing;

$\mathrm{f}[\mathrm{i}, \mathrm{dt}$, time_qtot] $]:=\mathrm{Tm} /$; phase[i]===melting;

$\mathrm{f}\left[\mathrm{i}_{-}, \mathrm{dt}\right.$, time_qtot] $:=\mathrm{Tv} / ;$ phase[i]===vaporizing;

$\mathrm{TB}=0.22 ; \mathrm{TE}=0.26$; 
Plot $[$ shape $[t],\{t, T B, T E\}$, PlotRange- $>\{0,100\}]$

-Graphics-

RhoMeat=6500.;RhoAl=2700.;RhoU=12200.;

fval $=0.5$;

fvu=1-fval;

DenRat=(RhoU/RhoAl);

fmal $=0.212$;

fmu=1-fmal;

Echem $=350000.0$

$w w=E c h e m * 5100$;

time $=\mathrm{TB}$;

$\mathrm{Do}[\mathrm{To}[\mathrm{i}]=300 ; \mathrm{Tc}[\mathrm{i}]=300 ; \operatorname{xm}[\mathrm{i}]=0 ; \operatorname{xv}[\mathrm{i}]=0 ; \operatorname{orf}[\mathrm{i}]=0 ;,[\mathrm{i}, 1, \mathrm{~m}\}]$;

$\mathrm{dtt}[\mathrm{i}] \mathrm{i}:=10 * \mathrm{dx}^{*} \mathrm{dx} * \mathrm{rho}[\mathrm{i}] * \mathrm{cp}[\mathrm{i}] /(2 * \mathrm{k}[\mathrm{i}])$;

$\mathrm{dt}=\overline{\mathrm{Min}}[\mathrm{Table}[\mathrm{dtt}[\mathrm{i}],\{\mathrm{i}, 1, \mathrm{~m}\}]]$;

$\mathrm{nt}=$ Floor[(TE-TB)/dt] -1 ;

Print["dt= ",dt," nt= ",nt];

$\mathrm{dt}=0.000278413 \mathrm{nt}=142$

Do[

$s=$ Table[vv[i,j,dt],\{j,m\},\{i,m $\}]$;

sinv=Inverse $[s] ;(*$ invert the matrix *)

$\mathrm{qq}=$ Table[f[i,dt,time,qtot],\{i,m $\}]$;

ans=sinv.qq;

$\operatorname{Do}[\mathrm{Tc}[\mathrm{i}]=\operatorname{ans}[[\mathrm{i}]]$;

If $[$ phase[i] $===$ melting, $x m[i]+=(k 1[i] * T o[i-1]-k 2[i] * T o[i]+k 3[i] * T o[i+1]+q[i$,time,qtot $]-$ $\mathrm{bb}[\mathrm{i}] *(\mathrm{To}[\mathrm{m}]-\mathrm{Tinf})) * \mathrm{dt} /(\mathrm{rho}[\mathrm{i}] * h s f[\mathrm{i}]) ;, 0]$;

If $[$ phase[i] $==$ =vaporizing, $\mathrm{xv}[\mathrm{i}]+=(\mathrm{k} 1[\mathrm{i}] * \mathrm{To}[\mathrm{i}-1]-\mathrm{k} 2[\mathrm{i}] * \mathrm{To}[\mathrm{i}]+\mathrm{k} 3[\mathrm{i}] * \mathrm{To}[\mathrm{i}+1]+\mathrm{q}[\mathrm{i}, \mathrm{time}, \mathrm{qtot}]-$ $\mathrm{bb}[\mathrm{i}] *(\mathrm{To}[\mathrm{m}]-\mathrm{Tinf})) * \mathrm{dt} /(\mathrm{rho}[\mathrm{i}] * \mathrm{hfg}[\mathrm{i}]) ;, 0]$;

$,\{\mathrm{i}, 1, \mathrm{~m}\}]$;

If $[$ Mod[numtimesteps,5] $=0=0 \|$ numtimesteps $>=60$,

Print[numtimesteps," ",time," ",To[1]," ",xv[1]," ",phase[1]," ", q[1,time,qtot]," ",orf[1]," ",qs[qtot,time]," ",qchem[1]]];

$\operatorname{Do}[\operatorname{To}[\mathrm{i}]=\operatorname{Tn}[\mathrm{i}]$;

$x \times 1[i$, numtimesteps $]=\{$ time, $T o[i]\}$;

$\mathrm{xx} 2[\mathrm{i}$, numtimesteps] $=\{$ time, $\mathrm{xm}[\mathrm{i}]\}$;

$\mathrm{xx3}[\mathrm{i}$, numtimesteps] $=\{$ time, $\mathrm{xv}[\mathrm{i}]\}$;

$\mathrm{xx} 4[$ i, numtimesteps] $=\{$ time, $\operatorname{orf}[\mathrm{i}]\}$;

$\mathrm{xx} 5[\mathrm{i}$, numtimesteps] $=\{$ time, $\mathrm{q}[\mathrm{i}, \mathrm{time}, \mathrm{qtot}]\}$;

$\mathrm{xx} 6[$ i,numtimesteps $]=\{$ time,qchem $[\mathrm{i}]\}$;

xx7[i,numtimesteps] $=\{$ time,qs[qtot,time] $\}$;

$,\{\mathrm{i}, 1, \mathrm{~m}\}]$

To[i] $=\operatorname{Tn}[\mathrm{i}]$

time $+=d t$ 
UpdateRF[dt];

, \{numtimesteps, $1, \mathrm{nt}\}]$;

Print[Finished];

$$
\begin{array}{llll}
9 & -11 & 9
\end{array}
$$

50.221114301 .8190 solid $4.2907710 \quad 1.0610410 \quad 4.2907710 \quad 17.0951$ $\begin{array}{llll}9 & -11 & 9\end{array}$

100.222506303 .9130 solid $7.84088102 .4133310 \quad 7.840881017 .5112$

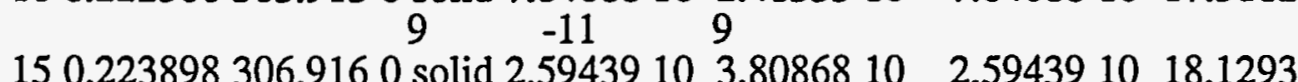
$\begin{array}{llllllll}15 & 0.223898306 .916 & \text { solid } 2.59439 & 10 & 3.8086810 & 2.59439 & 10 & 18.1293\end{array}$ 200.22529309 .8870 solid $1.8130910 \quad 5.2409510 \quad 1.8130910 \quad 18.7668$ $\begin{array}{lll}10 & -11 & 10\end{array}$

250.226682315 .3020 solid $2.6724510 \quad 6.7620310 \quad 2.6724510 \quad 19.9992$ $\begin{array}{lll}10 & -11 & 10\end{array}$

300.228074326 .5630 solid 4.02536 $10 \quad 8.4526210 \quad 4.0253610 \quad 22.8866$ $10 \quad-10 \quad 10$

350.229466345 .2040 solid $7.0504410 \quad 1.0492210 \quad 7.0504410 \quad 28.8331$ $\begin{array}{lll}11 & -10 & 11\end{array}$

400.230858375 .8660 solid $1.0844310 \quad 1.3331810 \quad 1.0844310 \quad 43.072$ $\begin{array}{lll}11 & -10 & 11\end{array}$

450.23225428 .0160 solid $1.9245310 \quad 1.8507210 \quad 1.9245310 \quad 90.7794$ $\begin{array}{lll}11 & -10 & 11\end{array}$

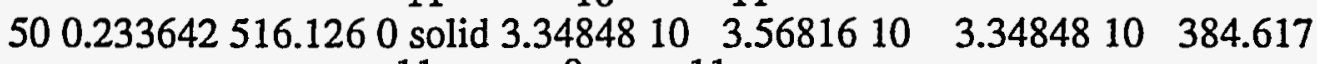
$\begin{array}{lll}11 & -9 & 11\end{array}$

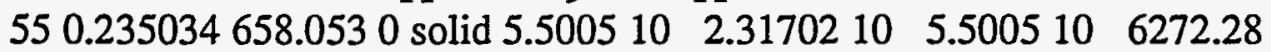

600.236426870 .3140 melting $8.5352710^{11} 1.9824910 \quad 8.5352610 \quad 850699$.

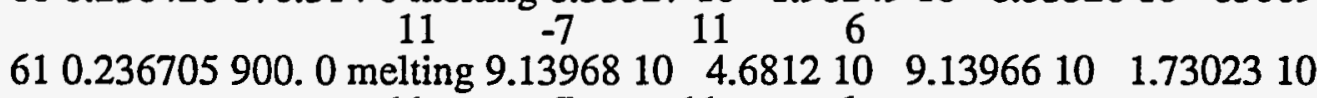
$\begin{array}{llll}11 & -7 & 11 & 6\end{array}$

620.236983900 .0 liquid $9.7374110 \quad 7.3799110 \quad 9.737410 \quad 1.7302310$

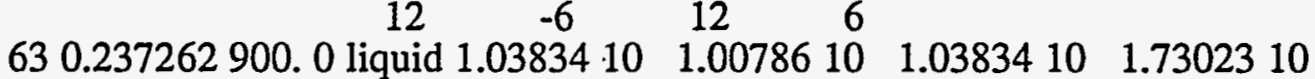

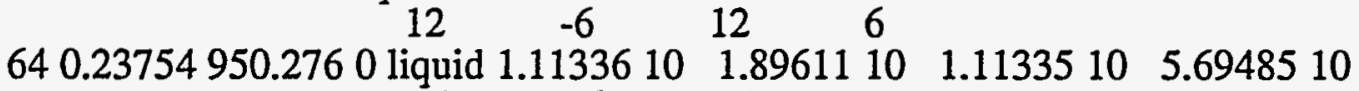
$12 \quad-6 \quad 12$

650.2378181023 .860 liquid $1.1786610 \quad 6.7143410 \quad 1.1786310$

\subsection{0}

$12 \quad 12$

660.2380971083 .060 liquid $1.2439410 \quad 0.00002420571 .2438310$

8
1.1214210

$12 \quad 12$

670.2383751150 .820 liquid $1.2894710 \quad 0.00009333061 .2890310$

\section{$\stackrel{8}{4} .4316710$}

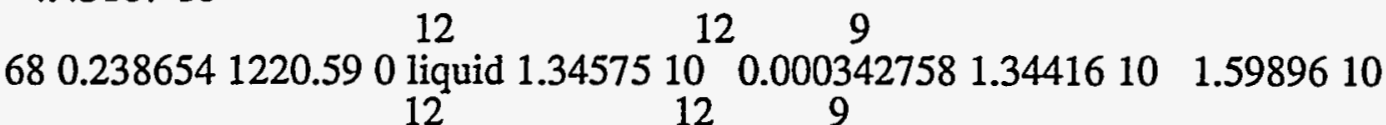


690.2389321288 .80 liquid $1.4026510 \quad 0.001103991 .3977710 \quad 4.8786910$ $12 \quad 12 \quad 10$

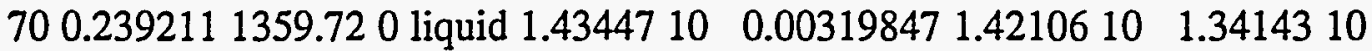
12

$12 \quad 10$

710.2394891431 .990 liquid $1.4777510 \quad 0.00825181 .4454410 \quad 3.2316310$ 12

$12 \quad 10$

720.2397671503 .680 liquid $1.5422810 \quad 0.01876071 .4752610 \quad 6.7017610$

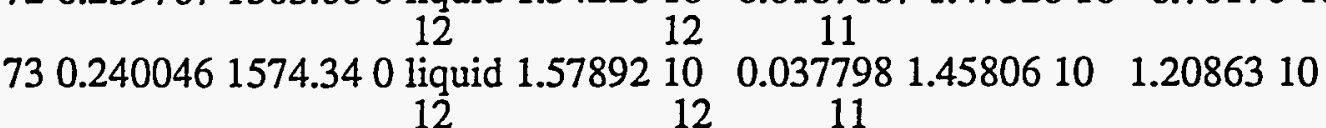
740.2403241643 .040 liquid $1.6624210 \quad 0.06814331 .4709710 \quad 1.9145310$ $12 \quad 12 \quad 11$

750.2406031712 .680 liquid $1.7194910 \quad 0.1121481 .44413102 .7536110$ $12 \quad 12 \quad 11$

760.2408811780 .970 liquid 1.79381100 .1700041 .43523103 .5857610 1212

770.2411591849 .540 liquid 1.8342610 12

780.2414381915 .990 liquid 1.8293910

$790.12 \quad 12$

790.2417161978 .390 liquid 1.7963410

8002419952036.480 liquid 17352510

$12 \quad 12$

810.2422732089 .450 liquid $1.649410 \quad 0.5613591 .1920810 \quad 4.573210$ $12 \quad 12 \quad 11$

820.2425512136 .510 liquid $1.5411710 \quad 0.6318731 .1275310 \quad 4.1363410$ $12 \quad 12 \quad 11$

830.242832176 .390 liquid $1.4297510 \quad 0.6941161 .0665110 \quad 3.6324410$ $12 \quad 12 \quad 11$

840.2431082209 .10 liquid $1.3136210 \quad 0.7477691 .00173103 .1188910$

850.2433872234 .50 liquid $1.1871710 \quad 0.7931749 .2399210 \quad 2.6317610$ $12 \quad 11 \quad 11$

860.2436652252 .040 liquid $1.0886210 \quad 0.8310318 .69608102 .1901110$ $11 \quad 11$

870.2439442264 .10 liquid $9.9019410 \quad 0.8622988 .0953810 \quad 1.8065710$ $11 \quad 11$

880.2442222271 .0 liquid $8.9570710 \quad 0.8879357 .4769110 \quad 1.4801610$ $11 \quad 11 \quad 11$

$890.24452273 .5 \cdot 0$ liquid $8.1182910 \quad 0.9088436 .9114110 \quad 1.2068910$

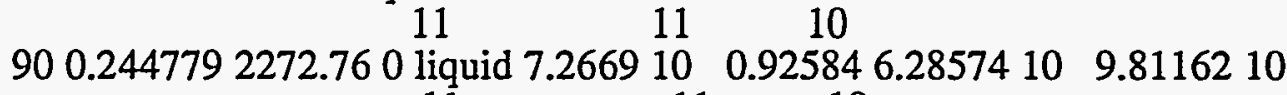
$\begin{array}{lllcllll}91 & 0.2450572268 .89 & 0 \text { liquid } 6.55682 & 11 & 0.939621 & 10.7609610 & 7.95863 & 10\end{array}$ $11 \quad 11$ 920.2453362263 .060 liquid 5.9041710 $11 \quad 11$

930.2456142255 .640 liquid 5.3155910 $11 \quad 11$

940.2458922246 .990 liquid $4.7987810 \quad 0.9671434 .3751110 \quad 4.2366610$ $11 \quad 11 \quad 10$

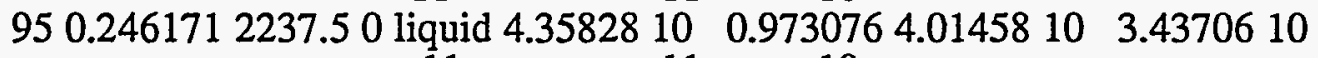
$\begin{array}{lll}11 & 11 & 10\end{array}$ 
960.2464492227 .580 liquid $3.8910310 \quad 0.977893 .61182102 .7921310$

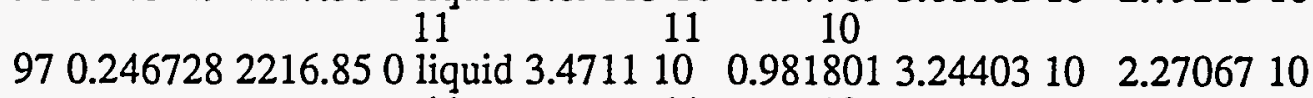
980.2470062205 .530 liquid 3.1335210 11 11 11 990.2472842194 .120 liquid 2.9096410 $11 \quad 11$ 1000.2475632183 .350 liquid 2.5535710 1010.2478412172 .080 liquid 2.2197810 $11 \quad 11$ 1020.248122160 .360 liquid 1.9968310 1030.2483982148 .950 liquid 1.9386510 1040.2486772139 .011 11 11 1040.2486772139 .0 liquid 1.6279710 1050.2489552128 .450 liquid 1.5177710 1060.2492332118 .730 liquid 1.3065610 10702495122108980 liquid 1287511 1070.2495122108 .980 liquid 1.287510 1080.249792100 .570 liquid 1.0977510 1090.2500692092 .070 liquid 9.5203910 $10 \quad 10$ 1100.2503472083 .740 liquid 8.815910 $10 \quad 10$

1110.2506252076 .090 liquid 7.3793510 $10 \quad 10$

1120.2509042068 .460 liquid 6.2783210 $10 \quad 10$

1130.2511822061 .050 liquid 5.4412910

1140.2514612053 .990 liquid 5.0966510 $10 \quad 10$

1150.2517392047 .60 liquid 5.3503510 1160.2520182042 .260 liquid 4.9806710

1170.2522962037 .410 liquid 4.5496710 $10 \quad 10$

1180.2525742032 .940 liquid 4.3805710

1190.2528532028 .990 liquid 3.3422710 $10 \quad 10$ 1200.2531312024 .820 liquid 3.0623810 1210.253412020 .990 liquid 3.0899710 $10 \quad 10$ 1220.2536882017 .690 liquid 2.7218710 $10 \quad 10$

$0.9849822 .948610 \quad 1.8492310$ 10

$0.9875742 .7587410 \quad 1.5090610$ 10

$0.9896932 .4300710 \quad 1.2349910$ 10

$0.9914272 .1185510 \quad 1.0122710$ 9

0.992851 .91372108 .3115510

9

0.9940191 .87022106 .8428110 9

$0.9949841 .571410 \quad 5.6567510$

9

0.9957821 .47094104 .6826710

$0.9964441 .2676710 \quad 3.8893310$ 9

0.9969941 .25513103 .2371110 9

0.9974531 .0707102 .7051210

$0.9978389 .2939210 \quad 2.2646610$ 9

0.9981598 .62589101 .9001210 9

$0.998437 .2194510 \quad 1.5989810$ 9

$0.9986586 .1435110 \quad 1.3480710$ 9

$0.9988515 .3273910 \quad 1.13910$

8
0.9990135 .0001910 9.6464410 8

$0.9991525 .2684110 \quad 8.1934110$ 8

$0.9992694 .9108410 \quad 6.9831410$ 8

$0.999374 .4900210 \quad 5.965110$ 8

0.9994564 .32951105 .1054610 8

$0.9995293 .2984810 \quad 4.3790210$ 8

0.9995923 .0248103 .7586210 8

0.9996473 .05765103 .2318110 8

0.9996942 .69402102 .7845110 8 
1230.2539662014 .570 liquid $2.4028810 \quad 0.9997342 .37886102 .4021710$ $10 \quad 10 \quad 8$

1240.2542452011 .620 liquid $2.365610 \quad 0.9997692 .34485102 .0748810$ $10 \quad 10 \quad 8$

1250.2545232009 .040 liquid $2.0858110 \quad 0.9997992 .0678610 \quad 1.7949210$ $10 \quad 10$

1260.2548022006 .60 liquid $2.0363310 \quad 0.9998252 .0207910 \quad 1.5543210$ $10 \quad 10$

1270.255082004 .450 liquid 1.6502110 $10 \quad 10$

1280.2553582002 .30 liquid 1.0770810

12902556371999.990 liquid 1354410 $10 \quad 10$

1300.2559151998 .150 liquid 1.8453710 $10 \quad 10$

1310.2561941996 .920 liquid 2.1783210 $10 \quad 10$

1320.2564721996 .150 liquid 1.5008110 $10^{\circ}$

1330.2567511995 .030 liquid 1.0495110 $10 \quad 10$

1340.2570291993 .720 liquid 1.2189210

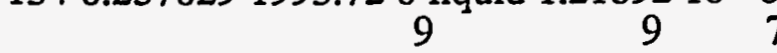

1350.2573071992 .70 liquid $9.6603210 \quad 0.9999489 .61595104 .437110$ $9 \begin{array}{lll}9 & 7\end{array}$

1360.2575861991 .620 liquid 4.06927100 .9999554 .03056103 .8713410 9907

1370.2578641990 .240 liquid 1.67389100 .999961 .64012103 .3768110 9 9 97

$\begin{array}{lllll}138 & 0.2581431988 .810 \text { liquid } 9.8764310 & 0.9999659 .8469710 & 2.9463710\end{array}$ 9 9 7

1390.2584211988 .150 liquid 4.03368100 .999974 .00793102 .5758910 9 9 97

1400.2586991987 .140 liquid 9.6182100 .9999739 .59569102 .2508710 $10 \quad 10$

1410.2589781986 .660 liquid 1.12192100 .9999771 .11995101 .9696110 9

1420.2592561986 .380 liquid 7.7479100 .999987 .73066101 .7244710

Finished

Tcoefsol $=2.25 * 10^{\wedge}-5$;

Tcoefliq $=1.17 * 10^{\wedge}-4$

(* TA - average temperature *)

ta[ts] $:=$ Sum[Part[xx1[node,ts],2], \{node, $1, \mathrm{~m}\}] / \mathrm{m}$;

$(*$ tr - Temperature time rate of change $*$ )

$\operatorname{tr}[$ node_ts]:=Part[xx1[node,ts]-xx1[node,ts-1],2]/Part[xx1[node,ts]-xx1[node,ts-1],1];

(* tra - average rate of change of temp for the plate*)

$\operatorname{tra}[$ ts_]:=Sum[tr[node,ts], $\{$ node, $1, \mathrm{~m}\}] / \mathrm{m}$;

(* expth - expansion thermal *)

(* texprate - thermal expansion rate for the plate *)

expth[node_ts_]:=Tcoefsol*tr[node,ts] /; $\operatorname{Part}[\mathrm{xx} 1[$ node,ts],2]<Tm; 
expth[node_ts_]:=Tcoefliq*tr[node,ts] /; Part[xx1[node,ts],2]>Tm \&\& Part[xx1[node,ts],2]<Tv; expth[node_,ts]:=tr[node,ts]/Part[xx1[node,ts],2]/; Part[xx1[node,ts],2]>Tv;

expth[node_ts]: $=0 / ; \operatorname{Part}[\mathrm{xx} 1[$ node,ts],2]===Tm;

expth[node_ts] $:=0 / ; \operatorname{Part}[\mathrm{xx} 1[$ node,ts],2]===Tv;

texprate[ts]: $=$ Sum $[\operatorname{expth}[$ node,ts], $\{$ node $, 1, \mathrm{~m}\}] / \mathrm{m}$;

(* qm - quality of the melt *)

(* mv - quality of the vapor *)

qm[ts_]:=Sum[Part[xx2[node,ts],2], \{node, $1, \mathrm{~m}\}] / \mathrm{m} ;$

$\mathrm{qv}[\mathrm{ts}]$ ]:=Sum[Part[xx3[node,ts],2], \{node, $1, \mathrm{~m}\}] / \mathrm{m}$;

vfaln[i_]:=fval $/ ; \mathrm{i}<=\mathrm{n}$;

vfaln[i] $[=1 /$; $>$ n ;

(* Fractional rate of change of volume due to various factors *)

(* ger - Gas Expansion Rate

(* VMR - Volumetric Melting Rate

(* VVR - Volumetric Vaporization Rate

(* VOFR - Volumetric Oxide Formation Rate

(* QMR - Quality Melt Rate

(* QVR - Quality Vaporization Rate

*)

*)

$*)$

*)

*)

rhosolid=2700; rholiquid $=2500$; rhovapor $=1.0$;

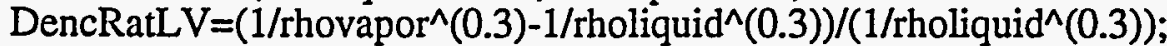

DencRatSL $=\left(1 /\right.$ rholiquid^$^{\wedge}(0.3)-1 /$ rhosolid $\left.^{\wedge}(0.3)\right) /\left(1 /\right.$ rhosolid $\left.^{\wedge}(0.3)\right)$;

qmr[node_ts_]:=Part[xx2[node,ts]-xx2[node,ts-1],2]/Part[xx2[node,ts]-xx2[node,ts-1],1];

qvr[node_ts_]:=Part[xx3[node,ts]-xx3[node,ts-1],2]/Part[xx3[node,ts]-xx3[node,ts-1],1];

vmr[ts_]:=Sum[DencRatSL*qmr[node,ts]*vfaln[node],\{node, $1, \mathrm{~m}\}] / \mathrm{m}$;

$\operatorname{vvr}[\mathrm{ts}]:=$ Sum[DencRatLV*qur[node,ts] ${ }^{*}$ vfaln[node],\{node, $\left.\left.1, \mathrm{~m}\right\}\right] / \mathrm{m}$;

ger[ts]:=Sum[tr[node,ts]/ Part[xx1[node,ts],2] , \{node,1,n\}]/m;

$\mathrm{ff}=0.01$;

TotalExpansionRate[ts] $:=(1-\mathrm{ff}) *(\mathrm{vmr}[\mathrm{ts}]+\mathrm{vvr}[\mathrm{ts}]+\mathrm{texprate}[\mathrm{ts}])+\mathrm{ff} * \mathrm{ger}[\mathrm{ts}]$

IntegralTotExp[ts]:=Sum[TotalExpansionRate[tt]*dt,\{tt,2,ts\}]

ListPlot[Table[\{Part[xx1[1,ts],1],TotalExpansionRate[ts]\},\{ts,2,nt $\}]$,

PlotJoined $\rightarrow$ True,

PlotRange- $>$ All,

AxesLabel-> "time (s)","Fractional Exp rate (1/s)" $\}]$

ter $=1$;

(* ter total expansion *)

Do[ter* $=(1+$ TotalExpansionRate[tt]*dt);

$\mathrm{qwq}[\mathrm{tt}]=\{\operatorname{Part}[\mathrm{xx} 1[1, \mathrm{tt}], 1]$, ter -1$\}$

$,\{t t, 2, n t\}]$

ListPlot[Table[qwa[tt],\{tt,2,nt $\}]$,

PlotJoined $\rightarrow$ True,

PlotRange- $>$ All,

AxesLabel-> ["time (s)","Expanded fraction" $\}]$

$\operatorname{Do}[\operatorname{eff}[\mathrm{ts}]=\{$ Part $[\mathrm{xx} 1[1, \mathrm{ts}], 1], \mathrm{ta}[\mathrm{ts}]$, TotalExpansionRate[ts],Part[qwq[ts],2]\},\{ts,2,nt $\}]$;

ListPlot[Table [\{Part[xx1[1,ts],1],ta[ts]\},\{ts,2,nt $\}]$,

PlotJoined $->$ True,

PlotRange- $>$ All,

AxesLabel->\{ "time (s)","average temp (K)" $\}$ ] 
-Graphics-

-Graphics-

-Graphics-

bsb1[i] $]:=(\operatorname{Sum}[\operatorname{Part}[\mathrm{xx} 4[\mathrm{j}, \mathrm{i}], 2],\{\mathrm{j}, 1, \mathrm{n}\}]) / \mathrm{n}$;

ListPlot[Table[\{Part[xx4[1,i],1],bsb1[i] $\},\{\mathrm{i}, 1, \mathrm{nt}\}]$,

PlotJoined $\rightarrow$ True,PlotRange- $>$ All,

AxesLabel-> "time (s)"," fraction of reacted fuel" \}];

ListPlot[Table[\{Part[xx1[1,i],1],Part[xx1[1,i],2]\},\{i,1,nt $\}]$,

PlotJoined $\rightarrow$ True,

PlotRange- $>$ All,

AxesLabel->\{"time (s)"," temp (K)" $\}]$

ListPlot[Table[\{Part[xx1[m,i],1],Part[xx1[m,i] 2$]\},\{i, 1, n t\}]$,

PlotJoined $\rightarrow$ True,

PlotRange->All,

AxesLabel-> "time (s)"," temp (K)" $\}]$

szs1 $=$ ListPlot[Table[ $\{\operatorname{Part}[\mathrm{xx5}[1, \mathrm{i}], 1], \operatorname{Part}[\mathrm{xx5}[1, \mathrm{i}], 2]\},\{\mathrm{i}, 1, \mathrm{nt}\}]$,

PlotJoined $\rightarrow$ True,PlotRange- $>$ All,

AxesLabel $\rightarrow$ ["time (s)"," Q fission (W/m^3)" $\}$;

szs2=ListPlot[Table[ $\{\operatorname{Part}[\mathrm{xx6}[1, \mathrm{i}], 1], \operatorname{Part}[\mathrm{xx6}[1, \mathrm{i}], 2]\},\{\mathrm{i}, 1, \mathrm{nt}\}]$,

PlotJoined $\rightarrow$ True,PlotRange- $>$ All,

AxesLabel-> "time (s)"," Q chemical (W/m^3)" \}];

szs3=ListPlot[Table $[\{\operatorname{Part}[\mathrm{xx} 7[1, \mathrm{i}], 1], \operatorname{Part}[\mathrm{xx} 7[1, \mathrm{i}], 2]\},\{\mathrm{i}, 1, \mathrm{nt}\}]$,

PlotJoined $\rightarrow$ True,PlotRange- $>$ All,

AxesLabel-> "time (s)"," Q total (W/m^3)" $\}$ ];

Show[szs1,szs2,szs3]

-Graphics-

-Graphics- 
-Graphics-

(*

THIS IS A REVISED DISPERSION MODEL THAT USES THE

TIME ENERGY DATA FROM THE EXPERIMENTS AND TEMPERATURE

DEPENDANT CHEMICAL REACTION RATES FUEL- ALUMINUM

This copy has chemical reaction rates included in the

model

LAST UPDATED 4-19-95

*)

Renormalized pulse width was used to a narrower band width.

Print["Date last updated =",Date[];

Date last updated $=\{1995,4,21,8,39,3\}$

$\mathrm{l}=0.000635 ; \mathrm{m}=10 ; \mathrm{dx}=\mathrm{l} / \mathrm{m} ; \mathrm{n}=\mathrm{Round}[\mathrm{m} * .4] ; \operatorname{time}=0 ; \operatorname{Tinf}=300 ;$

timespan $=35^{*} 10^{\wedge}-3$; volmeat $=2 * \mathrm{dx} * \mathrm{n}^{*}\left(25^{*} 10^{\wedge}-3\right) *\left(70^{*} 10^{\wedge}-3\right)$;

$\mathrm{Do}\left[\mathrm{xx}[\mathrm{i}]=\mathrm{i}^{*} \mathrm{dx}-\mathrm{dx} / 2,\{\mathrm{i}, 1, \mathrm{~m}\}\right] ; \mathrm{qtot}=14200 ; \mathrm{Tm}=900 . ; \mathrm{Tv}=2700$;

Do $[\mathrm{To}[\mathrm{i}]=300 ; \mathrm{Tc}[\mathrm{i}]=300 ; \mathrm{xm}[\mathrm{i}]=0 ; \mathrm{xv}[\mathrm{i}]=0,\{\mathrm{i}, 1, \mathrm{~m}\}]$;

$\mathrm{k}[\mathrm{i}] \mathrm{i}=39.91 / \mathrm{i}<=\mathrm{n} ; \quad$ (* assign $\mathrm{k}$ to the meat $*)$

$\mathrm{k}[\mathrm{i}]:=\mathrm{kcl}[\mathrm{To}[\mathrm{i}]] / ; \mathrm{i}>\mathrm{n} ; \quad(*$ assign $\mathrm{k}$ to the clad $*)$

rho[i] $]:=6550.0 / ; i<=n ;(*$ assign meat density *)

rho[i] $]:=2700.0 / ;$ i $>n$; (* assign clad density *)

$\mathrm{cp}[\mathrm{i}] \mathrm{:}=\operatorname{cpcl}[\mathrm{To}[\mathrm{i}]] / ; \mathrm{i}>\mathrm{n} ; \quad(*$ assign clad cpecific heat $*)$

$\mathrm{cp}[\mathrm{i}]:=\mathrm{cpf}[\mathrm{To}[\mathrm{i}]] / ; \mathrm{i}<=\mathrm{n} ; \quad$ (* assign meat cpecific heat $*$ )

htc $=$ Interpolation $[\{\{150,13232\},\{350,13232\},\{410,14770\},\{726,12542\}$, $\{776,11561\},\{1256,9924\},\{1458,1750\},\{1526,1729\},\{1556,800\}$, $\{5000,800\}\}$,InterpolationOrder $->1]$;

$\mathrm{kcl}=$ Interpolation $[\{\{100,161\},\{400,177\},\{500,186\},\{600,193\}$,

$\{750,193\},\{850,193\},\{900,193\},\{930,193\}$,

$\{1200,84\},\{1300,84\},\{1500,84\},\{2000,84\},\{5000,84\}\}$,

InterpolationOrder- $>1]$;

cpcl=Interpolation $[\{\{100,878\},\{300,878\},\{366,942\},\{422,963\}$, $\{588,1034\},\{700,1067\},\{811,995\},\{1000,995\},\{2000,995\}$, $\{5000,995\}\}$,InterpolationOrder->1];

cpf $=$ Interpolation $[\{\{100,351\},\{300,351\},\{933,463\},\{1933,546\}$, $\{2500,546\},\{3500,546\},\{5000,546\}\}$, InterpolationOrder $->1]$;

hsf[i_]:=398000*fmal $/$; $<<=$;

hfg[i $]:=10800000 * \mathrm{fmal} / ; \mathrm{i}<=\mathrm{n}$;

hsf $[$ i $]:=398000 \quad / ;$ i $>$ n;

hfg[i] $]:=10800000 \quad / ; \mathrm{i}>\mathrm{n}$; 
151=ReadList["508.56",Number,RecordLists->True];

shape=Interpolation[151,InterpolationOrder $\rightarrow 1]$;

num=Part[Part[Position[151,Last[151]],1],1];

TimeBeg=Part[151[[1]],1];

TimeEnd=Part[151[[num]],1];

$\mathrm{cl}=\operatorname{Sum}\left[0.5^{*}\right.$ (shape[Part[151[[i]],1]]+shape[Part[151[[i+1]],1]])*

(Part[151[[i+1]],1]-Part[151[[i]],1]),\{i,200,500\}];

qs[qtot_time_]:=qtot*shape[time]/(volmeat*c1);

(* Functions : nrt - new reacted fraction

orf - old reacted fraction *)

$\operatorname{Tm} 1=863 ; \operatorname{Tm} 2=1970 ; \operatorname{Td}[\mathrm{i}]$ :=(To[i]-Tm1)/(Tm2-Tm1);

lamda[i] $:=\left(4 * 10^{\wedge}-4\right) E^{\wedge}(14.73 * \operatorname{Tanh}[1.8 * \operatorname{Td}[i]])$;

$\left.\mathrm{zl}\left[\mathrm{i}_{-}, \mathrm{dt}\right] \mathrm{d}\right]=\mathrm{NDSolve}[\{\mathrm{RF}[\mathrm{t}]=\mathrm{lamda}[\mathrm{i}]-\mathrm{lamda}[\mathrm{i}] * \mathrm{RF}[\mathrm{t}]$,

$\overline{R F}[0]==\operatorname{orf}[\mathrm{i}]\}, \mathrm{RF},\{\mathrm{t}, 0, \mathrm{dt}\}$, AccuracyGoal $->15]$;

$\mathrm{nrf}\left[\mathrm{i}_{-}, \mathrm{dt}\right]:=\mathrm{Part}[\mathrm{RF}[\mathrm{dt}] / . \mathrm{zl}[\mathrm{i}, \mathrm{dt}], 1]$

frr[i]:=lamda[i]-lamda[i]*orf[i];

UpdateRF[dt_]:=Do[orf [i] $]=\operatorname{nrf}[i, d t],\{i, 1, n\}]$

qchem[i] $]:=w w * f r r[i]$;

q[i_time_qtot_]:=qs[qtot,time]+qchem[i] $/ ; \mathrm{i}<=\mathrm{n} ;\left(^{*}\right.$ assign heat generation in the meat $*$ )

$\mathrm{q}\left[\mathrm{i}_{-}\right.$,time_qtot_]: $=0 / ; \mathrm{i}>\mathrm{n} ; \quad$ (* assign heat generation in the clad $\left.{ }^{*}\right)$

$\mathrm{bb}[\vec{i}]:=\mathrm{htc}[\mathrm{To}[\mathrm{m}]] / \mathrm{dx} / ; \mathrm{i}=\mathrm{m}$;

$\mathrm{bb}\left[\mathrm{i}_{-}\right]:=0 / ; \mathrm{i} !=\mathrm{m} ; \quad$ (* value for the heat transfer out of the plate *)

$\mathrm{k} 1[\mathrm{i}] \mathrm{]}:=(2 * \mathrm{k}[\mathrm{i}-1] * \mathrm{k}[\mathrm{i}] /(\mathrm{k}[\mathrm{i}-1]+\mathrm{k}[\mathrm{i}])) / \mathrm{dx} \mathrm{x}^{\wedge} / ; \mathrm{i} !=1$

$\mathrm{k} 1[\mathrm{i}] \mathrm{i}:=0 / ; \mathrm{i}==1$

$\mathrm{k} 2[\mathrm{i}] \mathrm{i}:=\mathrm{k} 1[\mathrm{i}]+\mathrm{k} 3[\mathrm{i}]$;

$\mathrm{k} 3[\mathrm{i}] \mathrm{]}:=(2 * \mathrm{k}[\mathrm{i}+1] * \mathrm{k}[\mathrm{i}] /(\mathrm{k}[\mathrm{i}+1]+\mathrm{k}[\mathrm{i}])) / \mathrm{dx} \mathrm{x}^{\wedge} / ; \mathrm{i} !=\mathrm{m}$

$\mathrm{k} 3[\mathrm{i}] \mathrm{]}:=0 / ; \mathrm{i}==\mathrm{m}$;

phase[i_]:= solid /; Tc[i] $<\mathrm{Tm}$;

phase[i] $]:=$ liquid $/ ; \mathrm{Tc}[\mathrm{i}]<\mathrm{Tv} \& \& \mathrm{Tc}[\mathrm{i}]>=\mathrm{Tm} \& \& \mathrm{xm}[\mathrm{i}]>=0.85$;

phase[i]]:= vapor $/ ; \quad \operatorname{Tc}[\mathrm{i}]>=\mathrm{Tv} \& \& \mathrm{xv}[\mathrm{i}]>1 ;$

phase[i] $]:=$ melting $/ ; \quad T c[i]>=\operatorname{Tm} \& \&$ xm[i] $<0.85$;

phase[i]]:= vaporizing $/ ; \quad \operatorname{Tc}[\mathrm{i}]>=\operatorname{Tv} \& \& \mathrm{xv}[\mathrm{i}]<1 \& \& \mathrm{xv}[\mathrm{i}]>-0.01$;

$\operatorname{Tn}[\mathrm{i}]:=\mathrm{Tc}[\mathrm{i}] / ;$ phase $[\mathrm{i}]=!=$ melting \&\& phase[i] $=!=$ vaporizing;

$\operatorname{Tn}[\mathrm{i}]:=\operatorname{Tm} / ;$ phase $[\mathrm{i}]=$ melting ;

$\operatorname{Tn}[i]=\operatorname{Tv} / ;$ phase[i] $==$ vaporizing ;

$\mathrm{vv}\left[\mathrm{i}_{-} \mathrm{j}_{-}, \mathrm{dt}\right] \mathrm{l}=\mathrm{k1}[\mathrm{i}] / ; \mathrm{i}-1=\mathrm{j} \& \&$ phase[j]=!=melting \&\& phase[j]]=!=vaporizing $\mathrm{vv}\left[\mathrm{i} \_\mathrm{j}, \mathrm{dt}\right] \mathrm{d}:=-\mathrm{k} 2[\mathrm{i}]-\mathrm{rho}[\mathrm{i}] * \mathrm{cp}[\mathrm{i}] / \mathrm{dt}-\mathrm{bb}[\mathrm{i}] / ; \mathrm{i}==\mathrm{j} \& \&$ phase[j]=!=melting \&\& phase $[\mathrm{i}]=!=$ vaporizing

$\mathrm{vv}\left[\mathrm{i}_{-}, \mathrm{j}_{-}, \mathrm{dt}\right] \mathrm{]}:=\mathrm{k} 3[\mathrm{i}] / ; \mathrm{i}+1=\mathrm{j} \& \&$ phase[j]=!=melting \&\& phase[j]=!=vaporizing $v v\left[i_{-} j_{-}, d t\right]:=0 / ; i !=j \& \& i-1 !=j \& \& i+1 !=j$;

vv[i_,j_,dt_]:=1/; i==j \&\& phase[j]===melting;

$\mathrm{vv}\left[\mathrm{i}_{\mathrm{i}} \mathrm{j}, \mathrm{dt}\right] \mathrm{]}:=0 / ; \mathrm{i}-1=\mathrm{j} \& \&$ phase[j] ==-melting;

$v v\left[i_{-}, j_{-}, \mathrm{dt}\right]:=0 / ; \mathrm{i}+1=\mathrm{j} \& \&$ phase[j] $==$ melting;

$\mathrm{vv}\left[\mathrm{i}_{-} \mathrm{j}_{-}, \mathrm{dt}\right]:=1 / ; \mathrm{i}==\mathrm{j} \quad \& \&$ phase[j] $===\mathrm{vaporizing}$

$\mathrm{vv}\left[\mathrm{i}_{3}, \mathrm{j}_{-}, \mathrm{dt}\right]:=0 / ; \mathrm{i}-1==\mathrm{j} \& \&$ phase[j]===vaporizing;

$v v\left[i_{-}, j_{-}, \mathrm{dt}\right]:=0 / ; \mathrm{i}+1==\mathrm{j} \& \&$ phase[j]===vaporizing; 


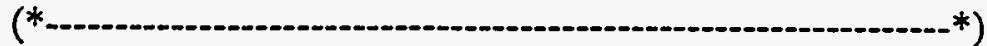

$\mathrm{f}[\mathrm{i}, \mathrm{dt}, \mathrm{time}, \mathrm{qtot}] \mathrm{l}:=-\mathrm{q}[\mathrm{i}, \mathrm{time}, \mathrm{qtot}]-\mathrm{To}[\mathrm{i}]^{*} \mathrm{rho}[\mathrm{i}]{ }^{*} \mathrm{cp}[\mathrm{i}] / \mathrm{dt}-\mathrm{bb}[\mathrm{i}]{ }^{*}$ Tinf $/ ;$ phase[i] $=!=$ melting \&\& phase[i] $=!=$ =vaporizing;

f[i_,dt_time_,qtot_]:= Tm /; phase[i]===melting;

$\mathrm{f}\left[\mathrm{i}_{-}, \mathrm{dt}, \mathrm{time}, \mathrm{qtot}\right] \mathrm{l}=\mathrm{Tv} /$; phase[i]===vaporizing;

qtot $=14200$;

RhoMeat=6500.;RhoAl=2700.;RhoU=12200;

fval $=0.5$;

fvu=1-fval;

DenRat $=($ RhoU/RhoAl);

fmal $=0.212$;

$\mathrm{fmu}=1-\mathrm{fmal}$;

Echem $=350000.0$

$\mathrm{ww}=\mathrm{E}$ chem $* 5100$

9

1.78510

time $=0.22$;

$\operatorname{Do}[\mathrm{To}[\mathrm{i}]=300 ; \mathrm{Tc}[\mathrm{i}]=300 ; \mathrm{xm}[\mathrm{i}]=0 ; \mathrm{xv}[\mathrm{i}]=0 ; \operatorname{orf}[\mathrm{i}]=0 ;\{\mathrm{i}, 1, \mathrm{~m}\}]$;

$\mathrm{dtt}[\mathrm{i}] \mathrm{i}:=2 * \mathrm{dx} * \mathrm{dx} * \mathrm{rho}[\mathrm{i}] * \mathrm{cp}[\mathrm{i}] /(2 * \mathrm{k}[\mathrm{i}])$;

$\mathrm{dt}=\operatorname{Min}[$ Table[dtt[i], $\{\mathrm{i}, 1, \mathrm{~m}\}]]$;

$\mathrm{nt}=\mathrm{Floor}[(0.03) / \mathrm{dt}]-1$;

Print["dt= ",dt," nt= ",nt];

$d t=0.0000556826 n t=537$

Do[

$s=$ Table[vv[i,j,dt],\{j,m $\},\{\mathrm{i}, \mathrm{m}\}]$;

sinv $=$ Inverse $[s] ;(*$ invert the matrix *)

$\mathrm{qq}=$ Table[f[i,dt,time,qtot],\{i,m\}];

ans $=$ sinv.qq;

$\mathrm{Do}[\mathrm{Tc}[\mathrm{i}]=$ ans[[i] $]$;

If $[$ phase[i] $===$ melting, $\quad x m[i]+=(k 1[i] * T o[i-1]-k 2[i] * T o[i]+k 3[i] * T o[i+1]+q[i, t i m e, q t o t]-$ $\mathrm{bb}[\mathrm{i}] *(\mathrm{To}[\mathrm{m}]-\operatorname{Tinf})) * \mathrm{dt} /(\mathrm{rho}[\mathrm{i}] * \mathrm{hsf}[\mathrm{i}]) ;, 0]$;

If $[$ phase[i] $==$ vaporizing, $x v[i]+=(k 1[i] * T o[i-1]-k 2[i] * T o[i]+k 3[i] * T o[i+1]+q[i$, time,qtot $]-$ bb[i]*(To[m]-Tinf))*dt/(rho[i] *hfg[i]);,0]; $,\{\mathrm{i}, 1, \mathrm{~m}\}]$;

If[Mod[numtimesteps,5] $=0$ \| numtimesteps $>=60$,

Print[numtimesteps," ",time," ",To[1]," ",xv[1]," ",phase[1]," ", q[1,time,qtot]," ",orf[1]," ",qs[qtot,time]," ",qchem[1]]];

Do[To[i] $=\operatorname{Tn}[\mathrm{i}]$;

$\operatorname{xx1}[\mathrm{i}$, numtimesteps $]=\{$ time, $\mathrm{To}[\mathrm{i}]\}$;

$\mathrm{xx} 2[\mathrm{i}$, numtimesteps] $=\{$ time, $\mathrm{xm}[\mathrm{i}]\}$;

$\mathrm{xx} 3[\mathrm{i}$, numtimesteps] $=\{$ time, $\mathrm{xv}[\mathrm{i}]\}$;

$\mathrm{xx} 4[$ i, numtimesteps] $=\{$ time, $\operatorname{orf}[\mathrm{i}]\}$;

$\mathrm{xx}[$ [i,numtimesteps] $=\{$ time, $q[\mathrm{i}$, time, $\mathrm{qtot}]\}$;

$\mathrm{xx6}$ [i,numtimesteps] $=\{$ time,qchem[i] $\}$;

$\mathrm{xx} 7[\mathrm{i}$, numtimesteps] $=\{$ time,qs[qtot,time] $\}$; 
$,\{\mathrm{i}, 1, \mathrm{~m}\}]$

To[i] $=\operatorname{Tn}[\mathrm{i}]$

time + = dt;

UpdateRF[dt];

,\{numtimesteps, $1, \mathrm{nt}\}]$;

Print[Finished];

$$
\begin{array}{llll}
10 & -12 & 10
\end{array}
$$

50.220223301 .5670 solid $1.6733310 \quad 2.1126410 \quad 1.6733310 \quad 17.0458$

$$
\begin{array}{lll}
10 & -12 & 10
\end{array}
$$

100.220501303 .8470 solid $2.0822410 \quad 4.8124410 \quad 2.0822410 \quad 17.4977$

$$
\begin{array}{llll}
10 & -12 & 10
\end{array}
$$

150.22078305 .9450 solid $2.330110 \quad 7.5823810 \quad 2.330110 \quad 17.9265$

$$
\begin{array}{lll}
10 & -11 & 10
\end{array}
$$

200.221058308 .3030 solid $2.6726210 \quad 1.0425610 \quad 2.6726210 \quad 18.4236$

$$
\begin{array}{llll}
10 & -11 & 10
\end{array}
$$

250.221336310 .9380 solid $3.502510 \quad 1.3351910 \quad 3.502510 \quad 18.9988$

$$
10 \quad-11 \quad 10
$$

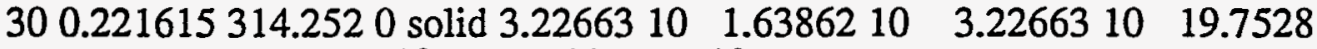
$\begin{array}{llll}10 & -11 & 10\end{array}$

350.221893317 .3420 solid $4.328710 \quad 1.9534210 \quad 4.328710 \quad 20.4886$ $\begin{array}{llll}10 & -11 & 10\end{array}$

$40 \quad 0.222172321 .1560$ solid $4.2619110 \quad 2.2819210 \quad 4.2619110 \quad 21.4423$

$$
\begin{array}{lll}
10 & -11 & 10
\end{array}
$$

450.22245324 .9070 solid $4.9208310 \quad 2.6253910 \quad 4.9208310 \quad 22.4321$

$\begin{array}{llll}10 & -11 & 10\end{array}$

500.222728329 .2490 solid $6.2380610 \quad 2.9861510 \quad 6.2380610 \quad 23.6468$ $\begin{array}{lll}10 & -11 & 10\end{array}$

550.223007334 .5470 solid $7.0358610 \quad 3.3694810 \quad 7.0358610 \quad 25.2362$ $\begin{array}{llll}10 & -11 & 10\end{array}$

600.223285340 .3070 solid $7.2253210 \quad 3.7804610 \quad 7.2253210 \quad 27.1099$ $\begin{array}{llll}10 & -11 & 10\end{array}$

610.223341341 .4510 solid $7.3705310 \quad 3.8662510 \quad 7.3705310 \quad 27.5014$ $\begin{array}{lll}10 & -11 & 10\end{array}$

620.223397342 .6130 solid $7.5679410 \quad 3.953310 \quad 7.5679410 \quad 27.9059$ $\begin{array}{llll}10 & -11 & 10\end{array}$

630.223452343 .8060 solid $7.8581310 \quad 4.04167 \quad 10 \quad 7.85813 \quad 10 \quad 28.3281$ $10 \quad-11$

640.223508345 .050 solid $8.1400910 \quad 4.1314410 \quad 8.1400910 \quad 28.7769$ $\begin{array}{lll}10 & -11 & 10\end{array}$

650.223564346 .3440 solid $8.337510 \quad 4.2226910 \quad 8.337510 \quad 29.2525$ $\begin{array}{lll}10 & -11 & 10\end{array}$

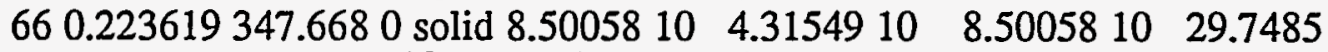
$\begin{array}{lll}10 & -11 \quad 10\end{array}$

670.223675349 .0130 solid $8.599310 \quad 4.4098910 \quad 8.599310 \quad 30.2626$ $\begin{array}{llll}10 & -11 & 10\end{array}$

680.223731350 .3630 solid $8.9704610 \quad 4.5059410 \quad 8.9704610 \quad 30.7892$

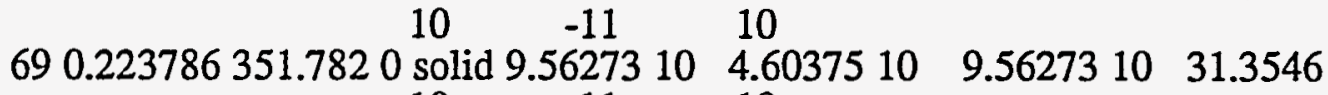
$\begin{array}{lll}10 & -11 & 10\end{array}$

700.223842353 .3230 solid $9.6325510 \quad 4.7035210 \quad 9.6325510 \quad 31.982$ $\begin{array}{lll}10 & -11 & 10\end{array}$

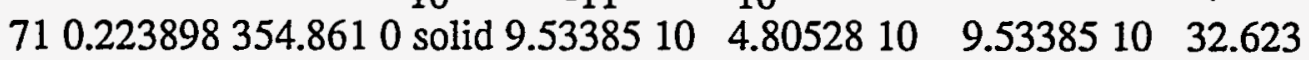




\section{$\begin{array}{llll}10 & -11 & 10\end{array}$}

720.223953356 .3550 solid $9.4351210 \quad 4.9090410 \quad 9.4351210 \quad 33.2604$ $\begin{array}{lll}10 & -11 & 10\end{array}$

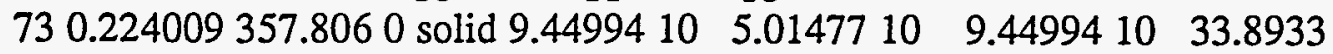

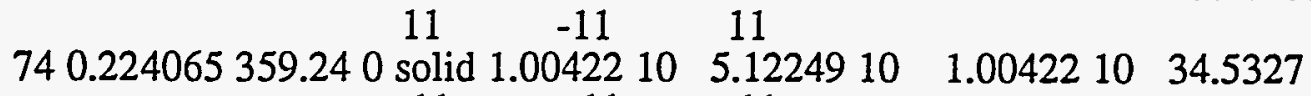
750.224121360 .7940 solid $1.0416310 \cdot 5.2324310 \quad 1.0416310 \quad 35.2411$ $\begin{array}{llll}71 & -11 & 11\end{array}$ $\begin{array}{llllll}760.224176362 .4140 \text { solid } 1.0416310 & 5.3447210 & 1.0416310 & 35.9983\end{array}$

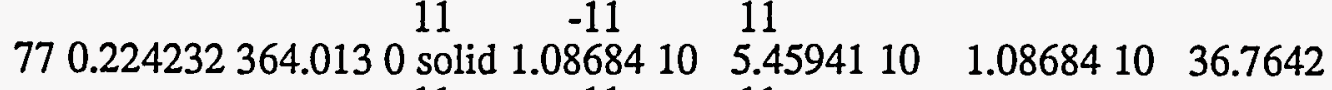

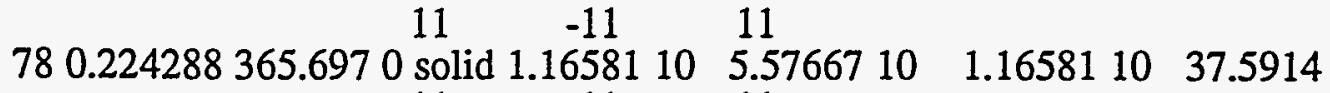

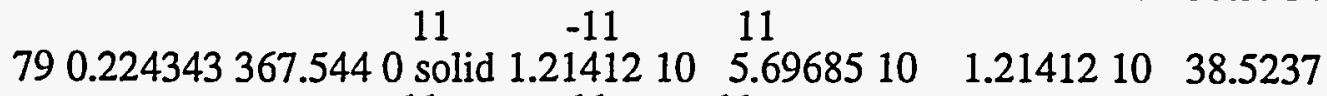

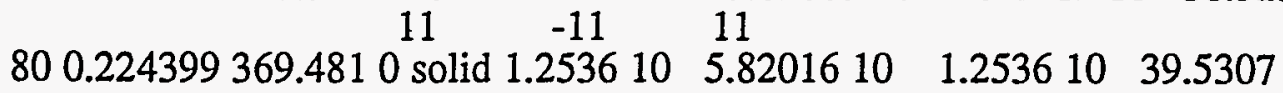

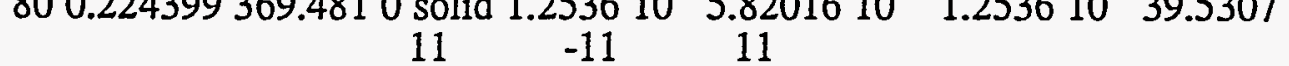
810.224455371 .4870 solid $1.2543610 \quad 5.9468310 \quad 1.2543610 \quad 40.6056$ $\begin{array}{llll}11 & -11 & 11\end{array}$

820.22451373 .470 solid $1.2689610 \quad 6.0769210 \quad 1.2689610 \quad 41.7016$ $11 \quad-11 \quad 11$

830.224566375 .4610 solid $1.3479310 \quad 6.2105410 \quad 1.3479310 \quad 42.8369$ $\begin{array}{llll}11 & -11 & 11\end{array}$

840.224622377 .610 solid $1.4000210 \quad 6.3481210 \quad 1.4000210 \quad 44.1026$

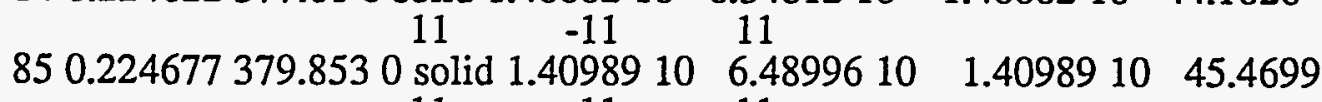

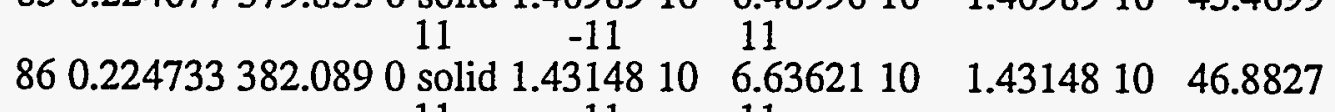

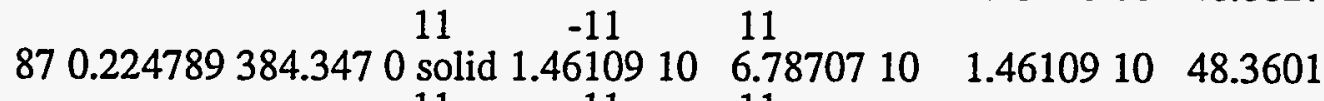

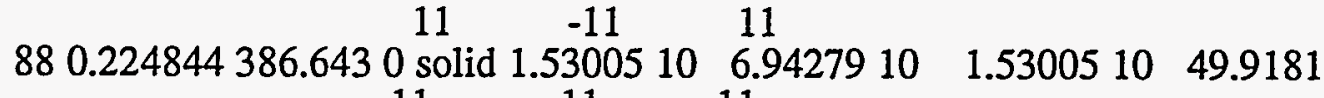

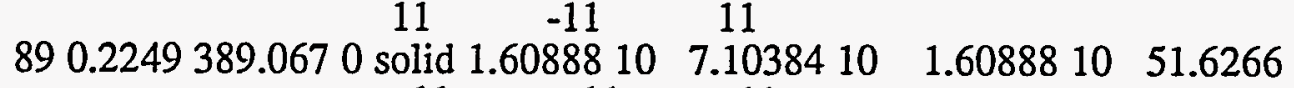
$11-11 \quad 11$

900.224956391 .6420 solid $1.5792610 \quad 7.2707810 \quad 1.5792610 \quad 53.5152$ $\begin{array}{llll}11 & -11 & 11\end{array}$

910.225011394 .1150 solid $1.5638410 \quad 7.4436110 \quad 1.5638410 \quad 55.4041$ $11 \quad-11 \quad 11$

920.225067396 .5180 solid $1.6033310 \quad 7.622410 \quad 1.6033310 \quad 57.3136$ $\begin{array}{llll}11 & -11 & 11\end{array}$

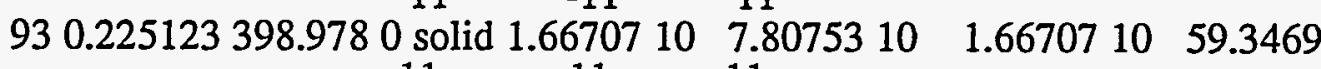

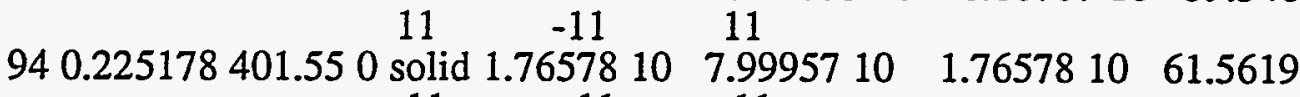
050.225234404 .31505011 950.225234404 .3150 solid $1.8281510 \quad 8.1993710 \quad 1.8281510 \quad 64.0486$

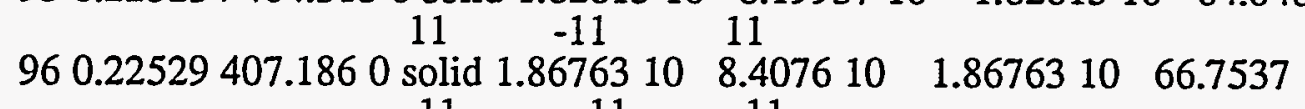
$\begin{array}{lllll} & 11 & -11 & 11\end{array}$ 970.225346410 .1110 solid $1.9071210 \quad 8.6248610 \quad 1.9071210 \quad 69.6438$

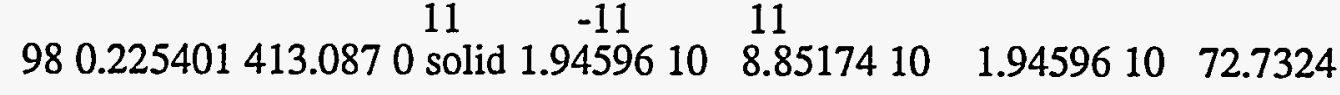


990.225457416 .1120 solid $1.9558310 \quad 9.0889310 \quad 1.9558310 \quad 76.0329$ $\begin{array}{llll}11 & -11 & 11\end{array}$

1000.225513419 .1190 solid $1.9723910 \quad 9.3368710 \quad 1.9723910 \quad 79.4833$ $\begin{array}{lll}11 & -11 & 11\end{array}$

1010.225568422 .1230 solid $2.0118810 \quad 9.59613 \quad 10 \quad 2.0118810 \quad 83.1081$ $11 \quad-11 \quad 11$

1020.225624425 .1740 solid $2.0641 \quad 10 \quad 9.8674710 \quad 2.064110 \quad 86.9841$ $\begin{array}{lll}11 & -10 & 11\end{array}$

1030.22568428 .3020 solid $2.133210 \quad 1.0151910 \quad 2.133210 \quad 91.1711$ $\begin{array}{lll}11 & -10 & 11\end{array}$

1040.225735431 .5430 solid $2.17110 \quad 1.0450610 \quad 2.1711095 .753$ $\begin{array}{llll}11 & -10 & 11\end{array}$

1050.225791434 .8270 solid $2.1907410 \quad 1.0764610 \quad 2.1907410 \quad 100.661$ $\begin{array}{lll}11 & -10 \quad 11\end{array}$

1060.225847438 .110 solid $2.2766810 \quad 1.1094810 \quad 2.2766810 \quad 105.854$

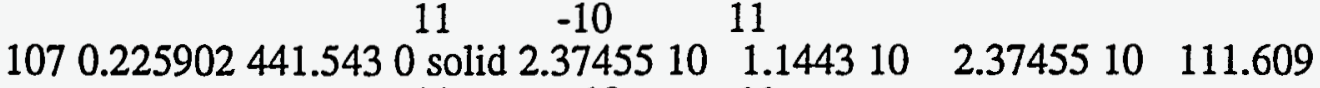
$11 \quad-10 \quad 11$

1080.225958445 .1510 solid $2.4535210 \quad 1.1811210 \quad 2.4535210 \quad 118.04$ $\begin{array}{lll}11 & -10 & 11\end{array}$

1090.226014448 .8890 solid $2.525210 \quad 1.2201610 \quad 2.525210 \quad 125.146$ $\begin{array}{lll}11 & -10 & 11\end{array}$

1100.226069452 .740 solid $2.5745510 \quad 1.2616410 \quad 2.5745510 \quad 132.971$ $\begin{array}{lll}11 & -10 & 11\end{array}$

1110.226125456 .6510 solid $2.6372510 \quad 1.3057710 \quad 2.6372510 \quad 141.484$ $\begin{array}{lll}11 & -10 & 11\end{array}$

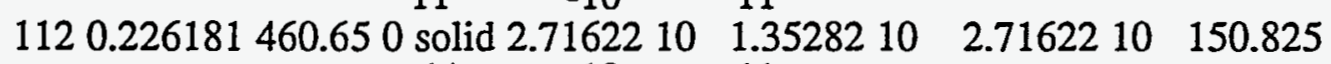
$\begin{array}{llll}11 & -10 & 11\end{array}$

1130.226236464 .7730 solid $2.8081210 \quad 1.4031 \quad 10 \quad 2.8081210 \quad 161.182$ $11 \quad-10 \quad 11$

1140.226292469 .0460 solid $2.9068310 \quad 1.4569910 \quad 2.9068310 \quad 172.76$

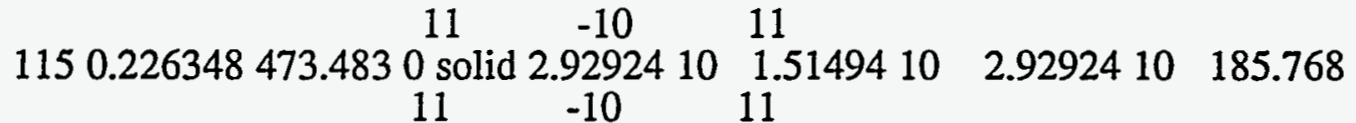

1160.226404477 .910 solid $2.9434610 \quad 1.5772810 \quad 2.9434610 \quad 199.843$ $\begin{array}{llll}11 & -10 & 11\end{array}$

1170.226459482 .3080 solid $3.0224310 \quad 1.6443610 \quad 3.0224310 \quad 215.006$ $\begin{array}{lll}11 & -10 & 11\end{array}$

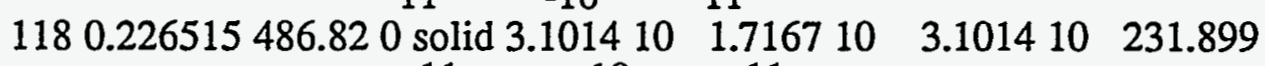
$\begin{array}{lll}11 & -10 & 11\end{array}$

1190.226571491 .4450 solid $3.1803710 \quad 1.7949210 \quad 3.1803710 \quad 250.748$ $11 \quad-10 \quad 11$

1200.226626496 .180 solid $3.26410 \quad 1.8797110 \quad 3.26410 \quad 271.815$ $11 \quad-10 \quad 11$

1210.226682501 .0340 solid $3.3528410 \quad 1.9718710 \quad 3.3528410 \quad 295.456$ $\begin{array}{llll}11 & -10 & 11\end{array}$

1220.226738506 .0170 solid $3.4283510 \quad 2.0723510 \quad 3.4283510 \quad 322.098$

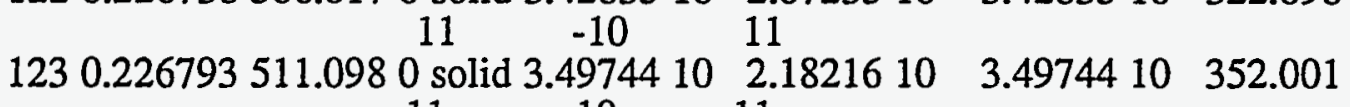

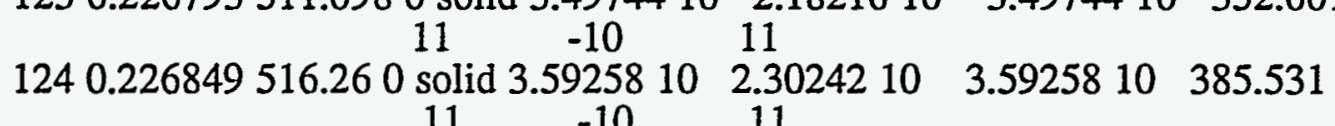
1250.226905521 .5590 solid $3.6937810 \quad 2.4345710 \quad 3.6937810 \quad 423.619$ 


\section{$\begin{array}{lll}11 & -10 & 11\end{array}$}

1260.22696527 .0050 solid $3.822110 \quad 2.5802810 \quad 3.822110 \quad 467.096$ $\begin{array}{llll}11 & -10 & 11\end{array}$

1270.227016532 .6560 solid $3.9220410 \quad 2.7416810 \quad 3.9220410 \quad 517.399$

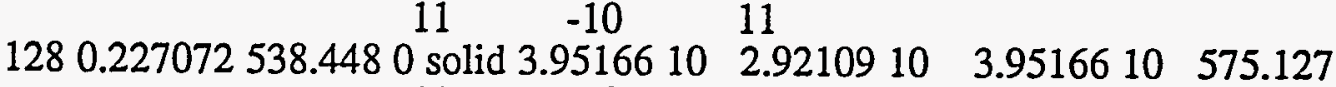

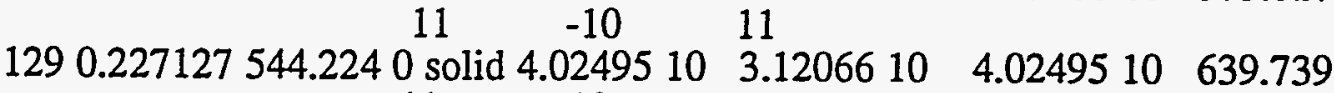
$\begin{array}{llll}11 & -10 & 11\end{array}$ 1300.227183550 .0780 solid $4.143410 \quad 3.3431810 \quad 4.143410 \quad 713.331$

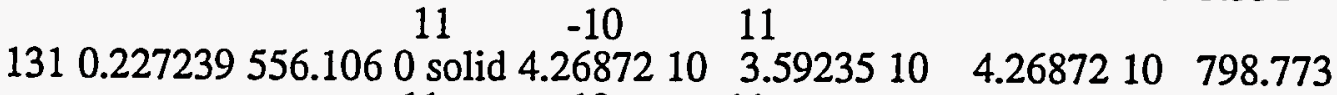

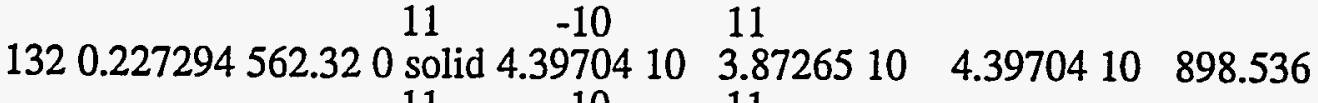

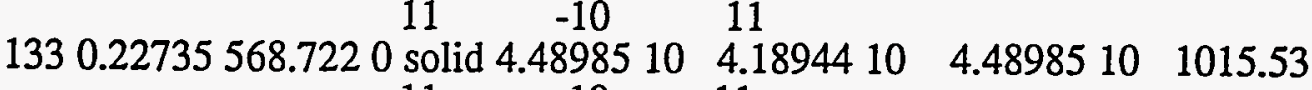

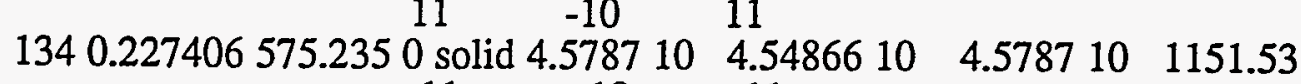

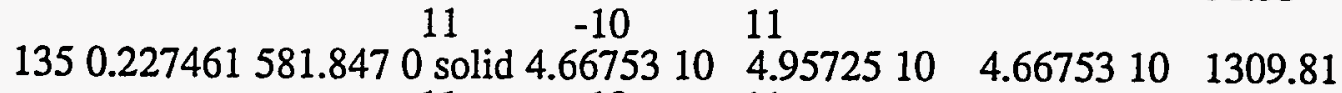

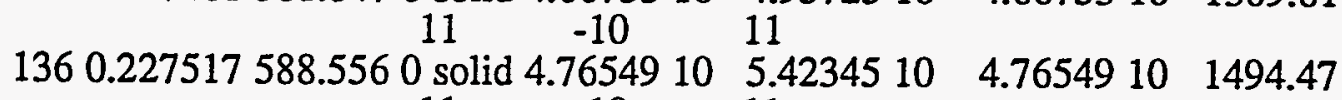
$\begin{array}{llll}11 & -10 & 11\end{array}$

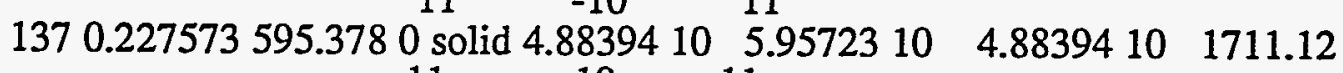

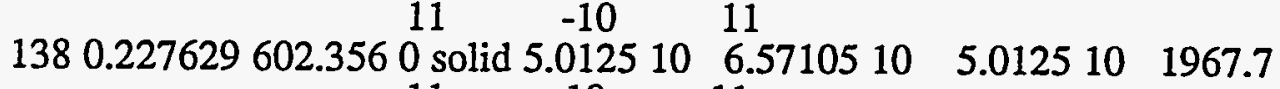
$\begin{array}{lll}11 & -10 & 11\end{array}$

1390.227684609 .5060 solid $5.150710 \quad 7.280310 \quad 5.150710 \quad 2273.63$ $\begin{array}{llll}11 & -10 & 11\end{array}$

1400.22774616 .8470 solid $5.2747610 \quad 8.1041110 \quad 5.2747610 \quad 2640.87$

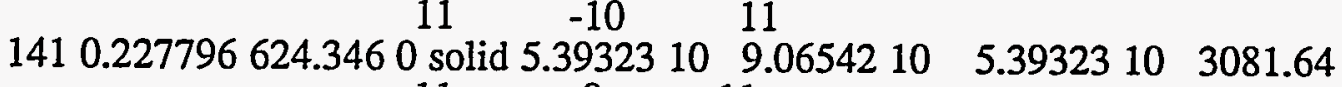

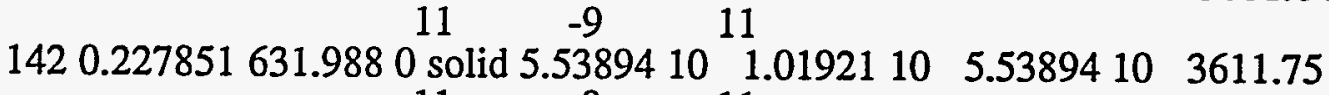

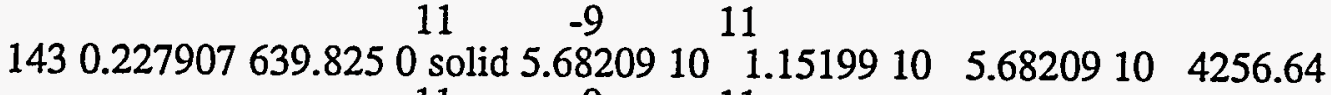

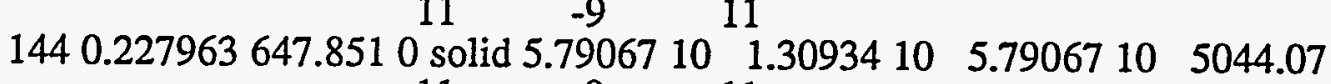

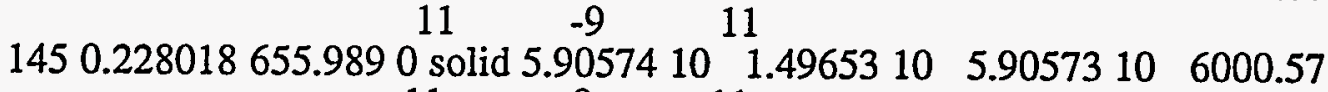

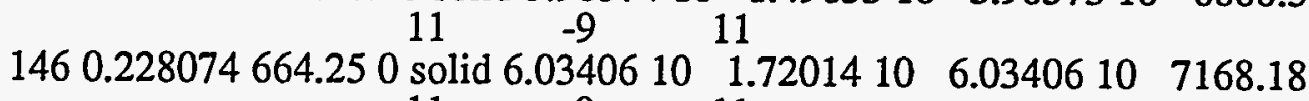

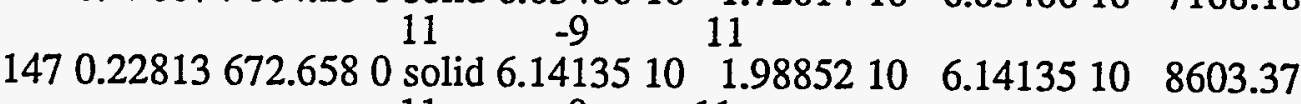

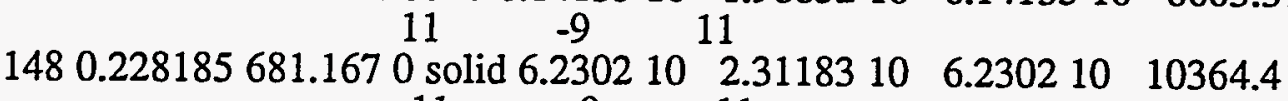
$\begin{array}{lll}11 & -9 & 11\end{array}$

1490.228241689 .7370 solid $6.3917910 \quad 2.7024410 \quad 6.3917910 \quad 12521.4$ $\begin{array}{lll}11 & -9 & 11\end{array}$

1500.228297698 .5140 solid $6.5793410 \quad 3.177210 \quad 6.5793410 \quad 15219.2$

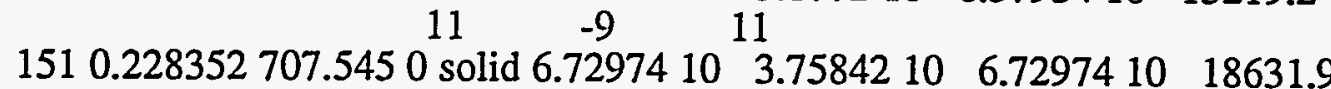

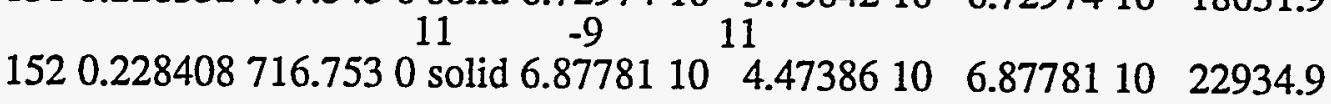




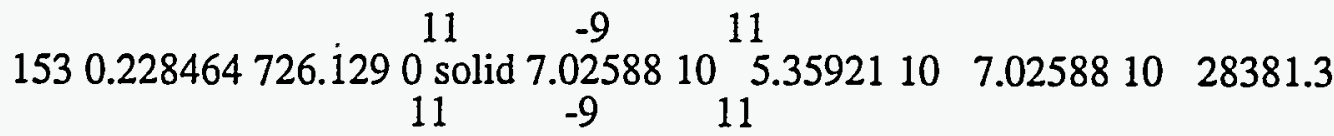

1540.228519735 .670 solid $7.1877310 \quad 6.4605210 \quad 7.1877310 \quad 35304.4$ $\begin{array}{lll}11 & -9 & 11\end{array}$

1550.228575745 .3990 solid 7.37529107 .83836107 .375291044169$. $\begin{array}{lll}11 & -9 \quad 11\end{array}$

1560.228631755 .3630 solid $7.5464610 \quad 9.5739610 \quad 7.5464610 \quad 55637.4$ $\begin{array}{lll}11 & -8 & 11\end{array}$

1570.228686765 .5270 solid $7.704410 \quad 1.1773210 \quad 7.704410 \quad 70501.1$ $\begin{array}{lll}11 & -8 & 11\end{array}$

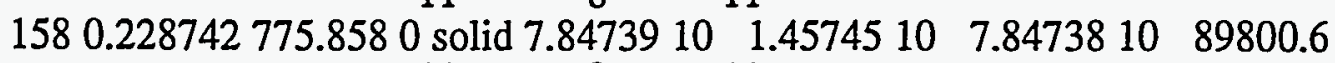

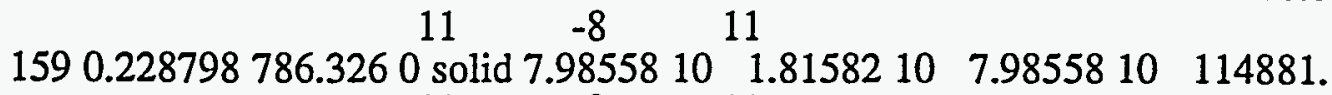

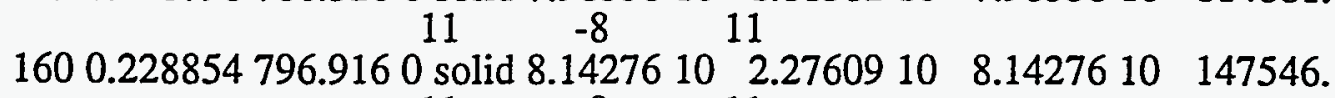
$11 \quad-8 \quad 11$

1610.228909807 .6620 solid $8.3023410 \quad 2.8699810 \quad 8.3023310 \quad 190381$. $\begin{array}{llll}11 & -8 & 11\end{array}$

1620.228965818 .5650 solid $8.4701510 \quad 3.6397710 \quad 8.4701510246770$. $\begin{array}{llll}11 & -8 & 11\end{array}$

1630.229021829 .6380 solid $8.6306610 \quad 4.6422810 \quad 8.6306610321372$. $\begin{array}{lll}11 & -8 & 11\end{array}$

1640.229076840 .8630 solid $8.7787310 \quad 5.953310 \quad 8.7787310420269$. $\begin{array}{llll}11 & -8 & 11\end{array}$

1650.229132852 .2120 solid $8.96644107 .673510 \quad 8.9664410551438$. 11

1660.229188863 .7590 solid $9.1836109 .9416610 \quad 9.1835910727098$. $\begin{array}{lll}11 & -7 & 11\end{array}$

1670.229243875 .5540 solid $9.4007710 \quad 1.29502109 .4007610964426$.

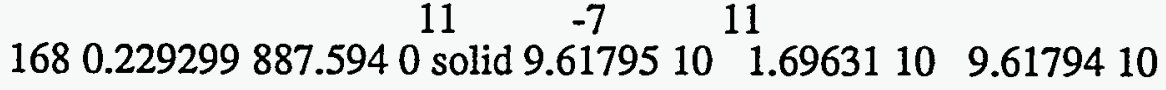

\subsection{0 \\ 6}

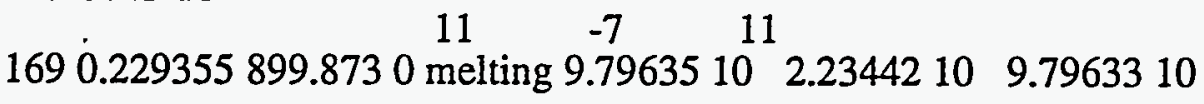
6
1.72499
10

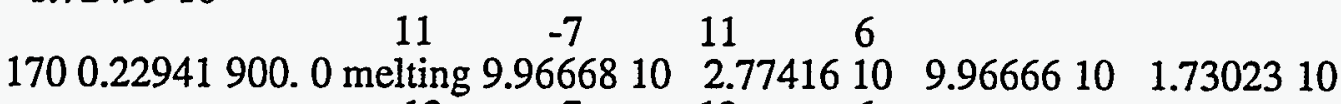
$\begin{array}{lllll}12 & -7 & 12 & 6\end{array}$

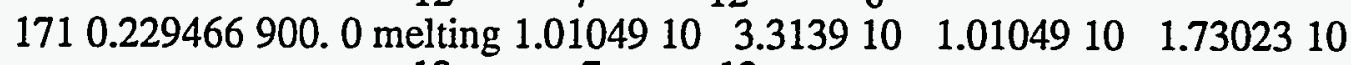

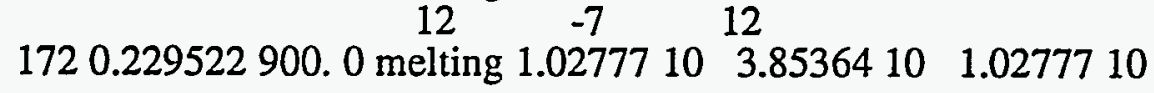

6

1.7302310

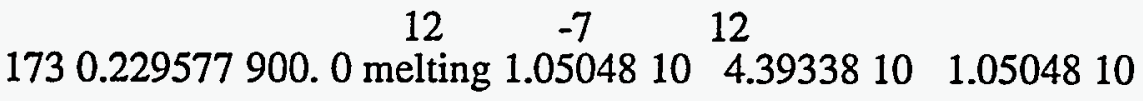

1.7302310 
$12 \quad-7 \quad 12$

1740.229633900 .0 melting $1.0690810 \quad 4.9331210 \quad 1.0690710$ 6

1.7302310

$\begin{array}{llll}12 & -7 & 12\end{array}$

1750.229689900 .0 melting $1.0848710 \quad 5.4728710 \quad 1.0848710$

6

1.7302310

$\begin{array}{llll}12 & -7 & 12\end{array}$

1760.229744900 .0 melting $1.10224106 .0126110 \quad 1.1022410$

6

1.7302310

$\begin{array}{lllll}12 & -7 & 12 & 6\end{array}$

1770.2298900 .0 liquid $1.12001 \quad 10 \quad 6.5523510 \quad 1.1200110 \quad 1.7302310$ $\begin{array}{lllll}12 & -7 & 12 & 6\end{array}$

1780.229856900 .0 liquid $1.13877107 .0920910 \quad 1.1387610 \quad 1.7302310$

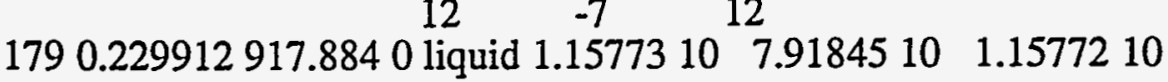
6

2.6490310

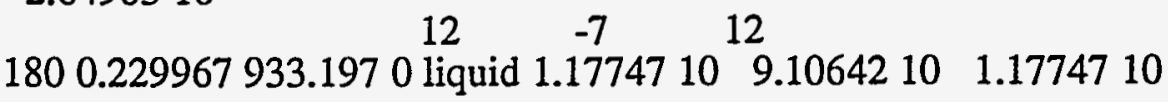
3.8082310

$\begin{array}{lllllll}181 & 0.230023 & 12 & -6 & 12 & & \\ 946.386 & 0 \text { liquid } 1.19762 & 10 & 1.07278 & 10 & 1.19761 & 10\end{array}$ 6

5.1974910

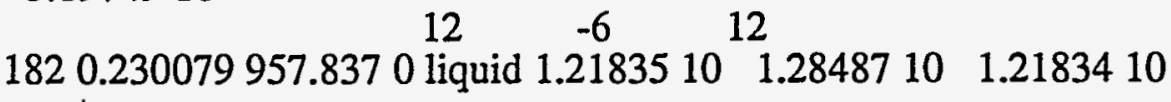

6.7988910

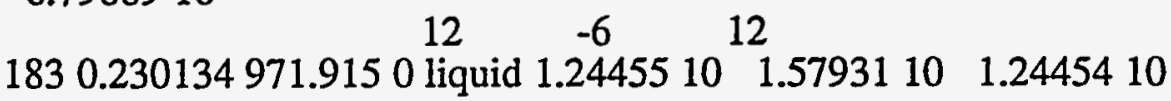

6

9.438810

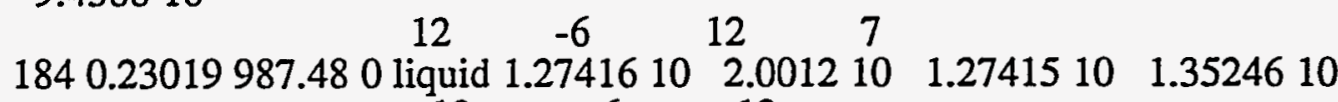
$\begin{array}{lll}12 & -6 & 12\end{array}$

1850.2302461003 .860 liquid $1.2932710 \quad 2.6148610 \quad 1.2932510$

$\stackrel{7}{7} 1.9671710$

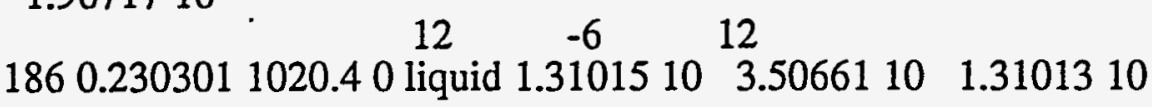


2.8586710

7

$\begin{array}{llll}12 & -6 & 12\end{array}$

1870.2303571036 .770 liquid $1.330910 \quad 4.7910210 \quad 1.3308610$
7
4.1173710

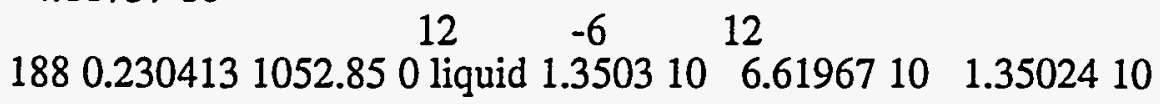

7
5.8620610

1890.2304681068 .510 liquid $1.3651310^{-6} 9.1858410 \quad 1.3650510$ 7
8.2262510

1900.2305241083 .610 liquid $1.3825210 \quad 0.00001272541 .3824110$

\section{$\stackrel{8}{1.13466} 10$}

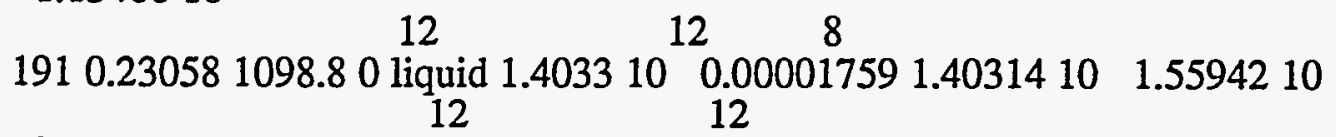

1920.2306351114 .420 liquid $1.4247110 \quad 0.00002429531 .424510$

8
2.14949
10

$\begin{array}{llllll}193 & 0.230691 & 1130.57 & 12 & 12 & \\ \text { liquid } 1.44651 & 10 & 0.00003358 & 1.44621 & 10\end{array}$

$\stackrel{8}{8} 10$

1940.2307471147 .290 liquid $1.458410 \quad 0.00004648891 .4579810$

$$
8
$$

4.1381210

1950.2308021164 .380 liquid $1.4686910^{12} 0.00006442221 .4681110$

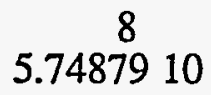

1960.2308581181 .740 liquid $1.484710^{12} 0.00008926391 .4839110$ 8
7.9633210

1970.2309141199 .410 liquid $1.5034910^{12} 0.0001235621 .5023910$ $\stackrel{9}{1.09947} 10$ 
1980.2309691217 .330 liquid $1.5305510 \quad 0.0001706921 .5290410$ 9

1.510810

1990.2310251235 .540 liquid $1.5510710 \quad 0.0002351731 .5490110$

9

2.0669610

2000.2310811253 .870 liquid $1.5636610^{12} 0.0003226721 .5608510$ 9

2.8048210

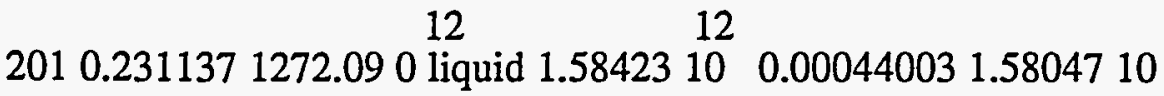

9

3.7618710

2020.2311921290 .30 liquid $1.6091510 \quad 0.0005958291 .6041610$

$\stackrel{9}{9} 10$

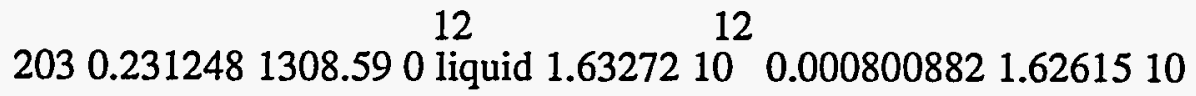

9

6.5726510

$12 \quad 12 \quad 9$

2040.2313041327 .0 liquid $1.6562510 \quad 0.001068521 .6476810 \quad 8.578510$

2050.2313591345 .580 liquid $1.6775410 \quad 0.001415151 .6664310$

10

1.1109810

$12 \quad 12$

2060.2314151364 .330 liquid $1.6976110 \quad 0.001860531 .6833310$

10

1.4274110

2070.2314711383 .250 liquid $1.7133710 \quad 0.00242821 .6951810$

10

1.8192510

2080.2315261402 .280 liquid $1.7272112 \quad 0.003145351 .7042310$

10

2.2981110

$12 \quad 12$

2090.2315821421 .390 liquid $1.7389110 \quad 0.004043011 .7101510$ 
10

2.8763110

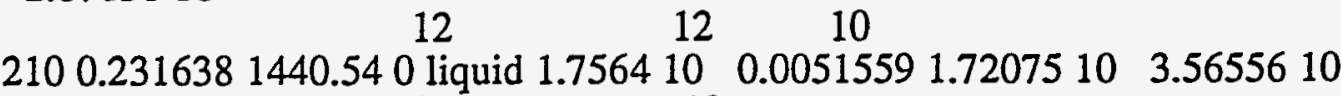
12

12

2110.2316931459 .830 liquid $1.777410 \quad 0.006523951 .7335810$

10

4.3825110

2120.2317491479 .30 liquid $1.8041910 \quad 0.008192291 .7507610$

10

5.3436410

$\begin{array}{llcccc}213 & 0.231805 & 1499.02 & 12 & 12 & 10 \\ \text { liquid } & 1.8333710 & 0.010212 & 1.7686910 & 6.46781 & 10\end{array}$ $\begin{array}{lll}12 & 12 & 10\end{array}$

2140.231861519 .010 liquid $1.8661410 \quad 0.0126391 .7884410 \quad 7.7706910$ $12 \quad 12$

2150.2319161539 .280 liquid $1.8954410 \quad 0.01553441 .8027610$

10

9.2679310

2160.2319721559 .730 liquid 1.91338100 .01896031 .8037510

11

1.0963210

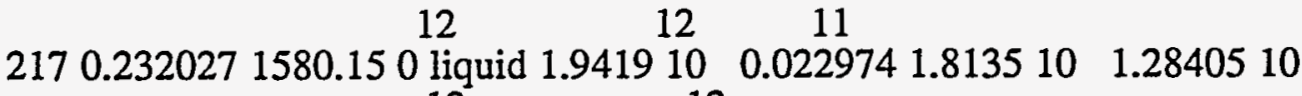

$12 \quad 12$

2180.2320831600 .670 liquid $1.9813610 \quad 0.02763671 .8322510$

11

1.4911310

$12 \quad 12$

2190.2321391621 .450 liquid $2.0132610 \quad 0.03301361 .8413710$

11

1.7188710

2200.2321941642 .320 liquid $2.04279 \begin{array}{llll}12 & 0.0391625 & 1.84631 & 10\end{array}$

11

1.9648410

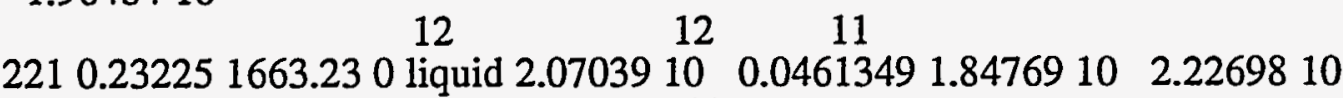
1212

2220.2323061684 .160 liquid $2.1006410 \quad 0.05397521 .8503410$

11

2.5029710

12

$12 \quad 11$ 
2230.2323621705 .170 liquid $2.1462410 \quad 0.06272281 .8671210 \quad 2.791210$ $12 \quad 12 \quad 11$

2240.2324171726 .50 liquid $2.1867910 \quad 0.07242191 .87748103 .0930610$ $12 \quad 12 \quad 11$

2250.2324731748 .090 liquid $2.21410 \quad 0.08310431 .87353103 .4046210$ $12 \quad 12$

2260.2325291769 .710 liquid 2.25113100 .09478091 .8792210

11

3.7191610

$\begin{array}{lcrccc}227 & 12 & 12 & 11 & & \\ 0.232584 & 1791.52 & 0 \text { liquid } 2.297610 & 0.107459 & 1.8940310 & 4.035710\end{array}$ $12 \quad 12 \quad 11$

2280.232641813 .670 liquid $2.324310 \quad 0.1211441 .88910 \quad 4.3530410$ $12 \quad 12 \quad 11$

2290.2326961835 .820 liquid $2.3423610 \quad 0.135811 .8761610 \quad 4.6619210$ $12 \quad 12$

2300.2327511857 .850 liquid 2.3880810

2310.2328071880 .190 liquid 2.4312810

0.1514131 .89245104 .9563510 $12 \quad 12$

2320.2328631902 .820 liquid 2.4454710

2330.2329181925 .30 liquid 2.4669910 $12 \quad 12$

2340.2329741947 .770 liquid 2.5059410

$12 \quad 12$

2350.233031970 .550 liquid 2.5227610

2360.2330851993 .350 liquid 25193610 $12 \quad 12$ $12 \quad 12$

2370.2331412015 .860 liquid 2.5302110 $12 \quad 12$

2380.2331972038 .30 liquid 2.5443610 12 12

2390.2332522060 .750 liquid 2.5510710

2400.2333082083 .120 liquid 2.5546510 $12 \quad 12$

2410.2333642105 .370 liquid 2.5554610

2420.233422127 .490 liquid 2.5505110 $12 \quad 12$

2430.2334752149 .420 liquid 2.5372610

$12 \quad 12$

2440.2335312171 .040 liquid 2.5297910

2450.2335872192 .480 liquid 2.5268210 $12 \quad 12$

2460.2336422213 .820 liquid 2.4995610 $12 \quad 12$

2470.2336982234 .690 liquid 2.4632710 $12 \quad 12$

2480.2337542254 .980 liquid 2.4500110

$0.1679231 .9072310 \quad 5.2405610$ 11

$0.1852961 .894410 \quad 5.510710$ 11

$0.2034571 .8913310 \quad 5.7565510$ 11

0.2223321 .90812105 .9782110 11

0.2418541 .90486106 .1789110

$\begin{array}{ccc}11 & 2619381.8841310 & 6.3522410\end{array}$ 11

$0.2824821 .8808910 \quad 6.4931710$ 11

0.3033951 .88385106 .605110 $0.3245871 .8821610 \quad 6.6890910$ $\begin{array}{ccc}11 & & \\ 0.345969 & 1.8801910 & 6.7445810\end{array}$ 11

$0.3674521 .8782210 \quad 6.772410$ 11

$0.3889531 .8731310 \quad 6.773810$ 11

$0.410391 .8622710 \quad 6.7498610$ 11

0.4316851 .85962106 .7016910 11

$0.4527711 .8635710 \quad 6.632510$ 11

0.473591 .84505106 .5450610 11

0.494081 .81939106 .4388910 11

$0.5141881 .8184310 \quad 6.315810$ 
12 12

2490.2338092275 .060 liquid 2.4338510 12 12 2500.2338652294 .880 liquid 2.4034910 12 12 2510.2339212314 .240 liquid 2.3736310 12 12 2520.2339762333 .150 liquid 2.3454910 12 12 2530.2340322351 .640 liquid 2.3230310 $12 \quad 12$ 2540.2340882369 .80 liquid 2.3048110 $12 \quad 12$ 2550.2341432387 .710 liquid 2.2694410 $12 \quad 12$ 2560.2341992405 .110 liquid 2.2290710 $12 \quad 12$ 2570.2342552421 .90 liquid 2.1954110 12 12 2580.234312438 .210 liquid 2.1639310 $12 \quad 12$ 2590.2343662454 .070 liquid 2.1414210 $12 \quad 12$ 2600.2344222469 .630 liquid 2.1145110 $12 \quad 12$ 2610.2344772484 .810 liquid 2.0806710 $12 \quad 12$ 2620.2345332499 .510 liquid 2.044210 $26302345892513.12 \quad 12$ $\begin{array}{ll}12 & 12\end{array}$ 2640.2346452527 .340 liquid 1.9707110 12

2650.23472540 .480 liquid $1.9363710 \quad 0.7771841 .5861410 \quad 3.5022910$ $12 \quad 12$ 2660.2347562553 .130 liquid 1.9064110 2670.2348122565 .370 liquid 1876710 $12 \quad 12$ 2680.2348672577 .190 liquid 1.8466910 $12 \quad 12$ 2690.2349232588 .590 liquid 1.8167610 $12 \quad 12$ 2700.2349792599 .580 liquid 1.7867310 $12 \quad 12$ 2710.2350342610 .150 liquid 1.7571810 $272023509262031012 \quad 12$ 2720.235092620 .310 liquid 1.7281110 2730.2351462630 .090 liquid 1.7019510 $12 \quad 12$ 2740.2352012639 .520 liquid 1.6764810 $12 \quad 12$ 2750.2352572648 .610 liquid 1.6389510

$0.7878991 .5713410 \quad 3.3506910$ 11

$0.7981451 .5563310 \quad 3.2037710$ 11

0.8079381 .54053103 .0616210 11

0.8172921 .52433102 .9242910 11

0.8262241 .50755102 .791810 11

0.8347471 .49076102 .6641310 11

$0.8428791 .4739810 \quad 2.5412710$ 11

0.8506331 .45963102 .4231610 11

0.8580241 .4455102 .3097610 11

0.8650681 .41885102 .2009810 


$$
12 \quad 12 \quad 11
$$

2760.2353132657 .20 liquid $1.6029810 \quad 0.8717791 .39332102 .096610$ 12 12 2770.2353682665 .30 liquid 1.5712610 2780.2354242672 .990 liquid 1.5408210 $12 \quad 12$ 2790.235482680 .280 liquid 1.5119110 2800.2355352687 .220 liquid 1.4808910 12 12 2810.2355912693 .760 liquid 1.4488310 12 11 $0.8781691 .3716110 \quad 1.9965410$ 11

$0.8842531 .3507410 \quad 1.9007510$ 11

$0.8900441 .33110 \quad 1.809110$ 11

$0.8955551 .3087510 \quad 1.7214710$ 11 $0.9007981 .2850510 \quad 1.6377310$ 12 2820.2356472699 .90 .00139536 vaporizing $1.4304210 \quad 0.9057861 .2746410$ 11 1.5577410 $12 \quad 12$ 2830.2357032700 .0 .00296837 vaporizing $1.4141210 \quad 0.9105221 .2661710$ 11

1.4794610 $12 \quad 12$ 2840.2357582700 .0 .00462258 vaporizing 1.38595100 .9150211 .2454410 11

1.4050810 2850.2358142700 .0 .00633085 vaporizing $1.3571710 \quad 0.9192931 .2237310$ 11 1.3344410 2860.235872700 .0 .00806208 vaporizing $1.3257810 \quad 0.9233511 .1990510$ 11 1.2673510

2870.2359252700 .0 .00981597 vaporizing $1.2996510 \quad 0.9272041 .1792910$ 11 1.2036410 2880.2359812700 .0 .0116011 vaporizing $1.2797810 \quad 0.9308641 .1654710$ 11 1.1431210 $12 \quad 12$ 2890.2360372700 .0 .0133967 vaporizing $1.2569710 \quad 0.934341 .1484110$ 11 1.0856510 $12 \quad 12$ 2900.2360922700 .0 .0151871 vaporizing 1.23276100 .9376411 .1296510 
11

1.0310710

2910.236148 2700. 0.0169509 vaporizing $1.2054210 \quad 0.9407761 .107510$ 10

9.792310

2920.2362042700 .0 .0186778 vaporizing $1.1782410 \quad 0.9437541 .0852410$ 10

9.2999710

$12 \quad 12$

2930.2362592700 .0 .0203831 vaporizing 1.15777100 .9465821 .0694510 10 8.832410

$12 \quad 12$

2940.2363152700 .0 .0220531 vaporizing 1.13514100 .9492671 .0512610 10

8.3883310

2950.2363712700 .0 .0236583 vaporizing $1.1062510 \quad 0.9518181 .0265810$ 10

7.9665810

1212

2960.2364262700 .0 .0252128 vaporizing 1.08364100 .9542411 .0079810 10

7.5660410

$12 \quad 11$

2970.2364822700 .0 .0267373 vaporizing 1.06799100 .9565419 .9613810 10

7.1856310

$12 \quad 11$

2980.2365382700 .0 .0282161 vaporizing $1.0485210 \quad 0.9587269 .8027810$

10

6.8243510

1211

2990.2365932700 .0 .0296391 vaporizing $1.0273210 \quad 0.9608029 .6250910$

10

6.4812310

3000.236649 2700. 0.0309864 vaporizing $1.0019410 \quad 0.9627729 .4038910$

10

6.1553510

11

11 
3010.2367052700 .0 .0322558 vaporizing $9.7758810 \quad 0.9646449 .191310$ 10

5.8458610

$5.8458610 \quad 11 \quad 11$

3020.236762700 .0 .0334993 vaporizing $9.6872510 \quad 0.9664229 .1320610$

10

5.5519310

$11 \quad 11$

3030.2368162700 .0 .0347024 vaporizing $9.5514210 \quad 0.968119 .0241410$

10

5.2727710

$11 \quad 11$

3040.2368722700 .0 .0358211 vaporizing $9.2978610 \quad 0.9697148 .7970910$

10

5.0076510

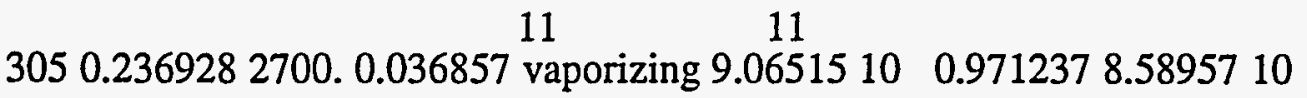

10

4.7558610

$11 \quad 11$

3060.2369832700 .0 .0378133 vaporizing $8.8536810 \quad 0.9726838 .4020110$ 10

4.5167210

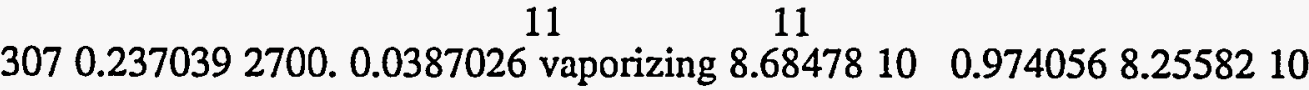

10

4.2896110

$11 \quad 11$

3080.2370952700 .0 .0395308 vaporizing $8.5348910 \quad 0.9753618 .1274910$ 10 4.0739210

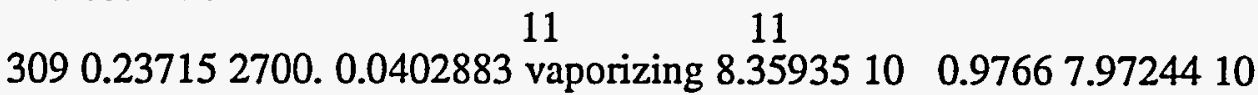

10

3.8690810

$11 \quad 11$

3100.2372062700 .0 .0409756 vaporizing $8.1893210 \quad 0.9777767 .8218710$ 10

3.6745410

11

11

3110.2372622700 .0 .0416146 vaporizing $8.0820110 \quad 0.9788947 .7330310$

10

3.4897710 
3120.2373172700 .0 .042194 vaporizing $7.9388310 \quad 0.9799557 .607410$ 10

3.314310

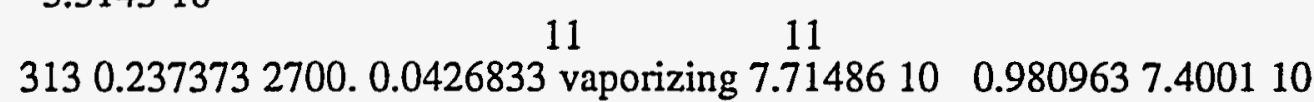
10

3.1476510

$11 \quad 11$

3140.2374292700 .0 .0430955 vaporizing $7.5374710 \quad 0.981927 .2385310$ 10

2.9893810

$11 \quad 11$

3150.2374842700 .0 .043445 vaporizing $7.4039910 \quad 0.9828297 .1200810$ 10

2.8390710

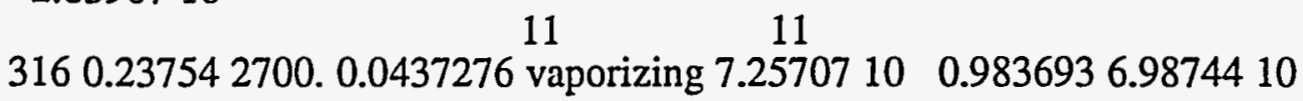

10

2.6963210

$11 \quad 11$

$3170.2375962700,0.0439409$ vaporizing $7.1053210 \quad 0.9845136 .8492410$

10

2.5607410

$\begin{array}{lcccc}318 & 0.237651 & 11 & 11 & \\ 2700 . & 0.0440914 \text { vaporizing } 6.9724510 & 0.9852916 .7292610\end{array}$

10

2.4319810

$11 \quad 11$

3190.2377072700 .0 .0441793 vaporizing 6.83925100 .9860316 .6082810

10

2.309710

$11 \quad 11$

3200.2377632700 .0 .0441985 vaporizing $6.6894410 \quad 0.9867336 .4700810$

10

2.1935610

$11 \quad 11$

3210.2378182700 .0 .0441459 vaporizing $6.5336810 \quad 0.98746 .3253510$

10

2.0832710

3220.2378742700 .0 .0440157 vaporizing $6.3652610 \quad 0.9880346 .1674110$

10 
1.9785110

$\begin{array}{cccc}11 & 11 & & \\ 323 & 0.23793 & 2700 . & 0.0438084 \\ \text { vaporizing } 6.2026610 & 0.988636 & 6.0147610\end{array}$ 10

1.8790310

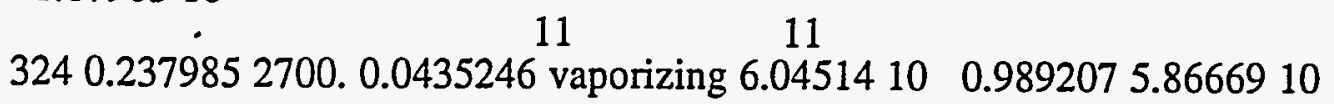
10

1.7845510

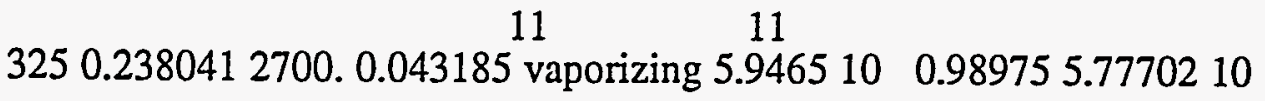
10 1.6948210

3260.2380972700 .0 .0427995 vaporizing $5.8688910 \quad 0.9902655 .7079310$ 10

1.609610

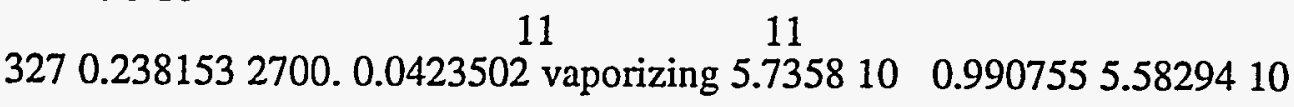

10

1.5286710

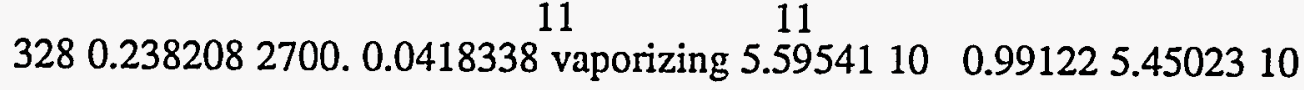
10

1.451810

3290.2382642700 .0 .0412403 vaporizing $5.4301710 \quad 0.9916615 .2922910$ 10

1.378810

3300.238322700 .0 .0405729 vaporizing $5.2791810 \quad 0.992085 .1482410$

10

1.3094710

$11 \quad 11$

3310.2383752700 .0 .0398402 vaporizing $5.1541510 \quad 0.9924795 .0297910$ 10

1.2436310

$11 \quad 11$

3320.2384312700 .0 .0390465 vaporizing $5.0404210 \quad 0.9928574 .9223110$ 10

1.181110

$11 \quad 11$

3330.2384872700 .0 .0381958 vaporizing $4.9357810 \quad 0.9932164 .8236110$ 
10

1.1217110

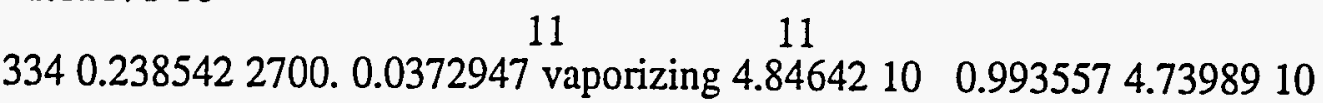
10

1.0653110

$11 \quad 11$

3350.2385982700 .0 .0363467 vaporizing $4.7620910 \quad 0.9938814 .6609110$ 10

1.0117410

$11 \quad 11$

3360.2386542700 .0 .0353394 vaporizing $4.6399710 \quad 0.9941894 .5438810$ 9

9.6087210

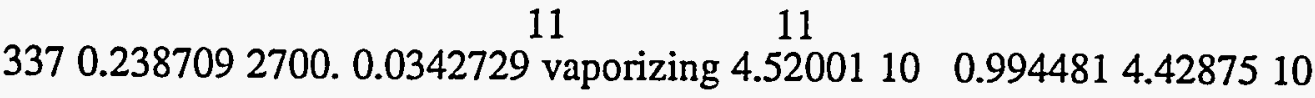
9

9.1255810

$11 \quad 11$

3380.2387652700 .0 .033153 vaporizing $4.4167110 \quad 0.9947584 .3300510$ 8.6667310 9

3390.2388212700 .0 .0319803 vaporizing $4.3136410 \quad 0.9950224 .2313310$ 9

8.2309510

3400.238876 2700. 0.0307551 vaporizing $4.2107810 \quad 0.9952724 .1326110$ $\stackrel{9}{9} 1.8170810$

238932 2700. 0.0294842 vaporizing 4.12521 $10 \quad 0.995514 .0509710$

9

7.4240210

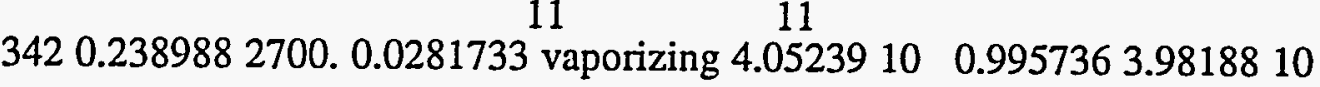
7.0507310

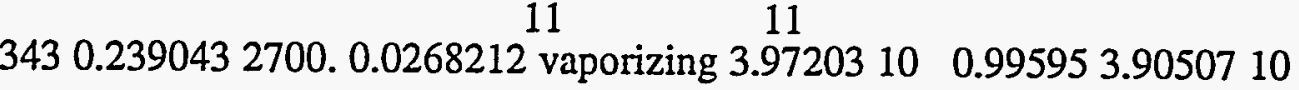
9 6.6962110

$\begin{array}{cccc}11 & 11 & & \\ 344 & 0.239099 & 2700 . & 0.025428 \\ \text { vaporizing } 3.88969 & 10 & 0.9961543 .82609 & 10\end{array}$ 
6.35951 10

3450.2391552700 .0 .0239837 vaporizing $3.7783710 \quad 0.9963473 .7179710$ 6.0397410

$11 \quad 11$

3460.2392112700 .0 .022488 vaporizing 3.66861100 .9965313 .6112510

$\stackrel{9}{9} 10$

3470.2392662700 .0 .0209432 vaporizing $3.56710 \quad 0.9967053 .5125310$ 9
5.4476310

$11 \quad 11$

3480.2393222700 .0 .0193535 vaporizing $3.4771810 \quad 0.9968713 .4254410$ 5.1737110

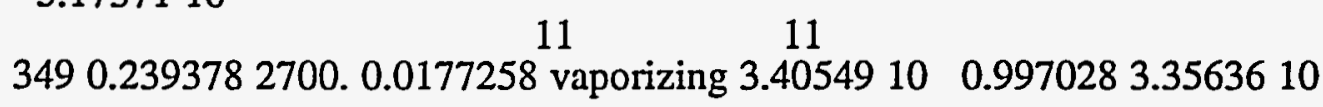
$\stackrel{9}{9} 10135710$

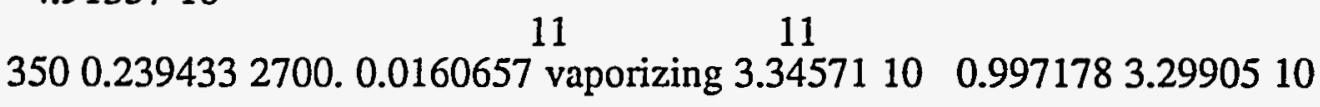
$\stackrel{9}{9} 10$

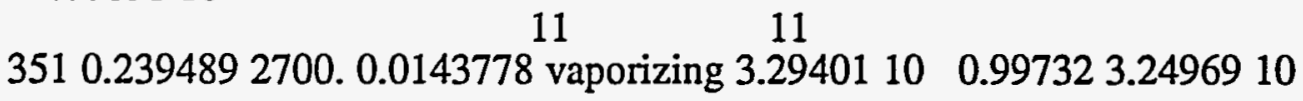
$\stackrel{9}{4} 10$

$11 \quad 11$

3520.2395452700 .0 .0126609 vaporizing $3.2345110 \quad 0.9974543 .1924210$ $\stackrel{9}{9} 10$

3530.23962700 .0 .0109156 vaporizing $3.1731710 \quad 0.9975823 .1331910$ $\stackrel{9}{9} 9973910$

3540.2396562700 .0 .00914269 vaporizing 3.11193100 .9977043 .0739710 $\stackrel{9}{3.79639} 10$

$11 \quad 11$ 
3.605510

Finished

\$Aborted

Tcoefsol $=2.25 * 10^{\wedge}-5$;

Tcoefliq $=1.17 * 10^{\wedge}-4$

$\mathrm{nt}=350$;

(* TA - average temperature *)

ta[ts_]:= Sum[Part[xx1[node,ts],2], $\{$ node, $1, \mathrm{~m}\}] / \mathrm{m}$;

$(*$ tr - Temperature time rate of change $*)$

$\operatorname{tr}[$ node_ts_]:=Part[xx1[node,ts]-xx1[node,ts-1],2]/Part[xx1[node,ts]-xx1[node,ts-1],1];

(* tra - average rate of change of temp for the plate*)

$\operatorname{tra}[\mathrm{ts}]:=S u m[\operatorname{tr}[$ node, $t \mathrm{~s}],\{$ node, $1, \mathrm{~m}\}] / \mathrm{m}$;

(* expth - expansion thermal *)

(* texprate - thermal expansion rate for the plate *)

expth[node_ts_]:=Tcoefsol*tr[node,ts] /; Part[xx1[node,ts],2]<Tm;

expth[node,ts_]:=Tcoefliq*tr[node,ts] /; Part[xx1[node,ts],2]>Tm \&\& Part[xx1[node,ts],2]<Tv;

expth[node_ts_]:=tr[node,ts]/Part[xx1[node,ts],2]/; Part[xx1[node,ts],2]>Tv;

expth[node_,ts] $:=0 \%$ Part[xx1[node,ts],2]===Tm;

expth[node_ts_]:=0/; $\operatorname{Part}[\mathrm{xx} 1[$ node,ts],2] $===\mathrm{Tv}$;

texprate[ts_]:=Sum[expth[node,ts],\{node, $1, \mathrm{~m}\}] / \mathrm{m}$;

(* qm - quality of the melt *)

$(* \mathrm{mv}$ - quality of the vapor *)

qm[ts_]:=Sum[Part[xx2[node,ts],2], \{node, $1, \mathrm{~m}\}] / \mathrm{m}$;

qv[ts_]:=Sum[Part[xx3[node,ts],2], \{node, $1, \mathrm{~m}\}] / \mathrm{m}$;

vfaln[i_]:=fval $/ ; \mathrm{i}<=\mathrm{n}$;

vfaln[i] $]:=1 / ; i>n$;

(* Fractional rate of change of volume due to various factors *)

(* ger - Gas Expansion Rate

(* VMR - Volumetric Melting Rate

(* VVR - Volumetric Vaporization Rate

(* VOFR - Volumetric Oxide Formation Rate

(* QMR - Quality Melt Rate

(* QVR - Quality Vaporization Rate

*)

*)

$*$ )

*) rhosolid=2700; rholiquid=2500; rhovapor $=1.0$;

DencRatLV $=\left(1 /\right.$ rhovapor $^{\wedge}(0.3)-1 /$ rholiquid^ $\left.(0.3)\right) /(1 /$ rholiquid^ $(0.3))$;

DencRatSL $=(1 /$ rholiquid^ $(0.3)-1 /$ rhosolid^$(0.3)) /\left(1 /\right.$ rhosolid $\left.{ }^{\wedge}(0.3)\right)$;

qmr[node_ts_]:=Part[xx2[node,ts]-xx2[node,ts-1],2]/Part[xx2[node,ts]- $x \times 2$ [node,ts-1],1];

qvr[node_ts] :=Part[xx3[node,ts]-xx3[node,ts-1],2]/Part[xx3[node,ts]-xx3[node,ts-1],1];

$\mathrm{vmr}\left[\mathrm{ts}_{\mathrm{S}}\right]:=$ Sum[DencRatSL*qmr[node,ts]*vfaln[node], \{node, $\left.\left.1, \mathrm{~m}\right\}\right] / \mathrm{m}$;

$\operatorname{vvr}\left[t_{s}\right]:=S u m[$ DencRatLV*avr[node,ts] $*$ vfaln[node],\{node, $\left.1, \mathrm{~m}\}\right] / \mathrm{m}$;

ger[ts_]:=Sum[ tr[node,ts]/ Part[xx1[node,ts],2], \{node, $1, \mathrm{n}\}] / \mathrm{m}$;

$\mathrm{ff}=0.01$;

TotalExpansionRate[ts_]:=(1-ff)*(vmr[ts]+vvr[ts]+texprate[ts] $)+\mathrm{ff}^{*} \mathrm{ger}[\mathrm{ts}]$

IntegralTotExp[ts_]:=Sum[TotalExpansionRate[tt]*dt, $\{\mathrm{tt}, 2, \mathrm{ts}\}]$ 
ListPlot[Table[\{Part[xx1[1,ts],1],TotalExpansionRate[ts]\},\{ts,2,nt $\}]$,

PlotJoined $\rightarrow$ True,

PlotRange- $>$ All,

AxesLabel->\{"time (s)","Fractional Exp rate (1/s)" $\}$ ]

ter $=1$;

(* ter total expansion *)

Do[ter* $=(1+$ TotalExpansionRate $[\mathrm{tt}] * \mathrm{dt})$;

qwq[tt $]=\{\operatorname{Part}[\mathrm{xx} 1[1, \mathrm{tt}], 1]$, ter -1$\}$

$,\{\mathrm{tt}, 2, \mathrm{nt}\}]$

ListPlot[Table[qwq[tt],\{tt,2,nt\}],

PlotJoined $\rightarrow$ True,

PlotRange->All,

AxesLabel->\{"time (s)","Expanded fraction" $\}]$

Do[eff[ts]=\{Part[xx1[1,ts],1],ta[ts],TotalExpansionRate[ts],Part[qwq[ts],2]\},\{ts,2,nt\}];

ListPlot[Table[\{Part[xx1[1,ts],1],ta[ts]\},\{ts,2,nt\}],

PlotJoined $->$ True,

PlotRange->All,

AxesLabel->\{"time (s)","average temp (K)" $\}]$

-Graphics-

-Graphics-

-Graphics-

ListPlot[Table[\{Part[xx1[1,i],1],Part[xx1[1,i],2]\},\{i,1,nt\}],

PlotJoined $\rightarrow$ True,

PlotRange->All,

AxesLabel->\{"time (s)"," temp (K)" $\}]$

ListPlot[Table[\{Part[xx1[m,i],1],Part[xx1[m,i],2]\},\{i,1,nt $\}]$,

PlotJoined $\rightarrow$ True,

PlotRange- $>$ All,

AxesLabel->\{"time (s)"," temp (K)" $\}]$

-Graphics-

-Graphics-

szs1 $=\operatorname{ListPlot}[$ Table[ $\{\operatorname{Part}[\mathrm{xx} 4[1, \mathrm{i}], 1], \operatorname{Part}[\mathrm{xx} 4[1, \mathrm{i}], 2]\},\{\mathrm{i}, 1, \mathrm{nt}\}]$,

PlotJoined $\rightarrow$ True,

PlotRange- $>$ All,

AxesLabel->\{"time (s)"," temp (K)"\}] 
szs2=ListPlot[Table[\{Part[xx4[3,i],1],Part[xx4[3,i],2]\},\{i,1,nt $\}]$, PlotJoined $\rightarrow$ True,

PlotRange->All,

AxesLabel- $>$ ["time (s)"," temp (K)" $\}]$

szs3 $=$ ListPlot[Table[ $\{\operatorname{Part}[\mathrm{xx} 4[\mathrm{n}, \mathrm{i}], 1], \operatorname{Part}[\mathrm{xx} 4[\mathrm{n}, \mathrm{i}], 2]\},\{\mathrm{i}, 1, \mathrm{nt}\}]$,

PlotJoined $\rightarrow$ True,

PlotRange->All,

AxesLabel->\{"time (s)"," temp (K)" \}];

Show[szs1,szs2,szs3]

-Graphics-

-Graphics-

-Graphics-

szs1=ListPlot[Table[\{Part[xx5[1,i],1],Part[xx5[1,i],2]\},\{i,1,nt\}],

PlotJoined $->$ True,PlotRange- $>$ All,

AxesLabel-> ["time (s)"," Q (W)"\}];

szs2=ListPlot[Table[\{Part[xx6[1,i],1],Part[xx6[1,i],2]\},\{i,1,nt $\}$,

PlotJoined $\rightarrow>$ True,PlotRange- $>$ All,

AxesLabel->\{"time (s)"," $Q(W) "\}]$;

szs3=ListPlot[Table[\{Part[xx7[1,i],1],Part[xx7[1,i],2]\},\{i,1,nt\}],

PlotJoined $\rightarrow$ True,PlotRange- $>$ All,

AxesLabel->\{"time (s)"," Q (W)"\}];

Show[szs1,szs2,szs3]

-Graphics- 
1.

2.

3.

4.

5.

6.

7.
W. G. Craddick

E. C. Fox

V. Georgevich

R. M. Harrington

S. A. Hodge

S. H. Kim

D. L. Selby
8.

9-11.

12

13.

14.

15-16.
D. B. Simpson

R. P. Taleyarkhan

C. D. West

ORNL Patent Section

Central Research Library

Laboratory Records

Department

External Distribution

17 S. Navarro-Valenti, 16 River Street \#2, South Natick, MA 01760

18. M. L. Corradini, Department of Nuclear Engineering, 1500 Johnson Drive, University of Wisconsin, Madison, Wisconsin, 53706-1687

19. M. L. Hyder, SRTC, Westinghouse Savannah River, Co., 1991 South Centennial Avenue, Bldg. 1, Aiken, South Carolina, 29803

20. R. T. Lahey, Nuclear Engineering and Engineering Physics, Rensselaer Polytechnic Institute, JEC 5048, Troy, New York, 12180-3590

21. M. Z. Podowski, Nuclear Engineering and Engineering Physics, Rensselaer Polytechnic Institute, JEC 5048, Troy, New York, 12180-3590

22 -23.DOE, Office of Scientific and Technical Information, P.O. Box 62, Oak Ridge, Tennessee 37831

24. Sung-Tack Shin, KIDA, Chongryang P.O. Box 250, Togondae-mun-gu, Seoul, 130-650, South Korea

25. Kun-Joong Yoo, KAERI, P.O. Box 105, Yusung-gu, 305-600, South Korea

26. Jong-In Lee, KINS, P.O. Box 114, Yusung-gu, 305-600, South Korea

27. Tom King, U.S. Nuclear Regulatory Commission, MS T10-E37, Washington, D.C. 20555

28. Joe Donoghue, U. S. Nuclear Regulatory Commission, Washington, D. C. 20555

29. T. Fuketa, Reactivity Accident Laboratory, Japan Atomic Energy Research Institute, Tokai Research Establishment, Takai-Mura, Ibaraki-Ken, 319-11 Japan

30. T. G. Theofanous, University of California at Santa Barbara, Department of Chemical \& Nuclear Engineering, Santa Barbara, California 93106

31. K. Soda, Director, Office of Planning, Japan Atomic Energy Research Institute, 2-2, Uchisaiwai-Cho, 2-Chome, Chiyoda-ku, Tokyo 100, Japan

32. K. Ishijima, Reactivity Accident Laboratory, Japan Atomic Energy Research Institute, Tokai Research Establishment, Takai-Mura, Ibaraki-Ken, 319-11 Japan

33. N. Ohnishi, Dept. of Research Reactor Operation, Japan Atomic Energy Research Institute, Toakai Research Establishment, Takai-Mura, Ibaraki-Ken, 319-11 Japan

34. K. Soyama, Dept. of Research Reactor Operation, Japan Atomic Energy Research Institute, Toakai Research Establishment, Takai-Mura, Ibaraki-Ken, 319-11 Japan

35. T. Kodaira, Dept. of Research Reactor Operation, Japan Atomic Energy Research Institute, Toakai Research Establishment, Takai-Mura, Ibaraki-Ken, 319-11 Japan 